\title{
ATTRACTING AND RETAINING VILLAGE MIDWIVES IN INDONESIAN REMOTE POSTINGS: \\ 'SUCCESS CASES' FROM WEST NUSA TENGGARA
}

BY

ENDAH SETYANINGSIH

\begin{abstract}
A thesis submitted to the Victoria University of Wellington in fulfilment of the requirements for the degree of Doctor of Philosophy in Health
\end{abstract}

VICTORIA UNIVERSITY OF WELLINGTON 



\section{ABSTRACT \\ "When midwifery is in place, there is much less need for emergency interventions." - Petra ten Hoope-Bender at Bulletin WHO}

(Shetty, 2013)

Accessing health professionals, such as midwives, is essential reducing the maternal and child mortality rates. However, attracting and retaining midwives to remote areas of Indonesia is not a simple task. Many midwives in Indonesia prefer to work in cities due to better facilities, incomes, and proximity to families. In order to increase their numbers in remote areas, policy-makers and other related stakeholders must better understand those factors that attract them to, as well as retain them in, these remote areas.

This study explored key success factors that influenced midwives to work and stay in remote areas of Indonesia, and the policies of the Government of Indonesia (GoI) which influenced their attraction and retention to such areas.

The 'Success Case' evaluation method was used with Appreciative Inquiry. This combined approach has not been used before in the field of public policy to study health professionals in marginalised areas. However, it enabled the identification of key success factors from the best performing cases in order to obtain better evidence, thus assisting policy-makers and other related stakeholders to craft better strategies for attracting and retaining midwives in remote areas of Indonesia.

The West Nusa Tenggara (Nusa Tenggara Barat or NTB) Province was chosen as the study location because it provided an excellent opportunity to examine the 'success cases' (six districts) and the 'less success cases' (two districts) which were determined based on the coverage of midwives from 2010-2014. Fifty-seven participants from the 'success cases', fourteen participants from the 'less success cases', and four other relevant participants were interviewed. These included civil servant midwives, nationally- and regionally-contracted midwives, volunteer midwives, and national and local government officials. Thematic analysis included the voice of the government officials, and documents analysis as part of data triangulation. A multifaceted framework which consists of personal, organisational and societal factors was used as the conceptual framework for this study. 
While some of the results were similar to previous studies, this study revealed some unique factors. Economic stability attracted midwives to remote areas in both the 'success cases' and the 'less success cases'. Community support played a major role in their retention. Personal, family and individual prestige were identified as other important factors influencing midwives to stay in remote areas. Cultural and religious beliefs constructed midwives' viewpoints about their work and life in general, which influenced their motivation.

It was found that many government programmes focus only on a limited number of policy initiatives, such as monetary incentives, to influence workers' behaviours, and neglect the potentially important role that other, non-monetary factors may be playing. Policy-makers need to consider a broad range of motivational determinants which could potentially improve programmes and policies for attracting and retaining midwives in remote areas of Indonesia.

This study concludes by offering recommendations for the GoI in order to improve the recruitment and retention of midwives in remote areas of Indonesia, and suggests further areas for research.

Key words: Village Midwives; Success Cases; Remote Areas, Multifaceted Approach 


\section{ACKNOWLEDGEMENTS}

This dissertation has developed not just out of my own hard work but also out of the goodwill of others. First of all, I would like to express my special appreciation and thanks to my supervisors: Prof. Jacqueline Cumming for her support and valuable advice in this thesis process; Dr. Lynne Russell for her encouragement and faith in me throughout which have been extremely helpful; and Dr. Jenny Neale for always being available for my questions and giving generously of her time and vast knowledge. She always knew where to look for answers while leading me to the right perspectives.

I also would like to express my sincere thanks to all my research participants. My fieldwork would have been impossible without the support of my travel buddy, Wulan Septianingsih. She supported me with important information and accompanied me from the top of Lombok Island to the bottom of Sumbawa Island with her motorbike. Wulan and her family (Om Mulyono, Tante Sujiati and Uli) patiently taught me the basic local language and kept the journey safe, joyful and memorable - thanks to you.

I am especially indebted to Ministry of Foreign Affair for granting me a doctoral scholarship; to the Health Services Research Centre of the School of Government, Faculty of Commerce, Victoria University of Wellington (VUW) for providing me with grants to carry out data collection in Indonesia, attend conferences, and take English for Speakers of Other Languages (ESOL) courses; and to the SurfAid team (Andrew Judge, Anne Wuijt, and Bang Lamhot) for the great support.

My gratitude also goes to the New Zealand Aid team at VUW, Dr. Helena Cook and Linsell Richards for their hands on and amazing support during my study; to the Student Learning Support Services team, especially Dr. Xiaodan Gao for her extraordinary support throughout this difficult writing process; my ESOL teacher, Prue Walker, for her expert comments on producing a better kind of English academic writing; Victoria International office for their invaluable support in organising my visa and other administration; and to the Faculty of Graduate Research team, especially Dr. Lizzy Towl, for providing brilliant workshops during my study. 
Thank you also to the Indonesia Students Association, especially to Jazz and Pak Zaki who have patiently listened and helped make my crazy ideas come true; and the Indonesia Embassy in New Zealand, especially Pak Ferry, Pak Wanton and Pak Budi for allowing me to take part in many cultural activities here in Wellington.

Special thanks also to the 'the quiz gang' at the Old Government Building: Jenny, Maggy, Janet, Megan, Lesley, Ausaga, Marianna, and Emma. I know that I am going to miss the morning quiz time as it has been my other learning source about general knowledge, particularly about New Zealand.

In addition, during the long process of my writing this thesis, I believe the support from my friends both emotionally and academically was undeniable. Their true friendship and kindness has sustained me through this rollercoaster journey of completing this difficult task. So, big thanks to: Railway West Wing crews, Aftab, Cherry, Jessica, Ha, Vy, Ali, and Mphahy; and office mates, Emma - for the fun walk and talk during the day so we both could release the stress - and Tara and Molly for the company. You guys have contributed immensely to my personal and professional time at VUW.

It was great pleasure to share this long journey with my partner in crime and flatmate, Tenri (Bu Direktur). Thanks for all the joyful moments that we have shared together. It was also a great pleasure to share the experiences of living in Wellington with Mbak Asih, Lydia Blue, Cikgu, Avi, Mbak Anita Anas, TJ, Jill Fernandes, Mas Tomo, Teh Lya, Richard, Lina, Finn, Alex Hill, Pakjira Leelerphan, Shih Min Loo, Matthew Book, Mbak Restu, Ghifary, Syva, Sila, mbak Ruly, Mas Nino, Mbak Endang, Bu Shinta, Bu Ella, Kia, Andre, Mbak Wiwin, Jacq and Alan.

One of the reasons I did this $\mathrm{PhD}$ was because of my nieces, Olga, Dita, and Dinda. I hope by my example you know that you can achieve your dream if you work hard. To my sisters (Mbak Wati and Mbak Indri) and my brother (Mas Bimo), thank you for the support. My deep thank you to Ibu (mother) and Bapak (my Dad in heaven). Words cannot express how grateful I am for all of the sacrifices and allowing me to grow to be a person that I want to be. Your prayer for me was what sustained me this far. To my Melbourne family, Linda, Leighton, Kerry, Claire, Gordon and Ethan - thank you. Finally, I cannot express sufficient gratitude to Chris for his amazing support and providing great insight into my decision-making. Thank you. 


\section{TABLE OF CONTENTS}

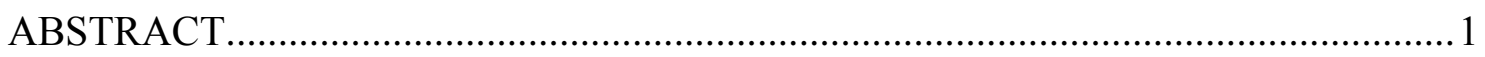

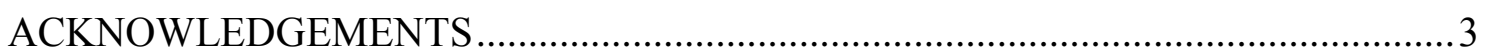

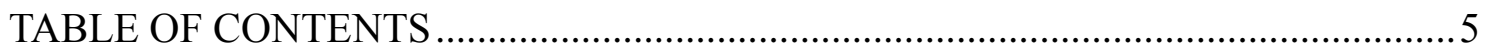

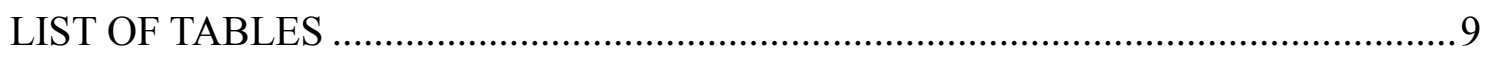

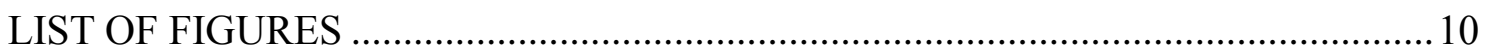

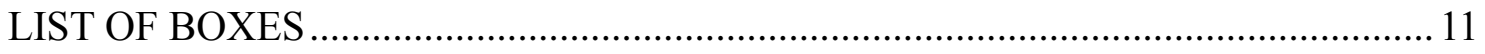

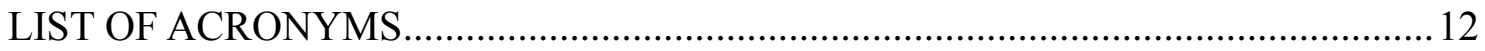

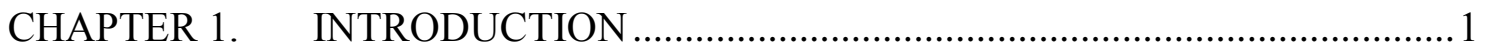

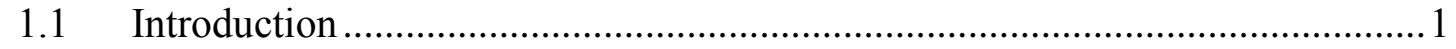

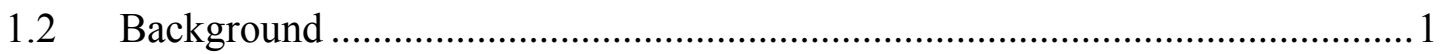

1.3 Purpose of the Research and Research Questions......................................... 6

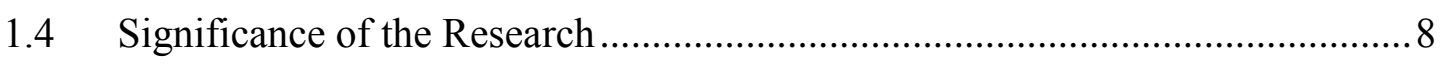

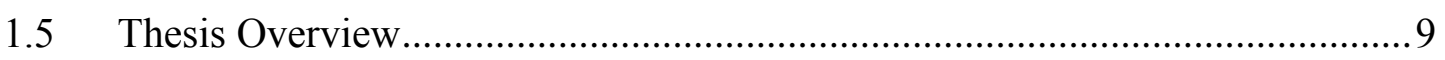

CHAPTER 2. CONTEXTUAL BACKGROUND ................................................... 11

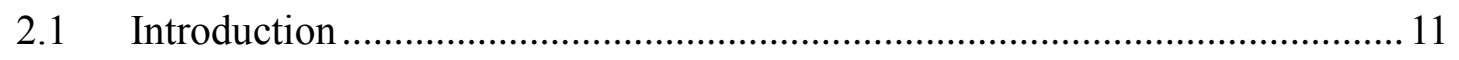

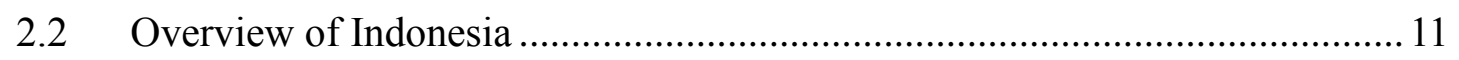

2.3 Health Priority: Reducing Maternal and Neonatal Rates ................................ 14

2.4 The History of Village Midwives: Why it became prominent ......................... 17

2.5 Indonesian Health System: Improving Maternal and Child Health ..................27

2.6 Village Midwives: The Frontline of Health Provider in Remote Areas ............30

2.7 The Provision of Village Midwives ............................................................. 31

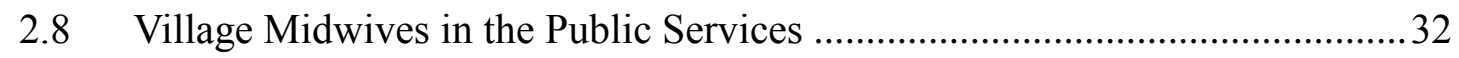

2.9 Village Midwives in Private Services and Practices ....................................... 33

2.10 Collaboration between Midwives and Traditional Birth Attendants..................34

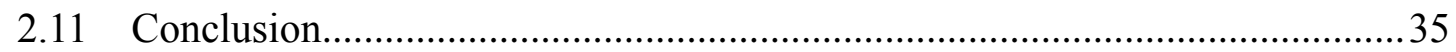

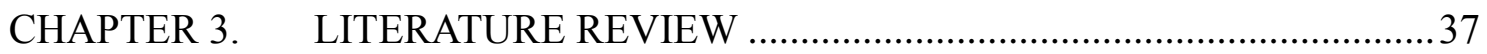

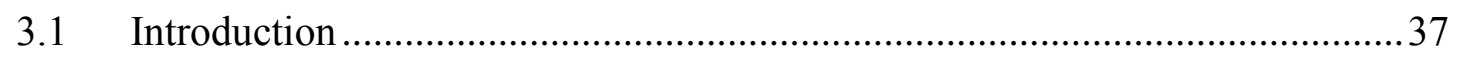

3.2 Motivation: In the Work Context ................................................................... 37

3.3 Recruitment: Attracting Health Workers to Remote Areas .............................. 40

3.4 Retention: Retaining Health Workers in Remote Postings ............................. 45

3.5 Decentralisation: Recruitment and Retention ............................................. 48

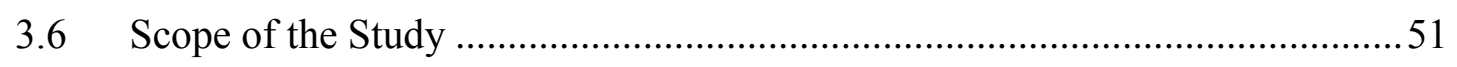




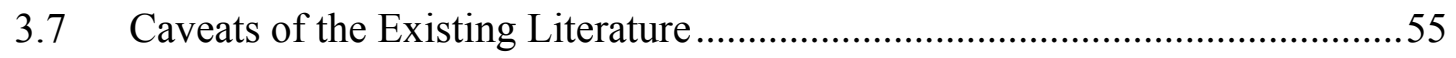

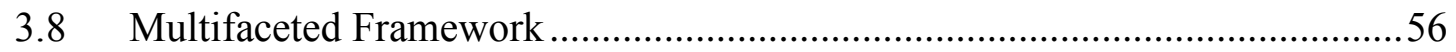

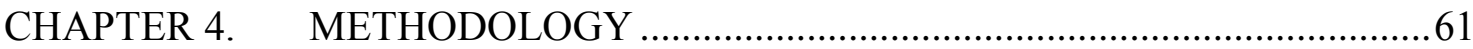

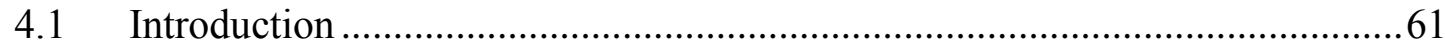

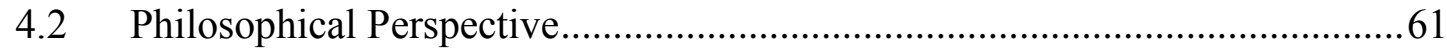

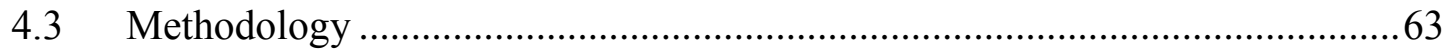

4.3.1 Success Case Method Blended with Appreciative Inquiry .......................64

4.3.2 Selection of the 'Success and Less Success Cases': Desk Study ..............70

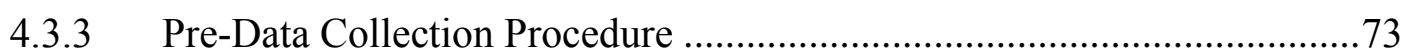

4.3.4 Interview and Documenting the 'Success and Less Successful' Cases ....76

4.3.5 Study Participants: Demography ..........................................................78

4.3.6 Permission and Invitation to Participate ................................................ 82

4.3.7 Anonymity or Privacy of Participants......................................................83

4.3.8 Researcher Position: The Need for Travel Buddy ...................................85

4.4 Managing My Data: Thematic Analysis Approach ........................................89

4.5 Familiarising Myself with the Data.............................................................. 90

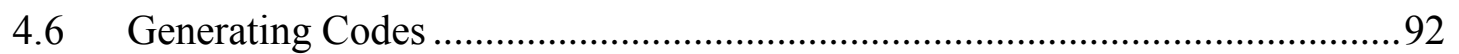

4.7 Searching and Reviewing Potential Themes ................................................93

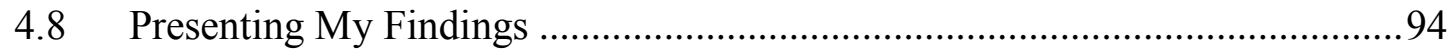

CHAPTER 5. ATTRACTION TO WORK IN REMOTE AREAS ..........................97

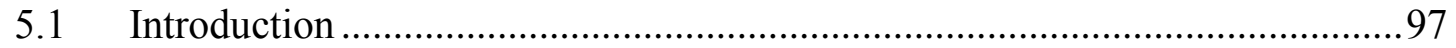

5.2. Village Midwives: Who Are They? .............................................................97

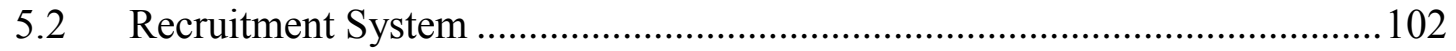

5.2.1 The Need for Health Workers Analysis .............................................. 103

5.2.2 Job Descriptions and Personnel Specifications......................................108

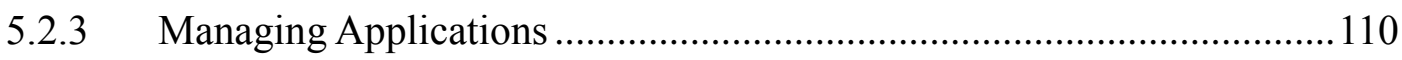

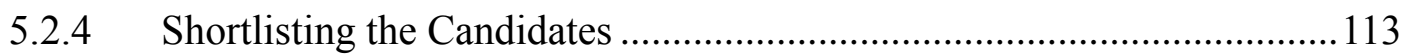

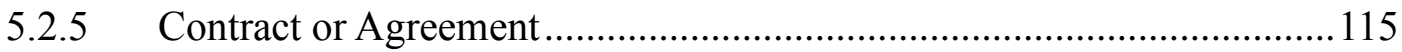

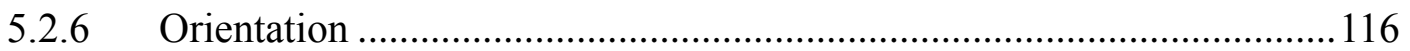

5.3 Key Factors that Attract Midwives to Remote Areas .................................... 117

5.3.1 Better Income: Economic Stability …................................................. 118

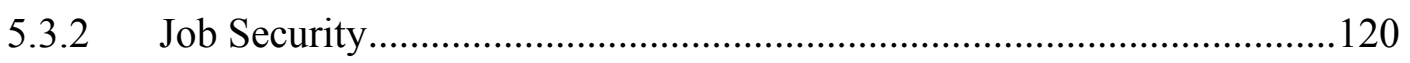

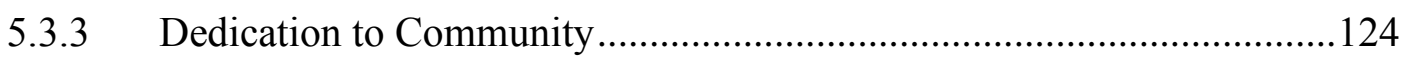

5.3.4 More Experiences to Obtain Better Skills ............................................126

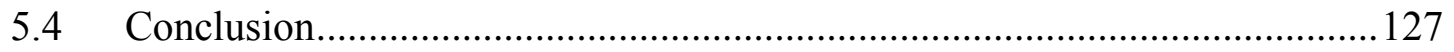


CHAPTER 6. RETAINING MIDWIVES IN REMOTE AREAS .......................... 131

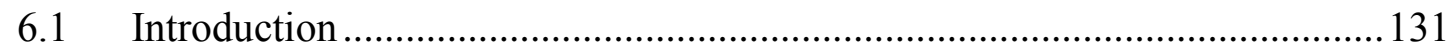

6.2 Key Factors that Retain Midwives in the 'Success Cases' ............................ 131

6.2.1 Community Support: Neighbourhood Solidarity..................................... 132

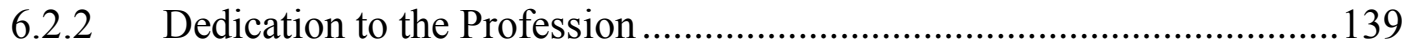

6.2.3 Direct Financial Incentives ................................................................ 141

6.2.4 Locally Hired: 'Familiarity and Less-Culture Shock' ............................ 145

6.2.5 Cultural and Religious Beliefs .......................................................... 145

6.3 Key Factors that Retain Midwives in the 'Less Success Cases' ..................... 149

6.3.1 Community Support: Neighbourhood Solidarity.................................. 149

6.3.2 Direct Financial Incentives ................................................................ 151

6.3.3 More Experiences to Obtain Better Skills ............................................ 152

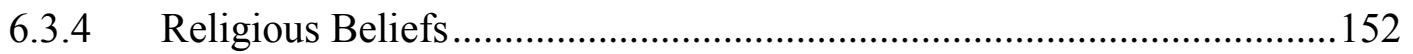

6.3.5 Family Support: Parents and Husbands ............................................. 153

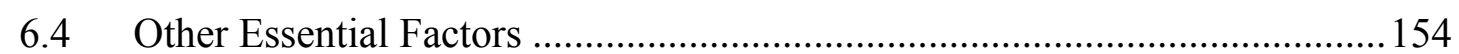

6.4.1 "Hopeful Attitude": Opportunity to Growth ............................................. 155

6.4.2 Prestige and Powerless............................................................................ 156

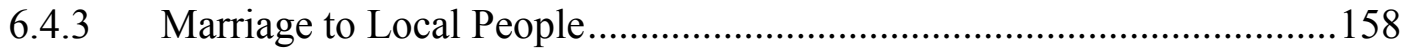

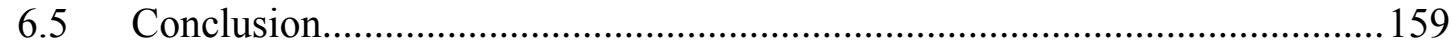

CHAPTER 7. POLICIES/PROGRAMMES vs REALITY .................................... 163

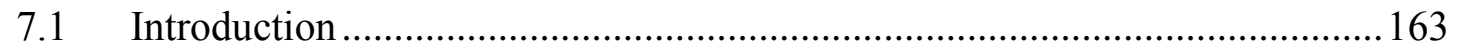

7.2 National Government Policies and Strategies .............................................. 163

7.2.1 Nationally Contracted Health Workers .............................................. 171

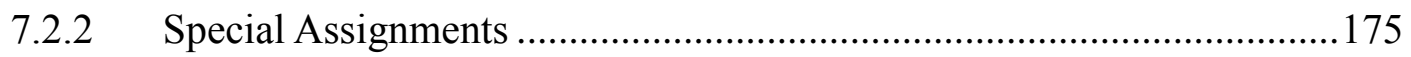

7.2.3 Nusatara Sehat (Healthy Indonesia Programme) .................................176

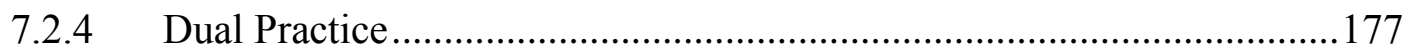

7.2.5 'A Village Midwife Programme' ........................................................... 178

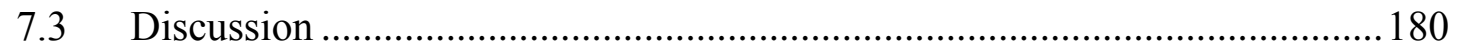

7.4 Local Government Policies or Strategies .................................................. 182

7.5 The 'Success Cases': The Local Strategies .................................................. 185

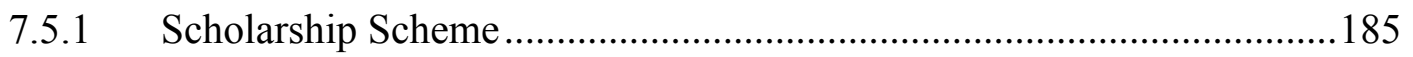

7.5.2 Regionally Contracted Programme or PTT Daerah ............................. 187

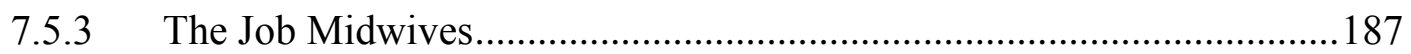

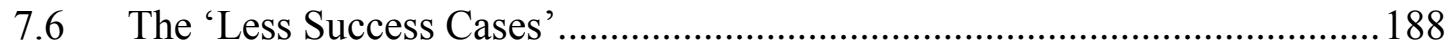

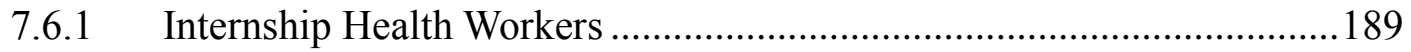

7.6.2 Regionally Contracted Programme....................................................... 191

7.7 The 'Success Cases' and The 'Less Success Cases' ...................................... 192 


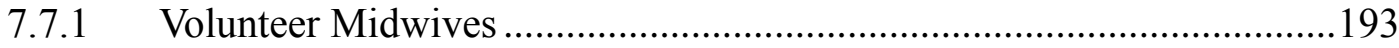

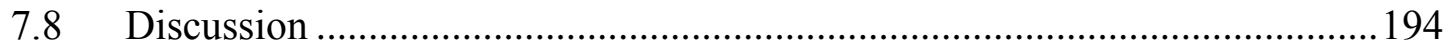

7.8.1 Do the Key Factors Match Up with the Existing Policies? .......................195

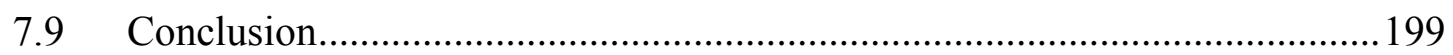

CHAPTER 8. DISCUSSION AND CONCLUSION …………………….............. 203

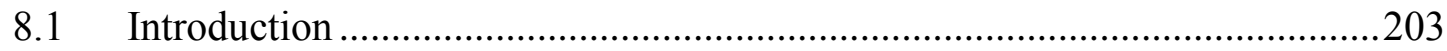

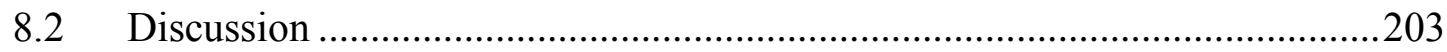

8.2.1 Similar Factors Emerge in Both Cases ...................................................203

8.2.2 Factors that Differ: 'The Success Cases' …….........................................213

8.2.3 Factors that Differ: The 'Less Success Cases' .......................................217

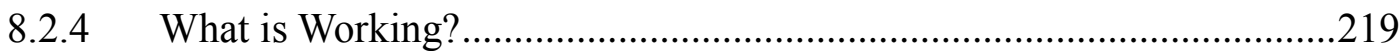

8.2.5 The Government of Indonesia in Facilitating Recruitment and Retention

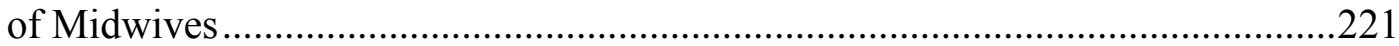

8.3.1. LIVE - L is for Local Hiring ...............................................................226

8.3.2. LIVE - I is for Investing in Career Options ............................................228

8.3.3. LIVE - $\mathrm{V}$ is for Values and Beliefs.....................................................232

8.3.4. LIVE - E is for Evolution of Midwifery Training .................................232

8.3 Limitations and Recommendations for Further Research...............................233

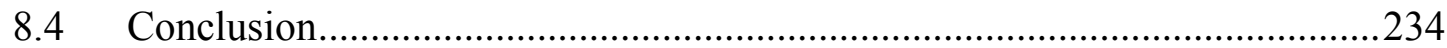

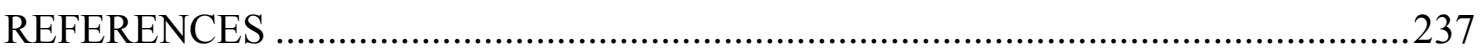

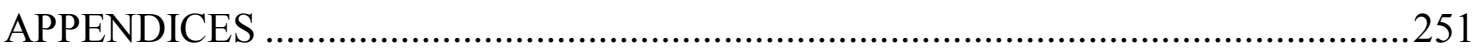




\section{LIST OF TABLES}

Table 1: Review of Literature Surrounding Work Motivation of Health Workers .52

Table 2: Coverage of Midwives in the 13 Provinces Categorised as Underdeveloped by the KDPDTT

Table 3: Average Number of Midwives per Village in the West Nusa Tenggara Province

(Nusa Tenggara Barat) between 2010 and 2014 . .73

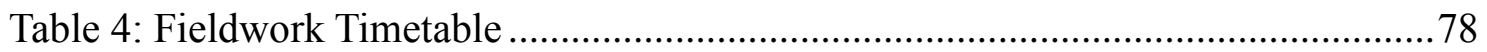

Table 5: Differences between Remote and Very Remote Areas ...................................79

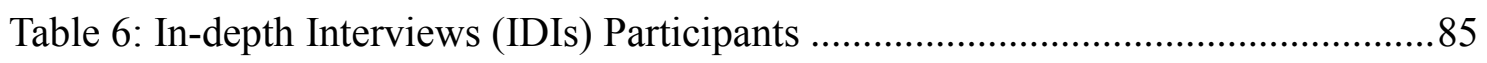

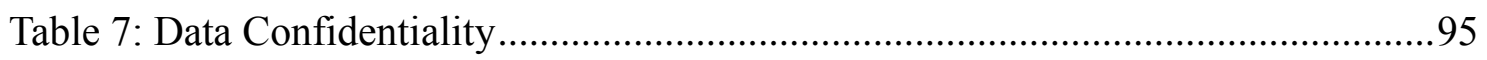

Table 8: Age, Marital status, Origin, Initial Qualifications, Years in village, and Employment Status of the Village Midwives .............................................................98

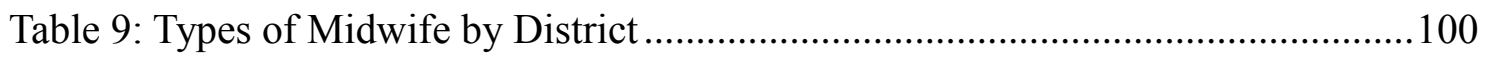

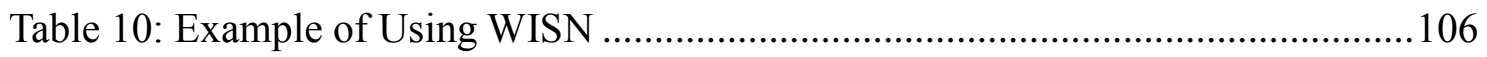

Table 11: Summary of National Government Policies ............................................... 167

Table 12: Monthly Salary and Incentives for Pegawai Tidak Tetap ............................ 172

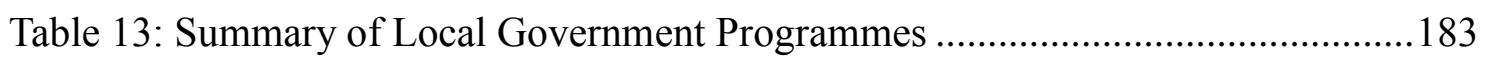

Table 14: Key Factors of Attracting and Retaining Midwives in Remote Areas ..........220 


\section{LIST OF FIGURES}

Figure 1: Map of Indonesia (Adapted from www.freeworldmaps.net) .........................11

Figure 2: Trend of Maternal Mortality Rate in Indonesia from 1994-2015 (Ministry of

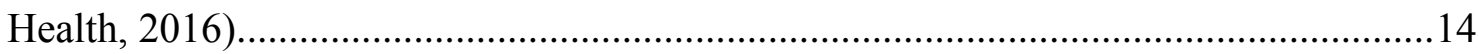

Figure 3: Maternal Mortality Rate Among Sout-East Asia Countries in 2010 (WHO,

$2013)$

Figure 4: Trend of Neonatal Mortality Rates in Indonesia from 1990-2015 ..................16

Figure 5: Neonatal, Infant, and Under Five Mortality Rates among South East Asia

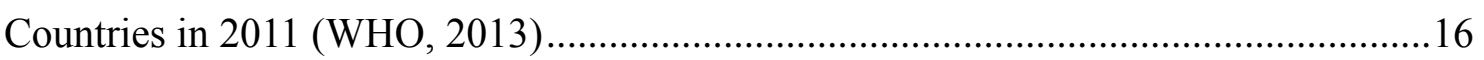

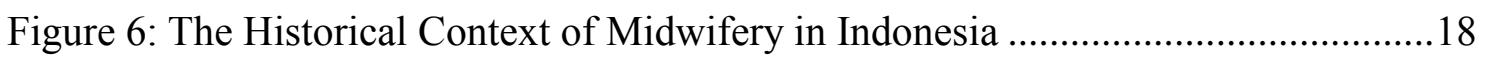

Figure 7: The History of Midwifery Educational Pathway ........................................22

Figure 8: Health Services and the Referral System (Adapted from GHWA, 2013) .......28

Figure 9: Transaction Processes (Maehr \& Braskamp, 1986) ........................................39

Figure 10: The Multifaceted Conceptual Framework (Franco et al., 2002) ...................57

Figure 11: The Adaptation of Multifaceted Conceptual Framework ...............................60

Figure 12:'Success Case Method' Procedure (Adapted from Brinkerhoff, 2003)..........67

Figure 13: Steps in Obtaining a Research Approval Letter ..........................................75

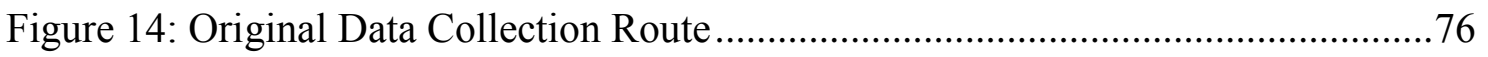

Figure 15: Accessing Remote and Very Remote Villages in NTB ...............................80

Figure 16: Steps of the Thematic Analysis Approach (Adapted from Braun and Clarke,

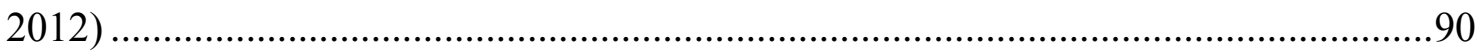

Figure 17: Example of Developing and Redefining Themes......................................93

Figure 18: Recruitment Systems (Adapted from Kurniati \& Efendi, 2012).................103

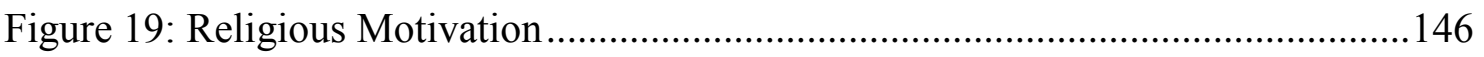

Figure 20: The National and Local Government's Policies/Programmes: ...................196

Figure 21: Key Factors that attract and retain midwives in remote areas: The 'Success

Cases' and The 'Less Success Cases' ............................................................................198

Figure 22: Interaction between Policies and Key Factors ........................................201

Figure 23: Pictorial Representation of the Adapted Framework (Adapted from Franco et

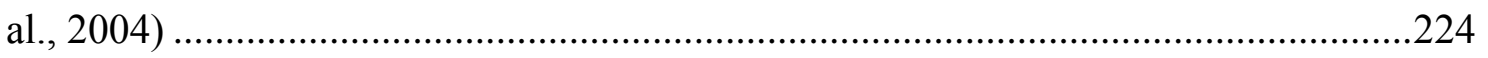

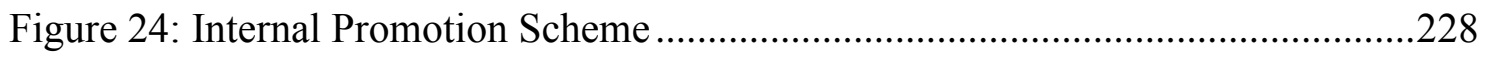

Figure 25: Developing Dual Practice Scheme .......................................................231

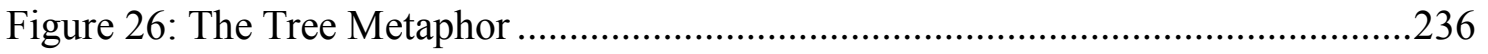




\section{LIST OF BOXES}

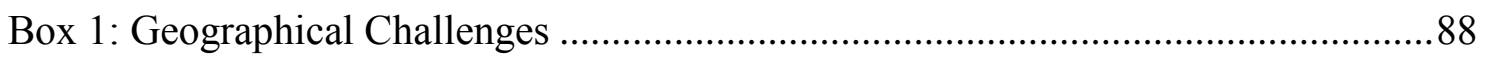

Box 2: Nationally contracted midwife/PTT Pusat 1 - A 'Success Case' ...................... 124

Box 3: Ikatan Bidan Indonesia (Indonesian Midwives Association) Theme Song ...... 141

Box 4: Nationally contracted midwife/PTT Pusat 2 - A 'Success Case' ...................... 148 


\section{LIST OF ACRONYMS}

\begin{tabular}{|c|c|}
\hline AI & Appreciative Inquiry \\
\hline $\mathrm{ANC}$ & Antenatal Care \\
\hline ASEAN & Association of South East Asian Nations \\
\hline AWT & Available Working Time \\
\hline$B A P P E D A$ & $\begin{array}{l}\text { Badan Perencanaan Pembangunan Daerah (Regional } \\
\text { Development Planning Agency) }\end{array}$ \\
\hline BAPPENAS & $\begin{array}{l}\text { Badan Perencanaan Pembangunan Nasional (National } \\
\text { Development Planning Agency) }\end{array}$ \\
\hline$B D D$ & Bidan di Desa ('A Village Midwife Programme') \\
\hline BEONC & Basic Emergency Obstetric and Neonatal Care \\
\hline$B K D$ & $\begin{array}{l}\text { Badan Kepegawaian Daerah (Regional Human Resources } \\
\text { Agency) }\end{array}$ \\
\hline BLHP & $\begin{array}{l}\text { Badan Lingkungan Hidup dan Peelitian (Environmental and } \\
\text { Research Agency) }\end{array}$ \\
\hline BPJS & Badan Penyelenggara Jaminan Sosial (Social Security Agency) \\
\hline CAF & Category Allowance Factors \\
\hline CEONC & Comprehensive Emergency Obstetric and Neonatal Care \\
\hline $\mathrm{DCE}$ & Discrete Choice Experiment \\
\hline $\mathrm{DHO}$ & District Health Office \\
\hline ESOL & English for Speakers of Other Languages \\
\hline FKTP & Fasilitas Kesehatan Tingkat Pertama (Primary Health Care) \\
\hline GoI & Government of Indonesia \\
\hline GHWA & Global Health Workforce Alliance \\
\hline HEC & Human Ethics Committee \\
\hline$I B I$ & Ikatan Bidan Indonesia (Indonesian Midwives Association) \\
\hline IDI & In-depth Interview \\
\hline IFLS & Indonesia Family Life Survey \\
\hline IMR & Infant Mortality Rate \\
\hline KDPDTT & $\begin{array}{l}\text { Kementrian Desa, Pembangunan Daerah Tertinggal dan } \\
\text { Transmigrasi (Ministry of Villages, Development of } \\
\text { Disadvantaged Regions and Transmigration of the Republic of } \\
\text { Indonesia) }\end{array}$ \\
\hline KEMENPAN & $\begin{array}{l}\text { Kementrian Negara Pemberdayagunaan Aparatur Negara } \\
\text { (Ministry of Human Resources) }\end{array}$ \\
\hline LSC & 'Less Success Case' \\
\hline MDG & Millennium Development Goal \\
\hline 'MEP' & 'Midwives Extension Programme' \\
\hline MMR & Maternal Mortality Rate \\
\hline $\mathrm{MoH}$ & Ministry of Health \\
\hline$M P R$ & $\begin{array}{l}\text { Majelis Permusyawaratan Rakyat (People's Consultative } \\
\text { Assembly of Indonesia) }\end{array}$ \\
\hline $\mathrm{NGO}$ & Non-Government Organisation \\
\hline NMR & Neonatal Mortality Rate \\
\hline$N T B$ & Nusa Tenggara Barat (West Nusa Tenggara province) \\
\hline PDR & People's Democratic Republic \\
\hline $\mathrm{PHO}$ & Provincial Health Office \\
\hline
\end{tabular}




\begin{tabular}{ll}
\hline PNS & Pegawai Negeri Sipil (civil servant midwife/midwives) \\
\hline Polindes & $\begin{array}{l}\text { Pondok Bersalin Desa (Village Birthing Centre/s or 'birthing } \\
\text { house/s') }\end{array}$ \\
\hline Posyandu & Pos Pelayanan Terpadu (Integrated Post) \\
\hline PTT Daerah & $\begin{array}{l}\text { Pegawai Tidak Tetap Daerah (regionally contracted } \\
\text { midwife/midwives and doctor/s) }\end{array}$ \\
\hline PTT Pusat & $\begin{array}{l}\text { Pegawai Tidak Tetap Pusat (nationally contracted } \\
\text { midwife/midwives and doctor/s) }\end{array}$ \\
\hline Puskesmas/PKM & Pusat Kesehatan Masyarakat (Community Health Centre/s) \\
\hline Pustu & Puskesmas Pembantu (Sub-healthcare Centre/s) \\
\hline SBA & Skilled Birth Attendant \\
\hline SC & 'Success Case' \\
\hline SCM & Success Case Method \\
\hline SDG & Sustainable Development Goals \\
\hline STR & Surat Tanda Resgistrasi (Indonesian midwifery registration) \\
\hline TA & Thematic Analysis \\
\hline TBA & Traditional Birth Attendant \\
\hline UNDP & United Nations Development Programme \\
\hline UNICEF & United Nations Children's Fund \\
\hline UNFPA & United Nations Population Fund \\
\hline VUW & Victoria University of Wellington \\
\hline WHO & World Health Organisation \\
\hline WISN & Workload Indicators of Staffing Need \\
\hline
\end{tabular}





\section{CHAPTER 1. INTRODUCTION}

'All people, everywhere, shall have access to a skilled, motivated, and facilitated health worker within a robust health system'

(The Global Health Workforce Alliance, 2015)

\subsection{Introduction}

Access to health professionals or health services for every human being in the world is essential. This issue has been a cause for concern for both developed and developing countries for some time. One response, highlighted by the World Health Organisation (WHO) (2012) in their Sustainability Development Goal number three "improving health and well-being of the people" - has been to focus on the importance of managing health workforces in less desired areas internationally.

After working and living for more than five years in remote islands of the Indonesian archipelago (for example, Nias Island, Mentawai Island, Bima, and some areas in East Java), I came to appreciate the importance of midwives for the health and wellbeing of such communities and decided to explore this topic further. In this chapter I provide a background and the rationale for the research including the research questions.

\subsection{Background}

The Global Health Workforce Alliance (GHWA) (2015) points out that health workers are the key component of health systems. Equal distribution of health workers has not been attained in many countries though, affecting people's access. Poor access to health workers and health services has high potential to limit or at least not improve community health outcomes. According to Fankernberg and Thomas (2001), ability to access village midwives improved the body mass index of women in their reproductive age. The research shows that the percentage of women with a body mass index less than 21 declined from $44 \%$ to $41.3 \%$, while the percentage of those whose body mass index was less than 18.5 delcined from $12.8 \%$ to $10.9 \%$ when there was better access. 
Further, Frankernberg, Buttenheim, Sikoki, and Suriastini (2009) also indicate that medically trained midwives in communities could influence women's patterns of healthcare use during pregnancy and delivery. Pregnant women were more likely to receive iron tablets during their pregnancy and deliver their babies in a medically oriented facility or assisted by medically trained provider. It is, therefore, undeniably important that health workers play an essential role in improving health services and health outcomes at a community level.

According to the United Nations Population Fund (UNFPA) (2011), globally, approximately 35,000 women experience birth complications every day, resulting in around 900 deaths per day. Indonesia's Maternal Mortality Rate (MMR) ranks third highest in South East Asia after Cambodia and Lao People's Democratic Republic (PDR) (220, 250 and 470 per 100,000 live births respectively) (WHO, 2013). In 2010, one in 210 mothers died during pregnancy or following childbirth in Indonesia (Countdown, 2012; UNICEF, 2013), unlike developed countries where only one in 40,000 maternal deaths occurred (Baird, Ma, \& Ruger, 2011).

The United Nations Children's Fund (UNICEF) (2012) points out that geographic disparities contribute to mortality rates for those aged under five years. Eastern Indonesia, namely West Sulawesi, South Kalimantan, and the West Nusa Tenggara Province (Nusa Tenggara Barat or NTB) experienced high neonatal mortality, 90 per 1000 live births, while the Neonatal Mortality Rate (NMR) in Java was lower in these Eastern provinces of Indonesia at around 45 per 1,000 live births in 2007.

In order to reduce the high mortality rates among mothers and children, since the 1960s, the Government of Indonesia (GoI) has been committed to developing the Indonesian health workforce as part of its health sector reform. The GoI has introduced a number of programmes and policies focussed on the recruitment and retention of health workers. In the early 1990s it introduced a progressive approach to accelerate the distribution of health workers, especially midwives, so that the targeted reduction of the MMR and the Infant Mortality Rates (IMR) could be achieved (Shiffman, 2003). 
'A Village Midwife Programme' (Bidan di Desa or BDD) was introduced by the GoI in 1989 in an attempt to help reduce the high MMR and NMR by providing one midwife for each village (Frankenberg, Suriastini, \& Thomas, 2005; Shankar et al., 2008; Shefner-Rogers \& Sood, 2004; R. Shrestha, 2010). Efendi (2012) also points out the effort of the GoI in providing health care in remote and very remote areas by introducing various policies, such as compulsory service, contracted staff, and the special assignment for strategic health workers (i.e. doctors, midwives, and nurses).

Thus, the rate of midwives per capita in Indonesia increased from 35 per 100,000 population in 1996 (Rokx et al., 2010) to 49.56 per 100,000 population in 2014 (Ministry of Health, 2015), although that ratio has fluctuated. This fluctuation is likely due to the number of midwives moving back to urban areas when their village midwifery contract ends or when it is not extended beyond the contract end date. Another reason may be the geographical difficulties (comprising mountainous, forest locations, and remote islands) in many areas of Indonesia. This situation has been a great challenge to the deployment of health professionals (Efendi, 2012). Efendi (2012) also points out that health workers prefer to work in urban areas because they offer better facilities and opportunities. Additional reasons that prevent health workers from moving to remote areas, include salaries, transportation difficulties, no updated information, poor working conditions, limited career options, and lack of security (Dieleman, Cuong, Anh, \& Martineau, 2003; Egger, Lipson, \& Adams, 2000; Zinnen, Paul, Mwisongo, Nyato, \& Robert, 2012)

Another report from the WHO (2013) demonstrates the difficulties experienced by many countries, including Indonesia, in attracting and retaining health workers. In Indonesia, some of the main challenges are the high turnover rate of health workers, low morale and motivation (WHO, 2010a), and the payment system which has not effectively encouraged an equal or equitable distribution of health workers (Rokx et al., 2010). Thus, the availability and accessibility of health workers, particularly in remote villages, remains an issue. 
As a result, the shortage of health workers, particularly in remote areas is seen to be inevitable. Efendi (2012) indicates that most remote islands in Indonesia lack trained health personnel, even though policy required public services assignments of one to five years after graduation (in 1992, the policy was modified). The disparity in workforce distribution between urban and rural areas is also concerning according to Efendi et al. (2016). For instance, latest figures indicate a high ratio of physicians per 100,000 population in Jakarta, the capital city of Indonesia (117 per 100,000), compared to other provinces, such as $N T B$ in the eastern part of Indonesia (105 per 100,000) (Ministry of Health, 2015). The disparity in midwives and nurses also occurs between provinces in Indonesia (Ministry of Health, 2015).

The GHWA and WHO (2013) point out that many countries, including Indonesia, have experienced challenges in providing equal access to healthcare at the community level, particularly in remote areas. Indonesia, along with 36 other countries (31 countries in Africa and five countries in South East Asia), has a density of Skills Birth Attendants (SBAs) ${ }^{1}$ lower than 22.8 per 10,000 population and a coverage of births attended by SBAs of less than 80\% (GHWA \& WHO, 2013 )

Achadi et al. (2007) report that some villages in Indonesia have either no, or a very limited number of midwives. Their 2007 study identified that $23.1 \%$ of villages were without a midwife, $32 \%$ of villages had two to four midwives per 10,000 population, and $65.3 \%$ of villages had six midwives per 10,000 population. A study conducted by D'Ambruoso et al. (2007) in a similar period of time identified that village midwives in rural areas of West Java had to serve up to five villages.

A comprehensive study was conducted by Anderson et al. (2004) on the production, distribution and performance of physicians, nurses and midwives in Indonesia. In order to achieve the WHO global recommended target of 2.28 health workers per 1,000 by 2035 , Indonesia needs to increase the number of health workers by $78 \%$ from the current level (e.g. 4,063 physicians in 2004) (Anderson et al., 2004).

${ }^{1}$ SBA is defined as a "health professional, such as midwife, doctor or nurse who has been educated and trained to proficiency in the skills needed to manage normal (uncomplicated) pregnancies, childbirth and the immediate postnatal period and in the identification, management and referral of complications in women and newborns" (WHO, 2004, p. 1) 
The number of medical schools, including midwifery schools has increased. This has affected the number of midwives. In 2011, the total number of midwives was 115,948 ( 0.49 per 1,000 population) which improved noticeably from 79,661 (ratio 0.37 per 1,000 population) midwives in 2005 . Despite the increases in the total number of health workers in Indonesia, there are still substantial staffing gaps (Anderson et al., 2004). There is still an inconsistency in the availability of health workers, such as midwives between urban and remote areas, and as a result the effort in reducing maternal and neonatal mortality and morbidity will remain compromised.

The importance of midwives in improving the health outcomes of mothers and children has been shown in many studies (D'Ambruoso et al., 2007; Ministry of Health, 2011b; Ronsmans et al., 2009; Thind \& Banerjee, 2004; Thompson, 1998; UNICEF, 2012; UNFPA, 2011). They all agreed that women who receive appropriate and regular check-ups from health professionals such as midwives are less likely to experience maternal or neonatal deaths.

In the remote villages of Indonesia, midwives are seen as frontline health workers. Based on my experiences working and living in some these remote areas of Indonesia, I belive village midwives play an important role in the health outcomes of the community. The village midwives are often the only health provider in remote and very remote areas where people count on their services $24 / 7$. Their roles are not just taking care of women and children, but also providing basic healthcare for people in the community. In addition, having midwives in remote areas and very remote areas can save people in the villages from travelling to the city in order to seek healthcare services which are mostly located there or in sub-districts. 
Midwives continue to be one of the main health providers in remote areas (Rokx et al., 2010). The National Development Planning Agency or Badan Perencanaan Pembangunan Nasional (BAPPENAS, 2012) also suggested that both in rural and urban areas, midwives are the highest proportion of birth attendance health workers followed by other SBAs. In Indonesia, in 2011, 65.48\% of births were assisted by midwives in urban areas, and $62 \%$ of births assisted by midwives in rural areas. In the same year, only $24.86 \%$ births were assisted by doctors in urban areas, and $9.15 \%$ of births assisted by doctors in rural areas. Thind and Banerjee (2004) have shown that a decrease in maternal and neonatal mortality in some areas in Indonesia is attributed to the utilisation of SBAs, which predominantly is utilisation of the village midwives.

The role village midwives play in assisting women before, during and after their pregnancy, through the provision of mother and child health services, is significant. It includes detecting danger signs and complications during pregnancy, organising referrals, providing contraception information and services, and providing information about breastfeeding. As Barclay (2008) points out, midwives are an asset to communities because they have the potential to create connections for the care of women. They are also more able than doctors and nurses to pay attention to women's emotional and practical support needs during and after pregnancy.

Decades of policies and programmes have been implemented, but the issue has remained. Attracting and retaining midwives requires continuous effort and a move away from short-term approaches to long-term plans that involve political commitment and 'real' investment. It seems that the factors that operate to attract and retain midwives to remote postings are not well understood in the Indonesian context.

\subsection{Purpose of the Research and Research Questions}

The WHO (2010a) suggests that in order to attract and retain health workers in rural areas, some innovative interventions are needed. For instance, intervention could encompass recruiting students with a rural background and embedding a rural curriculum so that students are more familiar with the rural situation. 
Thus, this study focuses on human resource management and health policy, in particular, for attracting and retaining midwives in remote villages of Indonesia. This research explores the important factors that contribute to the success of recruitment and retention of midwives in remote areas of Indonesia, and, with a broader perspective, explores a range of factors, including recognition of personal, organisational and environmental factors. It is based on the assumption that having midwives in rural and remote areas of Indonesia depends on two interconnected aspects: first, the factors that influence midwives to work and stay in rural and remote areas; and second, the extent to which the policies and programmes of the GoI respond to and facilitate factors that influence recruitment and retention of midwives in rural and remote areas of Indonesia.

According to Rockers et al. (2013), policy-makers need to understand the needs and expectations of health workers in order to develop better policy. In the context of my study, understanding key factors that attract and retain midwives may provide part of the solution to improving Indonesia's access to health workers in remote areas and thereby improve the health outcomes of Indonesian women.

Thus, the main research question of my study is 'How can there be better recruitment and retention of village midwives in remote areas of Indonesia?'

The three sub-questions that arise from this are:

1. What are the key factors that attract midwives to remote areas of Indonesia?

2. What are the key factors that retain midwives in remote areas of Indonesia?

3. To what extent do the policies and programmes of the GoI respond to and facilitate factors that influence recruitment and retention of midwives in remote areas of Indonesia' 


\subsection{Significance of the Research}

This research is concerned with investigating factors important to the recruitment and retention of midwives in remote areas of Indonesia, thus contributing to the recruitment and retention literature related to human resources management and organisation, psychology, and health policy. Through its evaluation of GoI policies surrounding recruitment and retention of midwives in remote areas, the study also contributes specifically to Indonesian health policy literature. Despite the evaluation aspects, this study is a case study focusing on the analysis of information from midwives and government officials, as well as examining government documents. This study accentuates what works best in attracting and retaining midwives to remote postings.

Health workforce studies have been undertaken in many countries (Dolea, Stormont, \& Braichet, 2010; Liu, Dou, Zhang, Sun, \& Yuan, 2015), not only in regard to the association between the role of midwives in the community and the health status of mothers and children, but also in relation to recruitment and retention of health workers. However, there is a paucity of research that specifically explores the issue of the recruitment and retention of midwives and particularly in remote areas of Indonesia. Previous international research tends to focus on specific health workers, such as doctors and nurses, but largely ignores the midwifery workforce. In addition, previous research in Indonesia shows there is very little qualitative research on midwives. This research gap is discussed further in Chapter Three (pg. 37).

In addition, it is important to know how programmes and policies are able to respond to the factors that satisfy midwives working in remote areas, such as those that might encourage them to stay longer or permanently in these areas. Furthermore, cultural factors such as belief systems have not been explored which is a factor that may have a significant influence on the recruitment and retention of midwives in remote areas of Indonesia. 
This research plays an important role, then, in providing research findings about an area where little is specifically known, including in regard to cultural factors that influence the recruitment and retention of midwives in Indonesia. In its important contribution to new knowledge, the research has developed a better understanding of both cultural and contextual specific factors, and strategies for improving the recruitment and retention of midwives in remote areas of Indonesia.

In addition, a novel approach underpins the methodology. The use of the Success Case Method (SCM) blended with Appreciative Inquiry (AI) is an evaluation technique that is predominantly used in the private or business sectors. In this research, SCM and AI are used in the field of health policy to study midwives in marginalised areas.

\subsection{Thesis Overview}

This thesis consists of eight chapters, they are:

\section{Chapter One: Introduction}

Chapter One contains background information relating to the study.

\section{Chapter Two: Contextual Background}

Chapter Two begins with an overview of the characteristics of Indonesia. This is followed by the history of midwives and health systems in Indonesia. This chapter also discusses the importance of having midwives in communities, especially in remote villages.

\section{Chapter Three: Literature Review}

Chapter Three begins by discussing the literature concerning the key factors that influence health workers to work in remote areas, particularly in remote settings in developing countries. Secondly, it discusses the literature concerning the key factors that retain health workers in remote postings in developing countries. Finally, it outlines some motivational frameworks related to recruitment and retention of health workers in remote areas. 


\section{Chapter Four: Methodology}

Chapter Four discusses the methodological approach that was implemented in order to answer the research questions. It elaborates on the research methodology and the analytical approach, which includes the positioning of the study within a theoretical framework. It then discusses the data analysis strategy selected, Thematic Analysis (TA).

\section{Chapter Five: Attraction to Work in Remote Areas}

Chapter Five starts with the explanation of different types of midwives in both 'success cases' and 'less success cases' in NTB. It then goes on to discuss the six steps of the recruitment system and the key factors that attract midwives to remote postings in NTB. Key factors in attracting midwives in remote areas in both cases are also discussed.

\section{Chapter Six: Retaining Midwives in Remote Areas}

Chapter Six discusses the main findings concerning the key factors that retain midwives in both 'success cases' and 'less success cases' in NTB.

\section{Chapter Seven: Policies/Programmes versus the Key Factors}

Chapter Seven evaluates the assortment of policies the GoI has 'tried out' to address issues surrounding the recruitment and retention of midwives in remote areas, including current policies. The extent to which existing policies or programmes respond to midwifery recruitment and retention issues in remote areas of Indonesia is discussed, alongside the extent to which those current policies or strategies facilitate factors that influence midwives to take up remote postings.

\section{Chapter Eight: Discussion and Conclusion}

Chapter Eight elaborates on the key findings and where these key findings sit within existing studies of recruitment and retention of health workers in remote areas. In addition, it discusses how understanding these key factors impact on improving policies and programmes regarding recruitment and retention systems in Indonesia and other countries in a similar situation. This discussion chapter is also used as the foundation for building recommendations for further research and for providing evidence to policy-makers about how best to craft policies and programmes related to the recruitment and retention of midwives in remote areas of Indonesia. 


\section{CHAPTER 2. CONTEXTUAL BACKGROUND}

\subsection{Introduction}

Chapter Two provides the contextual background to the research. It begins with an overview of the cultural and geographic situation of Indonesia, followed by the country's health development focuses, and an explanation of the Indonesian health system. Outlining the history and the position of the Indonesian context will also be explored in this chapter.

\subsection{Overview of Indonesia}

Geographically, Indonesia is located between two continents - Asia and Australia - and two oceans - the Indian and the Pacific. Indonesia and New Zealand are relatively close in terms of proximity, even though there is no shared border, as is the case with Indonesia and Australia. Indonesia is the largest archipelago in the world with around 17,000 islands. Its five major islands are Sumatra, Java, Kalimantan, Sulawesi and Papua (Figure 1).

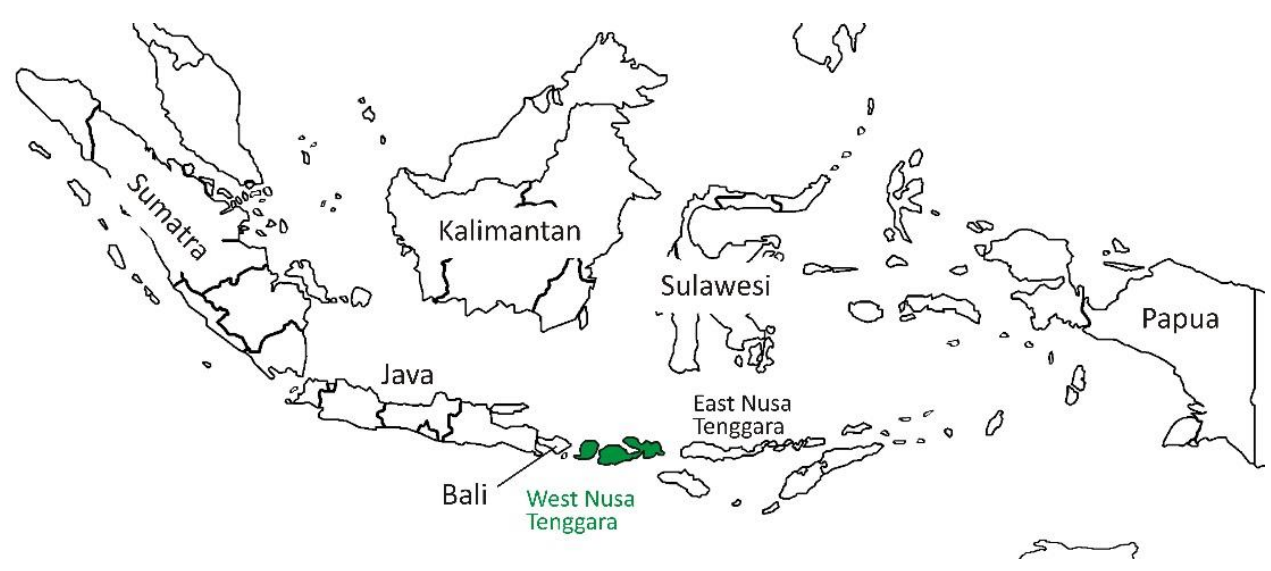

Figure 1: Map of Indonesia (Adapted from www.freeworldmaps.net)

Indonesia comprises 300 ethnic groups, most of which live on the larger islands and which speak a wide range of languages. There is just one national official language, called Bahasa Indonesia, and that is used for daily communication in formal and informal sectors. Each province still embraces their own local language for their daily conversation. For instance, people in NTB use their local languages, such as Sasak, Samawa or Mbojo, for their daily conversation. 
Socially, Islam is the predominant religion in Indonesia with almost $90 \%$ of the total population belonging to this faith. Yet Indonesia is considered a secular country and implements a policy called Guided Democracy (Forshee, 2006). Despite its dispersion and diversity, Indonesia's national catchphrase is 'unity in diversity', which demonstrates that it values difference while seeing itself as one nation. The ideology of Pancasila (five principles) is used as the basis of governing the country. These five principles are:

1. Ketuhanan yang Maha Esa (belief in the one and only God)

2. Kemanusian yang adil dan beradap (a just and civilised humanity)

3. Persatuan Indonesia (the unity of Indonesia)

4. Kerakyatan yang dipimpin oleh hikmat kebijaksanaan dalam permusyawaratan dan perwakilan (democracy, led by the inner wisdom of deliberations and representation)

5. Keadilan sosial bagi seluruh rakyat Indonesia (social justice for all people of Indonesia).

Since Indonesian independence in 1945, the values of Pancasila have been introduced to all Indonesians without exception, which acknowledges the differences in culture, tolerance, pluralism, and social justice. These values have been a great foundation in order to tie various differences throughout the archipelago.

Indonesian is more water $\left(3,257,483 \mathrm{~km}^{2}\right)$ than island $\left(1,922,570 \mathrm{~km}^{2}\right)$. Java Island is the most populous and most developed island, particularly in comparison to those islands in the eastern part of Indonesia - West Papua, West Nusa Tenggara, East Nusa Tenggara, Gorontalo and North Maluku. These areas are more likely to have remote and very remote areas due to the nature and the typology of the areas. The slow development in the eastern part of Indonesia is attributed to unequal distribution of development prior to reformation in 1998. The centralised government system where the priority for development mostly occurred in the Western part of Indonesia, such as Java Island, created a significant gap between Western and Eastern Indonesia. 
Demographically, Indonesia is the fourth most populous country after China, America and India. According to the latest Census in 2010, the population of Indonesia is around 237,641,326 inhabitants - 119,630,913 males and 118,010,413 females (Ministry of Health, 2013). 44\% of the total population live in urban areas (UNFPA, 2011), which means $66 \%$ of the total population live in rural areas. Yet the availability of health professionals in remote areas is lower than in urban areas.

In addition, the number of women of reproductive age (15-49 years) is $64,292,000$ or $22 \%$ of the total population (UNFPA, 2011). Given its large female population with almost a quarter being categorised as of reproductive age, it is essential to ensure that Indonesian women are afforded their right to the best possible healthcare during pregnancy and childbirth.

In developing countries including Indonesia, women's health, especially maternal health, deserves special attention because women play such an important role in families, bearing and raising children (Andajani-Sutjahjo \& Manderson, 2004; Nancy \& Edith, 1994; Theodore, 2007).

Economically, agriculture is the dominant sector providing income to Indonesian households. Even though progress can be seen in rural areas, poverty remains high, with $13.8 \%$ of the rural population being considered impoverished, compared to $8.2 \%$ in one of the urban areas (UNFPA, 2011). People who live in rural areas often experience a lack of access to education, healthcare and other public services, exacerbating poor health.

The remoteness of areas presents a serious challenge to the delivery of health services. D'Ambruoso, Byass, Qomariyah and Ouédraogo (2010) and D'Ambruoso, Byass and Qomariyah (2010) describe the problematic issues in remote areas of Indonesia, including availability, affordability and safety of transportation. In some remote areas, walking, motorbikes and long boats (Indonesian traditional boats made from bamboo or drums) are the only forms of transport, and the already difficult access conditions are worsened in the rainy seasons as the roads become slippery. Limited facilities, such as poor access to clean water, electricity, sanitation, and healthcare services exacerbate the difficulties in people's lives. 


\subsection{Health Priority: Reducing Maternal and Neonatal Rates}

Reducing the MMR and NMR is a constant issue for global public health, and particularly in Indonesia. In response to the Nairobi Safe Motherhood Conference in 1987, safe motherhood became a prominent issue in Indonesia (Shrestha, 2010).

Following the Millennium Development Goals (MDGs) framework which 'expired' in September 2015, and then the replacement Sustainable Development Goals (SDGs), Indonesia is still striving to achieve the MDGs target (i.e. 102 per 100,000 live births) and lower mortality rates of other Association of South East Asian Nations (ASEAN) countries. With an actual average annual rate of reduction for both maternal and child mortality of less than 5\% (WHO, 2013) Indonesia might not be able to reach these expectations though (Figure 2).

The maternal and neonatal mortality rates are important indicators in measuring health status in Indonesia. The MMR is defined as the number of women who die from a pregnancy complication or its treatment (not including accidents or incidental cases) either during pregnancy, whilst giving birth, or in the immediate post-natal period (42 days after giving birth), without taking into account length of pregnancy, per 100,000 live births. Even though the number of MMR has reduced gradually over the time, the rate is still alarming.

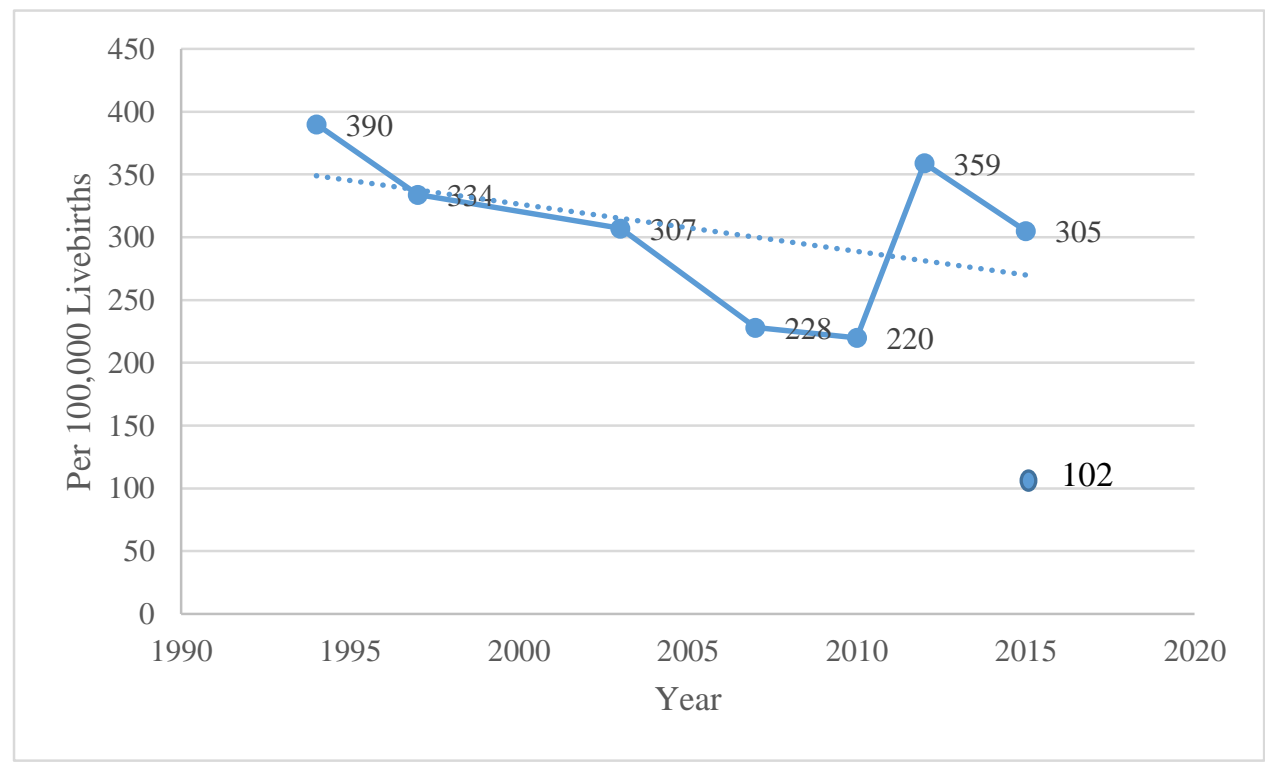

Figure 2: Trend of Maternal Mortality Rate in Indonesia from 1994-2015 (Ministry of Health, 2016) 
Indonesia's MMR ranks third in South East Asia countries after Lao PDR and Cambodia - 220, 470, and 250 per 100,000 live births respectively (WHO, 2013) (Figure 3). Compared to developed countries, maternal and child mortality rates in Indonesia are significantly higher. In 2010, one in 210 mothers died during pregnancy or following childbirth (Countdown, 2012; UNICEF, 2013), unlike industrialised countries where only one in 40,000 maternal deaths occurred (Baird et al., 2011).

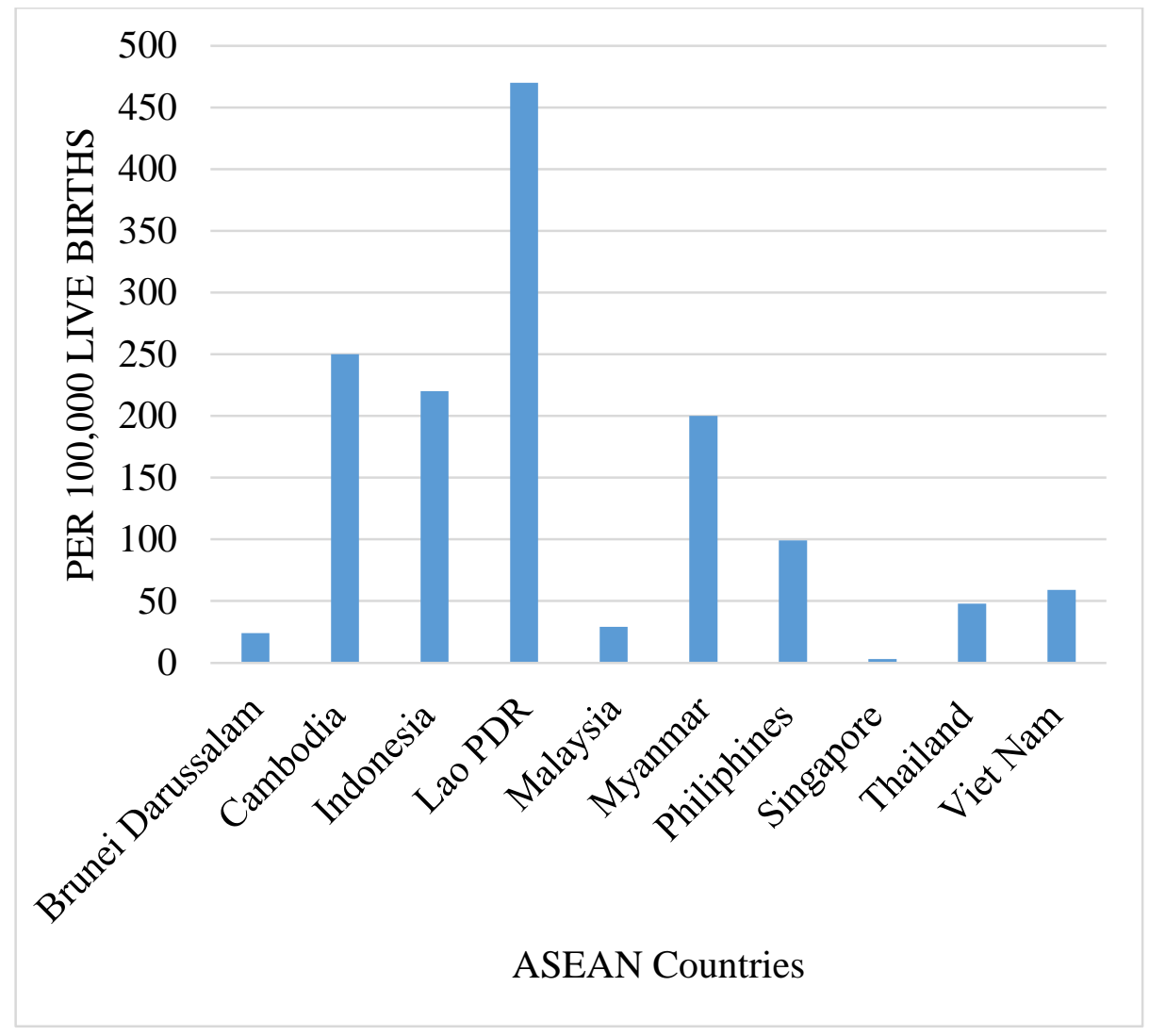

Figure 3: Maternal Mortality Rate Among Sout-East Asia Countries in 2010 (WHO, 2013)

Another important indicator to measure Indonesians' health status is NMR. According to the UNICEF (2012) and Countdown (2012), every three minutes a child aged under five years dies in Indonesia, and $48 \%$ of these are newborn babies. The NMR measures the number of babies who die within the first month after birth (0-28 days) per 1,000 live births in the same year (Ministry of Health, 2013). Even though Indonesian NMR decreased from 32 deaths per 1,000 live births in 1990 to 19 deaths per 1,000 live births in 2015 (Ministry of Health, 2016), the reduction has been stagnant (Figure 4). 


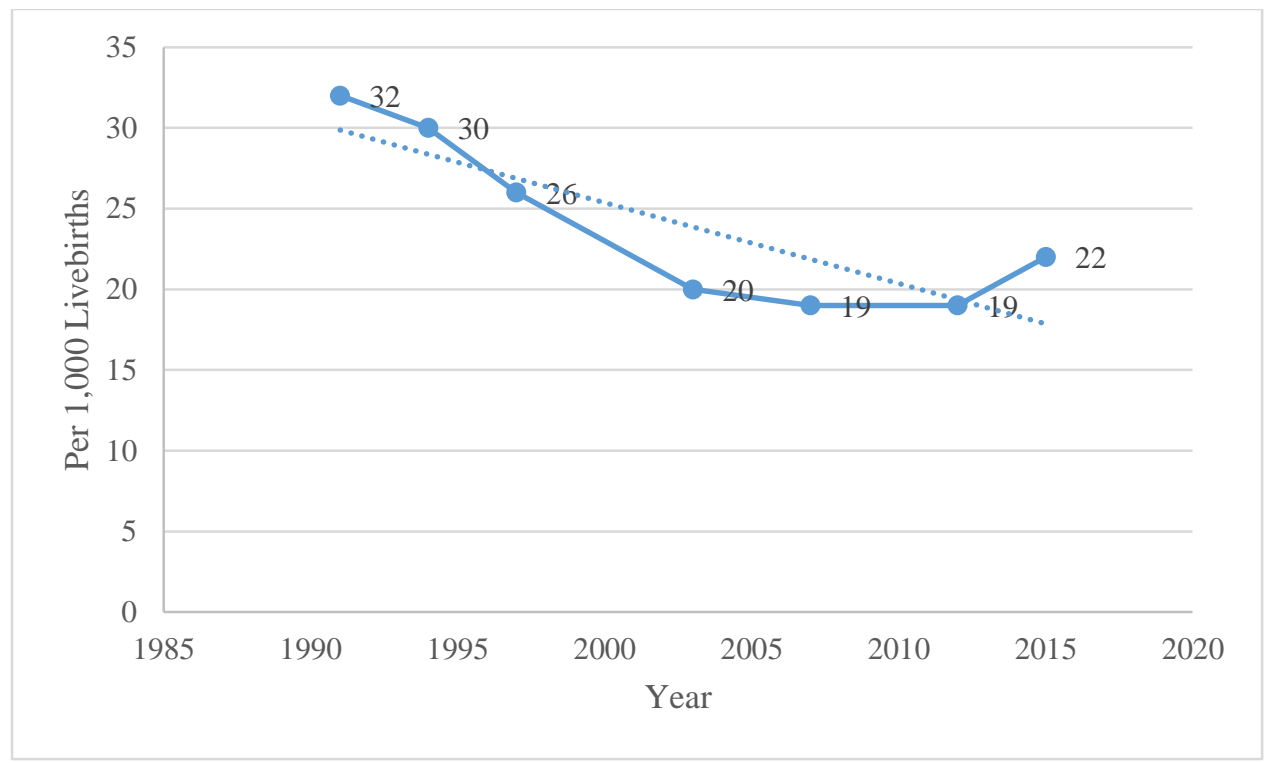

Figure 4: Trend of Neonatal Mortality Rates in Indonesia from 1990-2015 (Ministry of Health, 2016)

Currently, Indonesia's NMR is ranked fourth highest amongst the ten ASEAN countries with 32 per 1,000 live births (WHO, 2013) which points to a significant difference between industrialised and non-industrialised countries (Figure 5). For example, in New Zealand and Australia, in 2011, the mortality rates for children aged under five years were six per 1,000 live births (WHO, 2013).

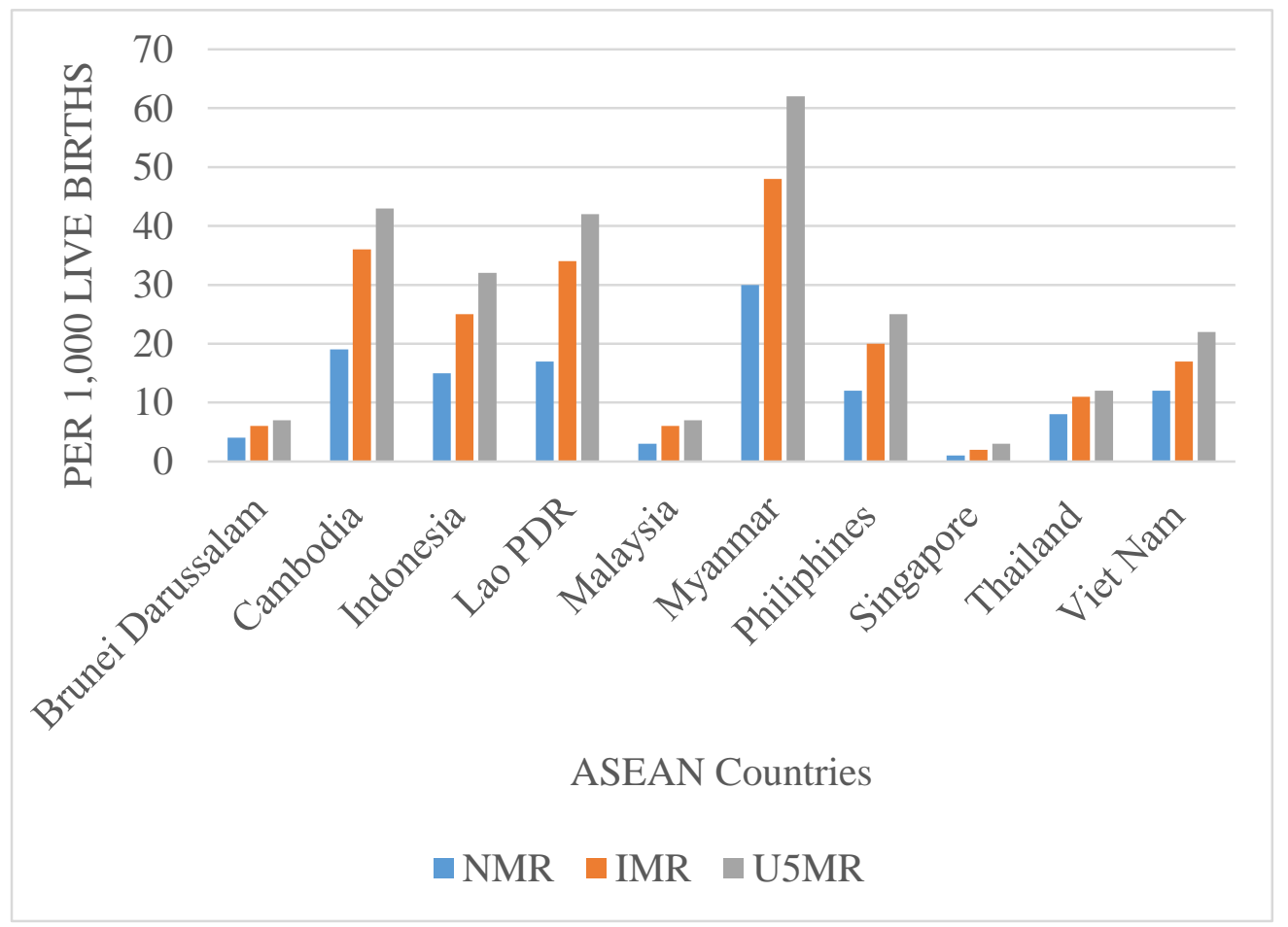

Figure 5: Neonatal, Infant, and Under Five Mortality Rates among South East Asia Countries in 2011 (WHO, 2013) 
Many studies point out that poor maternal and neonatal health in remote areas is attributable to poor accessibility to health providers, particularly midwives (D’Ambruoso et al., 2007; Hatt et al., 2007; Ronsmans et al., 2009). The WHO (2004) also suggests the importance of "continuum of care' ${ }^{2}$ for pregnant women which requires a functional healthcare system. In this case, the availability of midwives in remote areas is a crucial component in providing a 'continuum of care', so that the health outcomes of mothers and children in remote areas can be maintained and improved.

In addition, the GHWA and WHO (2013) also highlights the central role of health workers to accelerate the progress of universal health coverage ${ }^{3}$. It stated that universal health coverage will not be achieved without health professionals that are fit for purpose and fit to practise. Prior to exploring the role of midwives in the Indonesian health system, the following section discusses the history of midwives in Indonesia and the Indonesian health system in general.

\subsection{The History of Village Midwives: Why it became prominent}

A comprehensive and chronological understanding of the transformation of the Indonesian political system and policies or programmes on deployment of health providers is described in this section (Figure 6). In terms of political systems, beginning in the fourth century, the now Republic of Indonesia transformed from a monarchy, and colonialism, to eventual independence in 1945. From 1965-1966, a coup occurred whereby General Soeharto became the new leader replacing the first president Soekarno. A new era was established, under Soeharto's leadership was based on absolute power and a centralised system. Military dictatorship flourished. As a result, many violations of human rights arose, such as the banning of newspapers, exploitation of natural resources, and jailing of dissidents (Forshee, 2006).

\footnotetext{
${ }^{2}$ Continuum of care starts with the woman and her family in their own home, then at the first level of healthcare, and involves the provision of high-quality midwifery care. This care can continue from pregnancy, birth and postnatal periods (WHO, 2004).

${ }^{3}$ Universal health coverage means to urge governments' commitment in providing all people with access to affordable and quality health care services (GHWA \& WHO, 2013 ).
} 


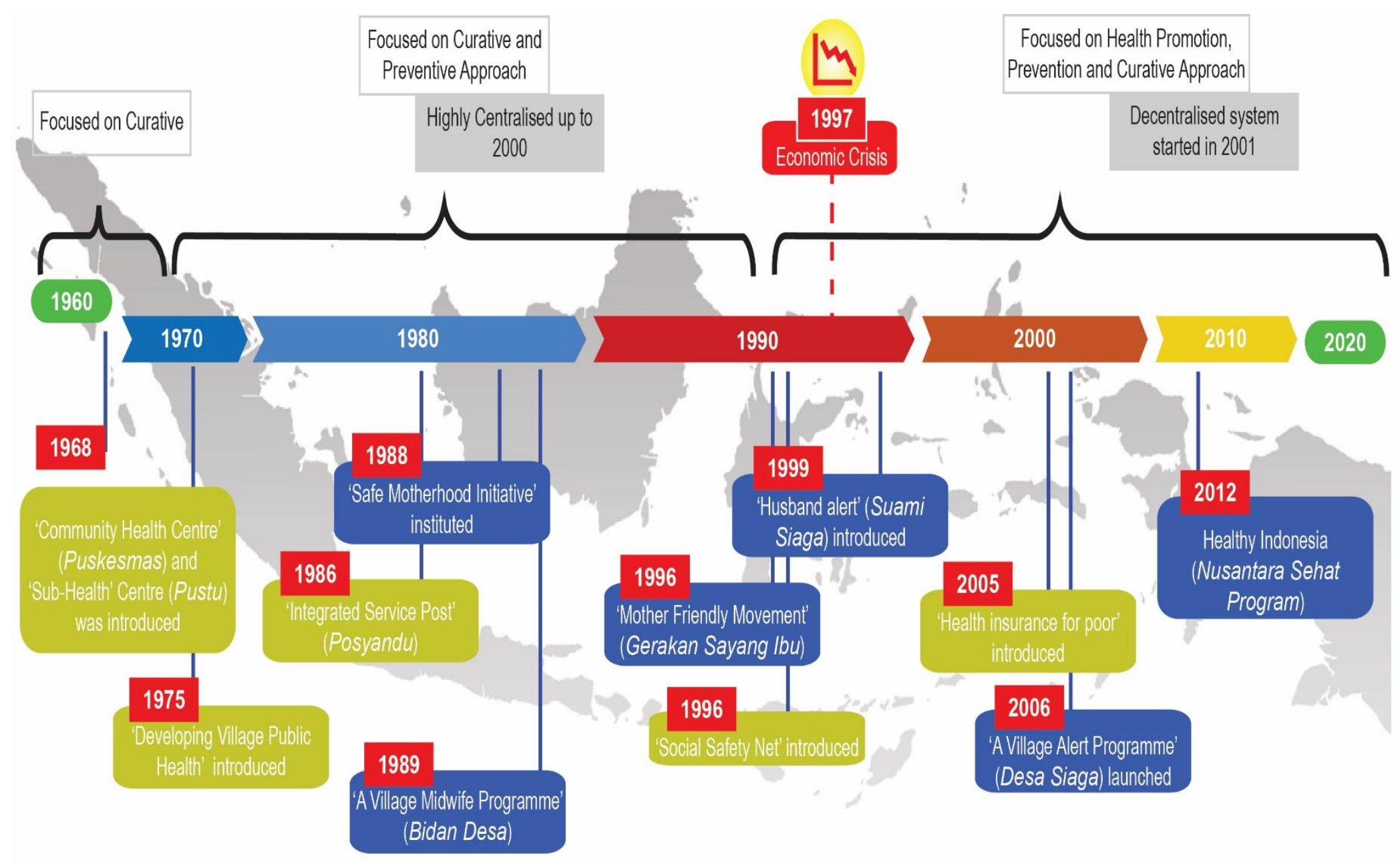

Figure 6: The Historical Context of Midwifery in Indonesia 
Under Soeharto's authoritarian leadership, various infrastructures, such as roads, medical clinics, bridges, and schools were developed. As a result, in a short period of time, the Republic of Indonesia achieved vast growth in literacy and the economy. In 2011, the Indonesian literacy rate of those aged 15 years and over reached $92.8 \%$, with differences existing between males (95\%) and females (89\%) (UNFPA, 2011), and urban (95.7\%) and rural areas (89.9\%) (Ministry of Health, 2013).

In 1997, Indonesia suffered from the monetary crisis that swept South East Asia. Failure to carry out economic reforms is one of a variety of reasons why Soeharto was ousted after his 30 years of leadership. In May 1998, Soeharto stepped down after four university students were shot and killed in Jakarta prompting massive riots. After these traumatic incidents, the reformation era started which unlocked military power and allowed the media and people more freedom. Further changes occurred from 2004 to date, where the economy has been growing considerably with average annual growth of between $4 \%$ and $6 \%$. Since, then, the number of those living in poverty has decreased. In 2012 , the percentage of people living in poverty was approximately $11.7 \%$. This number is slightly lower than in 2011 when the percentage was $12.5 \%$ (Ministry of Health, 2013).

The democratic process was continued by the Indonesia government who launched a radical transformation from a centralised system to a decentralised system in 2001 (Heywood and Choi, 2010; WHO, 2007). This system was expected to provide more opportunity for local governments to develop their regions based on local needs. These political transformations, namely the government system, economic, education and infrastructure development, have affected the health services and health workers of Indonesia.

At the dawn of independence in 1950, according to Heywood and Choi (2010), the health system of Indonesia focused on the construction of health infrastructures such as Puskesmas at sub-district level and public hospitals at the district level (Rokx et al., 2010). In a similar manner, the economy stability and highly authoritarian regime of the second president of Indonesia influenced the accelerating of the development of health infrastructures (Heywood \& Choi, 2010; Kristiansen \& Santoso, 2006). These interventions indicate that the GoI had attempted to improve access to health services for communities, particularly in the rural areas. 
In 1968, Puskesmas and Pustu were introduced by the GoI in every province in Indonesia. Puskesmas are the back bone of health care in Indonesia and responsible for organising health development in communities (Frankenberg \& Thomas, 2001; Ministry of Health, 2013). Apart from Puskesmas, Pustu were built as an extension of Puskesmas with an aim of enhancing quality and outreach of the Puskesmas. Both health facilities are expected to provide basic health care to the community in general, as well as obstetric and neonatal care to women.

After four decades of their implementation the number of Puskesmas increased significantly from 9,321 units in 2011 to 9,754 units in 2015 (Ministry of Health, 2016). Puskesmas provide outpatient and inpatient services and 6.358 units are Puskesmas non-treatment which only provide outpatient services (Ministry of Health, 2016). The ratio between Puskesmas and the population also increased from 1.16 Puskesmas per 30,000 population in 2011 to 1.17 Puskesmas per 30,000 population in 2013 (Ministry of Health, 2016). The increase in the average ratio of the population able to access these health facilities indicates the effort the government has put into bringing health services closer to communities.

In 1975, the GoI launched other health interventions, including 'Developing Village Public Health' (Pembangunan Kesehatan Masyarakat Desa or PKMD), which, in 1986, was developed into 'Integrated Service Post' (Pos Pelayanan Terpadu or Posyandu) (Leimena, 1989). These programmes were the first community-based health interventions raising the community awareness of health. According to the Posyandu handbook that was published by the Ministry of Health, Posyandu should be run by two to five health volunteers from the community. Every Posyandu provides five basic care services, including mother and child health services, family planning, immunisation, nutrition, and diarrhoea control. The programme also tends to focus health promotion on healthy lifestyles and other issues related to improving the health status of the community. 
The Posyandu's kader has potential to support the work of village midwives because they are able to mobilise women and children to attend Posyandu; thus women and children can receive basic health care every month. This means that village midwives are able to regularly monitor the health status of pregnant women and of children. Despite the significant increase of the number of Posyandu in every village in Indonesia within a short period of time, some challenges remain, such as improving the quality of Posyadu's kader as well as their facilities (Laimena, 1989).

In 1989 an innovative intervention, in terms of reducing maternal and child mortality was launched by the GoI called 'a village midwife programme' (Bidan di Desa) (Shiffman, 2003; Shrestha, 2010). This programme was initiated by the GoI right after the international conference in Nairobi, Kenya 1987, on Safe Motherhood Initiative. The Safe Motherhood Initiative became prominent in many countries, including Indonesia, which prioritised reducing maternal death and ways to address this issue. In order to achieve the Safe Motherhood goals, one of the initiatives provided good-quality maternal health services, which included skilled care for both routine and complicated cases (Shiffman, 2003).

However, Swaminathan, Matsumoto and Nugent (2010) point out that from 1991-1992, there was limited availability of village midwives in Indonesia, particularly in rural and remote areas. In order to improve the availability of midwives in rural or remote Indonesia, the GoI trained 54,000 midwives between 1990 and 1996 (Shiffman, 2003).

The transformation of educational pathways can be seen in Figure 7. Initially, the training was through the midwifery school (Sekolah Bidan), a one-year programme where students enrolled at the end of their junior high school. Unfortunately, this programme was closed in 1984 due to policy-makers' ignorance of the health status of women prior to the Safe Motherhood Conference. As part of the response to the Safe Motherhood Conference the Sekolah Bidan programme was re-opened by the GoI in 1989 (Heywood, Harahap, Ratminah, \& Elmiati, 2010; Hennessy, Hicks, \& Koesno, 2006). 


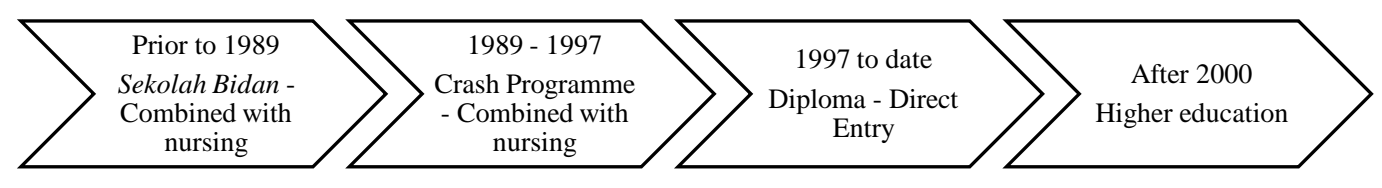

Figure 7: The History of Midwifery Educational Pathway

To qualify as a midwife, the students undertook midwifery training in addition to basic nursing training. The programme was called 'crash' programme or Midwifery Training Programme (Program Pendidikan Bidan). The 'crash' programme type A was for students with nursing school backgrounds, who then trained for an additional oneyear in midwifery (Hennessy et al., 2006; Heywood et al., 2010). The midwives under this programme were deployed to rural and remote villages in Indonesia soon after they finished their training. Up to 1995, midwives under this programme had the privilege of being promoted as civil servants (Heywood, et al. 2010). However, in 1996, the automatic promotion to a civil servant for midwives was abolished (Heywood, et al. 2010). The GoI then launched a nationally contracted based midwives programme in order to attract midwives to work in rural or remote areas with a three-year contract (with potential extensions up to six years) and generous financial incentives (Heywood, et al. 2010).

Due to high demand for midwives as well as the willingness of the GoI to provide adequate health services to the community, in 1993, the 'crash' programme type B was launched. This programme required students with a nursing diploma to be trained an additional one year in midwifery subjects. However, after two years this programme was closed. In 1996, the combination of nursing and midwifery education was replaced by a direct entry pathway. Direct entry pathway is defined as a three-year course in which students enrol at the end of their senior high school. Interestingly, in the early stages of midwifery training, the GoI added various standards for entry which were difficult to understand, such as being of sufficient height and weight. 
Additionally, for certain periods of time, the educational pathway for midwives was only at the diploma level. Midwives did not have post-basic or continuing professional development training (Hennessy et al., 2006). In response to this issue, inservice competence-based training was introduced, which involved care after a normal birth, basic emergency obstetric and neonatal care, and post-abortion care. In 2000, the GoI offered a four-year programme for midwives and since then midwives have been able to pursue higher education such as bachelors and masters degrees.

A major shift of political focus on health, particularly maternal health, has impacted on the quantity of midwives as well as on the improvement in quality of maternal health in Indonesia. A major shortcoming in midwifery education was solved by this village midwives programme.

As already mentioned, the 'boom' period occurred after the Safe Motherhood Initiative when many midwives were trained and deployed throughout the archipelagos. Initially, there were only 13,000 midwives in 1989 (Shiffman, 2003). The number of midwives increased to around 68,000 in 1997 and 52,042 of these midwives were deployed in Indonesian villages (Shiffman, 2003). The availability of midwives has been increasing since the programme started. Based on the latest report from the Ministry of Health (2016), the number of midwives in Indonesia reached 111,736 in 2015. This indicates that there is a limited problem with the supply of midwives. Focus must fall on the distribution and utilisation of midwives in the community.

The distribution of midwives reached its peak in 1997 where $94 \%$ of villages (52,042 out of 54,120 villages) had one midwife (Shiffman, 2003). However, the GoI set a new target for the ratio of midwives in the community of 120 midwives per 100,000 population to be met in 2019 (Ministry of Health, 2016). Based on the latest Indonesian health profile, the ratio of midwives in the community was 43.74 per 100,000 population in 2015 . This number is still far from the target, but the ratio has potential to increase by having midwifery schools in various areas in Indonesia. 
In 2015, there were 151 midwifery schools offering diploma level education in Indonesia which produced around 34,401 new graduates (Ministry of Health, 2016). The number of schools has potential to increase each year which might affect to the number of graduates they produce. Recently, the Ministry of Education and Culture and the Ministry of Health launched a regulation No. 355/E/0/2012 regarding delegation of responsibility in organising health schools (diploma degree) from the Ministry of Health to the Ministry of Education and Culture. This regulation then updated the Minister of Education Decree and Culture No. 507/E/O/2013 with an Amendment to Ministerial Decree Education and Culture No. 355/E/O/2012. Thus, the teaching at midwifery schools is the responsibility of Education and Culture, but outside the schools setting aspect, such as technical teaching remain the responsibility of the Ministry of Health.

The Indonesian government did not stop with these approaches. Other interventions have been introduced, such as the 'Mother Friendly Movement' (Gerakan Sayang Ibu). Similar to other interventions that have been launched by the GoI, the goal of Gerakan Sayang Ibu is to accelerate the reduction of maternal and neonatal mortalities through empowerment of women, caregivers, and communities (ShefnerRogers \& Sood, 2004). This programme was the result of a collaboration between the Ministry of Women's Roles and the Johns Hopkins University Centre for Communication Programmes (Shefner-Rogers \& Sood, 2004). It produces information, education, and communication materials on the indirect contributory factors to maternal and neonatal mortalities, using a 'three delays framework' - delay in making decisions and recognising danger signs during pregnancy, delay in receiving care, and delay in receiving good quality of care (UNDP, 2004). Moreover, male participation prenatally, during and postnally, have become the main communication objective of the programme (Shefner-Rogers \& Sood, 2004). 
According to Shefner-Rogers and Sood (2004), to support the Gerakan Sayang Ibu programme, the 'Alert Husband' programme (Suami SIAGA) was first introduced in East Java, South Sulawesi, and South Sumatera in 1999. The programme basically promoted husbands' roles and participation in birth preparedness and maternal mortality prevention. The campaigns used various media, such as television, radio, brochures, stickers, T-shirts, hats, pins and interpersonal communication materials. The results of the effect of the 'Alert Husband' campaign suggest that this programme increased husbands' knowledge and behaviours towards pregnant women, especially husbands with higher incomes, those exposed to multiple media, and those who talked to others about becoming an 'Alert Husband' (Shefner-Rogers \& Sood, 2004). Although the programme was stopped in 2000, a similar method of campaigning was utilised to promote 'Alert Midwives' and the 'Village Alert' programme (Bidan SIAGA and Desa $S I A G A$ ) as the continuation of 'Alert Husband'.

The 'Village Alert' programme was introduced in 2006 with an aim to empower the community to attain healthy living (Ainy, Makky \& Fajar, 2012). A study of the Desa SIAGA programme in Salatiga revealed there were several benefits in implementing it, including improving knowledge, practices and attitudes of communities towards health, particularly maternal and neonatal health (Ainy et al., 2012).

Desa SIAGA empowers pregnant women through birth preparedness and complication readiness. However, based on a Desa SIAGA guidance book, only $56.1 \%$ of villages are categorised as 'Village Alert' (Ministry of Health and Ministry of Home Affair, 2010). Ainy et al. (2012) indicate that this low percentage is due to the inconsistency of communities' participation in village forums and that communities only participate when there is a health issue. Despite the weaknesses of this programme, it could support the presence of midwives in communities by empowering then to be alert in case of an emergency. Midwives' tasks in managing emergency cases may then be optimised. 
The more recent health programmes focus on improving access to health professionals in remote areas, borders, islands, and areas with health problems. 'Healthy Nusantara' is a programme that was introduced under the Ministry of Health Regulation No. 23 year 2015 on Special Assignment of Team Based Health Workers in supporting the Healthy Nusantara Programme. The striking advantage of this programme is its focus which emphasises difficult and undesired areas, so that those communities can access health professionals. It means the GoI has a great intention to distribute health workers equally throughout the archipelagos.

The GoI also formulated an intervention that was specifically intended for families living in poverty, so that they can access medical treatment and health facilities such as Puskesmas and hospitals. The programme includes free food supplements for pregnant women and children under five years old. Unfortunately, the implementation has not been as smooth as expected because health cards were not distributed appropriately. For instance, a large number of health cards (40\%) were owned by middle and upper income families instead of poor families (Ministry of Health, 2008). Another issue emerging from this programme is its financing system. In implementing the programme, a 'lump sum' was given to health providers, public hospitals or Puskesmas, but when the grants ran out the users of health services were expected to pay for the services.

Improvements have been made by introducing a new health insurance scheme for the poor, managed by a state owned enterprise (PT. ASKES) in 2005. This new strategy was expected to overcome the flaws of the previous programme with regard to health financing. Making institutional and health personnel services free of charge is a critical intervention by the GoI in order to improve access to health services, especially for poor families. This programme empowers the community to have access to health personnel or facilities. Since 2011, all health insurance schemes have been organised by one state owned enterprise called Social Security Agency (Badan Penyelengara Jaminan Sosial or BPJS). This programme has helped Indonesian citizens to access health care services. 
To sum up, since 1990, Indonesia's health policy has transformed significantly, reflected in an increase of health facilities and personnel. The emphasis of programmes or policies has been on increasing or prioritising health supply, such as midwives in rural and remote areas of Indonesia. Yet, despite the significant improvement in number of health practitioners, both in urban and rural areas, deployment practise and unequal distribution remains a serious concern. Therefore, the following sections explore the health situation and system in relation to the provision of midwives in Indonesia.

\subsection{Indonesian Health System: Improving Maternal and Child Health}

The provision of midwives, particularly in remote areas, depends on various factors, for instance, the outreach and organisation of the health system are two critical components for the success of strategies for the provision of village midwives. The Directorate General of Health Services of the Ministry of Health of the Republic Indonesia illustrates how health services and the referral system in Indonesia adheres to the government hierarchy. Services are divided into three main layers: (i) first level services - sub-district; (ii) second level services - district; and (iii) third level services province and national. The layers of health services indicate their location as well as the complexity of care that they provide (Figure 8).

In terms of maternal and neonatal health services, basic healthcare starts at the community level. At the community level of services, pregnant women have the option of either a village midwife at the Village Birthing Centre or 'birthing house' (Pondok Bersalin Desa or Polindes ${ }^{4}$ ), or at a private practice. In cases of emergency, mothers are referred to Puskesmas that provide Basic Emergency Obstetric and Neonatal Care (BEONC) or to a hospital with Comprehensive Emergency Obstetric and Neonatal Care (CEONC). Puskesmas are Indonesia's backbone of healthcare, responsible for organising health development in communities (Frankenberg \& Thomas, 2001; Ministry of Health, 2013). As an extension of Puskesmas, Sub-healthcare Centres (Puskesmas Pembantu or Pustu) were built with an aim of enhancing the quality and outreach of the Puskesmas.

\footnotetext{
${ }^{4}$ Polindes or Podok Persalinan Desa (home birthing facilities) were first introduced in 1999 in order to provide primary healthcare for mothers and children. They are located in villages and constructed using village budgets.
} 


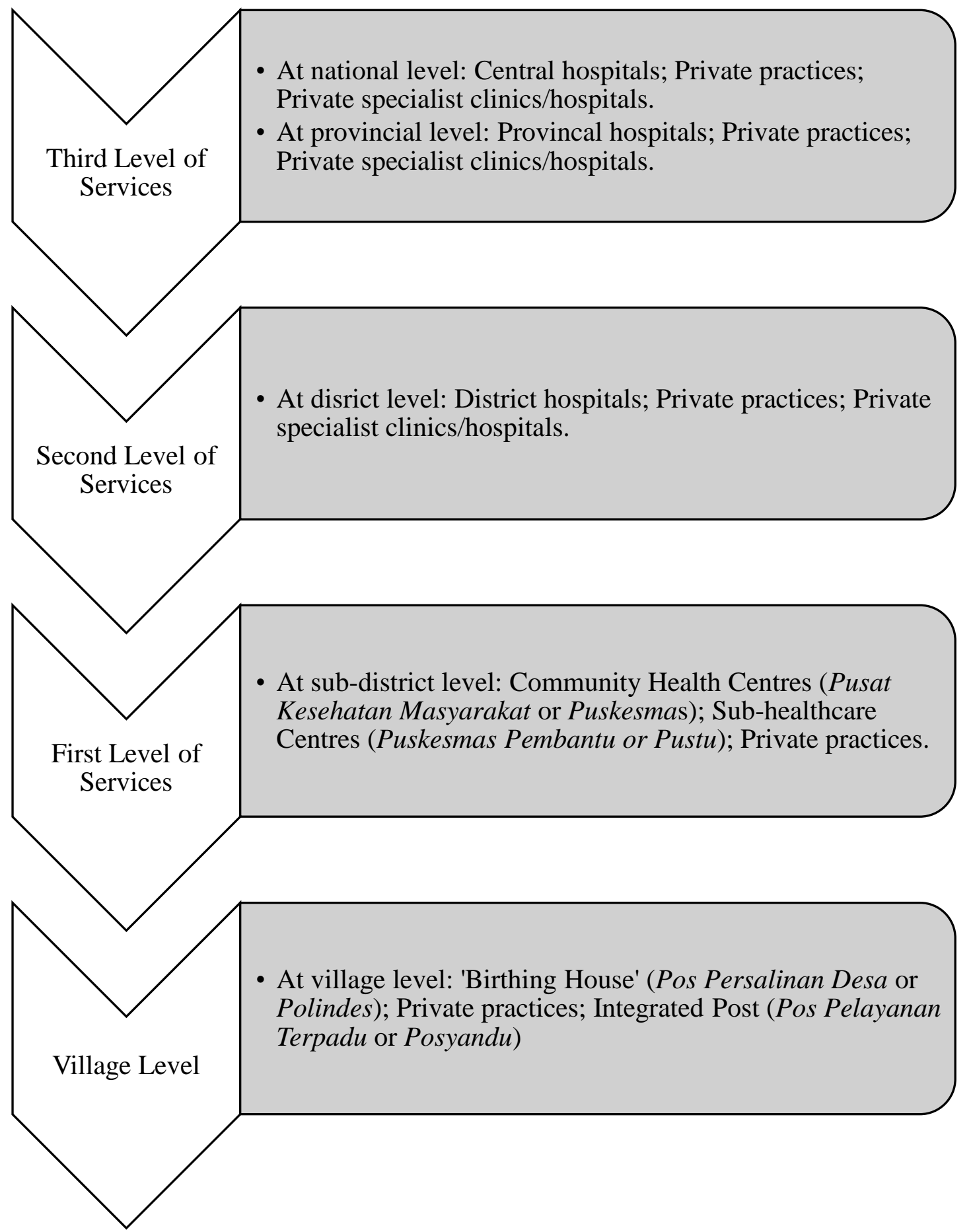

Figure 8: Health Services and the Referral System (Adapted from GHWA, 2013)

Like other countries, the MoH (2013) emphasises the significance, of basic as well as comprehensive, obstetric and neonatal care in order to reduce maternal and neonatal mortalities. Shetty (2013) points out that the focus of many governments on maternity is primarily on emergency obstetric care and facility-based childbirth. 
The UNFPA (2011) suggests, however, that central government also provides a budget to support professional health personnel and public health facilities throughout Indonesia. Enhancing the health facilities, especially BEONC and CEONC, is vital, but it requires other support beyond the health sector, namely good infrastructure, such as roads and transportation from rural to urban areas. Improving this infrastructure may take time and will require a lot of money. Without ignoring these hurdles, deploying health personnel, such as midwives, closer to communities may more easily benefit maternal and neonatal populations, especially in remote areas of Indonesia.

In 2011 there were 9,510 Puskesmas 3,152 of which were Puskesmas treatment centres (providing outpatient and inpatient services) and 6,510 of which were Puskesmas non-treatment centres (only providing outpatient services), but the percentage of Puskesmas in Indonesia has increased around 2-4\% each year since then (Ministry of Health, 2011b). According to the MoH (2012), in 2008 the ratio of Puskesmas per 100,000 population was 3.74 and in 2012 this had increased to 3.89 . The increase in the average ratio indicates the success of the government's effort to bring health services closer to communities.

Even though the number of Puskesmas has increased since they were introduced by the GoI in 1968 (Heywood \& Choi, 2010; Kristiansen \& Santoso, 2006), their isolated locations, poor working conditions and their limited facilities present barriers for midwives and other health professionals serving and providing optimal services to communities (Ronsmans et al., 2009).

The second and third levels of healthcare in Indonesia are the hospitals that focus on curative and rehabilitative services. According to the latest profile report on Indonesian health produced by the $\mathrm{MoH}$ of Indonesia (2013), there were 1,540 public hospitals throughout Indonesia in 2012. Despite the high number of hospitals constructed, the ability to deliver healthcare is measured by the inpatient capacity that hospitals can provide, and Rokx et al. (2010) show that compared to other lower income countries, such as Lao PDR and Vietnam, Indonesia's ratio of hospital beds to 1,000 population is low. Hence, the GoI has attempted to increase the numbers of beds in hospitals, moving from a ratio of 65.38 hospital beds per 100,000 population in 2008 , to 94.55 per 100,000 population in 2012 (Ministry of Health, 2013). The hope is that with the increasing number of beds in hospitals, access to health services will improve. 
Despite the overall number of Puskesmas and public hospitals throughout Indonesia, there is usually only one Puskesmas located in each sub-district while public hospitals are located at the district level. This causes a barrier for people who live in the remote areas of Indonesia (Heywood \& Choi, 2010; Kristiansen \& Santoso, 2006).

\subsection{Village Midwives: The Frontline of Health Provider in Remote Areas}

Based on these challenges, namely limited beds in Puskesmas and hospitals, as well as the less strategic location of those health facilities, it is clear that having midwives closer to communities is essential for Indonesian maternal healthcare. When midwives are in place, there is less need for emergency interventions because problems requiring attention are managed or referred before they become life-threatening complications (Hoope-Bender, Campbell, Fauveau, \& Matthews, 2011). Although some maternal complications cannot be prevented or predicted at an early stage, this does not mean that these complications cannot be tackled. With midwives in communities, better detection of danger signs in pregnancy is possible, thereby improving management of the need for referrals to the nearest health services such as Puskesmas or hospitals (D’Ambruoso et al., 2007).

"When midwifery is in place, there is much less need for emergency interventions" - Petra ten Hoope-Bender at Bulletin WHO (Shetty, 2013, p. 804)

A plethora of literature suggests that women who receive appropriate and regular antenatal care and who are attended to by midwives are less likely to experience neonatal deaths than mothers who do not receive these services (D'Ambruoso et al., 2007; Ministry of Health, 2011b; Ronsmans et al., 2009; Thind \& Banerjee, 2004; Thompson, 1998; UNICEF, 2012; UNFPA, 2011). Ronsmans et al. (2009), for example, assert that the high MMR in remote areas of Indonesia is directly attributable to the fact that only one-third of all births in two districts in Banten, West Java, were managed by midwives. 
In Indonesia, village midwives have both official and unofficial roles. Their official roles involve the provision of basic healthcare to mothers and children - caring for pregnant women, providing delivery care and postpartum check-ups for women and infants, and providing healthcare for children under five years old (Kurniati \& Efendi, 2012). Their unofficial roles encompass the provision of general medical care to adults, healthcare for the elderly, and family planning (Kurniati \& Efendi, 2012).

Although general practitioners, nurses and midwives are categorised as the strategic health workers of Indonesia (Ministry of Health, 2011a), in the case of maternal and child health, the role of midwives is crucial. Midwives are more likely to have adequate or advanced knowledge of safe delivery processes and reproductive health in comparison to other health providers and Traditional Birth Attendants (TBAs) ${ }^{5}$ because they are specifically trained in midwifery skills for three years.

Having midwives closer to communities, particularly in remote villages, is, therefore, important for improving maternal and child health. For instance, pregnant mothers do not have to go to Puskesmas to be monitored during their pregnancy. Instead they can just visit their village midwives, and this reduces their traveling time significantly. In addition, having midwives could minimise the risks related to maternal and child health.

Midwives' status in communities is also significant. Highly respected people in communities are considered role models and midwives are regarded in this way, thereby having the opportunity to create a difference in the health of communities, particularly that of women and children (Barclay, 2008).

\subsection{The Provision of Village Midwives}

In Indonesia, health personnel are defined as doctors, dentists, specialists, nurses, midwives, nutritionists, pharmacists and other health workers (Ministry of Health, 2013). In 2012, the MoH reported that there were 76,523 physicians, 235,496 nurses, 126,276 midwives, 31,223 pharmacists, and 97,904 other health practitioners in Indonesia (Ministry of Health, 2013).

\footnotetext{
${ }^{5}$ TBAs are usually respected members of the community. They have traditional roles that involve assiting delivery, reciting prayers, providing herbal drinks, and postpartum care.
} 
The ratio between midwives and the population increased slightly over two decades from 35 per 100,000 population in 1996 to 37 per 100,000 population in 2006 (Rokx et al., 2010), and by 2012 had increased further to 52 per 100,000 population (Ministry of Health, 2013). These shifts may be explained by the strong commitment of the GoI to deploy midwives in every village of Indonesia through $B D D$. However, this number is still low compared with other health professionals such as nurses (96 nurses per 100,000 population in 2012) (Ministry of Health, 2013).

Even though the number of health personnel has increased significantly over the past decades, ensuring there are sufficient health personnel such as midwives working in remote areas remains a challenge. Many underdeveloped regions have a smaller percentage of midwives than developed regions. For instance, most areas in eastern Indonesia - Maluku, East Nusa Tenggara, and Papua $-68.8 \%$ of Puskesmas have a low proportion of midwives. The urbanisation that has occurred in most areas of Indonesia has contributed to this challenge, with many midwives preferring to work in urban areas. Rokx et al. (2010) suggest that many midwives move to bigger cities after they finish their contracts (i.e., Pegawai Tidak Tetap or PTT) because they believe urban areas offer more job opportunities (Rokx et al., 2010).

Ideally, all levels of the health system must have midwives to improve the health outcomes for mothers and children. This includes midwives in the public health services, private health services, and in the community.

\subsection{Village Midwives in the Public Services}

There is a shortage of health personnel in the public health services of Indonesia, particularly in remote areas. The 2007 report of the Indonesia Family Life Survey (IFLS) indicated that the average facility staffing levels of public health services - Puskesmas and Pustu - required improvement. The ratio between midwives and Puskesmas was 10.77 (Ministry of Health, 2013), which was slightly lower than the ratio between nurses and Puskesmas (11.13). Of most concern, however, was the drop in midwives who work in public health facilities in rural settings. 
The percentage of midwives in rural Puskesmas decreased from $7.3 \%$ in 1997 to $3.5 \%$ in 2007 (Rokx et al., 2010). In fact, the IFLS reported there were less than $1 \%$ of midwives located in rural Pustu in 2007. This overall decline in the number of midwives in the rural public health setting may be a reflection of the preference of midwives to work in private health facilities located in urban areas.

\subsection{Village Midwives in Private Services and Practices}

The Indonesian health system encompasses both public and private health services, and in contrast to the staffing at public health services, many midwives provide their services privately. This is directly due to the Dual Practice programme that was introduced by the GoI in the 1970s, in an attempt to entice doctors and midwives to stay longer in appointed locations. The programme's aim of improving and retaining the supply of health services in rural and remote areas of Indonesia is based on the concept of providing more opportunity for health workers to generate greater income. Dual Practice means that public employees (i.e. midwives) are able to provide private practice in their own homes, thereby allowing them to earn more income by operating after office hours (Rokx et al., 2010).

The number of private midwife practices in urban areas of Indonesia has grown significantly under the Dual Practice programme, going from 988 in 1996, to 18,684 in 2006. In rural areas, the number of midwifery private practices has also grown exponentially: in 1996 the number was 16,290 but by 2006 that number had increased to 25,932 (Rokx et al., 2010). Ensor, Nadjib, Quayyum, and Megraini (2008) point out that almost $75 \%$ of midwives' incomes came from private clinical practice. They also report that the mean private income for midwives at this time under $B D D$ was USD 2,508 per year, with just $10 \%$ of midwives having an annual income of more than USD 11,000 (Ensor et al., 2008).

It seems then, that the opportunity to open private practices in their deployment areas could be one of the solutions to attract as well as retain midwives. However, the resultant provision of service is not evenly spread. Despite the greater number of midwifery private practices in rural areas overall, it is in the more concentrated urban areas that most growth has occurred, suggesting urban areas remain a greater attraction to midwives. 


\subsection{Collaboration between Midwives and Traditional Birth}

\section{Attendants}

With decreased access to midwives, pregnant women in remote Indonesia often favour the use of TBAs over SBAs. This is in contradiction to the GoI's statement that only trained midwives are responsible for childbirth. In fact, childbirth in many isolated places of Indonesia is often solely attended to by clinically untrained TBAs (Shetty, 2013). Thind and Banerjee (2004) explain the association between utilisation of untrained birth attendants and home delivery. In their study of 10,692 home deliveries, they found more than half were assisted by TBAs. Fewer were assisted by doctors, midwives, nurses, family members or friends. This is probably due to a lack of midwives or a strong local culture that favours babies being delivered by TBAs. Many mothers in rural areas prefer to deliver their babies at home assisted by TBAs.

A study by Titaley, Dibley and Roberts (2009) conducted in several provinces of Indonesia - Lampung, Jogjakarta, North Sulawesi, Bali, NTB, and East Nusa Tenggara - revealed this was not uncommon. A high percentage of childbirths take place outside health facilities, particularly in remote areas.

A strong traditional belief further encourages women or families to use TBAs (Agus, Horiuchi, \& Porter, 2012; Titaley, Hunter, Dibley, \& Heywood, 2010). Culture or beliefs are one of the absolute determinants of women's health-seeking behaviour in Indonesia (Penny, 1994), so obeying the advice of TBAs is considered essential (Agus et al., 2012; Wulandari \& Klinken Whelan, 2011).

The TBA is a hereditary job, with TBAs usually coming from the village; they are, therefore, considered very trustworthy. Their position in communities is held in very high regard - in fact, they are considered to be as important as religious leaders (Agus et al., 2012). Other Indigenous communities, such as Samoa, similarly regard TBAs in this way (Barclay, 2008). Ambaretnani (2012) explains that even though TBAs are mostly illiterate, they are able to understand and communicate well with local people. This is an important aspect of their service in communities. They also do not receive any kind of payment, either cash or in the form of gifts (Ambaretnani, 2012). Consequently, TBAs have an enhanced ability to reach the wider community (Titaley, Dibley, \& Roberts, 2010). 
The important role TBAs play in enhancing maternal and child health in rural areas cannot, therefore, be underestimated. However, they have limited training in modern health practices. To address this, Indonesia introduced a partnership programme between midwives and TBAs (Shetty, 2013). Under this programme, TBAs are trained to perform the cleaning or massaging of both mothers and newborn babies (Ambaretnani, 2012).

Acknowledging and engaging 'close-to-community' providers, such as TBAs, can benefit village midwives and ultimately communities. Two important elements midwives can learn from TBAs are how they communicate with pregnant mothers and how they provide comfort to them. In fact, D'Ambruoso et al. (2007) suggest TBAs and other informal health practitioners could be 'a weapon' for midwives to access communities. TBAs can be an advocate for village midwives, by encouraging pregnant women to seek midwives prior to, during pregnancy, and postnatally (WHO, 2004). It is important to note that an effective collaboration can be achieved if only both parties have mutual respect recognising each other's contribution to the 'continuum of care'.

\subsection{Conclusion}

It can be seen that Indonesia has been striving to reduce maternal and child mortality for decades. High MMR and NMR often occur in remote areas of Indonesia; this is due to the difficulty of access which exacerbates the situation. Lack of health professionals, such as midwives in remote areas, is also attributed to limited facilities and poor road conditions.

As discussed earlier, accessibility to midwives for expectant and new mothers is more likely to improve the health outcomes of pregnant women and their babies. Thus, it is worth exploring the challenges and opportunities in attracting and retaining midwives, especially in remote areas of Indonesia. The next chapter reviews literature on work motivation for health workers in such situations. 


\section{CHAPTER 3. LITERATURE REVIEW}

\subsection{Introduction}

An uneven distribution of health workers between urban and remote areas has been a problem for many years in both developed and developing countries. Researchers and policy-makers all over the world have accordingly been interested in identifying or implementing solutions to address this for some time (Franco, Bennett, \& Kanfer, 2002). Understanding workers' motivation is crucial because motivation affects workers' performance. In the context of this study, performance is related to attracting as well as retaining health workers in remote areas.

In order to contribute to the existing evidence, then, in this chapter ${ }^{6}$, the nature of motivation and how motivation influences health workers' performance is firstly discussed. Secondly, the literature on key motivational factors that attract and retain health workers in their workplaces, particularly in remote or undesired areas, is discussed. Thirdly, the caveats from the existing literature are examined, indicating the scope of this research. Finally, the conceptual framework of the research is discussed.

\subsection{Motivation: In the Work Context}

There are many definitions of motivation. Motivation often describes as willingness of a person to accomplish his/her goals in life or in work situation (Pritchard \& Ashwood, 2008). Robertson and Smith (1985) describe it as a psychological concept influenced by the strength and direction of human behaviour. Similarly, (Baron, 1991, p. 1) defines motivation as "the internal process that activate[s], guide[s], and maintain[s] behaviour (especially goal-directed behaviour)", and (Hollyforde \& Whiddett, 2002, p. 3) refer to it as the inner strength pushing or pulling an action of a person.

\footnotetext{
${ }^{6}$ A description of the process used in gathering material for this review is included in the following Methodology Chapter.
} 
Motivation is 'dynamic' and prone to changes. Thus, it is important to acknowledge the actors that have potential to influence individual motivation. Kanfer (1990) states that motivation is not merely attributed to the individual, but is an intense interaction process between individuals and their work environment. According to (Kanfer, 1999), it is the psychological mechanisms that govern human actions in different circumstances. Similarly, Pritchard and Ashwood (2008, p. 6) define "motivation is the process used to allocate energy to maximise the satisfaction of needs". Franco, Bennett, Kanfer, and Stubblebine (2004) also refer to this interactive nature of motivation. Thus, environment plays a significant role in shaping individual motivation.

In the work context, motivation can be defined as "an individual's degree of willingness to extend and maintain an effort towards organisational goals" (Franco et al., 2002, p. 1255). Humorously, Herzberg (2003, p. 48) describes motivation as a result of a "kick the person" approach, which he refers to as a concept of 'movement' and not 'motivation'. 'Movement' is defined as a reaction of fear of punishments or fear of failure in achieving extrinsic rewards, while 'motivation' is defined as "a function of growth from getting intrinsic rewards out of interesting and challenging work" (Hollyforde \& Whiddett, 2002, p. 3).

'Motivators', as the main cause of job satisfaction, can be defined as intrinsic factors, such as being employed in an interesting job offering challenges and responsibility (Herzberg, 2003; Pugh \& Hickson, 2007; Syptak, Marsland, \& Ulmer, 1999). Intrinsic motivation is related to the inner self, such as one's religious or spiritual beliefs and intellectual capacity (Ghauri, 2011).

On the other hand, Ghauri (2011) points out that every action performed by an individual is forced by motivation, extrinsically; that is, related to an extrinsic factor which usually manifests in the form of materials such as benefits and rewards. Similarly, Franco et al. (2002) point out that intrinsic motivation is more likely to be influenced by external factors which could be family, neighbourhood, school, and community. 
Herzberg (2003) also argues that extrinsic factors may include incentives provided by the organisations in the form of salary, work status, allowance, and career development. These incentives are also labelled 'hygiene' factors, because they do not support workers' job satisfaction (Herzberg, 2003). This indicates that to a certain degree, external factors have the power to influence work motivation, yet are not the defining factors. In addition, motivation or worker motivation is dynamic and involves transaction processes or interaction between external and internal factors. Figure 9 illustrates the transcation processes which trigger as well as maintain workers' motivation.

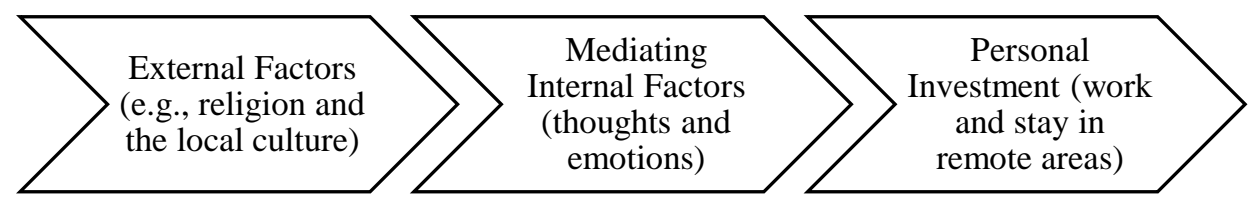

Figure 9: Transaction Processes (Maehr \& Braskamp, 1986)

This indicates that external factors cannot be ignored because of their role in influencing workers' decisions through the mediation process of thoughts and emotions. The transaction process looks like a simple process, yet it could take a short or long time to process the various external influences to finally become a definite decision.

Personal investment, in this case midwives' decisisons to work and stay in remote areas, may be driven by environmental factors. In order to understand why midwives behaved in a particular way, and the key factors that influence them, the following sections will explore the literature on factors that attract and retain midwives in remote areas of Indonesia.

These sections are expected to provide an initial uderstanding of various key factors that attract and retain health workers in remote areas. This is also used to inform an appropriate conceptual framework and methodology for my study. 


\subsection{Recruitment: Attracting Health Workers to Remote Areas}

'What are the key factors that influence midwives to remote postings?' and 'Is there any specific policy that attracts health workers to remote postings?' There are limited studies that solely focus on midwives' work motivation in remote areas as most studies emphasise other types of health workers. Recent research from Efendi et al. (2016) explores the motivation of medical, nursing and midwifery students. This research covered western, central and eastern areas of Indonesia which means that it is more likely to incorporate the varied characteristics of the research participants. Efendi et al. (2016, p. 3) used the Discrete Choice Experiment (DCE) as their research methodology which is "a quantitative research method that can measure the strength of preference and trade-offs of the health workers' different job characteristics that can influence their decision to take up rural postings". The guide for conducting a DCE can be found in WHO and other agencies' reports (WHO et al., 2012).

While this might be an appropriate methodology to identify the key factors that attract health workers to remote postings, it has the potential to neglect other factors, because only six factors were considered: quality of facilities, housing, length of work commitment, study assistance, salary, and management. As the research was only conducted in three public universities in Indonesia, the results might be quite different if the research included private universities. Private students generally come from the city and may be more reluctant to go to remote postings. Also, private students pay relatively higher tuition fees and may anticipate a higher salary after they graduate.

Efendi et al. (2016) determined there are two main factors that influence health workers (which include midwifery students) to remote postings, namely financial and non-financial incentives. According to Efendi et al. (2016) non-financial incentives are valued by midwifery students. Midwifery students, however, pay more attention to the quality of the facilities, such as the birthing equipment. 
The most attractive offer for medical students is study assistance from the government. This is probably due to the expense of undertaking a medical degree, particularly in a private school in Indonesia. Interestingly, Efendi et al. (2016) also point out that management support, in this case support from the DHOs in Indonesia, is seen as an essential factor, with DHOs possibly being perceived as a source of information and training providers for health workers. Thus, based on this research, it seems that non-financial incentives should be embedded with financial incentives in order to attract more health workers to remote postings.

In contrast, nursing students tend to prefer a higher salary, maybe because their salary is lower than other health workers. In Indonesia, nurses receive a similar basic salary to midwives, but where midwives can receive additional government income, nurses do not have this opportunity.

Efendi et al. (2016) point out clearly that there is no single factor that attracts health workers to remote postings; rather, it is a combination of several factors, namely monetary and non-monetary incentives. Frehywot, Mullan, Payne, and Ross (2010) conducted a literature review of 'compulsory service' in 70 countries, both developed (e.g. Australia, Canada, Norway, Japan) and developing (e.g. India, Haiti, Indonesia, Thailand, Nigeria). Their findings are consistent with Efendi et al. (2016) in that both found a combination of two or more factors tend to attract health workers to remote postings.

Frehywot et al. (2010) use the term 'compulsory service' to describe the concept of working as government workers in remote areas for a defined length of time. The authors point out that a combination of 'compulsory service' with various incentives has the potential to attract health workers to remote areas. The incentives include education, employment, living-provisions, and a combination of those three supports. It seems that this approach is able to solve uneven distributions of health workers between urban and remote areas in the selected countries. 
Frehywot et al. (2010) suggest that a combination of 'compulsory service' and generous incentives (i.e. high salary and career advancement) for health workers have a significant impact on deploying health workers in remote villages. This study argues that this approach might be able to retain health workers in remote areas as well. Similarly, Efendi (2012) points out that financial incentives from both the Contract Staff and Special Assignment programmes have attracted health workers to remote areas of Indonesia. However, he also argues that non-financial incentives (i.e. continuing professional education and opportunity to be a $P N S$ ) should be considered by the GoI.

From these research studies - Efendi (2012), Frehywot et al. (2010), and Efendi et al. (2016) - it can be concluded that financial incentives play an important role in improving the availability of midwives in remote areas. However, solely providing a high salary is not an effective solution, as components other than just financial incentives are needed. Non-financial incentives include education, good facilities, length of commitment, a bonding system, career advancement and management support; and these are preferred by many health workers as to supports to financial incentives. Of these three studies, only one study (Efendi et al., 2016) included midwives as research participants.

Research by Liu et al. (2015) points out that a combination of 'compulsory service' and financial incentives, such as a scholarships, loans, loan repayments, and direct financial incentives are commonly used in different countries, both developed and developing, in order to attract and retain health workers in remote areas. Yet, the authors argue, the results are mixed. For instance, in the US this combination of policy works effectively in attracting and retaining health workers in remote areas. On the other hand, in Zambia the policy has failed to retain health workers in rural areas. These mixed results probably depend on different factors, such as political, economic and social realities, as well as the distribution practice of health workers, the availability of private health services, the health system, health financing, funding resources, engagement of actors, and legislation strategies. 
Peña, Ramirez, Becerra, Carabantes, and Arteaga (2010) show the importance of non-monetary incentives in determining doctors' behaviour in Chile. A retrospective, national data study implemented by Peña et al. (2010) shows that a combination of incentives (financial and non-financial) is able to attract doctors to work in rural areas. Non-monetary incentives, such as management support, relationship with family and colleagues, good working conditions, and good social relations, influence doctors' behaviour towards their clients and workplace. However, a clear pattern on how this combination works for midwives has not been addressed as studies focus only on attracting doctors.

Liu et al. (2015) established an interesting point about contextual factors which they categorised as macro (i.e. political, economic, and social); meso (i.e. health system); and micro (i.e. monitoring and evaluation systems, funding, legislation, and consultation). They indicate that factors on the macro level influence how governments or organisations formulate the policies, while those on the meso level are more likely to influence agenda setting. Implementation processes are mainly influenced at the micro level. This indicates that each context influences different policy stages that need to be considered by the policy-makers.

There is no 'one fit for all' approach in terms of crafting a policy or strategy in order to attract and retain health workers in remote areas; rather, it is important to consider the local context that might improve the effectiveness of recruiting and retaining health workers, particularly in undesired areas. However, the study of Liu et al. (2015) causes some concern, because it only provides limited information as to how each level of factors influence each policy process; for example, to what extent do macro levels influence policy formulation; to what extent do meso levels have an impact on agenda setting; or to what extent do micro levels influence policy implementation? This might be due to the type of research methodology that the authors used which was a literature review. In addition, like other studies, Liu et al. (2015) did not include midwives in their search terms. 
Globally, previous studies have shown that programmes or interventions motivate health workers to work in remote areas. Franco et al. (2004) show that policymakers in Jordan and Georgia, in promoting effective and realistic interventions, often neglect other factors that also influence health workers' job dissatisfaction, such as working conditions (inadequate facilities and equipment), workload, difficult environments, promotion opportunities, and culture. They suggest that non-monetary incentives may be more powerful than monetary incentives in regards to attracting and retaining health workers in rural and remote areas.

Focusing solely on monetary factors, such as salaries, retirement packages, job security and allowances, are not an effective policy to attract, moreover to keep health workers in their workplaces. Further, the authors point out the complexity of motivational determinants that influence health workers' choice of postings. The key determinants encompass self-efficacy, pride, management openness, job properties, and local values. While other researchers have failed to acknowledge the importance of local values and beliefs, Franco et al. (2004) argue the importance of local values and beliefs in shaping these key motivational determinants where values and beliefs are mediated by the larger societal context. Their research indicates the need for further research that focuses on the underpinning of local cultural beliefs. Although many studies point out the importance of local context, there is limited research that explores culture or beliefs systems as motivators.

As noted by other researchers, Franco et al. (2004) also emphasise that work satisfaction is influenced by financial incentives, yet non-financial incentives are more likely to boost job satisfaction. Non-financial incentives can be formed around many criteria, for instance, by providing workers with more freedom in making decisions, and recognising workers' contributions in their workplaces. It means that to improve job satisfaction requires multiple interventions or balanced approaches.

Franco et al. (2004) believe that there are no single determinants that influence health workers' motivation, rather they are complex factors that operate within a cultural context. They suggest that culture and beliefs should be considered in designing policy or crafting an effective strategy. The evidence suggests that it is essential to acknowledge the various factors that influence workers' motivation, to target both the recruitment and retention of health workers in their workplaces. 
To sum up, there is no clear distinction made in some literature between key factors that influence recruitment and those that affect retention. Most of the research indicates the connection between recruitment and retention of health workers. In order to attract or recruit health workers in remote areas, the policy-makers or health facilities managers need to provide a balanced incentive package, such as combining financial and non-financial incentives. It seems that financial incentives provide an initial attraction to health workers, yet it cannot guarantee to retain them.

\subsection{Retention: Retaining Health Workers in Remote Postings}

Financial and non-financial incentives are also found to be key factors in retaining health workers in remote areas. Dieleman et al. (2003) argue that financial and non-financial factors need to be considered to keep health workers in their workplaces as well as to improve their performance. Their findings show that there are five motivation and discouragement factors in the workplaces mentioned by health workers in Vietnam. The motivational factors include appreciation, support from managers and colleagues, stable jobs, training, and love for the work. Discouraging factors involve low income, difficult transportation, no updated information, lack of knowledge, and heavy workload.

Dieleman et al. (2003) indicate that providing only financial incentives is less likely to be effective in retaining and improving health workers' performance. They point out that the major factor that motivates health workers is appreciation of their work either from their superiors, colleagues or community. A low salary tends to discourage health workers from remaining in their postings, yet it is not the only consideration in withdrawing from their workplaces. 
As quoted by Dieleman et al. (2003), Herzberg's theory of motivation in workplaces emphasises that the intrinsic factors (i.e. achievement, recognition for achievement, responsibility, and advancement) determine job satisfaction. While extrinsic factors, such as a low salary, triggers dissatisfaction with their job. It is understandable that these non-financial factors play an important role in motivating health workers to stay and provide high quality care in their postings because it touches basic human needs like self-actualisation. Thus, the feeling of comfortableness with the job and the work environment might create a domino effect - where job satisfaction is achieved, better performance is more likely to be obtained.

Despite the limitations of the study by Dieleman et al. (2003), such as interviewing only two types of health worker, district preventive staff and Puskesmas staff, the qualitative research provides in-depth information about health workers' perceptions of what motivates and demotivates them. Thus, it has allowed the authors to explore the various factors that might influence motivation and discouragement in working areas, particularly in remote areas.

Jack, Canavan, Taylor, Bradley, and Ofori-Atta (2013) conducted qualitative research about recruitment and retention of workers in psychiatric hospitals in Ghana. The findings indicate that there are four factors that motivate psychiatric staff to remain in mental healthcare: a desire to help patients who are vulnerable and in need, positive day-to-day interactions with patients, intellectual or academic interest in psychiatry or behaviour, and a good relationship with colleagues. On the other hand, the four factors that demotivated these health workers were a lack of resources at the hospitals, a rigid supervisory hierarchy, lack of positive or negative feedback on work performance, and few opportunities for career advancement within mental health. 
These findings provide some interesting insights about both motivating and demotivating factors for health workers. For instance, Jack et al. (2013) indicate that religious beliefs are seen as one factor that motivates health workers to help patients who are vulnerable. The qualitative method that was implemented by Jack et al. (2013) is able to provide deeper understanding of people's perceptions about their experience in working areas or in life. Due to limited research about mental health workers in lowand middle-income countries, a qualitative study was valuable for the ideas it generated. Unfortunately, the findings do not explicitly explain or differentiate between factors that influence recruitment and retention. In the discussion chapter, the authors appear to generalise the findings into factors that motivate and demotivate hospital health workers to remain in mental healthcare.

A study from Zinnen et al. (2012) suggests similar findings to Peña et al. (2010). Zinnen et al. (2012) point out that working conditions need to be improved in order to satisfy health workers as well as increase their motivation to work in rural areas of Tanzania. The authors also suggest that training and supervision are other powerful factors that retain health workers in their workplaces. Both Zinnen et al. (2012) and Franco et al. (2004) provide an insight into knowledge of workers' motivation. They suggest that self-efficacy, pride, management openness, job properties, and social values are the key factors to remaining in their workplaces. These non-financial factors appear to have a great influence on reducing the turnover of health workers in remote areas.

Dolea et al. (2010) conducted a literature review to analyse the effectiveness of programmes or interventions to attract and retain health workers to work in rural and remote areas. Their research emphasises the indicators and methods used to measure the effects of rural interventions in retaining health workers. The results show that some interventions, such as clinical rotations in rural settings, providing allowances for nurses in South Africa, and for doctors, dental surgeons and pharmacists in Niger (ibid, p. 381), had positively influenced their future plans; a bonding scheme for post-graduate students in Australia (ibid) also showed an increase in the percentage of workers practising in rural areas; and a compulsory scheme and financial incentives in Japan, Australia and Mali has improved retention (ibid). 
The evidence shows that non-financial incentives could offer additional benefits in retaining health workers in remote areas. The dominant factors are related to the selfactualisation of the health workers, such as appreciation, growth opportunities, training and supportive management. It seems that intrinsic factors dominate health workers' motivation to stay in their workplaces. Another important aspect that needs to be considered are working conditions which include good facilities or equipment, housing provision, and access to services. Organisations and broader sector policy should pay more attention to non-financial incentives in order to obtain high work performances and help retain health workers in remote areas. Intrinsic factors that are influenced by beliefs systems and local values also play an important role in motivating the workers. For example, religious beliefs encourage health workers to provide their services to vulnerable patients or the community.

\subsection{Decentralisation: Recruitment and Retention}

In addition to the above literature about key factors that attract and retain health workers in remote areas, health sector reform, namely decentralisation has an indirect influence on health worker motivation. It is suggested by Bennett and Franco (2000) that sector reform is more likely to affect organisational motivation. The most common reform, one that has occurred in many ASEAN countries, is the change from centralised to decentralised government. An extensive body of literature also indicates that decentralisation is viewed positively by many countries. For instance, Kristiansen and Santoso (2006) point out that in Indonesia, as elsewhere, decentralisation seems to be an attractive solution to dealing with corrupt, dictatorial, and inefficient central bureaucrats. According to many politicians cited in Kristiansen and Santoso (2006), decentralisation is a means to enhance public services such as healthcare. Another study by Lakshminarayanan (2003) points out that in the Philippines, distribution of power through decentralisation enhances the quality of healthcare because services can be adjusted based on local need. 
Thus, decentralisation is meant to provide more opportunity for local government to develop their regions, based on local need. Through decentralisation, DHOs are able to employ strategic health workers, such as doctors, midwives and nurses. For instance, with decentralisation, local governments are able to offer better incentives - financial or non-financial - to potential applicants who want to work and stay in remote areas based on local government capability and culture.

According to Liu et al. (2015) decentralisation provides a great opportunity for formulating the agenda because decentralisation provides room for improvement based on local need or context for government, particularly local government. In the case of recruitment and retention of health workers, decentralisation should be a powerful tool for local government by which to craft strategic policy decisions (i.e. localising existing national policies) in order to improve the availability of health workers, especially in remote areas.

Decentralisation influences the recruitment and retention of health workers in Tanzania, according to Munga, Songstad, Blystad, and Mæstad (2009), who define decentralisation as the shifting of four major components - workload (deconcentration), management (delegation), decision-making (devolution), and financing (privatisation) from central government to local government.

Munga et al. (2009) point out that decentralisation may have an impact on improving the quantity and quality of public services because local government has more power to manage the availability of health workers. Decentralisation in Tanzania provides room for improvement based on local context and need. However, some concerns need to be addressed in order to achieve an effective strategy to attract and retain health workers to remote postings. This involves reducing bureaucracy that causes significant delays in selecting and deploying health workers in remote areas. The financial burden that has to be carried by local government is also one of the factors suggesting that decentralisation might have less power to improve the availability of health workers in remote areas. 
Studies from both Liu, Martineau, Chen, Zhan, and Tang (2006) and Munga et al. (2009) suggest that decentralisation has the potential to improve recruitment and retention of health workers in remote areas. Yet some challenges need to be addressed in order to support local government in crafting an effective strategy. It seems likely that decentralisation can have a positive impact on reducing maldistribution of health workers between urban and rural areas as long as factors such as financial resources to recruit and retain health workers are addressed.

In Indonesia, according to the Law of Republic of Indonesia No. 23 year 2014 decentralisation is defined as the transfer of government affairs by the central government to autonomous regions based on the principle of autonomy (Republik Indonesia, 2014). On the other hand, the implementation of decentralisation is difficult to achieve. It remains unclear whether decentralisation has provided more power to local government. Central government still plays an important role in several aspects, namely recruiting and allocating the number of health workers, as well as financial control (Rokx et al., 2010). The authors also point out that the MoH in Indonesia is still handling local staffing and programmes, for example, the deployment of health workers such as midwives is still not fully managed or controlled by local government. In reality, district governments still need to write their requests to provincial and then central government for health workers to be deployed in remote areas. This limitation creates a difficulty for local government to improving the availability of health workers in their areas.

Despite the pros and the cons of decentralisation, it is clear that changes in the government system have had a significant effect on the culture of the health sector organisations which also may affect workers' motivation. 'The domino effect' is inevitable since the nature of motivation is dynamic and interactive. Thus, understanding the complex factors of work motivation cannot be ignored. 


\subsection{Scope of the Study}

The literature review clearly shows that there are many factors that support the attraction and retention of health workers in their workplaces (Table 1). There are two main factors that contribute to work motivation, namely financial and non-financial incentives. The factors identified that attract health workers to remote postings or undesired areas are high salary, retirement benefits, job security, allowances, loans, and scholarships. These factors are also found to be important in retaining health workers in their workplaces.

The non-financial factors that attract health workers to work in undesired areas include the opportunity to obtain better education, quality of the facilities, management support, career advancement, political situation, culture, and the length of commitment. Additional work-based motivational factors important to health worker retention revolve around appreciation, support from community, training, love for the work, advancement, responsibility, positivity towards their patients, intellectual stimulus, working conditions, responsibility, and their relationship with other workers. 
Table 1: Review of Literature Surrounding Work Motivation of Health Workers

\begin{tabular}{|c|c|c|c|c|}
\hline Authors & $\begin{array}{c}\text { Research } \\
\text { Participants }\end{array}$ & Countries & Methodology & Findings \\
\hline \multicolumn{5}{|c|}{ Key Factors that Attract Health Workers } \\
\hline Efendi et al. (2016) & $\begin{array}{l}\text { Medical, } \\
\text { midwifery, and } \\
\text { nursing students }\end{array}$ & Indonesia & $\begin{array}{l}\text { Discrete Choices } \\
\text { Experiment }\end{array}$ & $\begin{array}{l}\text { Acknowledge the importance of combining } \\
\text { non-financial and financial incentives in order } \\
\text { to attract health worker }\end{array}$ \\
\hline $\begin{array}{l}\text { Frehywot et al. } \\
(2010)\end{array}$ & $\begin{array}{l}\text { Health workers } \\
\text { (doctors, nurses, } \\
\text { midwives, and } \\
\text { others) }\end{array}$ & $\begin{array}{l}70 \text { Countries both } \\
\text { developed and } \\
\text { developing } \\
\text { countries }\end{array}$ & Literature Review & $\begin{array}{l}\text { A combination of compulsory services and } \\
\text { various incentives (education, employment, } \\
\text { living provisions, and combination of those } \\
\text { supports) has a positive impact on recruiting } \\
\text { health workers }\end{array}$ \\
\hline Efendi (2012) & $\begin{array}{l}\text { Health workers } \\
\text { (doctors, nurses, } \\
\text { midwives) }\end{array}$ & Indonesia & Descriptive study & $\begin{array}{l}\text { A combination of incentives, high salary, and } \\
\text { career advancement is more likely to attract } \\
\text { health workers }\end{array}$ \\
\hline Franco et al. (2004) & Doctors and nurses & Georgia and Jordan & Mix-method & $\begin{array}{l}\text { Financial (salary, retirement package, job } \\
\text { security, and allowances) and non-financial (i.e. } \\
\text { management support, pride, self-openness, job } \\
\text { properties, self-efficacy) need to be considered } \\
\text { in attracting doctors and nurses }\end{array}$ \\
\hline Liu et al. (2015) & $\begin{array}{l}\text { Health workers } \\
\text { (excluding } \\
\text { midwives) }\end{array}$ & $\begin{array}{l}40 \text { countries from } \\
\text { high, middle, and } \\
\text { low income } \\
\text { countries }\end{array}$ & Literature review & $\begin{array}{l}\text { Compulsory service and financial incentives } \\
\text { (i.e. loan, loan repayment, direct financial } \\
\text { incentives) used to attract health workers }\end{array}$ \\
\hline
\end{tabular}


Key Factors that Retain Health Workers

Dieleman (2003) Health workers Vietnam Qualitative study Non-financial incentives, such as appreciation, support from managers, colleagues, stable job, training, love for the work achievement,

responsibility are more likely to retain health workers

\begin{tabular}{|c|c|c|c|c|}
\hline Jack et al. (2013) & $\begin{array}{l}\text { Mental health } \\
\text { workers }\end{array}$ & Ghana & Qualitative study & $\begin{array}{l}\text { Non-financial incentives, such as a desire to } \\
\text { help patients, positive day-to-day interactions } \\
\text { with patients, intellectual interest, good relation } \\
\text { with colleagues keep mental health workers in } \\
\text { their workplaces; religious belief has buffer } \\
\text { effect on stopping the workers from moving }\end{array}$ \\
\hline Pena et al. (2010) & Doctors & Chile & $\begin{array}{l}\text { Retrospective } \\
\text { national data }\end{array}$ & $\begin{array}{l}\text { Medical education, management, } \\
\text { environmental, relationship with family and } \\
\text { partner, working conditions, and social } \\
\text { relations play an important role in retaining } \\
\text { doctors }\end{array}$ \\
\hline Zinnen et al. (2012) & $\begin{array}{l}\text { Health worker } \\
\text { (medical officer, } \\
\text { nurses, public } \\
\text { health officers, } \\
\text { doctors) }\end{array}$ & Tanzania & $\begin{array}{l}\text { Cross-Sectional } \\
\text { survey }\end{array}$ & $\begin{array}{l}\text { Working equipment and conditions, training, } \\
\text { supervision are more likely to retain health } \\
\text { workers }\end{array}$ \\
\hline
\end{tabular}




\begin{tabular}{|c|c|c|c|c|}
\hline Dolea et al. (2010) & Health workers & $\begin{array}{l}\text { Developed } \\
\text { countries } \\
\text { (Australia, Canada, } \\
\text { Japan, New } \\
\text { Zealand, and USA); } \\
\text { Developing } \\
\text { countries (Africa } \\
\text { countries, Latin } \\
\text { America, or South } \\
\text { East Asia) }\end{array}$ & Literature Review & $\begin{array}{l}\text { Clinical rotation and bonding scheme have the } \\
\text { potential to retain health workers }\end{array}$ \\
\hline \multicolumn{5}{|c|}{ Decentralisation: Attracting and Retaining Health Workers } \\
\hline Munga et al. (2009) & Health workers & Tanzania & $\begin{array}{l}\text { An Exploratory } \\
\text { Qualitative }\end{array}$ & $\begin{array}{l}\text { Decentralisation gives an opportunity to } \\
\text { improve public health services through } \\
\text { improving the availability of health workers }\end{array}$ \\
\hline Liu et al. (2006) & Health workers & China & Case Study & $\begin{array}{l}\text { Decentralisation has the potential to improve } \\
\text { the provision of health workers in rural areas, } \\
\text { yet some challenges need to be addressed }\end{array}$ \\
\hline
\end{tabular}




\subsection{Caveats of the Existing Literature}

The above literature shows that work motivation involves interaction between various factors, both intrinsic and extrinsic. The intrinsic factors that motivate health workers encompass pride, intellectual stimulation, religious beliefs, self-efficacy, achievement, responsibility, and recognition. Extrinsic factors involve financial and non-financial factors. Higher salaries, loan repayments, and retirement packages are the main financial incentives that motivate health workers to work and stay in their workplaces. Non-financial incentives, such as study assistance, quality of facilities, management support, compulsory services, education, living provisions, appreciation from colleagues, community and supervisors, as well as the length of commitment, and freedom in making decisions, are found to be the key factors that attract and retain health workers in undesired areas.

Despite comprehensive information on recruitment and retention of health workers in remote areas, there are some caveats encompassing research participants, context, and methodology that need to be addressed.

These international studies tend to focus on doctors and nurses and largely ignore the midwifery workforce. A possible reason may be related to the health reform priority in each country. In terms of research methodology, previous research in Indonesia includes very little qualitative work on health workers' motivation, particularly that of midwives. Many studies tend to apply quantitative methods. Thus, the above literature has concentrated on common factors such as salary, poor facilities, career development, and management support. Unequal distribution of health workers between urban and remote areas remains a problem, probably due to policies that have been introduced by the policy-makers where context specific factors are not considered.

Franco et al. (2004) point out the importance of understanding culture or belief systems. In designing programmes or policies there is limited explanation of this specific aspect. The same situation occurs in the context of Indonesia. There is also very little focus to date on the cultural factors that influence the recruitment as well as retention of qualified midwives in remote areas that could have a more protective effect on work motivation of midwives. 
In order to include the important factors that attract and retain midwives in remote areas, a comprehensive conceptual framework that accommodates various key factors is needed. The following section explores how a multifaceted framework is used in this study.

\subsection{Multifaceted Framework}

As mentioned earlier, work motivation is complex as it involves transactional processes between personal and environmental factors. In order to understand the complexity of this transactional process, a multifaceted approach is an appropriate conceptual framework for my study.

The empirical literature from Franco et al. (2002) and Stretton and Bolon (2009) show the use of this multifaceted approach in order to understand the key factors that attract and retain health workers in their workplaces. They stated that this approach has the capacity to accommodate divergent knowledge from different fields. As mentioned by Franco et al. (2002), work motivation is a complex subject which involves many disciplinary knowledges, such as economics, psychology, organisational development, human resources management, and sociology.

Stretton and Bolon (2009) implemented this approach in order to examine various factors that attract and retain rural hospital administrators. They stated that better understanding of recruiting and retaining rural hospital administrators can be achieved by using a multifaceted approach because it incorporates a wide variety of subjects which are summarised into three main elements, namely the environment or the public, organisations, and personal factors (Figure 10). Franco et al. (2002) implemented this conceptual framework to understand the complexity of health workers' motivations. In addition, these two studies also demonstrate the flexibility of this conceptual approach. This conceptual framework is able to capture multiple layers of factors that influence midwives' motivation to work and stay in remote areas. 


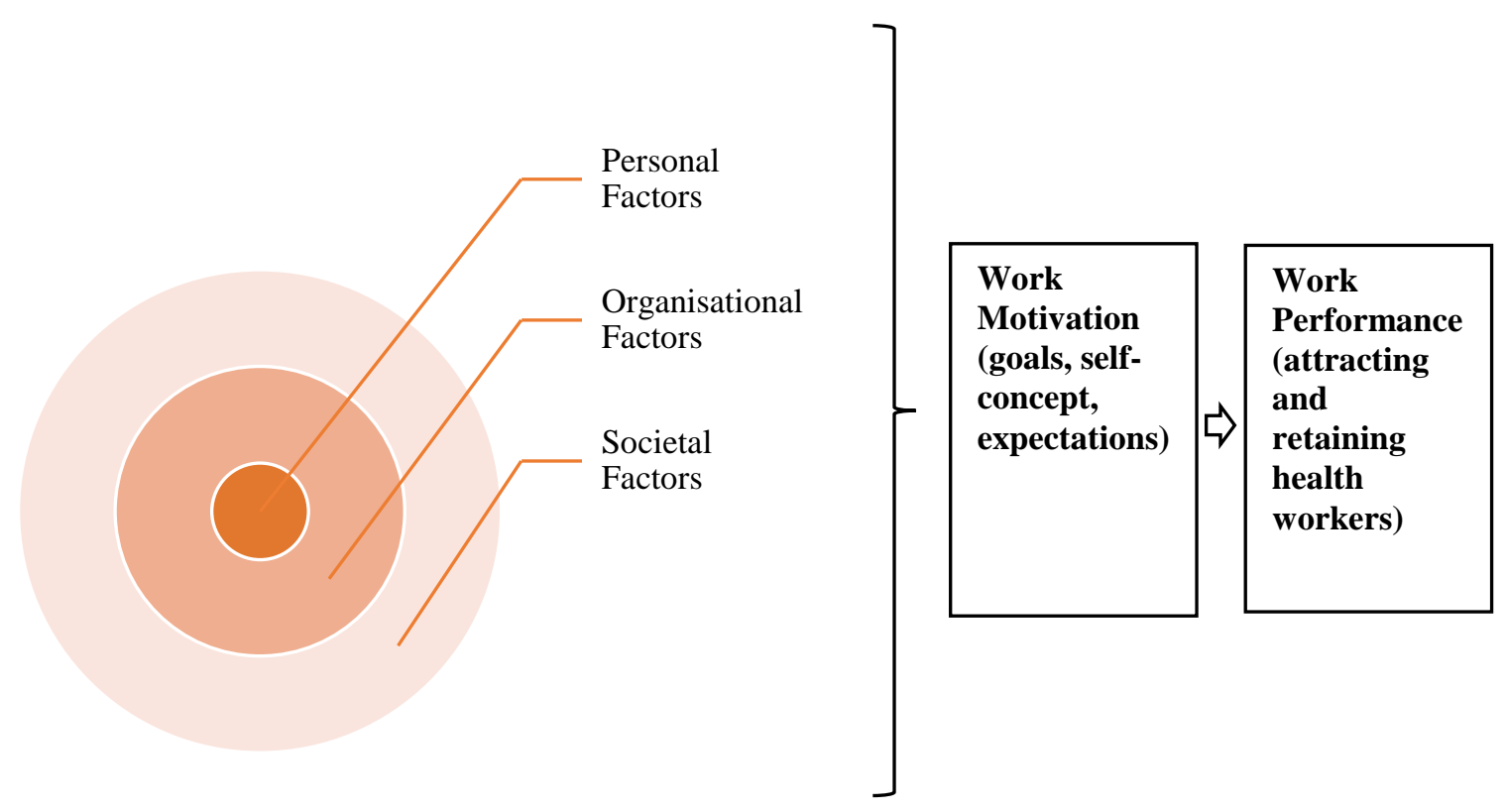

Figure 10: The Multifaceted Conceptual Framework (Franco et al., 2002)

According to Franco et al. (2002, p. 1256), work motivation operates at a personal level which encompass "will do" and "can do" components. "Will do" is defined as "the extent to which workers adopt organisational goals" while "can do" identifies "the extent to which workers effectively mobilise their personal resources to achieve joint goals" (Franco et al., 2002, p. 1256). It indicates that personal factors involve workers' willingness and capability to perform or carry out tasks. In addition to Franco et al.'s (2002) study, Stretton and Bolon (2009) explain that personal factors include education background, work experience, and the preferred lifestyle of the potential applicants. As a result, work motivation across health workers is varied even they were in the same environment.

Franco et al. (2002) also point out that worker motivation is more likely to be influenced by the institutions or organisations where they belong. Organisational factors in the work context, according to Franco et al. (2002), involve organisational and broader sector policies. Organisational factors also encompass physical characteristics and other variables, such as salary, benefits, and promotion opportunities (Stretton \& Bolon, 2009). Similarly, Franco et al. (2004) point out that in improving worker capability, the organisation should provide various supports, namely resources and open processes. This indicates that there is an interaction between personal and organisational factors which influence work performance. 
Finally, broader, societal factors also play an important role in shaping workers' motivation. Broader societal factors, such as cultural systems, construct personal and organisational factors (Franco et al., 2002). Culture is a complex construct (Lo Bianco, 2010; Schwartz, 1999). Many studies have attempted to define culture. For instance, (Schwartz, 1997, p. 70) defines culture as "all the patterns of thinking, feeling and acting that are shared by members of a society or other bounded social group (ethnic, religious, national, and so on)".

Interestingly, Franco et al. (2002, p. 1263) point out that culture has a unique effect on human beings which contributes to "mental programming". Stretton and Bolon (2009) suggest that culture carries values that exist in the community such as solidarity, pride, patriotism, faith, religion, and equality, which play an important role in shaping worker motivation and organisational views. Family, neighbourhood, schools, and community are the common carriers of values which frame individual behaviours (Franco et al., 2002). Therefore, it is important to analyse the influence of culture in attracting and retaining midwives in remote areas of Indonesia. Exploring the complexity of culture is beyond my study, though I acknowledge and analyse local culture that influences worker motivation, particularly midwives in remote areas.

Reflecting the diversity of the factors that attract and retain health workers in undesired areas, a conceptual framework which accommodates such multidimensional and multidisciplinary knowledge needs to be considered. In the context of attracting and retaining midwives in remote areas of Indonesia, an adaptation of the conceptual frameworks from Franco et al. (2002) and Stretton and Bolon (2009) is used to untangle the complexity of work motivation that influences midwives to remote postings. Similarly, Martin, Southall, Shea, and Marr (2008) suggest that such a multifaceted approach was able to identify the determinants in successfully negotiating complex feeding problems. This is because of the characteristics of the multifaceted approach, allowing trans-disciplinary collaboration and the inclusion of various levels of processes. 
Clearly, the multifaceted framework provides a useful foundation for understanding the various channels that influence health workers' motivation. The flexibility in adapting the framework is another advantage in applying this framework in my study. Franco et al. (2002) state that a multifaceted framework offers a structure to analyse the complexity of the information. However, the basic concept does not capture the complexity of the interactions.

Thus, I have proposed an adaptation to the existing conceptual framework as a result of my study which signals the complexity of the transaction processes (Figure 11). The adaptation of the framework is expected to show the intense interaction of the critical components of health workers' motivation. In order to improve work performance, it is important to examine the mechanism of each factor and its effects on motivation.

In addition, given the challenges of conducting research on worker motivation (i.e. incorporating factors that are hidden or cannot be seen) and the complexity of the interaction, my study attempts to use methodology that is suitable for combining with this framework. This is discussed in following chapter. 


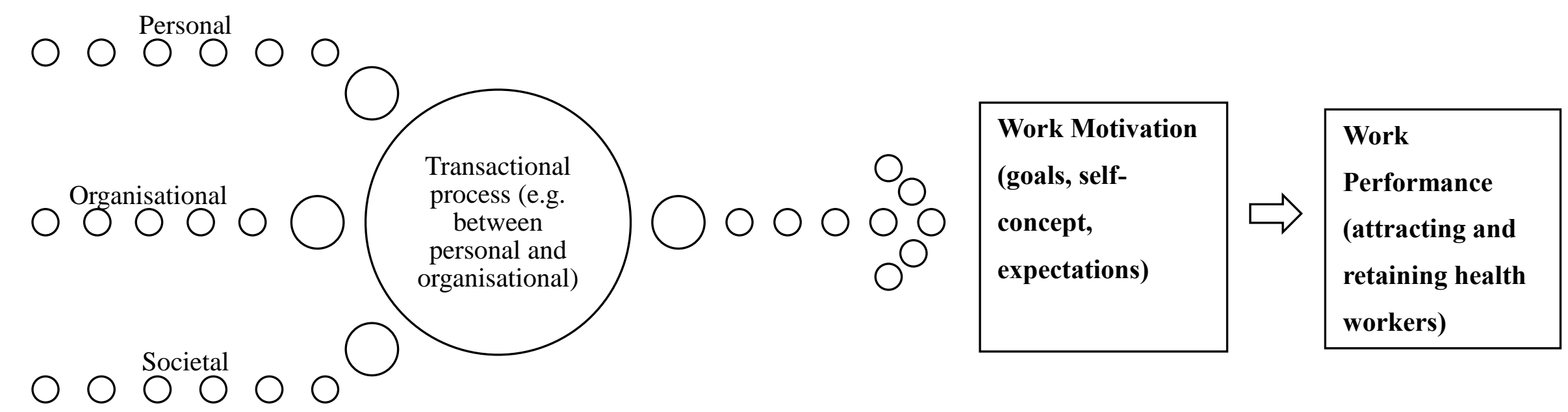

Figure 11: The Adaptation of Multifaceted Conceptual Framework 


\section{CHAPTER 4. METHODOLOGY}

\subsection{Introduction}

This chapter focuses on the methodological approach undertaken for this study. It starts with the philosophical perspective of the methodology in order to guide the study design. It then discusses in detail the implementation of SCM blended with AI as the evaluation technique for this study. This model is commonly used in business and recently in the field of education, yet this model has not been used in the field of public policy.

This chapter also explains the pre-data collection procedure that was needed prior to fieldwork in NTB. This included ethical consideration and research approval letters from various levels of government. Finally, this chapter discusses the use of TA as the data analysis strategy.

\subsection{Philosophical Perspective}

It has been argued that the first essential step to starting a research study is understanding the worldviews which underpin it, including the nature of 'the reality' or 'the truth' (ontology) and 'the art of knowing' (epistemology) (Crotty, 1998; Krauss, 2005). According to Crotty (1998), the worldview can be used as a lens that allows researchers to understand and explain human social reality.

My research is based on the assumption that having midwives in remote areas of Indonesia depends on two interconnected aspects, namely: understanding the key factors that attract and retain midwives in remote areas; and the role of policies and programmes of the GoI in responding to and facilitating factors that influence midwives to work and stay in their working areas. These assumptions are seen to be subjective in nature because they relate to the personal experiences, attitudes, and views of midwives towards living and working in remote areas. In addition, to support these assumptions, the information gathered should be based on individuals' knowledge and experience of the implementation of the policies or programmes at central, provincial, district, subdistrict and village levels. 
To capture these participant viewpoints, interpretivism is used as my research foundation. Intepretivism is based on the belief that "reality is subjective and constructed" (Lather, 2006). Crotty (1998) asserts that the interpretivist paradigm allows researchers to understand and explain human and social reality. Interpretivism as a perspective is more likely to employ a qualitative methodology or case study research strategy (Willis, 2007). Lather (2006) also agrees that interpretivism provides room to understand the different viewpoints of the participants; it lends itself to in-depth interaction with the research participants from various levels. Accordingly, this theoretical approach has the potential to untangle the complexity of the situations and examine participants' meaning (e.g. personal experiences, views and relevant policies) based in specific contexts.

A qualitative approach is implemented to obtain insight into how people interpret the world around them. Qualitative research is believed to be an appropriate methodology to understanding such phenomena because it shows participants' views of the research topic within their relevant contexts (Krauss, 2005), an understanding supported by Yin (2014) who endorses a qualitative approach for investigating new phenomena as well as obtaining participants' views. Creswell (2009) also points out that qualitative research is an appropriate method when complex exploration of problems or issues is needed that requires talking to people or sharing research participants' stories.

In the spirit of discovering various factors that influence midwives' motivation to work and stay in remote areas, quantitative methodology would potentially limit the information that needed to be gathered. Surveys or questionnaire approaches would not get in-depth information from the research participants (Curry, Nembhard, \& Bradley, 2009). Thus, I used a methodology that has the potential to allow research participants to express and elaborate their views, experiences, and practices without restrictions. In order to obtain such insights, I believe that a qualitative approach is the appropriate method to use. 


\subsection{Methodology}

In order to capture and understand the various factors, a literatrure review was conducted using Victoria University of Wellington (VUW) library databases, namely BioMed, Spring Link, Ebscohost, DOAJ, ProQuest, Elsevier, ProQuest, Bio Med Central, and other databases. In addition, Google Scholar, and Google Advanced Search, were used to access relevant studies. Databases were also browsed by various disciplines, namely, Health, Human Resources and Management, Psychology, Public Management and Policy, and Sociology. Various keywords related to attracting and retaining health workers, particulatly midwives were used. The search involved looking at books, academic journals, grey literatures (i.e. government or Non-Government Organisation reports), and anecdotal evidence, which although not scientifically rigorous evidence, is still considered of value.

The combination of search terms were implemented in finding the relevant literature. These are some examples of the search terms or keywords that were applied in searching related literature: "attracting"; " health worker"; "remote areas"; "retaining","recruitment", "undesired areas"; "nurses"; "midwife"; "midwives"; "doctors"; "physicians"; "recruitment"; "workers motivation"; "policies"; "programmes"; "job satisfaction"; "key factors"; "determinants"; and "remote postings".

Additionally, grey literature was identified by using the names of the organisations and programmes or interventions referenced in publised literature. Additionally, some books were located by using the VUW on-line catalogues searching system. Due to a large number of initial matches of literature, the searches were refined by analysing the abstracts, executive summaries, references, and tables of contents that appeared in the literature itself or citation.

The were some inclusion, exclusion and exception criteria that had been established for this literature review. Published and grey literature were included according to the following categories: 
1. Studies that explore key factors or determinants of work motivation of health workers, namely midwives, nurses, doctors, social workers, hospital administrators, and students with clinical backgrounds in remote or rural areas.

2. Reports or background documents on attracting/recruiting and retaining health workers, particularly midwives in remote areas.

3. Published and grey literature from developing countries in English and/or Bahasa Indonesia.

4. GoI policy documents on recruitment and retention of health workers, particularly midwives in remote areas of Indonesia.

Published and grey literature from developed countries which explored human resources in general were excluded. There was an exception in selecting the literature. Studies from developed countries (i.e the United States, Australia, etc.) that reviewed human resources for health with developing countries from developing countries as an area of interest were reviewed.

The search results uncovered five main types of publication which informed this literature review - research articles and evidence commentaries, anecdotal evidence, grey literature and books. The literature explored various parts of the world such as Africa, South-East Asia, Australia, and the United States. Publication dates ranged from 1950 to 2016.

\subsubsection{Success Case Method Blended with Appreciative Inquiry}

Methodology, according to Krauss (2005) and Crotty (1998), identifies the strategy, plan of action, or specific practice implemented to obtain knowledge. In order to select a methodology, there are several considerations to be made, including the aim and the scope of the study. The aim of this research is to discover a better way to attract and retain midwives in remote areas of Indonesia. Bearing in mind, too, that this research has an evaluative aspect though is not intended to evaluate a specific intervention or programme. It is a research case study with an emphasis on analysing interviews with professionals and government documents to determine what is working well in attracting and retaining midwives in remote areas of Indonesia. 
Smith (2002) suggests that several factors need to be considered when selecting a method for evaluation, such as what is to be evaluated, the purpose, resources available, and local context (Smith, 2002). Based on these considerations, (Brenes, 2012) suggests that evaluators or researchers need to carefully compare the advantages and disadvantages of selecting research methods based on the research purposes.

For the purpose of this study, the design is crafted on the SCM blended with AI. Both SCM and AI share two core principles: evaluation; and positive thinking. The combination of these two aspects creates a productive synergy because SCM focuses on assessing the impact of an intervention (Brenes, 2012; Piggot-Irvine, 2009), while AI focuses on the cultural change aspect of an intervention. According to Howieson (2011), combining AI with other traditional evaluation methods has the potential to gather deeper and richer understanding of the professional experience as well as practice.

SCM is a simpler, faster and more cost-effective evaluation technique proposed by Brinkerhoff (2003) and Brinkerhoff (2005) because it needs smaller samples and highlights only the best and the worst cases. Brinkerhoff and Dressler (2003) and Brinkerhoff (2005) point out that SCM allows evaluators or researchers to explore the answers to the research questions that require detailed understanding and specific answers about the contextual factors that distinguish the 'success cases' from the 'less success cases'.

Brinkerhoff (2003) explains that the SCM almost always looks at what he refers to as the 'less success cases'. The rationale behind exploring the 'less success cases' as well as the 'success cases' in my study was to examine whether factors that are found in the 'success cases' can also be found in the 'less success cases'. The combination of factors that are found in both the 'success cases' and the 'less success cases' can enlighten decisions-makers in their task of improving the impact of policies or programmes. 
Considering the above challenges, concerning limited numbers of prospective participants and geographical difficulties, I decided to try a new model and used SCM because of its relevance for practical application in the field. SCM was initially used in business sectors (Brinkerhoff, 2003) and has been proven to be effective in numerous business organisations (Brenes, 2012). This technique provides business organisations with the opportunity to renew themselves and become more effective and competitive in an easy, yet carefully crafted, structure (Brenes, 2012).

Recently, SCM has been used in the field of education. For instance, SCM was used by Brenes (2012) to explore the key factors that influence the success of the Latino community at the secondary school. Brenes (2012) points out that SCM was an appropriate technique because it counters the potential difficulty in locating the research participants. In addition, Brenes (2012) also suggests that SCM became a practical instrument to be implemented because the feedback provided significant information on how to improve the success rates of the students and prevent them from failing.

However, this evaluation technique has not been used in the Public Policy sphere. Brinkerhoff (2003) points out that to implement SCM, there are two main components to be considered, namely: locating potential success cases; and determining and documenting the nature of success.

This study applied modifications to the steps of SCM. The main modification occurred in the way I identified the 'success and less success cases'. Brinkerhoff (2003) uses the best and the least best people in the training. In my study the selection of cases was based on best regions and least best regions. I set a criteria for those cases based on the purpose of the research.

Five steps were implemented: (i) Situational Analysis - focus of the study; (ii) Identifying success and non-success cases - a desk study; (iii) Data collection interviews and documenting policies and programmes both documented and undocumented; (iv) Data Analysis - using TA; and (v) Presenting findings (Brinkerhoff and Dressler, 2005). Figure 12 illustrates the SCM procedures of this study in order to assist the understanding and uncover the key factors that motivate midwives to work and stay in remote areas and also to investigate the existing policies and programmes about the recruitment and retention of midwives in remote areas of Indonesia. 


\begin{tabular}{|c|c|c|c|}
\hline $\begin{array}{l}\text { (1) The main focus of the research: } \\
\text { How can qualified midwives be better } \\
\text { attracted and retained in remote areas of } \\
\text { Indonesia? }\end{array}$ & $\begin{array}{l}\text { Key factors that } \\
\text { motivate } \\
\text { midwives in } \\
\text { remote areas and } \\
\text { existing policies } \\
\text { and programme }\end{array}$ & $\begin{array}{l}\text { Work } \\
\text { Motivation } \\
\text { (goals, self- } \\
\text { concept, } \\
\text { expectations) }\end{array}$ & $\begin{array}{l}\text { Work } \\
\text { Performance } \\
\text { (attract and } \\
\text { retain health } \\
\text { workers) }\end{array}$ \\
\hline \multicolumn{4}{|c|}{ (2) Selection of the 'Success and Less success cases': } \\
\hline \multirow{3}{*}{$\begin{array}{l}\qquad \frac{\text { (5) Presenting the Findings and }}{\text { Recommendation: }} \\
\text { Findings are presented into three chapters }\end{array}$} & \multicolumn{3}{|c|}{$\downarrow$} \\
\hline & \multirow{3}{*}{\multicolumn{3}{|c|}{$\begin{array}{l}\text { (3) Interviewing and Documenting 'The Success and Less Success } \\
\qquad \text { Cases': } \\
\text { A range of officials and midwives were interviewed. AI technique was used } \\
\text { for the In-Depth Interviews (IDIs). Selecting and documenting the existing } \\
\text { policies and programmes from both the national and local government related } \\
\text { to recruitment and retention of midwives in remote areas }\end{array}$}} \\
\hline & & & \\
\hline (4) Data Analysis: & & & \\
\hline $\begin{array}{l}\text { Thematic Analysis was implemented } \\
\text { which compared the key findings from both } \\
\text { cases and compared the key findings with } \\
\text { the existing programmes and policies. }\end{array}$ & & & \\
\hline
\end{tabular}

Figure 12: 'Success Case Method' Procedure (Adapted from Brinkerhoff, 2003) 
In addition, the AI technique was incorporated in phase two of the SCM as a guide to develop the IDI instrument, in order to answer research questions by focusing on key factors that significantly influence midwives in remote areas. IDI offers freedom of expression for research participants' ideas, insights, and memories (Reinharz, 1992). Using the AI technique, the researcher established some structured focus, yet it did not limit or prohibit the participant from exploring their thoughts.

In this study, the first research question was intended to understand the important factors that motivate midwives to work and stay in remote areas. This also intended to understand the positive impact of these factors on midwives' motivation to work and stay in remote areas. The focal point of the second research question was to investigate whether the policies or programmes respond to or facilitate the recruitment and retention of midwives in remote areas. This research question was also expected to explore the undocumented approaches that were taken by the government that influence midwives' motivation to work in remote areas.

Based on those questions, instead of using a deficit model, a focus on positive questions was definitely preferred. A deficit model is not able to identify any item that creates high engagement and commitment to the work system, whilst AI had the potential to discover this aspect (Cooperrider, Whitney, \& Stavros, 2008). AI principles enable stakeholders to broaden their perspectives on the issue of recruiting and retaining midwives in rural and remote areas of Indonesia, by encouraging them to think about the relevance of issues from different angles and paradigms of knowledge and understanding (Howieson, 2011).

This AI technique was used to gain a richer and deeper understanding of the phenomena of human behaviour by combining a positive attitude with a constructive approach (Howieson, 2011).
AI is premised on a set of core principles that rest on the central assumption that in every organisation something works, and that by focusing on the things that work and by using positive thinking, imagery and language, the organisation can create a positive future. (Howieson, 2011, p.15) 
Contemporary AI posits a '5-D' model which encompasses Defining (what is the focus of inquiry), Discovery (research participants identify and appreciate the positive life story), Dream (create a clear vision for the organisation), Design (create clear statements of the possibility of the ideal organisation), and Deliver or Destiny (implementation) (Cooperrider et al., 2008; Priest, Kaufman, Brunton, \& Seibel, 2013). This indicates the importance of creating a supportive environment based on an “appreciative eye" (Cooperrider et al., 2008, p. 47).

Bushe and Kassam (2005) argue that the outcome of AI has the potential to construct new knowledge, models, or theories. Therefore, the questions for my research were formulated based on the 5-D model which aimed to gather new ideas and thus achieve new knowledge, models and theories. Some modifications to the model were applied to emphasise the Discover, Dream, and Design (3-D) stages. The Defining stage was identified as the research aim, but the Deliver or Destiny stages were not applicable because of the scope of the study.

In the study's implementation, questions were focused on the key ideas that identify the factors and programmes or policies that influence midwives to work and stay in remote areas (Discover). Participants were asked to classify their key important factors into their top three, where number one was the most significant and number three the least significant factor. Then, in establishing how important the various factors were, the top three received between 15 to 70 mentions. The benefit of using a qualitative approach was that it allowed me to learn in depth from a single story. While frequency of similar stories mattered, this was only a part of the 'story'. The participants were also required to create a vision or to share what they expected in order to attract and retain them in the workplaces (Dream). The question that followed gave them the opportunity to identify the potential solution to make that dream come true (Design). 
I decided to apply SCM blended with AI following some core principles which accentuate a positive way of thinking, rather than eliminating the negative. The findings were expected to uncover factors that have not been identified in previous studies, and determine whether or not these new factors would add value to existing knowledge. In addition, the findings were expected to provide evidence determining the success of how governments or other related stakeholders needed to be part of maintaining and improving midwives' motivation to work in remote areas.

As the researcher as well as the interviewer, I believe the significant effects of using this approach were that most participants were able to confidently share their experiences and provide potential solutions to untangling issues surrounding recruitment and retention of midwives in their areas.

\subsubsection{Selection of the 'Success and Less Success Cases': Desk Study}

Selection of the 'success and less success cases' is stage two of the SCM. In order to identify potential locations for the SCM, a set of criteria were developed. A desk study to identify relevant documents about the areas was conducted. The 'success cases' and 'less success cases' were decided based on two criteria: geographical conditions and the coverage of midwives. Initially, in terms of location, all data in each province in Indonesia on the coverage of midwives were retrieved from the $\mathrm{MoH}$ website. This occurred in February 2014. Locating underdeveloped regions or provinces was also conducted in order to narrow down the research locations. The status of each province in Indonesia (i.e. whether they were developed or underdeveloped) was also obtained from the website of the Ministry of Rural Development of Disadvantaged Regions and Transmigration of the Republic of Indonesia (Kementrian Desa, Pembangunan Daerah Tertinggal dan Transmigrasi or KDPDTT) in February 2014. 
The combination of underdeveloped regions or provinces with a high coverage of midwives was used in order to select the potential 'success cases'. Of the 34 provinces from Sabang (in Sumatera Island) to Marauke (on Papua Island), 13 were categorised as underdeveloped in 2014, according to KDPDTT: Aceh, Gorontalo, West Kalimantan, Maluku, North Maluku, West Nusa Tenggara, East Nusa Tenggara, Papua, West Papua, West Sulawesi, South Sulawesi, Central Sulawesi and South East Sulawesi. Based on this information, the potential research locations were narrowed from 34 in number to 13 .

The coverage of midwives was then compared across these 13 provinces because despite the GoI's stated goal of having at least one midwife in 95\% of Indonesian villages, this has not yet been achieved by most of the underdeveloped provinces which instead have a low coverage of midwives (less than 60\%). An exception was found in $N T B$ which, although categorised as an underdeveloped province, has a high coverage of midwives (above 80\%) (Table 2). NTB was selected as the study area because it fits the requirement of the SCM. Geographically, NTB is divided into two main islands - Lombok and Sumbawa. Each island consists of five districts but some of the areas are difficult to access.

Table 2: Coverage of Midwives in the 13 Provinces Categorised as Underdeveloped by the KDPDTT

\begin{tabular}{llcc}
\hline No. & Province & Number of Villages & $\begin{array}{l}\text { \% of Villages with } \\
\text { Midwives }\end{array}$ \\
\hline 1 & Aceh & 6,483 & 63.7 \\
\hline 2 & Gorontalo & 731 & 45.8 \\
\hline 3 & West Kalimantan & 1,967 & 60.3 \\
\hline 4 & Maluku & 1,024 & 50.3 \\
\hline 5 & North Maluku & 1,079 & 44.9 \\
\hline 6 & West Nusa Tenggara & 1,084 & 81.5 \\
\hline 7 & East Nusa Tenggara & 2,966 & 59.8 \\
\hline 8 & Papua & 3,924 & 24.3 \\
\hline 9 & West Papua & 1,439 & 23.4 \\
\hline 10 & West Sulawesi & 638 & 68.2 \\
\hline 11 & South Sulawesi & 2,982 & 80.7 \\
\hline 12 & Central Sulawesi & 1,815 & 62.8 \\
\hline 13 & South-East Sulawesi & 2,121 & 49.1 \\
\hline
\end{tabular}

Source: Adapted from The KPDPDTT report 2012 and the MoH report 2012 (retrieved 23 Feb 2013) ${ }^{7}$

\footnotetext{
${ }^{7}$ This reference is no longer accessible
} 
This inaccessibility was considered alongside other factors in determining whether NTB was the best research location. Other factors included the range of local government-specific programmes focussed on maternal health that were provided in the province. In 2009, the provincial government launched a programme with zero tolerance for maternal mortality called Angka Kematian Ibu Nol. This programme encouraged each DHO in $N T B$ to improve the availability of health workers, such as midwives, as the health pioneers in the remote areas.

The feasibility of data gathering in the area, and the time it would take, as well as financial constraints, were also considered when making the choice. I had developed a better network in one of the districts, while I was working as a Monitoring and Evaluation Officer at SurfAid in 2012, which influenced the final decision.

Even though the location of data collection was determined in the early stages, conducting situational analysis was another crucial part of this phase. This served to double-check whether NTB was an appropriate location for the study compared to other provinces in Indonesia. In this phase of the data collection, data were obtained from incountry offices (and websites) from the Agency for Development and Empowerment Human Resources of Health (Badan Pengembangan dan Pemberdayaan Sumber Daya Manusia Kesehatan) located at the MoH of the Republic of Indonesia in Jakarta.

Due to the uneven quality of the available data, decisions around inclusion and exclusion were made based on the best information available. To determine the 'success cases' and the 'less success cases', a simple formula was used to generate the average number of midwives per village in $N T B$ : the total number of village midwives per district divided by the total number of villages per district. 'Success cases' were identified as underdeveloped districts which had an average of more than two midwives per village between 2010 and 2014, and 'less success cases' were identified as underdeveloped districts that had an average of less than two midwives per village between 2010 and 2014 (Table 3).

Thus, with regards to the study design, NTB provided an excellent opportunity to evaluate both 'success cases' and 'less success cases', because within the province, there were some districts that were successful and some that were less so in terms of recruiting and retaining midwives. 
NTB has eight districts and two municipalities where, according to the 2014 KDPDTT report, all eight districts (i.e. West Lombok, East Lombok, Central Lombok, Dompu, Sumbawa, Sumbawa Besar, Bima and North Lombok) are classified as underdeveloped. The two municipalities (Mataram and the city of Bima) are categorised as developed areas. Therefore, all eight districts were selected for further examination.

Table 3: Average Number of Midwives per Village in the West Nusa Tenggara Province (Nusa Tenggara Barat) between 2010 and 2014

\begin{tabular}{|c|c|c|c|c|c|}
\hline \multirow[b]{2}{*}{ District } & \multicolumn{5}{|c|}{ Year } \\
\hline & 2010 & 2011 & 2012 & 2013 & 2014 \\
\hline \multicolumn{6}{|c|}{ 'Success Cases' } \\
\hline Dompu & & & & 3.1 & 5.5 \\
\hline North Lombok & 1.2 & 2.6 & 3.7 & 4.6 & 5.1 \\
\hline Sumbawa & 0.6 & 1.5 & 2.9 & 3.1 & 3.8 \\
\hline East Lombok & 1 & 0.8 & 0.9 & 2.1 & 2.5 \\
\hline Bima & & & 1.7 & 2 & 2.4 \\
\hline West Lombok & & 1.7 & 2.1 & 2 & 2.1 \\
\hline \multicolumn{6}{|c|}{ 'Less Success Cases' } \\
\hline Central Lombok & 1.3 & 1.5 & 1.5 & 1.4 & 2.1 \\
\hline Sumbawa Besar** & 1.6 & 1.9 & 2.5 & 2.5 & 4 \\
\hline
\end{tabular}

**Includes nurses; Sources: Adapted from Health Profile Report from 2010 to 2014 from eight DHOs in NTB.

Prior to conducting the third stage of SCM - interviewing and documenting the 'success and less success cases' - an approval to undertaken the research approval of this research was needed.

\subsubsection{Pre-Data Collection Procedure}

Two essential types of documentation needed to be obtained prior to gathering data in Indonesia. The first was ethical approval from Victoria University of Wellington VUW in New Zealand and the second was a research recommendation letter from the GoI.

\subsubsection{Ethical Consideration}

A completed human ethics application was submitted online to the Human Ethics Committee (HEC) of VUW. The approval process took approximately three weeks and was granted by the HEC on 4 December 2014; the approval letter was used as the basis for site approval required in Indonesia. 


\subsubsection{Research Approval Letter}

Three levels of approval were required from Indonesia's tiered government hierarchy: from the national, provincial and district levels.

Prior to data collection in NTB, under the law of the Ministry of Home Affairs number 64 year 2011, every researcher is advised to obtain a research recommendation letter. The letter can be obtained from the Administration Service Unit Directorate General of National Unity and Politics at the Ministry of Home Affairs in Jakarta.

The research recommendation letter for this study was granted on 26 January 2015. This letter is a legal document used as a basis for obtaining research approval letters at the provincial and district levels of government in Indonesia. The process of obtaining the research recommendation letter from the GoI for this study was relatively straightforward. The required documents (an ethical approval letter, an application letter, a summary of the research proposal, a copy of my identity card, and a statement letter to comply with the rules and regulations, e.g. local customs) were submitted to the Directorate General of National Unity and Politics at the Ministry of Home Affairs in Jakarta and within 14 working days the letter was issued. An important point to note for other researchers undertaking this process is that all documents had to be presented in Bahasa Indonesia.

The research recommendation letter was then submitted to the Environmental and Research Agency (Badan Lingkungan Hidup dan Penelitian or BLHP) at the provincial level of Indonesian government (i.e. in NTB) along with other documents, including a summary of the research proposal and the ethics approval letter from the HEC of VUW, in order to receive their research approval. Processing time for this was relatively fast; approximately within an hour a research approval letter was issued by the agency.

The next step in this process was gaining approval at the district level of the Indonesian government. This required submission of the same documents to each Regional Development Planning Agency (Badan Perencanaan Pembangunan Daerah or $B A P P E D A$ ) at the district level. 
Decentralisation has created slight variations around obtaining research approval letters from each district. These differences were mostly in regard to processing times, yet with this study, it was found to be relatively fast and simple. The approval process basically only took from between half a day to, at the most, less than a week in total. The biggest difference was with the Dompu district in Sumbawa Island where the approval letter was issued through National Unity and Politics instead of BAPPEDA.

Even though this added extra time to my research timetable, these approval letters were crucial documents for my research because they informed relevant stakeholders of the study's aim and target participants. They also served to ethically protect me should unexpected circumstances arise. In addition, completing this pre-data collection stage of my research increased my understanding about each district in NTB; it provided an overview of the character and the work systems of each area I was planning to visit. Figure 13 summarises the steps taken in obtaining research approval letters in Indonesia.

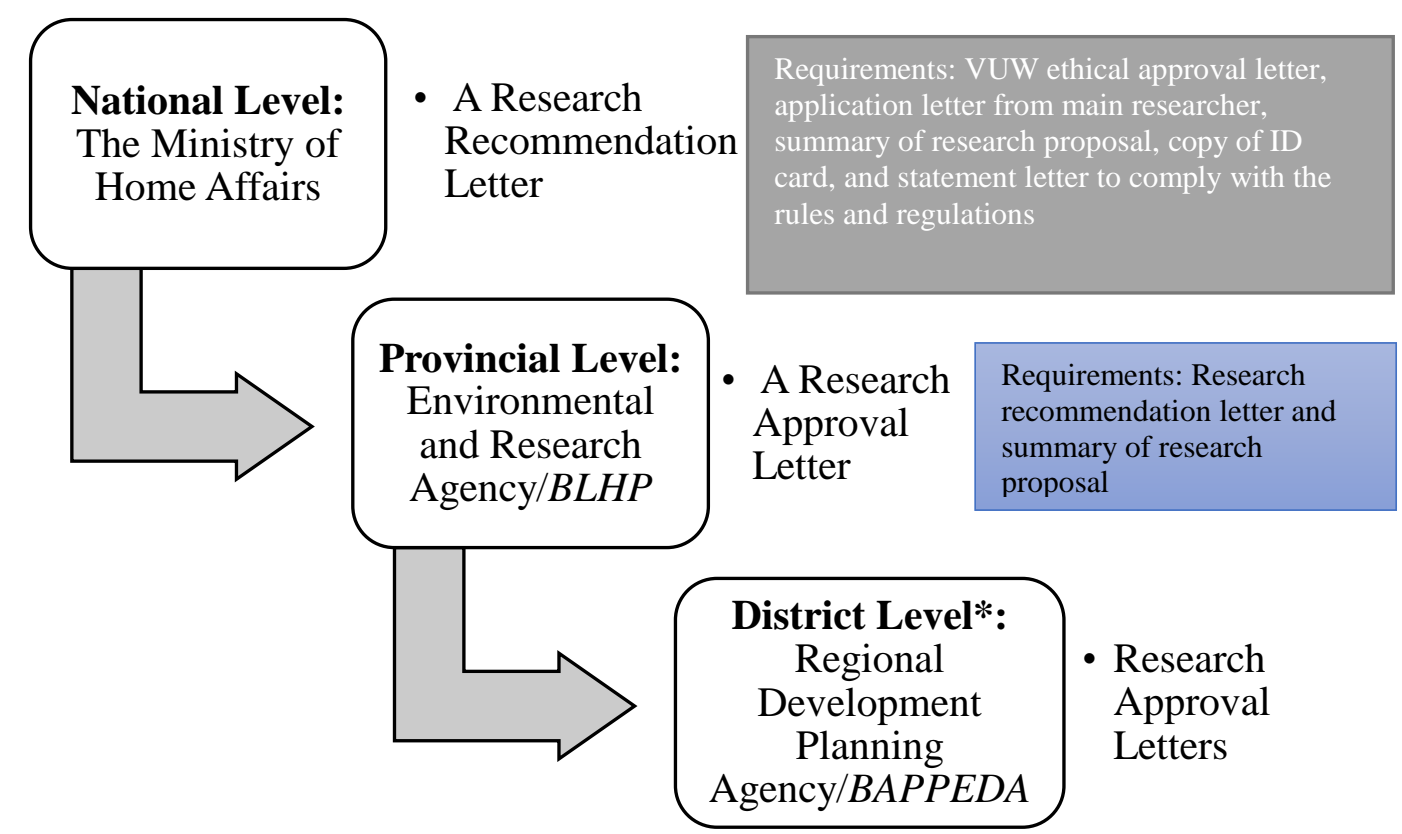

*Dompu district issued their approval letter through National Unity and Politics Agency

Figure 13: Steps in Obtaining a Research Approval Letter 


\subsubsection{Interview and Documenting the 'Success and Less Successful' Cases}

Once 'success cases' and 'less success cases' were determined, IDIs were conducted. This research method is a common technique implemented to collect knowledge or information (Crotty, 1998). Research questions investigate the views or perceptions of various stakeholders. In my research, these stakeholders were policymakers at national and local government levels, the Head of Indonesian Midwives Association (Ikatan Bidan Indonesia or IBI), and midwives.

Initially the data collection was divided into two parts. The first part was planned to explore the 'success cases' $(1,2,3,4,5$ and 6) and the second part would explore the 'less success cases' (7 and 8) (Figure 14). However, this plan needed to be changed due to the distance between districts. Geographical conditions were a barrier to conducting data collection as planned. To avoid high costs and optimise the time, a decision was made to collect the data on the basis of island location. Thus, I did not have to travel back and forth between islands. The travel from Lombok Island to Sumbawa Island can be by ferry (12 hours) or plane (40 minutes).

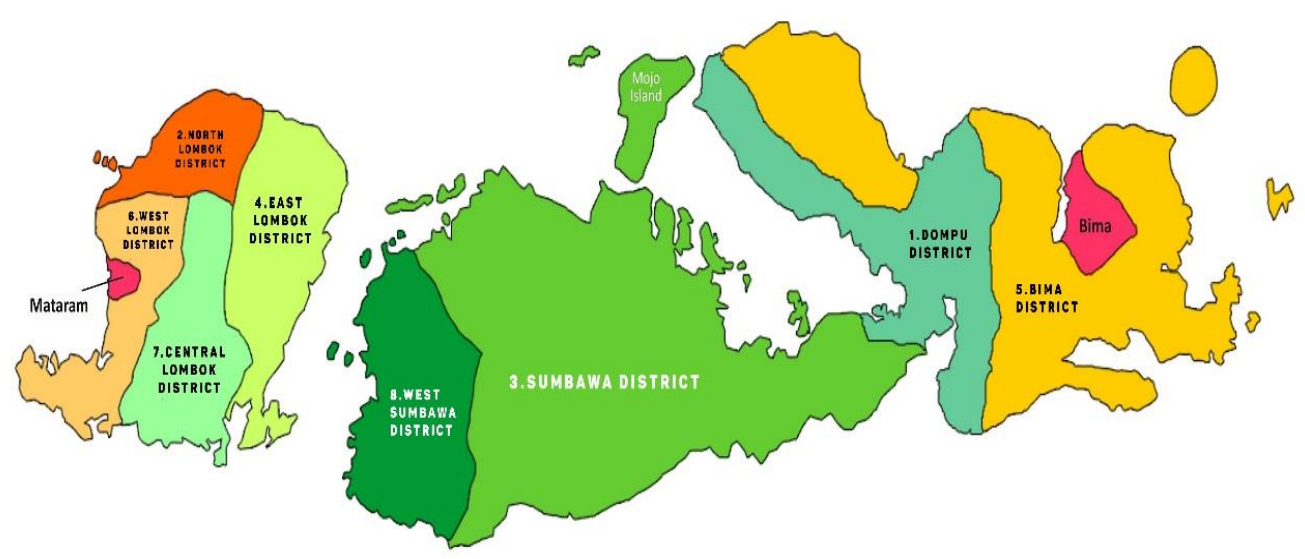

Lombok Island

Sumbawa Island

Figure 14: Original Data Collection Route 
In March 2015, I flew to NTB, to Lombok Island, for the first phase of the data collection. This is where the Provincial Health Office (PHO) is located. I visited the PHO to communicate information about the study and started to familiarise myself with the location and characteristics of the research areas. Then I spent time in four DHOs of Lombok Island to introduce myself as well as obtain the required research approval letter, and to collect lists of midwives in remote areas. The first district that I visited was West Lombok and Central Lombok. Then I visited East Lombok and North Lombok.

From mid-June to mid-July 2015 the data collection was stopped because of the fasting month. In Indonesia where the predominant population is Muslim, the fasting month is considered sacred, and, as a result, many people's activities mostly revolve around it. It was not the right time to interview or collect information from the research participants. Thus, I used the time to transcribe some interviews and conducted an initial data analysis. This process was useful to clarify some questions in order to gather thorough information.

For the second phase of the data collection, I flew to Sumbawa Island in August 2015 to collect the same data from another four DHOs, namely Bima, Dompu, Sumbawa and Sumbawa Besar districts. Table 4 provides information on the adaptation of the fieldwork timetable. 
Table 4: Fieldwork Timetable

\begin{tabular}{|c|c|c|}
\hline Group & Location & Time \\
\hline $\mathrm{MoH}$ & Jakarta & February 2015 \\
\hline $\mathrm{PHO}$ & Mataram - Lombok Island & March 2015 \\
\hline $\begin{array}{l}\text { DHO officers and Head } \\
\text { of Puskesmas }\end{array}$ & $\begin{array}{l}\text { Lombok Island - West Lombok, } \\
\text { Central Lombok, East Lombok and } \\
\text { North Lombok }\end{array}$ & $\begin{array}{l}\text { March - Early June } \\
2015\end{array}$ \\
\hline $\begin{array}{l}\text { District Health Offices } \\
\text { and Head of Puskesmas }\end{array}$ & $\begin{array}{l}\text { Sumbawa Island - Bima, Dompu, } \\
\text { Sumbawa, and Sumbawa Besar }\end{array}$ & $\begin{array}{l}\text { August - October } \\
2015\end{array}$ \\
\hline$I B I$ & $\begin{array}{l}\text { Jakarta, East Lombok, North } \\
\text { Lombok, West Lombok, Central } \\
\text { Lombok, Bima, Dompu, Sumbawa } \\
\text { and Sumbawa Besar }\end{array}$ & $\begin{array}{l}\text { March - October } \\
2015\end{array}$ \\
\hline $\begin{array}{l}\text { Midwives (senior, mid- } \\
\text { range and new) }\end{array}$ & $\begin{array}{l}\text { Lombok Island - West Lombok, } \\
\text { Central Lombok, East Lombok, and } \\
\text { North Lombok }\end{array}$ & $\begin{array}{l}\text { March - Early } \\
\text { June } 2015\end{array}$ \\
\hline $\begin{array}{l}\text { Midwives (senior, mid- } \\
\text { range and new) }\end{array}$ & $\begin{array}{l}\text { Lombok Island - West Lombok, } \\
\text { Central Lombok, East Lombok and } \\
\text { North Lombok }\end{array}$ & $\begin{array}{l}\text { August - October } \\
2015\end{array}$ \\
\hline
\end{tabular}

After all the initial information was gathered, I then determined my study participants based on a set of criteria.

\subsubsection{Study Participants: Demography}

A set of criteria was developed to select appropriate participants. In considering the midwives the criteria were based on their geographical situation and years of service. The first criterion was that the midwives had to be working in remote or very remote areas of Indonesia. According to Indonesia's MoH Decree number 949 year 2007 , there are two categories of these areas, namely remote and very remote. These areas are defined based on their geographical location, the area's access to transportation and their social economy (Table 5). 
Table 5: Differences between Remote and Very Remote Areas

\begin{tabular}{|c|c|c|}
\hline Criteria & Remote Area & Very Remote Area \\
\hline \multirow{4}{*}{$\begin{array}{l}\text { Geographical } \\
\text { Position }\end{array}$} & Difficult to reach area & Difficult to reach area \\
\hline & Mountains, inland, swamps & Mountains, inland, swamps \\
\hline & \multirow{2}{*}{$\begin{array}{l}\text { Prone to natural disasters, } \\
\text { such as earthquakes, } \\
\text { landslides and volcanic } \\
\text { eruptions }\end{array}$} & $\begin{array}{l}\text { Prone to natural disasters, such as } \\
\text { earthquakes, landslides and } \\
\text { volcanic eruptions }\end{array}$ \\
\hline & & $\begin{array}{l}\text { Borders regions with other } \\
\text { countries, such as land, small } \\
\text { islands or outmost island }\end{array}$ \\
\hline \multirow[t]{4}{*}{$\begin{array}{l}\text { Access to } \\
\text { transport }\end{array}$} & $\begin{array}{l}\text { Public transport used } \\
\text { (land/water/air) routinely, } \\
\text { maximum twice a week }\end{array}$ & $\begin{array}{l}\text { Public transport used } \\
\text { (land/water/air) routinely, } \\
\text { maximum once a week }\end{array}$ \\
\hline & \multirow[t]{3}{*}{$\begin{array}{l}\text { The travel time (round trip) } \\
>6 \text { hours }\end{array}$} & $\begin{array}{l}\text { The travel time (round trip) }>8 \\
\text { hours }\end{array}$ \\
\hline & & $\begin{array}{l}\text { Only air transport available to } \\
\text { reach the site }\end{array}$ \\
\hline & & $\begin{array}{l}\text { Transport system hindered by } \\
\text { climate or weather conditions } \\
\text { (e.g., wave height or typhoons) }\end{array}$ \\
\hline \multirow[t]{2}{*}{ Social Economy } & Difficult to meet basic needs & Difficult to meet basic needs \\
\hline & Security issue & Security issue \\
\hline
\end{tabular}

Source: Indonesia's Ministry of Health Decree number 949 year 2007 cited in Efendi (2012) 

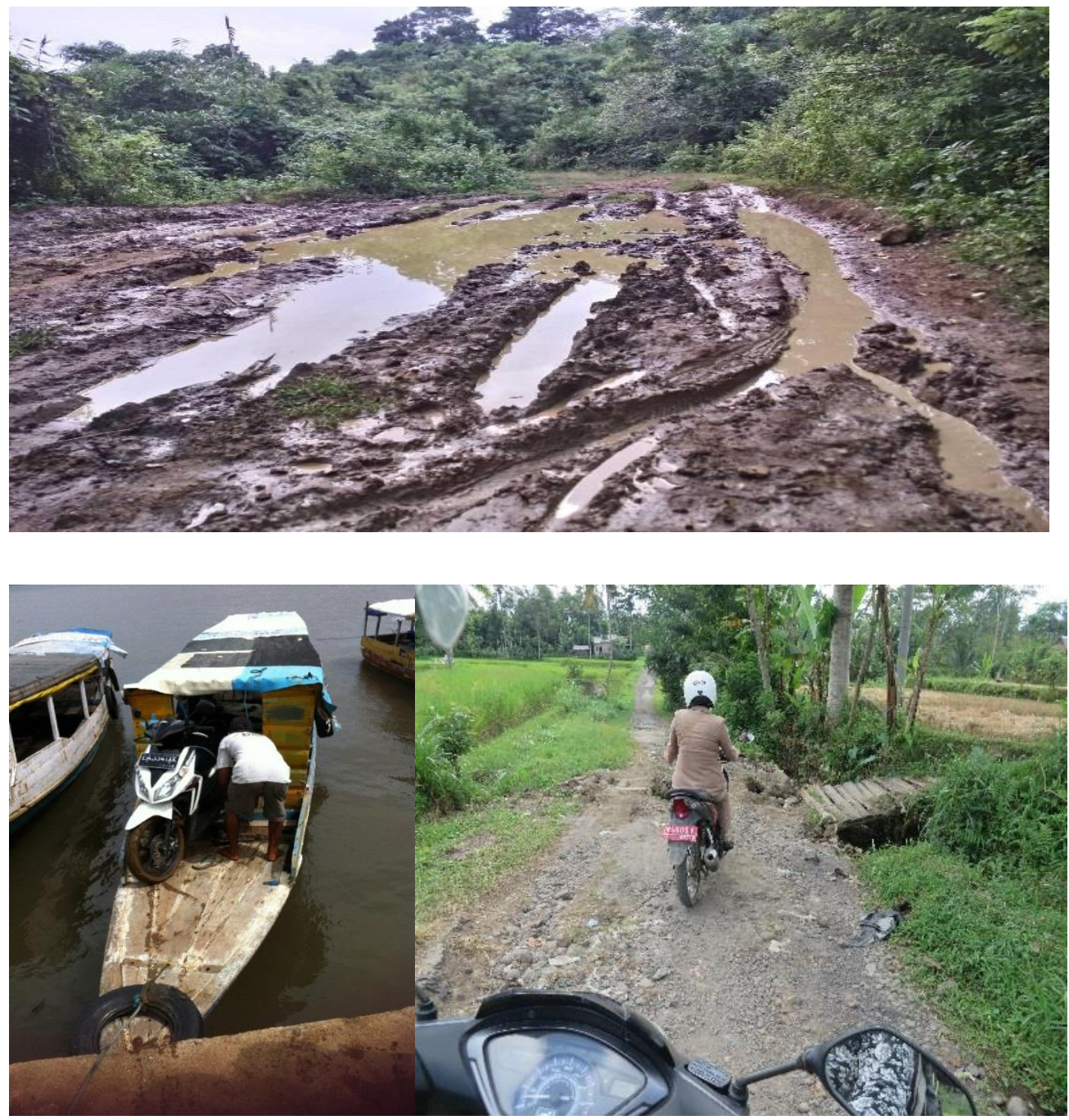

Figure 15: Accessing Remote and Very Remote Villages in NTB

The second criteria was the midwives' years of service. This was divided into three groups:

(1) One year or less

(2) More than one year's service, but less than seven years

(3) Seven years of service or more.

Using these criteria, the midwives were selected for inclusion in this study. Selection was done through consultation with the Heads of DHOs and Heads of Puskesmas from the list of midwives who work in remote or very remote areas of Indonesia, and midwives' years of service. Midwives were purposely selected within selected districts. An additional criterion was added to reflect various types of midwives available in each district; that is, those who were civil servants $P N S$, those who had national government contracts, those who had local government contracts, and volunteer midwives. 
In addition to midwives, information was gathered from government officials from national to local levels and the $I B I$. Government officials were selected based on the relevance of their positions in the government, and furthermore based on their knowledge and experience of recruitment and retention of midwives in remote areas. These participants were expected to share their experiences, values and knowledge about the recruitment and retention of midwives in remote areas, thus, the phenomenon of recruitment and retention of midwives could be identified. Using triangulation, the knowledge and experience from these groups were considered, alongside that of the midwives in order to improve the trustworthiness of the data (Perdok et al., 2016).

Due to the nature of this research, which looks at the implementation of the policies and programmes on the recruitment and retention of midwives, the recipients of the service were not interviewed. Even though the recipients have an impact on the retention of midwives, the recipients themselves have not been involved in determining the recruitment and retention of midwives in rural and remotes areas.

Each IDI started with some social conversation to create a relaxing and trusting atmosphere. Interviews typically lasted between 40 and 60 minutes. Most were conducted in the mornings, but some were also scheduled in the evenings and on the weekends as necessary. The interview guide was initially created in English, and later translated into Bahasa Indonesia, the official language of Indonesia.

IDIs with participants were conducted on the basis of their knowledge of and experience in recruiting and retaining midwives in rural and remote areas of Indonesia. The interviews used a semi-structured guide based on an AI technique (Appendix C, pg. 254). Below are the key points of the question that were asked of the different groups.

a) For policy-makers: The questions asked were about what worked best, in their experience, in recruiting qualified midwives and what worked best in retaining them (and how they knew this). They were also asked for their views on what was missing from current policies and programmes regarding recruitment and retention of qualified midwives in rural and remote areas of Indonesia, and what appropriate improvements had been implemented. 
b) For the Indonesian Midwives Association/IBI: The questions asked were about what worked best, in their experience, in recruiting qualified midwives and what worked best in retaining them (and how they knew this). They were also asked for their views on how the organisation had supported recruitment and retention of midwives in rural and remote areas of Indonesia.

c) For midwives: The questions asked were about their actual midwifery experience of recruitment and retention, their reasons for working where they did, and their reasons for staying. Again the focus of the questions for them was about what they believed worked best in recruiting qualified midwives to rural and remote areas of Indonesia, and what they believed worked best in retaining them.

By using these positive questions, I noticed that research participants were able to positively contribute to addressing the issue of attracting and retaining midwives by allowing them to explore emergent ideas and tensions in a positive manner. Personally, I feel AI was considered as an appropriate technique in the Indonesian context because it had positive impacts on the perception of the interview since most participants are more likely to engage with the interviewer.

While it was planned to interview around 64 participants, a higher number was achieved ( 75 research participants). This was due to the fact that there were eight districts selected as the research areas.

\subsubsection{Permission and Invitation to Participate}

An appointment was sought with most participants (particularly government officials such as MoH officers in Jakarta, the Heads of DHOs in each district in NTB, and the Head of $I B I$ ), to gain permission to conduct IDIs with them. Contact was initially made both through emails or short-message services (or SMS). A participant information sheet about the objectives of the overall study was attached in each email to a potential participant. 
In terms of time and locations of IDIs, these were decided based on mutual agreement, however, participants' preferences were most important. Most participants preferred to be interviewed in their offices during office hours. When participants cancelled appointments, rescheduled meeting times and places were proposed either by the researcher or the participants. Only one participant declined to be interviewed and a personal approach was taken with other officers to find a replacement.

A slightly different appointment system was undertaken with the village midwives. This was due to the remoteness of the areas that midwives lived in, which meant that many of them had limited access to internet and mobile phone signals. To access some remote villages in NTB (e.g. Batu Jangkeh in Sumbawa Island), specific transportations such as boat and trail motorbike were required, meaning it could take hours to arrive at a destination. An effective way to locate midwives in remote villages was to visit the Puskesmas located in the city. They were able to provide information to guide me to locations as well as advise on access to them. In some areas this meant I was accompanied by the Head of Puskesmas and the doctor to the villages; this was required in order to access the locations. The IDIs with the midwives occurred in their healthcare facilities, offices or homes.

\subsubsection{Anonymity or Privacy of Participants}

In general, prior to IDIs, confidentiality with regards to participants' involvement, and anonymity with regards to their stored data, were assured. Consent that encompassed their willingness to participate in the IDIs and to be audio-recorded was sought and obtained. Most participants were uncomfortable with signing written consents, so verbal consent was obtained. No participants received monetary incentives to be part of the research. A tote bag and notebook were instead provided as a gesture of appreciation for their participation at completion of the interview. This recognition is referred to in New Zealand as a 'koha' (the indigenous word for such a 'gift'). These koha items had been approved by the HEC of VUW. 


\subsubsection{The 'Success Cases'}

There were 57 participants from the 'success cases' which consisted of 15 government officials, six participants from the, and 36 midwives (Table 6). The government officials encompassed a varied range of officials, namely the head of DHOs, the head of Puskesmas, the head of human resources at DHO level, the secretary of DHOs, and the Regional Human Resources (Badan Kepegawaian Daerah or BKD). All of the research participants from this group were males with an average age of 42 years.

Another group of participants were from $I B I$ and village midwives. Since midwifery is a profession for females, all participants in this group were female. In general, midwives in Indonesia are women with a minimum of three years' midwifery training. There were 36 midwives interviewed.

\subsubsection{The 'Less Success Cases'}

There were fewer participants in the 'less success cases' than in the 'success cases' category. This is due to the fact that only two districts were categorised as 'the less success cases'. Fourteen participants were interviewed in the 'less success cases' consisting of four government officials, two IBI members, and eight village midwives. One of the four participants from the government officials was female. This group consisted of the heads of DHOs and the heads of Puskesmas.

\subsubsection{Other Participants}

Four IDIs were also conducted with government officials at the national (two respondents) and provincial levels (two respondents). These participants were not categorised as part of either the 'success cases' or the 'less success cases'. These participants were interviewed as part of the triangulation process in order to add, clarify or confirm the findings gathered in the field. 
Table 6: In-depth Interviews (IDIs) Participants

\begin{tabular}{|c|c|}
\hline The Participants & Total \\
\hline \multicolumn{2}{|l|}{ The 'Success Cases' } \\
\hline Government Officials & 15 \\
\hline Indonesian Midwives Association & 6 \\
\hline Midwives & 36 \\
\hline Total & 57 \\
\hline \multicolumn{2}{|l|}{ The 'Less Success Cases' } \\
\hline Government Officials & 4 \\
\hline Indonesian Midwives Association & 2 \\
\hline Midwives & 8 \\
\hline Total & 14 \\
\hline \multicolumn{2}{|l|}{ Other Participants } \\
\hline National Level (Ministry of Health and Indonesia Midwives Association) & 2 \\
\hline Provincial Level (Provincial Health Officer) & 2 \\
\hline Total & 4 \\
\hline Grant Total & 75 \\
\hline
\end{tabular}

I found it very interesting that the government officials were predominantly males. Out of 19 participants only four were females. It indicates that most of the decision-making positions were occupied by males. This study has not analysed this aspect, however, there might be an opportunity for further research in terms of gender and policy advising in recruitment and retention of midwives in Indonesia.

\subsubsection{Researcher Position: The Need for Travel Buddy}

As a researcher, positioning is crucial. Merriam et al. (2001) point out that the researcher is categorised into two main positions: the insider (indigenous and external insider); and the outsider (indigenous and external outsider). In this research, under certain circumstances, I, as the researcher was categorised as an indigenous outsider who had "experienced high levels of cultural assimilation into an outsider or oppositional culture, but remains connected with his or her indigenous community" (Merriam et al., 2001, p. 412). I am Indonesian but have some limitations in my knowledge of local languages and cultures. The advantage of being an indigenous outsider was that it allowed for a less biased standpoint. While Bahasa Indonesia is the official language, in remote areas local languages are usually spoken. To combat this possible language and cultural barrier, where necessary I was accompanied by a local who became a travel buddy and interpreter as well. 
The term 'travel buddy' in this study is defined as a person who helped and supported the researcher on a daily basis, such as accompanying me to the villages during my fieldwork. The travel buddy also functioned as an interpreter for two local languages, Sasak (Lombok people) and Samawa (Sumbawa people).

In order to find such a person, I contacted my previous Non-Government Organisation (NGO) before travelling to Indonesia regarding the possibility of them providing me with a suitable candidate to accompany me on my fieldwork. I set several criteria, such as: experience as an interpreter (able to fluently speak the local languages of Sasak, Mbojo and Samawa); familiarity with local culture; and experience in data collection. Since I would be travelling intensively with this person to each study site, I also requested a female companion. Fortunately, the NGO supported me by introducing an appropriate candidate. My travel buddy was a female, held a bachelor's degree in public health, had some excellent local language skills, and was resourceful, flexible and trustworthy.

Additionally, prior to conducting this phase of the data collection, I ensured that she understood what the objectives of the research were, as well as what the travel plans were, by providing 'mini training'. This training was conducted for approximately half a day at a hotel in Lombok. The training was only between myself as the researcher and the travel buddy. It was important to ensure that, as an interpreter, the travel buddy understood the ethics of conducting research, which meant understanding the importance of maintaining confidentiality. I also ensured that she understood the ownership of the research (i.e. that I maintained sole ownership of the data). At the conclusion of the training when I was confident the candidate provided was suitable, I provided her with an interpreter and travel buddy consent form to be signed.

Understanding the topic was essential information, so the interpreter was able to extrapolate participants' answers, understand each question and know why the researcher was asking the question. Another important thing was to ensure that the interpreter translated verbatim and did not summarise or add to what the participant responded. This translated interview process involved several steps: I asked questions in Bahasa Indonesia; the interpreter translated it into the participant's local language; the participant responded to the questions in their local language; and finally, the interpreter responded to me in Bahasa Indonesia. 
Employing a travel buddy was a crucial component of my fieldwork as it assisted me with effectively manoeuvring around remote and very remote villages. I am Indonesian, yet I realised that by having a travel buddy during my fieldwork, I was able to understand more about the local context or culture, which also made the research process safer.

Based on my experience, having a travel buddy that you as a researcher can trust, share difficulties with, have as a friend, and receive valuable support from when problems occur, is really helpful. Because you spend a lot of time together, however, it is also advisable to make time to do things separately. 


\section{Box 1: Geographical Challenges}

Remote areas can be defined differently in every country. For a developed country like New Zealand, remote areas are mostly accessible with transportation such as cars or motorbikes. It is just a matter of distance. On the other hand, remote areas in developing countries, such as in Indonesia are very difficult to access. It is not merely about the distance, as it also involves poor infrastructures.

Based on my experience during my fieldwork in some remote areas in West Nusa Tenggara (Nusa Tenggara Barat or NTB), I had to use various modes of transportation, and even had to walk for hours to get to villages. For one village, Labuan Aji, I had to catch a boat for three hours. The local people have to pay around IDR 10,000 [equal to USD 0.70]. Boats are the only transportation that we can use from and to the city or to other islands. Another remote village in Sumbawa district [Punik Village] requires special transportation. Because of the road condition it is not possible to use regular transportation such as a motorbike or car. In order to get there, 4WD cars or special motorbikes (i.e. trail) are the only transportation that you can use. I was very fortune because I was helped by the head of Puskesmas to get to that village. It was not only the distance but also the rocky road as well as the winding journey. I did my data collection during the dry season, thus I did not have to deal with the wet and slippery roads. I could not imagine doing fieldwork if it was a rainy season as I would not have been able to reach these villages.

As well as the challenging roads and the distances, living in remote areas has other issues, such as limited access to telecommunication, electricity, and clean water facilities. I stayed a night in some villages. In Labuan Aji, there was no electricity during day time. They have only electricity from 6pm to 6am and in other places there is zero access to electricity. Therefore, the community need to have generators or other equipment in order to support their activities.

Access to clean water is another challenging issue that has to be faced by the people who live in remote areas. For instance, in one remote village in Central Lombok District, the midwives have to walk for about 15 minutes each way to access clean water. This situation is pretty common in other areas. Apparently, many factors contribute to this problem, such as springs are limited or there is only limited budget to create wells.

Limited access to telecommunication is also a common problem in remote villages. Coming from Jakarta (the capital city of Indonesia), I have rarely experienced no coverage, yet many in remote villages face this issue daily. Communication with other organisations, institutions, or people were mainly taken by people going to the city.

Public services, namely healthcare facilities, schools, and entertainment are also limited. Many remote villages have only primary schools, thus to continue to higher education the parents send their children to the bigger cities. Another major drawback is limited health facilities, even basic healthcare facilities. The village people often have to walk or drive for hours to access primary healthcare facilities. Can you imagine if you are a pregnant woman or if you are a sick person?

Reflecting on travelling to around 34 remote villages from eight districts of NTB, living in remote villages is challenging. Moreover, if you are a village midwife, you have to take care of pregnant women with limited facilities. Being a midwife is a woman's job and many village midwives are single while some are married with children. Working as a midwife in the remote villages means they have to sacrifice their social lives, ignore their safety, and negotiate their children's education. Ironically, they have to take care of the patients, yet when they are sick, they have limited access to health treatment. A village midwife is the 'spearhead' of the health workers in the community. 


\subsection{Managing My Data: Thematic Analysis Approach}

Managing my data was another essential phase of the data collection process, undertaken in order to make sense of the phenomena of my study. The data analysis began by using a TA approach, a technique which provides a rich and detailed, yet complex, account of data (Braun \& Clarke, 2006). The TA approach was selected to analyse the data because of its ability to provide flexibility, meaning it was suited for use with multi-methods (Braun \& Clarke, 2012). The TA approach can also be used to analyse most types of qualitative data, such as that from interviews, secondary sources, and focus groups. In addition, the TA approach is appropriate for analysis of various types of research, including explorations of individuals' experiences, views, opinions and practices (Braun \& Clarke, 2012), and specifically for SCM blended with AI.

Some literature indicates no specific requirements for sampling sizes when applying a qualitative approach (Patton, 2001), but others urge caution when using a small number of interviews (i.e. five or less), however long or detailed (Creswell, 1998; Glaser \& Strauss, 1967; Morse, 1994). Creswell (2009) suggests 20-30 interviews for grounded theory, while Morse (1994) suggests approximately 30-50 interviews.

It is important to note, during data collection, most or all perceptions of the research participants to attain saturation (i.e. additional research participants to the study will not add more information or perspectives to the data set). The strategy in deciding an adequate sample size for qualitative research is subject to peer review, consensual validation, and judgement (Patton, 1990; Patton, 2002).

In regards to the amount of data that I collected (from 75 interviews), TA appeared to be an appropriate approach to apply as it provided detailed information and identified patterns across the data. The key concepts of TA are not simply to give a voice to the participants, rather, the involvement of the researcher is essential, dependent on how he/she plans to interpret or present the findings (Braun \& Clarke, 2006).

The quality of the TA approach must be weighed up against the researcher's analytic insights and critical analytic skills in interpreting the data (Braun \& Clarke, 2006). Themes do not automatically emerge. Rather, collecting, analysing and reporting on the findings could show systematic linkages between participants' experiences, views, or attitudes regarding the interest of the study (Braun \& Clarke, 2006). 
Four steps were used to analyse my data using the TA approach. These included familiarising myself with the data by generating initial codes, searching and reviewing potential themes, and presenting the findings (Figure 10).

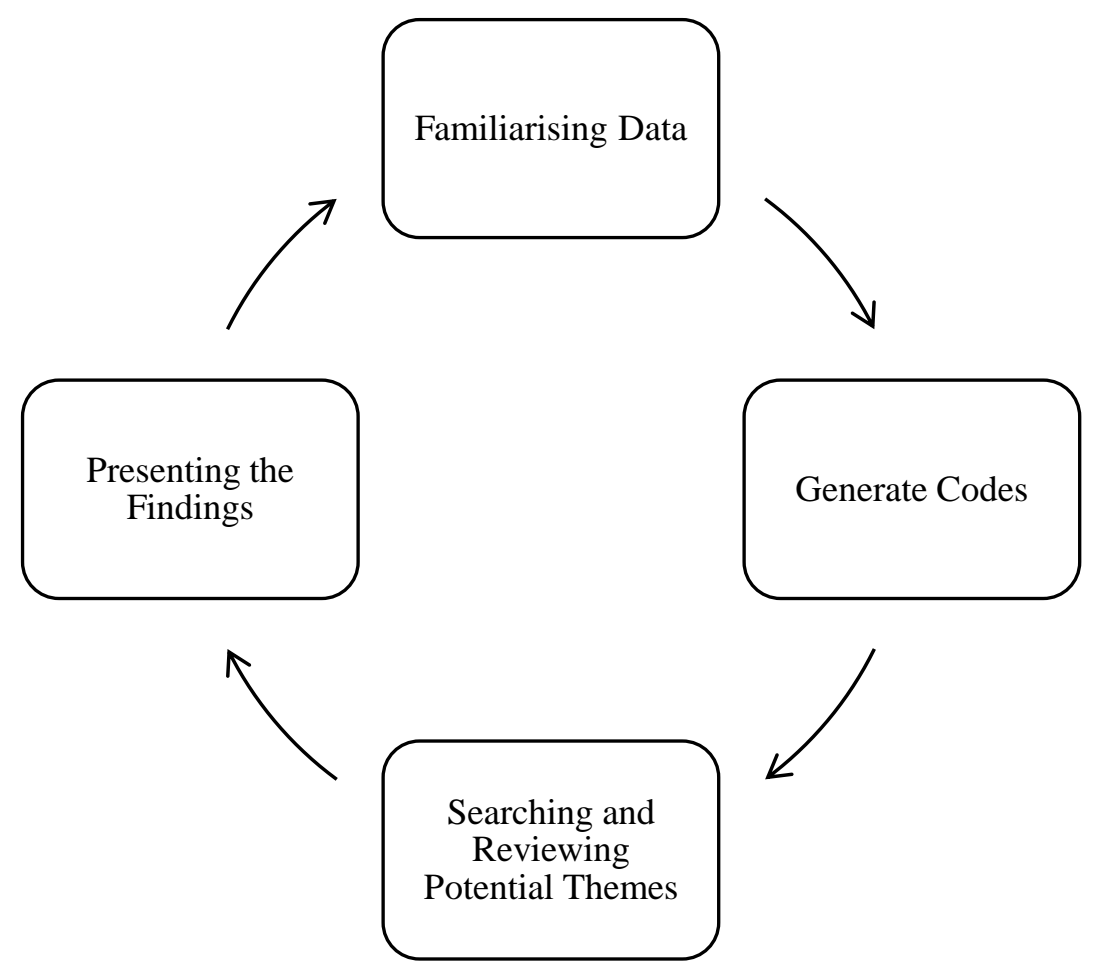

Figure 16: Steps of the Thematic Analysis Approach (Adapted from Braun and Clarke, 2012)

\subsection{Familiarising Myself with the Data}

In order to familiarise myself with the data, all data entry was undertaken by myself. Almost all the interviews were audiotaped using audio-recorders, and transferred or backed-up to computer and external hard-drives in order to avoid losing information. The files were then transcribed into Microsoft Word for Windows. These transcripts were used as the basis for providing the relevant information in preparation for the analysis. 
This resulted in approximately four to six pages of transcription for 30 minute interviews, and six to 12 pages of transcription for an hour interview. Even though some IDIs were conducted in local languages, the decision was made to use Bahasa Indonesia in transcribing them. Some of the transcripts were undertaken straight after the IDIs were conducted whilst others were not able to be undertaken immediately due to limited facilities (e.g. no electricity) or due to tiredness. These interviews were transcribed in between the data collection gap and after all the data were gathered. I found transcribing a time-consuming process. It took me around three to four months to finally finish transcribing 75 interviews.

Some transcriptions were also randomly picked from each group and translated into English to allow them to be reviewed by my supervisors. This process was undertaken in order to evaluate whether the IDIs were well-executed as well as sufficiently powerful to capture the reality.

Familiarising myself with the data involved reading and re-reading the transcripts time after time. According to Dierckx de Casterlé, Gastmans, Bryon and Denier (2012), re-reading the verbatim transcripts triggers recall of the non-verbal signals associated with the data collection, and helps the researcher comprehend the insights of the data's stories. Notes based on the initial analytic observations were accordingly made each time transcripts were read for the first time. The aim of this step was to graph the general idea of my research participants' views and experiences about the main issues they mentioned. This also allowed me to document any general ideas or impressions gained of the participants that may be significant to the data, such as the presence of tension, or the meaning behind words and/or questions. I found this process very useful because it guided more in-depth analysis and prompted memory of general ideas I wanted to present in my findings. 


\subsection{Generating Codes}

Generating initial codes began during the process of data familiarisation. Codes are specific information considered to be the building-blocks that combine to create themes. Clarke and Braun (2013) argue that coding is a common step that needs to be done in qualitative analysis. This step is considered as a method to reduce the data set which involves an analytical process to capture both a semantic and conceptual reading of the data (Clarke \& Braun, 2013).

After reading and re-reading transcripts, I coded using an iterative process, based in the first instance on the research objectives and interview questions. Computer software NVivo was used in the analysis in order to manage the data from the transcripts. I decided to use NVivo because it saved a lot of time in managing my data. This approach minimised the potential confusion that was highly likely to occur if I had only applied a pen and highlighter method.

The combination of a deductive and inductive approach was used in developing the codes. In my research, the deductive approach was implemented by using a 'framework approach' (Smith \& Firth, 2011) based on two groups: the 'success cases' and the 'less success cases'. I then divided the data into 'recruitment' and 'retention' in order to figure out key factors that influence them. These classifications were selected based on the SCM approach which emphasises 'success case stories' and 'what works best'.

An inductive approach was also implemented by collating the data relevant to each code. For example, many interesting issues such as 'community acceptance', 'family support', 'being thankful', and 'incentives' emerged from the transcripts as I read and re-read them. These emerging issues from the text were coded and assigned under the relevant categories.

The information gathered was coded and analysed by locating and interpreting themes based on key phrases found within the data. Each interview was analysed separately, with comparisons then undertaken by key participant group (e.g. midwives and officials). 


\subsection{Searching and Reviewing Potential Themes}

After all codes were identified, I scanned for the patterns or grouping of similar ideas or topics that helped in developing themes. A theme was defined as an overarching idea that covered several codes. This process required an active process which involved identifying the similarity across the data set as well as checking the relationship between codes (Clarke \& Braun, 2013).

In order to discover the themes, I created mind-maps with the help of NVivo software. These mind-maps allowed me to capture the overarching ideas, which then led to relevant themes (Figure 17). The emergent themes were then analysed in order to grasp the essence of the overall story of my data set.

A sub-theme also exists under the umbrella of a theme. I created some subthemes in order to organise concepts that focused on one notable specific element. The sub-themes that emerged included 'organisational attributes', 'personal attributes', and 'environmental attributes', selected based on the research framework mentioned in the previous chapter (i.e. using a multifaceted framework).

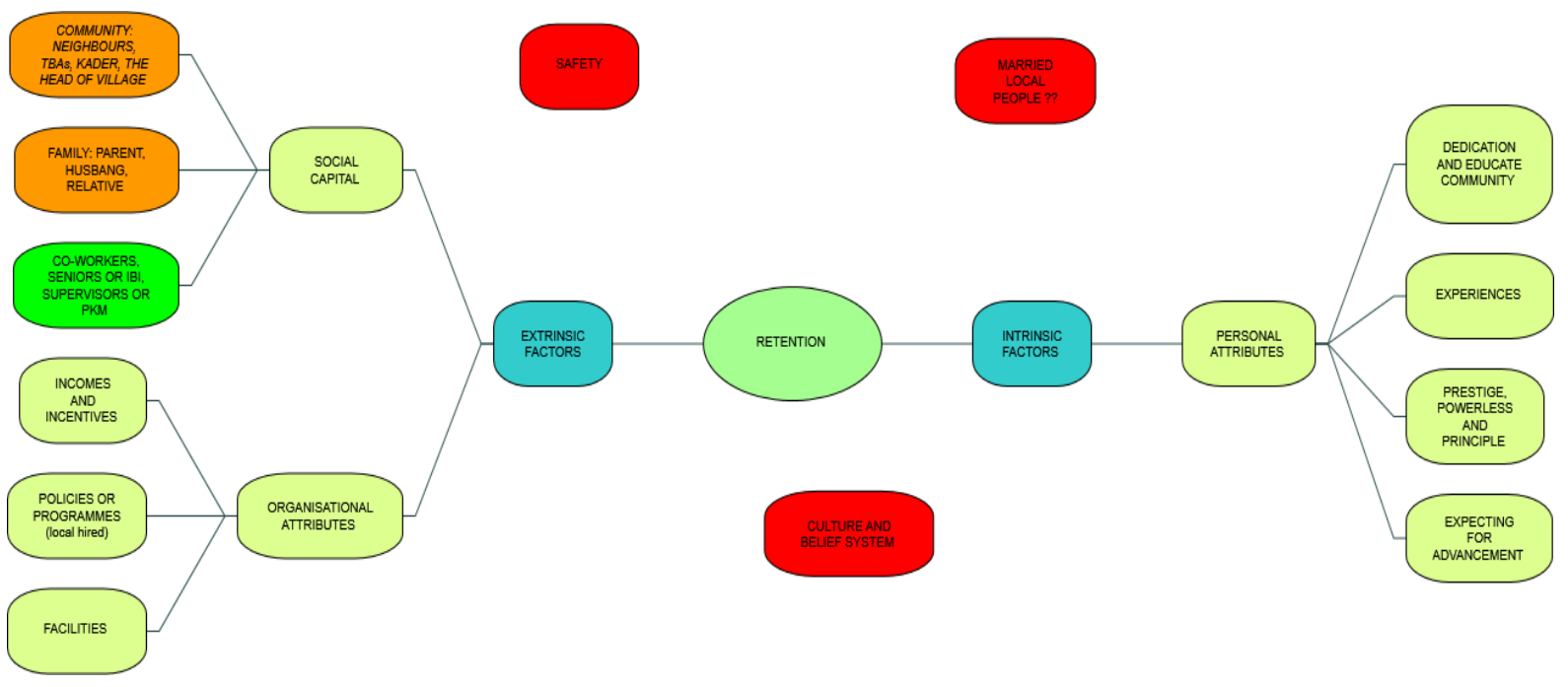

Figure 17: Example of Developing and Redefining Themes 


\subsection{Presenting My Findings}

Findings are presented in three different stories included within the recruitment chapter, retention chapter, and policy vs reality chapter. In each of the chapters, a vignette is inserted providing a living story of participants' experiences of recruitment and retention of midwives in rural and remote areas of Indonesia, particularly in NTB. The layout of each chapter is different based on what the findings showed.

In order to ensure the trustworthiness of a study, Merriam (2009) proposed four crititcal components for qualitative research, namely credibility, dependability, confirmability and transferability.

First, credibility in my study is shown by using multiple sources of data which allowed me to check my intepretation of the data set with another data set. Incorporating voices from various sources, including government officials and midwives themselves were implemented in order to strengthen the integrity of the findings.

Second, Merriam (2009) defines dependability and confirmability as a check and balance mechanism on data consistency. In other words, my study can be considered as dependable if the findings are consistent with the data presented. Krefting (1991) suggests coding the data repetitively. Thus, I coded a set of data and then after a period of time the same data set was coded again. Both sets of results were then compared in order to address the dependability and confirmability of my data. In qualitative research, Denzin and Lincoln (2000) argue that there is no single correct way to interpret the data. Validity is intepretative which heavily depends on the contextspecific understandings we, as researchers, bring to the observation (Ellis, 2004). In addition, regular consultation with my supervisors contributed to the dependability and confirmability of my findings.

Third, transferability is defined as a way to apply what we have learned or studied in a specific context to other similar contexts (Merriam, 2009). In this case, my study is expected to provide enough information and guidance to related stakeholders, thus it can apply to their situations. 
Confidentiality of the research participants was guaranteed by only stating the title of the research participants and the codes for the cases. SC stands for the 'success cases' and LSC the 'less success cases' (Table 7).

Table 7: Data Confidentiality

\begin{tabular}{lll}
\hline Sources & Code & Note \\
\hline Village Midwife & $\begin{array}{l}\text { Regionally Contracted } \\
\text { Midwife/PTT Daerah } \\
\text { Nationally Contracted } \\
\text { Midwives/PTT Pusat } \\
\end{array}$ & \\
& PNS & \\
\hline $\begin{array}{l}\text { Indonesia Midwifery } \\
\text { Association }\end{array}$ & $I B I$ & $\begin{array}{l}\text { Different levels of strata } \\
\text { namely national, district, } \\
\text { and sub-district level are } \\
\text { not mentioned in the } \\
\text { findings chapters }\end{array}$ \\
& & \\
\hline Government Officers & DHO & \\
& Puskesmas & \\
\hline 'The success cases' & SC & \\
\hline 'The less-success cases' & LSC & \\
\hline
\end{tabular}

The quote below is an example of how the confidentiality of the research participants was guaranteed.

With PNS status, better future career while PTT status is temporary. Our retirement years can be guaranteed if we were PNS ( $\underline{\text { Regionally }}$ contracted midwife/PTT Daerah $-S C$ )

For the allocation of the midwives in our area is allocated by the Ministry of Human Resources [Kementrian Negara Pemberdayaan Aparatur Negara or Kemenpan] ... We [DHO] proposed our need of health workers, in this case midwives to PHO... We calculated the ratio between midwives and number of population by using WISN [Workload Indicators of Staffing Need] and we realised that we still need more midwives $(\underline{\mathbf{D H O}-\boldsymbol{L S C})}$ 
Quotes from the 'success cases' and the 'less success cases' are presented in the findings chapters. Quotes were selected pooling all relevant statements based on the themes of the study. According to Struthers (2012), the idea which is then echoed by others indicates a sense of validation. Therefore, I compared the analysed data set with another analysed data set in order to find whether the same ideas appeared in the other data sources. I then sorted out the statements based on the proportions, repetitiveness, and overlapping information, thus the statements that best captured the essense of the themes were selected as the quotes to include.

In addition, two key terms used regularly throughout this thesis are defined here for reading comprehension. Firstly, 'midwives' (or 'midwife', 'village midwife', 'village midwives', 'volunteer midwife' and 'volunteer midwives'). These terms refer to a health worker or health workers who have three years' midwifery training.

Secondly, 'remote area' or 'remote areas'. These terms refer to 'difficult to reach' geographical areas: mountains, inland areas, swamps, and areas prone to natural disasters. Such areas often require special land, water and/or air transport to access. The frequency of public transportations to and within these areas is limited and round trip travel times can be more than six hours. 


\section{CHAPTER 5. ATTRACTION TO WORK IN REMOTE AREAS}

\subsection{Introduction}

As mentioned in Chapter Four, the data was analysed separately between the 'success cases' and the 'less success cases'. However, due to a lack of differences in the recruitment findings between the two cases, this chapter is presented based on the main themes that were identified rather than by the 'success cases' and the 'less success cases'.

The chapter begins by exploring several paths of recruitment based on the categories or types of midwives. I focus on the village midwives with their various employment statuses; contracted midwives as well as volunteer midwives. Finally, this chapter will identify some key factors that attract midwives to work in remote areas of $N T B$.

\subsection{Village Midwives: Who Are They?}

Through my study in the eight districts in NTB, I found that there are variations in the characteristics of village midwives. This encompasses age, marital status, place of origin, initial qualifications, years spent in the villages, and employment status. Table 8 summarises the characteristic of the village midwives from both, the 'success cases' and the 'less success cases'.

In the 'success cases', the majority of midwives had been working as village midwives for between one and seven years and their ages were mostly in the 20 to 29 years age range. These village midwives predominantly came from NTB and were not yet married. In the 'less success cases', village midwives ranged in age from 20 to 29 years and 30 to 39 years. Most of them were married and came from local areas. Most of these midwives had also been working in the village from between one year to seven years. 
Table 8: Age, Marital status, Origin, Initial Qualifications, Years in village, and Employment Status of the Village Midwives

\begin{tabular}{|c|c|c|}
\hline Categories & $\begin{array}{c}\text { 'The } \\
\text { Success Cases' }\end{array}$ & $\begin{array}{l}\text { 'The Less } \\
\text { Success Cases' }\end{array}$ \\
\hline \multicolumn{3}{|l|}{ Years in village } \\
\hline$\leq 1$ year & 6 & 3 \\
\hline$>1$ year $\leq 7$ years & 27 & 5 \\
\hline$>7$ years & 3 & 0 \\
\hline $\mathbf{N}$ & 36 & 8 \\
\hline \multicolumn{3}{|l|}{ Age } \\
\hline $20-29$ & 28 & 4 \\
\hline $30-39$ & 5 & 4 \\
\hline $40-49$ & 2 & 0 \\
\hline $50-59$ & 1 & 0 \\
\hline $60-69$ & 0 & 0 \\
\hline $\mathbf{N}$ & 36 & 8 \\
\hline \multicolumn{3}{|l|}{ Marital status } \\
\hline Married & 13 & 6 \\
\hline Not-married & 23 & 2 \\
\hline $\mathbf{N}$ & 36 & 8 \\
\hline \multicolumn{3}{|l|}{ Origin } \\
\hline Local & 29 & 6 \\
\hline Non-local & 7 & 2 \\
\hline (1) & 36 & 8 \\
\hline \multicolumn{3}{|l|}{ Initial qualifications } \\
\hline D1 & 3 & 8 \\
\hline D3 & 33 & 0 \\
\hline $\mathbf{N}$ & 36 & 8 \\
\hline \multicolumn{3}{|l|}{ Employment status } \\
\hline$P N S$ & 4 & 1 \\
\hline PTT Pusat Terpencil & 9 & 0 \\
\hline PTT Pusat Sangat & 7 & 3 \\
\hline Terpencil & 5 & 1 \\
\hline PTT Daerah & 11 & 3 \\
\hline Volunteer* & 36 & 8 \\
\hline $\mathbf{N}$ & & \\
\hline
\end{tabular}

*Include Mengabdi, Job, Intern or Maggang Midwives

I also found that there were several categories of midwives, those hired by the national government and those hired by regional or local government, which suggests that decentralisation has influenced the way recruitment systems work in Indonesia. 
Prior to decentralisation in 2001, the national or central government solely controlled the recruitment process of all health workers in Indonesia. In the national context, the provision of midwives was organised by the MoH. There were two types, namely PNS and nationally-contracted midwives (Pegawai Tidak Tetap Pusat or PTT Pusat). The number of midwives in each district, as well as the salaries for PNS and PTT Pusat are organised by central government using the state budget (Anggaran Pendapatan Belanja Nasional).

With the economic turmoil of 1997, the democratisation process was continued by the Indonesia government which launched a radical transformation from a centralised to a decentralised system under Laws No. 22/1999 and 25/1999 (Heywood \& Choi, 2010; WHO, 2007). Decentralisation is defined as a transfer of responsibility (fiscal, political and administrative) to the local authority, otherwise recognised as an extensive handover of roles and political power to the district government (Heywood \& Choi, 2010; Indrawati, 2002). The new system, in terms of the new fiscal balance, has given local government more freedom in planning, budgeting and implementing programmes (Indrawati, 2002). This system is expected to provide more opportunity for local government to develop their region based on local needs.

As a result of this transformation, each district in NTB has independence in recruiting midwives, based on their financial capability and local need. These include regionally-contracted midwives (Pegawai Tidak Tetap Daerah or PTT Daerah) and volunteer midwives (sukarela) (Table 9). Thus, there are four main categories of midwives the 'success and less success cases', namely, PNS, PTT Pusat, PTT Daerah, and volunteer midwives in both cases. 
Table 9: Types of Midwife by District

\begin{tabular}{|c|c|c|c|c|}
\hline \multirow[t]{2}{*}{ District } & \multicolumn{4}{|c|}{ Types of Midwives } \\
\hline & $P N S$ & PTT Pusat & $\begin{array}{c}\text { PTT } \\
\text { Daerah }\end{array}$ & Volunteer* \\
\hline \multicolumn{5}{|c|}{ 'Success Cases' } \\
\hline Dompu & $\sqrt{ }$ & $\sqrt{ }$ & - & $\sqrt{ }$ \\
\hline North Lombok & $\sqrt{ }$ & $\sqrt{ }$ & - & 'Mengabdi' \\
\hline Sumbawa & $\sqrt{ }$ & $\sqrt{ }$ & $\sqrt{ }$ & $\sqrt{ }$ \\
\hline East Lombok & $\sqrt{ }$ & $\sqrt{ }$ & - & 'Job' \\
\hline Bima & $\sqrt{ }$ & $\sqrt{ }$ & - & $\sqrt{ }$ \\
\hline West Lombok & $\sqrt{ }$ & $\sqrt{ }$ & $\sqrt{ }$ & $\sqrt{ }$ \\
\hline \multicolumn{5}{|c|}{ 'Less Success Cases' } \\
\hline Central Lombok & $\sqrt{ }$ & $\sqrt{ }$ & - & $\begin{array}{l}\text { 'Intern' or } \\
\text { 'Magang' }\end{array}$ \\
\hline West Sumbawa & $\sqrt{ }$ & $\sqrt{ }$ & $\sqrt{ }$ & $\sqrt{ }$ \\
\hline
\end{tabular}

*Some districts have different names for volunteer midwives.

In general, all midwives have the same responsibilities. The differences amongst these categories of midwives are mainly related to their employment status. According to my research participants, midwives with PNS status rank highest amongst categories of midwives, because of the combination of benefits that they received. PNS midwives receive a permanent contract and fixed income, as well as an opportunity for career development which makes PNS highly appealing to other types of midwives. The salary range for $P N S$ is varied based on their grade (i.e. grade one - A to E; up to grade four - A to E). The grade determines their salary which starts from IDR 1,488,500 (around USD 114) to IDR 5,620,300 (around USD 432) per month. On top of their monthly salary, PNS midwives receive other forms of financial incentives, such as a functional allowance, positional allowance, and performance allowance. The amounts of allowances that are received by PNS are varied based on their position, title and length of work commitment.

Midwives with a contracted status receive a monthly salary which can range from IDR 600,000 (around USD 46) up to IDR 4,000,000 (around USD 307) per month. An additional incentive from assisting with delivery is received by the village midwives ranging from IDR 300,000 (around USD 23) to IDR 600,000 (around USD 46). The salary received by $P N S$ compared to contracted midwives is not significantly different, but $P N S$ receive more allowances as well as a permanent contract. It cannot be denied that many village midwives or other health workers want to have PNS status. 
However, PNS midwives are mainly located in Puskesmas, and are rarely found in the villages, particularly in the isolated areas. Many midwives are accepted or promoted as a PNS and are then transferred by the government to Puskesmas or DHO as part of their reward. This condition has the potential to jeopardise health services in remote areas because remote villages are left with no or only junior midwives.

PNS status means that we have stable income. Secondly, it indicates an appreciation from government and community. The midwives feel more confidence if they have PNS status (The Indonesian Midwives Association/IBI-SC)

With PNS status comes a better future career, while PTT status is temporary. Our retirement years can be guaranteed if we were PNS (Regionally-contracted midwife/PTT Daerah - SC)

PTT Pusat are the second layer in the hierarchy of the employment status. The PTT Pusat scheme is only for midwives and doctors. The quota for PTT Pusat is determined by the $\mathrm{MoH}$ based on a request from the PHO. PTT Pusat are assigned to remote communities for a three year contract with the possibility of an extension to six years (Ministry of Health, 2008). In terms of benefits, the more difficult the areas where health workers work, the higher the incentive offered. For example, health workers in very remote areas receive higher financial incentives.

PTT Daerah is the next layer in the hierarchy of employment status, where regional or local government is able to utilise their local resources to hire a local workforce. Each district has a different standard in determining financial incentives based on the capability of the local government budget. The range of salary varies from USD 46 to USD 307 per month.

The last category in the hierarchy is volunteer midwives. Volunteer midwives are the most vulnerable category compared to other types of midwives because they have no contract or legal document which can protect them from losing their job. On the other hand, in order to ensure the availability of midwives in remote areas, hiring volunteer midwives seems to be the solution easiest to implement by the local government. 
However, volunteer midwives receive no salary because legally they are not registered in DHOs or Puskesmas. In the principle of humanity, some districts provide an allowance for the volunteer midwives; nominal payment is around IDR 200,000 (USD 15) to around IDR 300,000 (USD 23). Whether this allowance is given to volunteer midwives depends heavily on the institution's funds each month and its leaders.

To sum up, there are four main groups of midwives in each of the eight districts in NTB. The results indicate that $P N S$ are hardly found in the villages, particularly in the isolated villages. PNS are mainly located in Puskesmas. The three categories of midwives, PTT Pusat, PTT Daerah and volunteer midwives are mainly found in the remote or very remote villages. It seems that village midwives aim to be a $P N S$ because it provides the possibility of improving their career and having a secure job. Therefore, it is important to understand the key factors influencing midwives to work in remote areas. What are the best ways to recruit a village midwife?

\subsection{Recruitment System}

At the time of this study, six steps in the recruitment system were commonly implemented by the national and local government in NTB. This suggests that these steps are successfully navigated by the national and local government to select the various types of midwives, and even for volunteer midwives. These steps encompass an analysis of the need for health workers, job descriptions and specifications of personnel, managing applications, shortlisting candidates, arranging contracts or agreements, and then joining as a member of the organisation (Figure 18). 


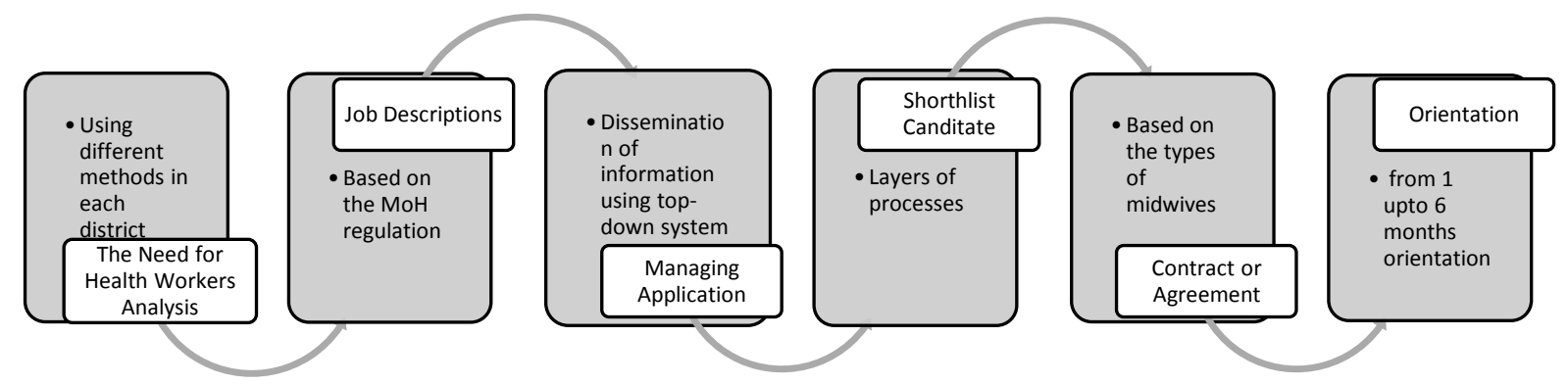

Figure 18: Recruitment Systems (Adapted from Kurniati \& Efendi, 2012)

\subsubsection{The Need for Health Workers Analysis}

Job analysis was mainly undertaken by the DHOs. This stage aims to analyse the need for and the availability of health wokers in their areas. In the Indonesian context, traditionally, the methodology used to calculate the need for health workers was based on the ratio between health workers per 100,000 population. For example, X number of midwives per 100,000 population.

However, nowadays, WISN is mostly used by each district in NTB in order to identify the number of midwives that they need to hire. For example, the 'success cases', namely those in East Lombok district, measured their need for health workers by using this method. In Central Lombok (the 'less success cases'), the same job analysis was conducted by the DHO alongside other professional organisations like $I B I$, in order to formulate the recruitment processes and identify the need.

There are eight steps to be considered in conducting WISN: namely determining the priority of health staff and health facility types; estimating available working time (AWT); defining workload components; setting activity standards; establishing standard workloads; calculating allowance factors; determining staff requirements based on WISN; and analysing and interpreting WISN results (WHO, 2010b). 
First, determining the priority of health staff and health facility type begins with creating a list of all health facility types, and their work units and the main staff categories working there. Then come the most difficult staffing problems which consider current and potential problems in the future. Next, which staff and health facilities should have the first, second and third highest priority are decided.

Second, AWT is estimated. It is assumed that health workers do not work every day throughout the year. Thus, the health workers should calculate, in either days or hours per year, their available time to do their work, taking into account authorised and unauthorised absences.

$$
\mathrm{AWT}=\mathrm{A}-(\mathrm{B}+\mathrm{C}+\mathrm{D}+\mathrm{E})
$$

Notes:

- AWT is the total available working time

- A is the number of possible working days in a year

- $\mathrm{B}$ is the number of days off for public holidays in a year

- $\mathrm{C}$ is the number of days off for annual leave in a year

- $E$ is the number of days off due to other leave, such as training etc, in a year.

Measuring AWT requires the following formulation: the number of possible working days in a year are determined and then multiplied by the number of weeks in one year (52). For example, midwives' working days in Puskesmas or Polindes (in East Lombok District) over one week is five days. The available time is five days multipled by 52 weeks, giving 260 possible working days in one year. Then, 260 (A) minus all possible absences, for instance 12 days off for public holiday (B), plus 14 days off for annual leave (C), plus 14 days off due to sick leave (D) plus 10 days off due to other leave (E) equals 210 days. This indicates that AWT of midwives in a health centre is 210 days in a year.

This number should be then converted to hours per day by multiplying AWT with $\mathrm{F}$ (the number of working hours in one day).

$$
\mathrm{AWT}=[\mathrm{A}-(\mathrm{B}+\mathrm{C}+\mathrm{D}+\mathrm{E})] \times \mathrm{F}
$$


For example, in a health centre a midwife works an average of 7.2 hours each day (a total of 36 hours divided by five working days). Thus, AWT by hours is found by multiplying 210 days in a year by 7.2 hours to give 1,512 hours a year.

Third, defining workload components encompasses health services, support and additional activities. Each health worker should identify from three up to five activities, thus the workload can be measured. For instance, the workload component of midwives includes antenatal care, deliveries, and post antenatal care (health service activities); recording and reporting (support activities); and supervision (additional activities).

Four, setting activity standards includes service standards and allowances standards for support and additional activities. A service standard means an activiy standard for health service activities. For instance, a midwife in Puskesmas in East Lombok District provides antenatal care with a unit time or rate of working 20 minutes per patient. An allowance standard is measued using actual working time or as a percentage of working time. As an example, a midwife allocates around $14 \%$ of working time which means $14 \%$ of 7.2 hours, or one hour of her working day.

Fifth, establishing standard workloads is an amount of work within a health services workload component that one health worker can do in a year. To calculate the standard workload the following formula is used:

Standard workload $=$ AWT in a year divided by unit time

or

Standard workload $=$ AWT in a year multiplied by rate of working

For instance, a midwife in Puskesmas in East Lombok, providing antenatal care for 20 minutes per patient is equivalent to three patients per hour. The standard workload for anatenatal care is 4,536 patients (1,512 hours per year x 3 patients).

Sixth, Category Allowance Factors (CAF) function to calculate the total number of health workers required for both health services and support activities. The formulation is below:

$\mathrm{CAF}=1 /[1-($ total allowance standard/100) $]$ 
Seventh, determining staff requirements based on WISN is the point where the number of health workers that are needed can be determined. This step requires annual service statistics from previous years for each facility that needs health staff. This step also requires data for each health services activity. Table 10 provides an example of determining staff requirements based on WISN calculation.

Table 10: Example of Using WISN

$\mathrm{AWT}=1512$ hours

\begin{tabular}{|c|c|c|c|c|}
\hline \multirow{5}{*}{$\begin{array}{l}\text { Health } \\
\text { services } \\
\text { activities of all } \\
\text { health staff }\end{array}$} & $\begin{array}{l}\text { Workload } \\
\text { component }\end{array}$ & $\begin{array}{l}\text { Annual } \\
\text { workload }\end{array}$ & $\begin{array}{l}\text { Standard } \\
\text { workload }\end{array}$ & $\begin{array}{l}\text { Required } \\
\text { number of staff } \\
\text { members }\end{array}$ \\
\hline & Antenatal care & 1,124 & 4,536 & 0.25 \\
\hline & Deliveries & 267 & 189 & 1.41 \\
\hline & Postnatal care & 812 & 2,268 & 0.36 \\
\hline & $\begin{array}{l}\text { Family } \\
\text { planning }\end{array}$ & 2,254 & 3,024 & 0.75 \\
\hline \multicolumn{4}{|c|}{ A. Total required staff for health service activities } & 2.77 \\
\hline \multirow[t]{4}{*}{$\begin{array}{l}\text { Support } \\
\text { activities of all } \\
\text { health staff }\end{array}$} & $\begin{array}{l}\text { Workload } \\
\text { component }\end{array}$ & \multicolumn{2}{|c|}{ Actual working time } & $\begin{array}{l}\text { Actual } \\
\text { working time } \\
\text { (percentage) }\end{array}$ \\
\hline & $\begin{array}{l}\text { Recording and } \\
\text { reporting }\end{array}$ & \multicolumn{2}{|c|}{30 minutes per day } & $6.9 \%$ \\
\hline & Meetings & \multicolumn{2}{|c|}{2 hours per month } & $1.6 \%$ \\
\hline & Home visiting & \multicolumn{2}{|l|}{3 hours per week } & $8.3 \%$ \\
\hline \multicolumn{4}{|c|}{ Total annual working time (percentage) } & $16.8 \%$ \\
\hline \multicolumn{4}{|c|}{$\begin{array}{l}\text { B. Category allowance factor }\{1 / \text { [ } 1 \text { - (total category allowance } \\
\text { factor percentage / 100)] }\end{array}$} & 1.2 \\
\hline \multirow[t]{4}{*}{$\begin{array}{l}\text { Additional } \\
\text { activities of } \\
\text { certain health } \\
\text { staff }\end{array}$} & $\begin{array}{l}\text { Workload } \\
\text { component }\end{array}$ & $\begin{array}{l}\text { Number of } \\
\text { staff members } \\
\text { performing the } \\
\text { work }\end{array}$ & $\begin{array}{l}\text { Actual } \\
\text { working time } \\
\text { per person }\end{array}$ & $\begin{array}{l}\text { Annual } \\
\text { working time } \\
\text { per person (for } \\
\text { all staff } \\
\text { performing } \\
\text { activity) }\end{array}$ \\
\hline & $\begin{array}{l}\text { Supervision of } \\
\text { midwifery } \\
\text { students }\end{array}$ & 1 & $\begin{array}{l}2 \text { hours, } 4 \\
\text { times per year }\end{array}$ & 8 hours \\
\hline & $\begin{array}{l}\text { Continuing } \\
\text { education }\end{array}$ & 2 & $\begin{array}{l}6 \text { days per } \\
\text { year each }\end{array}$ & 86.4 hours \\
\hline & $\begin{array}{l}\text { General } \\
\text { administration }\end{array}$ & 1 & $\begin{array}{l}2 \text { hours per } \\
\text { week }\end{array}$ & 104 hours \\
\hline \multicolumn{4}{|c|}{ Total IAS in a year } & 198.4 hours \\
\hline \multicolumn{4}{|c|}{$\begin{array}{l}\text { C. Individual allowance factor (Annual total actual working time } \\
\text { per person / AWT }\end{array}$} & 0.13 \\
\hline \multicolumn{4}{|c|}{ Total required number of staff based on WISN: $(\mathrm{A} x \mathrm{~B}+\mathrm{C})$} & 3.45 \\
\hline
\end{tabular}


The eighth stage is analysing and interpreting WISN results. The above calculation indicates that rounding numbers is needed as we are discussing human resources. In this example case, the Puskesmas in East Lombok needs four midwives. Finally, it is important to look at the gap between current health workers and required health workers. By comparing these two aspects, the institution is able to understand which health facilities are understaffed or overstaffed. For instance, in Puskesmas East Lombok, there are two midwives. According to WISN calculation, this Puskesmas needs four midwives. Thus, currently this Puskesmas experiences a shortage of two midwives, which means workload pressure is high. It means additional midwives are needed.

My findings indicate that DHOs in both cases favour the use of WISN because it allows them to calculate the need of health workers accurately.

The allocation of the midwives in our area is allocated by the Ministry of Human Resources [KEMENPAN] ... We [the DHO] proposed our need for health workers, in this case midwives, to PHO... We calculated the ratio between midwives and population by using WISN and we realised that we still need more midwives (DHO - LSC)

We [the DHO] used WISN to identify our need of midwives... We have just had training on how to calculate our need for health workers... it seems that this approach is more effective than the old approach (DHO$S C)$

It is argued that WISN is able to meet the challenge of poorly balanced numbers of health workers between urban and rural areas or between primary and secondary levels of care (WHO, 2010b). Workers' workload with activity (time) standards are the basis of the WISN method (WHO, 2010b). The results suggest that conducting the job analysis (e.g. using the WISN method) has helped DHOs in mapping their need for health workers accurately because this approach considers various factors, such as the workload and working hours. In comparison, the previous method failed to identify these two factors. As a result, remote areas are more likely to have one midwife on the basis that they have a smaller population than urban areas. Thus, the use of WISN might remedy the imbalanced distribution of midwives between urban and remote areas. 


\subsubsection{Job Descriptions and Personnel Specifications}

Job descriptions and personnel specifications were mainly formulated by the national government - the $\mathrm{MoH}$ - and then disseminated to all local governments in Indonesia. It indicates that the same standard of job descriptions and personnel specifications are applied in the eight districts in NTB.

Initially, under the first regulation of MoH number 5380/XI/1963, midwives were only allowed to assist with normal deliveries and were always accompanied by other health professionals. Currently, this situation has changed which allows midwives to take charge of delivery without doctors' supervision.

The regulation changed to the MoH regulation number 363/IX/1980 and then changed again to the $\mathrm{MoH}$ regulation number 623/1989 - there were two competencies included that allowed midwives to assist with normal delivery and allowed them to provide special treatment under the supervision of a doctor. The $\mathrm{MoH}$ regulation number 572/VI/1996 stipulated that midwives be allowed to provide independent services. These include provision of maternal and child care, family planning services, and public health promotion (Frankenberg \& Thomas, 2001).

In principle, in carrying out their job, midwives are obligated to collaborate, consult, and ensure good communication with their patients. In an emergency situation, midwives are allowed to perform some treatments with regards to saving lives. With the extensive power that has been given to the midwives, a set of personnel specifications needed to be addressed as well.

Personnel specifications were formulated by each DHO in both cases on the basis of $\mathrm{MoH}$ regulation. The Indonesian midwifery education system has transformed over time as a result of government commitment to improving the quality of health providers through additional training, particularly in the area of maternal health. In 1997, midwifery education was changed from one year after vocational nursing school, to a direct entry programme of three years' duration (Rokx et al., 2010). The aim of this education is to teach and manage competencies of midwives in order to improve the quantity and quality of midwives in the future (UNFPA, 2011). 
Currently, a 'direct entry' midwifery education programme is used to train midwives in Indonesia. The direct entry programme prepares individuals to become midwives based on general education prerequisites (UNFPA, 2011). Each village midwife is required to have graduated from the midwifery education programme and have an Indonesian midwifery registration (Surat Tanda Resgistrasi or STR) letter. According to the $\mathrm{MoH}$ regulation number 1796 year 2011, all health workers including midwives have to hold an STR.

... after they [midwives] have passed the competency test, they have to apply for STR; it is a must. Even though they have been working for so long, they have to have STR... if they don't have STR, they cannot work (Indonesian Midwives Association/IBI - SC)

The personnel specifications are the same for every type of midwife. The midwives apply to the DHO... They have to bring some essential documents such as certificate, STR, and application letter... (Nationally contracted midwife/PTT Pusat - SC)

In the beginning we [applicants] had to submit all the documents such as certificate, STR, transcripts, certificate of health to the DHO... (Volunteer midwife - LSC)

... all the documents are the same as if we wanted to apply for a civil servant position, no different... (Nationally contracted midwife/PTT Pusat - LSC)

As mentioned earlier, Indonesia has implemeted the same standards which named normal delivery care (Asuhan Persalinan Normal) throughout Indonesia in determining the job descriptions and personnel specifications. One of the advantages of implementing the same standards is the ability to control the quality of health services throughout the country. On the other hand, some local needs must be considered in order to have suitable job descriptions and personnel specifications for specific areas. For instance, isolated areas where facilities are limited and located far from health facilities are more likely to require more skillful or experienced midwives. The village midwives, particularly in remote areas, should have BEONC and CEONC skills. Thus, when an emergency occurs, they are able to provide the necessary treatment prior to referral. 
It is essential to have clear job descriptions as well as job specifications because this assists employers to have better access to qualified applicants. From the applicants' perspective, clear information on job specifications and personnel specifications may influence their decision in applying for a job. Thus, potential applicants have a better idea of the job expectations.

\subsubsection{Managing Applications}

The managing process is conducted after all applicants have lodged their applications within the timeframe decided by the employers, namely DHOs. The results suggest that there is not a clear timeframe for recruitment of village midwives. For PNS and PTT Pusat, the schedule is based on the national government and for PTT Daerah based on the local government. Different from the other categories of midwives, the recruitment schedule for volunteer midwives varies in each district. There is not a clear timeframe and it seems the recruitment could occur at any time based on the situation or the decision-makers, such as the head of Puskesmas at that time. One possible explanation is that the recruitment of volunteer midwives does not burden institutions financially or administratively because this type of midwife has no legal contract.

In terms of managing applicants, namely $P N S$ midwives, selection and recruitment were decided by the KEMENPAN. In general, the recruitment process is conducted by each division or agency. For regional government, the selection and recruitment of the health workforce is coordinated by $B K D$. The selection was finalised by the administration process at the National Human Resources Agency (Badan Kepegawaian Negara).

The MoH initiated the PTT Pusat scheme for both physicians and midwives. The selection and recruitment are centrally organised by $\mathrm{MoH}$ while the quota was determined by the $\mathrm{MoH}$ based on $\mathrm{PHO}$ requests.

Every year the need for midwives are proposed by the DHO to the MoH through Provincial Health Office... (Government Official PHO)

For PNS recruitment, we cannot do anything because everything is prepared and organised by the national government (DHO-SC) 
The allocation of the midwives in our area is allocated by the Ministry of Human Resources [KEMENPAN] ... We [the DHO] proposed our need for health workers, in this case midwives, to PHO... (DHO - LSC)

However, the deployment of PTT Pusat has to be based on the requirements stated in the $\mathrm{MoH}$ regulation number 154 year of 2002 article 12. The requirements are:

1. The areas should be categorised as remote or very remote, and located in poor districts.

2. PTT Pusat can be allocated to a 'normal' area as long as a recommendation letter is provided by the head of district. The district should also be categorised as a poor or undeveloped district that has a limited budget to hire local staff.

3. The areas should be also categorised as conflict areas.

4. Hospitals with emergency medical staff will be prioritised.

Managing applications such as those for PNS and PTT Pusat involved various actors such as the national and the local government, which suggests that the selection process could take longer than selecting PTT Daerah midwives.

PTT Daerah midwives were selected by the local government. The local government or district was able to utilise their local resources to hire a local workforce. There was not a third party (i.e. private agency) involved in managing the applicants. The only institution usually involved in this process was $I B I$ because $I B I$ has relevant knowledge that can assist DHOs in selecting the potential candidates. $B K D$ was also involved in selecting the candidates, mostly as an observer.

IBI are involved in the beginning of the selection process and have developed a written test... (Indonesian Midwives Association/IBI $S C)$

We [IBI] are involved from the beginning until the end of the selection process. This takes place in the local hospital. IBI Taliwang [name of city] was involved. The applicants were selected by IBI at the district level (Indonesian Midwives Association/IBI - SC)

... IBI and the DHO organised the selection process. The Family Health Division worked together with IBI in managing everything... (DHO-LSC) 
The DHOs, alongside $I B I$, are the dominant actors that play an important role in managing the applications. DHOs have a role in crafting the systems and $I B I$ have developed some selection tools - the written test and practical test. The involvement of $I B I$ has been a good contribution to this process because of their knowledge and expertise concerning workloads, the midwifery education system, and the working areas.

Another essential process prior to managing applications is distributing job vacancy information to all potential candidates. When living in remote areas, this can be very challenging due to limited facilities and infrastructures and poor access to good roads, electricity, mobile phone signals and internet connections. Thus, a pertinent question is how can employers disseminate job vacancy information equally to potential applicants?

The results suggest that information about vacancies is received by the potential applicants mostly from their relatives or friends. It is suggested that the 'word of mouth' approach has helped information be distributed to potential applicants. On the other hand, this approach might not reach the wider community because each person has limited networks. As a result, employers might end up with a small number of applicants.

... My uncle who works in the DHO informed me about the opportunity to apply for PTT Pusat midwives... (Nationallycontracted midwife/PTT Pusat - SC)

I received information about this job vacancy from my friend who works in Puskesmas (Volunteer midwife - SC)

... I received information from my friend to apply for PTT Daerah in 2009... (Civil servant midwife/PNS - SC)

My friend persuaded me to apply for this position to the DHO. So, we lodged our application letter to the DHO... (Nationally-contracted midwife/PTT Pusat - SC)

My uncle who works in Puskesmas provided the information about this job vacancy. I tried and got accepted (Nationally-contracted midwife/PTT Pusat - LSC) 
It is obvious that high technology or digital methods cannot be implemented in certain areas in $N T B$, so for difficult areas, an innovative approach needs to be considered. Perhaps developing good networks with village leaders as well as with $I B I$ in each isolated area has potential for reaching the wider community.

\subsubsection{Shortlisting the Candidates}

To shortlist candidates, most of the districts in both cases implemented layers of selection processes, such as administrative tests, written tests, practical tests and finally, interviews. The adminstrative test or documents selection were conducted in the beginning phase. The candidates had to complete the requirements as stated in the personnel specifications. The candidates who were able to complete all the requirements continued to the next phase, completing a written test. Passing the written test, the candidates then had to demostrate their skills in assisting mothers to deliver babies by using props provided by the test committee.

There are four phases of testing that candidates need to complete. An administrative test, a competency test, a written test, and a practical test. The selection was conducted by the DHO... (Puskesmas - SC)

... After they [the candidates] have passed the administration selection, they need to do a written test. DHO and BKD conduct these tests. After that they need to pass the ethics test. Finally, the names of candidates who have passed all processes are proposed to the central government... (Indonesian Midwives Association/IBI - SC)

First of all, I lodged my application to the DHO (i.e. including certificate, STR, transcript). The next day, I had to attend the interview, and then heard the announcement for the next round which was the written test (Nationally-contracted midwife/PTT Pusat - LSC)

I am a PTT Daerah midwife. I did not do any test at that time. I applied and got accepted straight away... (Regionally-contracted midwife/PTT Daeraht - LSC)

Prior to the layered system, candidates were shorlisted only based on administrative requirements and no tests were implemented. The intial selection process was much simpler than the current system. The layered system of selection has been responded to positively by its users (i.e. the DHOs or Puskesmas) and the midwives themselves. 
The layered system allows the institutions to have a clearer structure in selecting candidates. This also contributes to the selection of high quality candidates compared to previous selection processes which required only an administrative process. The employers or recruiters have tools to identify or measure the skills and capability of each potential candidate by applying the layers. Occasionally, an interview is also included in this selection process in order to ensure applicants' motivation and passion for being village midwives.

The written and practical tests are the most important processes to selecting better quality midwives. In these processes, applicants are expected to reach the average threshold ( $70 \%$ of the passing grade) for both tests. Even though these processes have not been proven empirically, my research participants commented that the tests have been a useful tool for selecting good quality midwives.

\section{I have to admit that I haven't had valid evidence, but based on my observation, the current selection process have selected a better quality of midwife. They [the midwives] have good motivation and spirit to work in their workplace... (DHO - LSC)}

There are written tests, practical tests, and interview tests. Why do we conduct this practical test? Because they [village midwives] will be dealing directly with people's lives. In particular, they are deployed in remote or very remote areas. They are expected to be independent... a village midwife should recognise what is happening in her workplace (Indonesian Midwives Association/IBI - SC)

This is better than before because we have to pass several tests such as administrative tests, written tests and other tests... (Nationallycontracted midwife/PTT Pusat - SC)

My findings also raise an interesting issue regarding nepotism and fairness. The research participants point out that the selection system is more likely to decrease the potential for nepotism and increase fairness. Every candidate, without exception, has an equal chance of being accepted as a villge midwife. Current systems are merit-based, where candidates are accepted based on their skills and ability to provide qualified care to mothers and children in remote areas. For instance, even though the candidates might have a relationship or family ties with a head of DHO or other high-ranking officials, they will not be accepted automatically. Acceptance is based entirely on their scores. 
... The aim of implementing this process is to avoid nepotism. Previously, a lot of people were suspicious that the candidates were only coming from government officials' relatives. This is a good solution to stop the doubtfulness of the people (Indonesian Midwives Association/IBI - SC)

... We have to avoid potential nepotism. Previously, many people assumed that DHOs only accepted their people. In reality, it was not like that. The tests were conducted in order to reduce negative sentiment as well. Secondly, because the quality of the new graduates is decreasing, we conducted tests in order to select qualified candidates (Indonesian Midwives Association/IBI - SC)

I think there is a test. It has to be a test because there are many new midwifery graduates. So, it is fair for everyone... (Nationally-contracted midwife/PTT Pusat - LSC)

Six years ago, many midwives were needed. Nowadays, many midwives need jobs, so it is easier to be a village midwife (Nationally-contracted midwife/PTT Pusat - LSC)

Shortlisting the candidates appears to have been formulated in recent years for several reasons, namely selecting the 'best of the best' candidates and promoting good governance by using a merit-based system. This process may have the potential to retain midwives in remote areas because it has the ability to select the most motivated midwives. In addition, contracts or agreements between employers and candidates must be completed in order to protect two parties from unexpected circumstances.

\subsubsection{Contract or Agreement}

After all the steps are completed, a contract or agreement is made on a legal basis with each midwife. These contracts are created to ensure all important components, such as the rights and obligations of midwives, are clearly stated.

The contract is issued by various government agencies based on the type of midwife. For PNS, the contract is provided by the national government. Similar to this, PTT Pusat also receive a contract from the national government; the difference is the duration of work. A permanent contract is given to PNS up to the age of 56 years, or up to 60 years depending on their position. Three year contracts are given to PTT Pusat with potential extensions up to six years. There are three types of PTT Pusat, namely 'normal', remote, and very remote areas. 
However, there is only one type of PTT Daerah, and their contracts are provided by the local government which is signed by the Governor and of varying duration starting from one year. For this type of midwife, the contract totally depends on the regional budget and varies in each district.

As mentioned previously, volunteer midwives have no legal basis (i.e. no contract with the local governments). While some areas provide an agreement letter which contains no guarantee of salary and incentives, other areas do not provide any letter of contract to volunteer midwives. The agreement may be issued by DHOs or Puskesmas.

To sum up, a contract is a legal document that binds all midwives to their duties. Having a contract also protects the employer from having a higher turnover of employees. A legal document such as a contract is essential and needs to be obtained by both parties, to protect both sides from misconduct.

\subsubsection{Orientation}

The last step of this recruitment process is an orientation programme for all selected midwives. Each district has freedom in deciding the length or duration of the orientation programme. The length could be as short as one month, or up to six months depending on the type of midwife.

The orientation programme introduces new midwives to their duties in their work areas. My research findings show that orientation is an essential process for midwives prior to working in the communities. The orientation is located in DHOs and Puskesmas.

The orientation time was at least six months in the DHO... (The Indonesian Midwifery Association/IBI - SC)

I said this is a very useful activity, for instance from Health Promotion Division, midwives can learn how to promote health in the community ... So, they learned first from their seniors in the DHO, so they can be ready when they were in the field... (The Indonesian Midwifery Association/IBI - SC) 
Providing orientation to the new midwives is critical because it introduces the various tasks that they need to do when they are in the actual workplace. It is believed that joining in the orientation has positive effects on midwives not only mentally but also towards improving their skills.

This section has described the recruitment processes which encompass six sequential steps. The recruitment process is thorough, impacting positively on the selection of appropriate candidates to be deployed in the remote villages. Having discussed these six steps, the next section addresses the key factors that influence the recruitment systems.

The recruitment system is similar to that of the Chartered Institute of Personnel and Development (2009) as cited by Kurniati and Efendi (2012), which aims to select the right candidates for the job. Thus, using a comprehensive recruitment process has the potential to enhance the quality of the institutions because more qualified midwives are selected. This process is also able to reduce the numbers of village midwives moving from their workplaces. The next question then, is what are the key factors that influence midwives who want to apply for work in the remote villages?

\subsection{Key Factors that Attract Midwives to Remote Areas}

Attracting new midwives to remote villages has been a major concern; Indonesia has a high MMR, around 12 times higher than New Zealand, at 220 per 100,000 live births compared with 17 per 100,000 live births (PMMRC, 2015; WHO, 2013). However, bringing midwives closer to remote villages is not a simple task.

In $1989, B D D$ was introduced by the GoI. This was the first and most significant intervention, known as 'a silver bullet' solution because it was able to improve the availability and accessibility of skilled health personnel in the villages of Indonesia.

Due to the limited numbers of trained midwives, nurses were trained for an additional year in midwifery skills, and then assigned to rural communities for three year contracts with the possibility of extensions to six years (Ministry of Health, 2008). The village midwives were recruited under this programme and, having met the required criteria, were appointed to $P N S$ positions. 
However, in the early 1990 s, the GoI introduced an overall policy of zero growth of PNS, in order to control public sector expenditure (Rokx et al., 2010). Thus, in 2000 the number of graduates directly recruited into PNS began to fall. This had a significant impact on reducing the number of health workers in the public sector. As a result, this policy prevented the $\mathrm{MoH}$ from deploying health workers, particularly midwives to remote areas.

A new policy was established in early 2000 - the recruitment of midwives under PTT Pusat schemes. Attractive salary packages were offered in order to attract new graduates to be village midwives. On top of their salary, midwives with PTT Pusat status received a monthly bonus amounting to as much as two times the base for very remote postings. Rokx et al. (2010) point out that offering a generous incentive package has attracted more midwives to remote postings. In addition, a significantly growing number of graduates entering the labour market after a prolific increase in the number of midwifery schools in Indonesia has also created a competitive environment. Starting a new position in remote areas provides a better opportunity to be accepted as well as to develop future careers.

In line with Rokx et al. (2010), this study indicates that monetary incentives, such as generous remuneration and job certainty, are two of the dominant factors that attract midwives to work in remote areas. This might suggest that economic stability becomes the defining factor for midwives in remote areas. Factors other than monetary factors, such as personal attributes, will also be discussed in this section. Personal interest plays a dominant role as well, especially for volunteer midwives in both the 'success cases' and the 'less success cases'.

\subsubsection{Better Income: Economic Stability}

Having a better income was one of the concerns mentioned by midwives in both the 'success cases' and the 'less success cases' during the interviews. High incomes tend to motivate midwives to apply for jobs in remote postings. However, volunteer midwives have no access to a fixed income because they have no legal document which leads to a limited salary or none at all. This indicates that factors other than money influence their decision to go to remote postings. 
I [a village midwife] decided to apply for a remote posting because the salary is bigger compared to 'normal'areas. The salary is more than double the 'normal' areas. 'Normal' areas receive IDR 1.4 million [around USD 107] and for remote areas, it is IDR 3.2 million [around USD 246] ... (Nationally-contracted midwife/PTT Pusat $S C)$

I applied to be a PTT midwife because better salary is offered (Regionally-contracted midwife/PTT Daerah - SC)

I always want to work and live in the village. For people who live in the remote village the salary is really good. I can buy land, a house and save a bit of money... (Nationally-contracted midwife/PTT Pusat $-S C)$

An attractive financial package has significantly contributed to attracting midwives to remote postings. With respect to Maslow's hierarchy of needs ${ }^{8}$, the motivation of village midwives in remote areas mainly falls in the lower order as it involves 'survival needs' (i.e. financial standpoint and safety needs).

Similar to Maslow's theory, lower needs, in this case better income, tend to take precedence over higher needs. The village midwives are attracted by generous monetary incentives in order to meet the fundamental needs of food, clothing and shelter (i.e. the basic needs of the family). Moreover, some midwives are 'the bread winners' in the family or simply want to save more money.

Policy-makers need to consider level one of Maslow's hierarchy of needs when developing policies or programmes. Monetary incentives need to be addressed in order to attract new graduates to remote areas of Indonesia, especially in NTB. However, paying attention to factors others then money is also essential, so the midwives can see themselves moving forward to the next level of needs (growth needs).

${ }^{8}$ Maslow's hierarchy of needs theory (1954) describes five basic universal needs that are essential to human existence - physiological needs, safety, love and belonging, as well as self-esteem. The highest order need is self-actualisation. 


\subsubsection{Job Security}

The results of this study suggest that the attraction of job security is able to trigger new graduates to come out from their comfort zone. Many are willing to move from their hometown because they see better opportunities for their career. Job security, in this case, is defined as a legal contract that is offered by the employers (i.e. the national or the local government) which stipulates the duties and obligations of the two parties, namely the midwives and the employers. The type of the contract could be a fixed-term contract or permanent.

Initially in 2008, I only received IDR 750,000 [around USD 57). I was thinking at that time the important thing is I have a job... (Regionally-contracted midwife/PTT Daerah - SC)

I was informed by my friend that West Sumbawa District required lots of midwives ... if I stayed in my hometown [West Java], I would only be an assistant of a senior midwife in their clinic. I received an offer from the DHO in East Lombok District. Since then I have moved to NTB and was deployed in KSB District (Nationally-contracted midwife/PTT Pusat - LSC)

Initially, I wanted to get lots of experience, but there is a bigger opportunity to be a village midwife here [NTB province] ... (Nationally-contracted midwife/PTT Pusat - LSC)

KSB needed lots of midwives, therefore I came and applied to be a village midwife in this area (Nationally-contracted midwife/PTT Pusat - LSC)

As defined earlier, the most appealing element is a legal contract issued by the government, at both local and national levels. A legal contract is seen as a protection by village midwives because it can prevent them from losing their job. This means that, at least for a certain amount of time, village midwives have stable earnings which lead to stability in the family financial situation. With the current situation, where finding a job is challenging for many graduates, obtaining assurances in terms of employment is highly valued. 
The first policy breakthrough which provided midwifery training for fresh graduate students in West Lombok District (the 'success cases') was introduced by the DHO. The Midwives Extension Programme (MEP) for remote areas was launched in 2008. The aim of the policy was to address the shortage of midwives in remote areas. Basically, this was a scholarship for high-achieving students from West Lombok District in which the contract was binding. The students had to commit to work in remote areas according to their home-base after graduation. Accordingly, the students signed an agreement that they would return to their home-base for 10 years.

Yes, it [the contract] is extended every year for 10 years. During that 10 years, we can apply for other employment statuses, such as PNS and PTT Pusat, as long as the position is for West Lombok District (Regionally-contracted midwife/PTT Daerah - SC)

These specific requirements are determined based on local needs. Even though the requirements are seen to be very harsh because they potentially limit midwives' growth in terms of their career, there are many new graduates interested in joining this programme.

From 165 people, around 35 people were accepted in the Midwives Extension Programme... there was one person withdrawn from the programme... (Regionally-contracted midwife/PTT Daerah - SC)

It is difficult to find a job at the moment, so I wanted to find something that offered me a job straight away after I graduated... (Regionally-contracted midwife/PTT Daerah - SC)

This is not the only job that they want, but they need this job. Frankly speaking, they [new graduates] don't want to work in the village because they are still young and haven't got married yet. But, they need the job to practise their skills (Puskesmas - SC)

The results seem to suggest that many new graduates have limited job options in $N T B$ for various reasons. One of those reasons might be that, as mentioned earlier, there is a high supply of midwives in Indonesia, particularly in NTB. 
According to some key informants in $N T B$, for the past five years the supply of health workers, especially midwives, has increased. This high supply is due to the expansion of midwifery schools in Indonesia including in NTB. The supply of health workers in NTB is produced by 21 institutions, from both health education and nonhealth education backgrounds. In 2003, there were 10 institutions that offered midwifery training in NTB but only one of these was a public institution. The rest were organised privately or privately owned.

The 10 institutions were the University of Nadhiatul Wathan Mataram, Stikes Mataram, Stikes Yarsi Mataram, Akbid Bhakti Kencana Mataram, Stikes Qamarul Uda Bagu, Stikes Hamzar Mamben, Akper Pemerintah Provinsi NTB, Akbid Harapan Bunda, Akbid Surya Mandiri and Setikes Yahya Bima. These institutions produce approximately 700 graduate students each year. Logically, NTB should not have problems in supplying midwives, and so high competition to get a job, particularly as a village midwife amongst new graduates, is inevitable.

On the other hand, an oversupply of midwives has the potential to risk other service delivery aspects, such as their quality. Many midwifery institutions put forward a high quantity of, rather than high quality of, graduates. In addition, oversupply of midwives could burden the government, as providing jobs for fresh graduates would potentially affect their annual budget.

The difficulty in finding jobs for new midwives has left village midwives with limited options. For instance, under MEP, those students who fail to comply with an MEP contract are obligated to pay a fine of three times their training expenditure. In addition, another (unexpected) requirement was mentioned by the participants: they were not allowed to get married during their first three years of service.

We have to pay three times our training costs if we refuse to be deployed in our home-based (remote areas) or quit the job before the contract finished (Regionally-contracted midwife/PTT Daerah - SC).

... We [regional contracted midwives] received a scholarship from the DHO. One of the requirements was we cannot get married in our first three years of service... We accept it as it is... (Regionally-contracted midwife/PTT Daerah - SC)

We [midwives under MEP] receive IDR 700,000 [USD 53]. Even though the petrol price has been increased several times, there have been no changes in our salary. Since 2001 we have received the same amount (Regionally-contracted midwife/PTT Daerah - SC) 
The results suggest that new graduates have to face a catastrophic option. Midwives are in a position whereby they have to accept a set of requirements - a long contract with a small salary per month and other restrictions - in order to secure a job. These requirements have the potential to infringe on people's rights in regards to freedom of choice. On the other hand, these specific requirements have a significant impact on retaining midwives in remote areas. Many midwives obey the rules or are afraid to move from their posted areas due to the consequences.

Such strict requirements, particularly the prohibition on marriage in the first three years of service, might have a protection effect, since entering married life at the age of 20 or 21 is seen as too young. However, this is a personal choice and the government should not be involved in their private sphere.

Despite the advantages and disadvantages of MEP, West Lombok District expected to increase the number of midwives in 2012. They expected that one village would be served by two midwives. During my fieldtrip in West Lombok District and North Lombok District (a regional expansion of West Lombok District), I found many PTT Daerah midwives under a MEP contract were deployed in remote or very remote areas. This indicates that the programme has attracted many midwives, and as a result, the distribution of midwives, especially to remote areas, is achieved.

The results indicate that monetary factors play an important role in motivating midwives to work in remote areas. This might suggest that job security and attractive remuneration should be considered in crafting policies or strategies for recruiting midwives in Indonesia. This might target both the recruitment as well as retention of midwives in remote areas of Indonesia.

In addition to better income and job security, there are other factors that attract PTT Daerah and volunteer midwives to remote postings. Some of these count as personal attributes. A dedication to community and the desire to gain more experience, for instance, were dominant factors mentioned by the research participants in both cases. These two motivators appear to be essential ingredients for village midwives, especially for volunteer midwives since they cannot expect a fixed income or job security. 
Box 2: Nationally contracted midwife/PTT Pusat $1-A$ 'Success Case'

I am a regionally contracted midwife in West Lombok District. I am 28 years old and I have been working in this remote village for about four years. At the moment, I live with my husband and with my baby boy in the 'birthing house' [Polindes]. I handle one village with four hamlets. I have to say that this village is categorised as a very difficult one because the houses are scattered. When I started in 2012, I had to walk to be able to reach the houses. At the moment, I can use a motorbike, but it is still very difficult because the road is not good. To date, the phone coverage is only available in certain points, so if you want to make a phone call you have to go to those places. For instance, I can only use my mobile phone if I go to the tree in front of my house.

This village had no electricity until 2015. Before electricity was available I used a torch to help the patients. I have a generator but I did not use it because it is too loud and it might disturb the patients or the neighbours.

Well, I decided to be a village midwife because of the uniform. Since I was a child I always want to wear 'the white uniform' because it looks different and good. My parents have always supported me to be a midwife. Fortunately, I received a scholarship from the local government to study midwifery for three years. After I graduated from midwifery training, I was deployed by the local government to this village.

To be honest, for the first two months I did not enjoy it and was shocked with the condition of the village. In addition, I only receive low salary. Since 2011, the salary has never been increased, I have only received around IDR 700,000 per month [NZD 72]. Yet I never told my parents about my difficulties. I come from a very religious family, so my parents have been told that money is not the only important thing in life, but also how you can be useful for others. 'Be thankful and be patient.' That keeps me in my workplace.

My husband is also a big support for my career. He told me that I should be thankful because I have a contract after I graduated. My husband has been promoted. He has been a volunteer nurse for years, so he knows the feeling not to have certainty in his status.

\subsubsection{Dedication to Community}

Although financial incentives and long-term contracts attract many applicants, these must be weighed against the potentially important role non-monetary factors play in decision-making. Ensor, Quayyum, Nadjib, and Sucahya (2009) and Frehywot et al. (2010) point out that there are significant factors other than money, such as culture and support from family members, that need to be addressed in recruiting and retaining midwives in remote areas. 
Through my study of factors that guide midwives toward remote postings, I found that dedication to community - particularly if that community is the midwife's hometown - is one of the essential elements in attracting midwives to remote areas. This factor becomes a priority for midwives who may have lived in communities where health is not a priority, or where many people in the community have limited knowledge about health, or even basic healthcare. Hence, some communities' ignorance of the importance of healthy life choices or practices motivates midwives to work in their own hometowns or in other remote settings.

Dedication to community, then, is defined as the willingness of midwives to help those in their communities improve their own health. It manifests through providing basic maternal and child healthcare or general basic healthcare.

I want to help my family have better access to basic healthcare (Volunteer midwife - LSC)

I want people in my community to have better understanding about health (Volunteer midwife - SC)

I want to help my community because their understanding about health is really low... When they [the people in the community] were sick, such as with a fever, they tended to go to the traditional healers. They were given an assortment of leaves to reduce the fever but it did not work (Volunteer midwife - SC)

The results confirm that there are factors other than financial incentives that attract midwives, especially volunteer midwives, to remote villages. This is consistent with the other literature that suggests that non-monetary incentives may be more powerful than monetary incentives in regards to attracting and retaining health workers in rural and remote areas (Peña et al., 2010; Zinnen et al., 2012).

Another non-financial incentive is the desire to improve skills. Some midwives feel that by working in remote settings, they have a better opportunity to practise their skills and thus obtain more experience. 


\subsubsection{More Experiences to Obtain Better Skills}

There are many ways to improve the skills of midwives, especially in assisting delivery. These could be joining a refresher workshop or on-the-job training. Interestingly, being a village midwife is seen as a way to improve midwifery skills because midwives will often have to assist a woman with delivery on their own.

I [a village midwife] will have richer experiences, especially where there is no midwife in the village. I feel like I will develop my skills if I am away from where I am from (Regionally-contracted midwife/PTT Daerah - SC)

According to me [a village midwife] living in the village helps you to be independent. In the city, doctors mostly assist the delivery, so I said to myself 'How can I learn or improve my skills?'... Then, my senior told me to go back to the village. I am here now and I think my senior is right (Regionally-contracted midwife/PTT Daerah - SC)

When we were students, we learnt how to do ANC and assisting labour. But, I did not practise my skills when I was a student. Now, I really work alone from ANC [antenatal care], assisting labour and until the babies reach five years old (Regionally-contracted midwife/PTT Daerah - SC)

I found a lot of cases that would never be found if you worked in urban areas (Volunteer midwife - SC)

If you work in very remote areas, you have to handle everything yourself (Volunteer midwife - SC)

Although village midwives are considered the lowest status in the hierarchy of employment, they believe that starting their career as village midwives is a good entry point because they can enrich their knowledge as well as enhance their skills. According to my observation during data collection, a village midwife is often the only health worker that the community can go to if they have health problems. The role of a village midwife, particularly in remote or very remote settings, involves more than just assisting with deliveries. In addition to practical skills, a village midwife is more likely to develop personally because they indirectly train in the situation where they have to make decisions based on their judgement. 
This factor should be considered by policy-makers in order to promote or convince new graduates that even though working in remote or very remote areas could be very challenging, many advantages could also be obtained. These include clinical skills, leadership skills, time management skills, as well as communication skills. Thus, midwives have the ability to solve problems when they work in the village.

On the other hand, many fresh graduates apply for remote postings because they have more opportunity to practise their skills than the limited practice they received while they were in midwifery training. This is an ironic situation, since the roles of midwives in remote or very remote postings are more demanding than those of urban midwives. Village midwives require better skills than urban midwives. As mentioned in the previous section, village midwives in remote and very remote areas should be equipped with emergency handling competency, as access to health facilities in these areas is challenging.

\subsection{Conclusion}

This chapter covered three main aspects - types of midwives, the six steps of the recruitment system, and key factors that attract midwives to remote postings. In general, both the 'success cases' and the 'less success cases' have similar patterns in recruiting various type of midwives, whether PNS, PTT Pusat, PTT Daerah, or volunteer midwives. Although the recruitment system has been working effectively in recruiting midwives, nevertheless some improvements are needed in some parts of the process.

For example, a frequent concern is transparency in selecting applicants. However, this issue has been countered to some extent by conducting layers of tests which suggest fairness in the selection process. Having a clear process of recruitment is more likely to recruit qualified midwives for remote areas.

The results are consistent with other studies which argue that financial incentives play a key role in attracting midwives to remote postings, such as that of Efendi et al. (2016), for example. In Indonesia, midwives with PTT Pusat status receive additional income based on the difficulties of their working areas. However, Efendi et al. (2016) also suggest that non-monetary incentives should be offered together with financial incentives. 
Personal attributes, such as dedication to their community and a drive to obtain better skills, can be highly motivating factors for midwives, but these have received little attention in previous studies. The attachment of village midwives to their communities is a unique connection which influences their decision to work in their hometown. This suggests that deploying midwives based on their hometown is likely to be attractive to midwives or fresh graduates.

These findings could compel midwifery institutions or schools to set a curriculum based on a deeper understanding of the value or culture of remote areas, and the value of working in remote areas, thus the students might be attracted to work in those areas. The government should also focus on the recruitment system for midwives who have local background or knowledge. Positive discrimination might be needed in order to attract and possibly retain midwives in remote areas of Indonesia.

My findings also highlight how acquiring more experience attracts midwives to remote areas. I believe that this finding has not been discussed in the previous studies. Working in remote areas means that midwives should be able to handle many maternal health-related issues independently and with limited facilities. As a result, village midwives consider working in remote areas as a learning centre for them to build a good foundation for their skills and to start their career. This experience is rarely found during their study, nor if they work in other health facilities or in urban areas. Clearly, this finding could compel policy-makers to create a 'compulsory internship' in remote areas for at least two years to all new graduates, students, or midwives who want to establish their private clinic.

This study provides some of the most convincing empirical evidence that worker motivation is influenced through a variety of channels. Motivating health workers to work in remote areas consists of organisational factors which involve providing financial incentives to those working in remote areas and a contract (preferably a long-term or permanent contract). Financial stability is a good foundation from which to move forward, yet to what extent financial incentives are able to keep midwives in remote postings needs to be considered. 
It should also be noted that broader coverage of factors other than financial incentives is required in crafting policies or strategies to attract midwives to remote areas. It seems that in the long-run, non-financial strategies may be more beneficial because they will not impact on the national or regional governments' annual budget allocation.

Finally, policy-makers and health facilities managers must recognise the importance of work motivation in order to attract and retain midwives in their workplaces, particularly in the difficult areas, as these involve more complex issues than in urban areas. The next chapter will discuss factors important in retaining midwives in remote areas. 


\section{CHAPTER 6. RETAINING MIDWIVES IN REMOTE}

\section{AREAS}

\subsection{Introduction}

Many factors contribute to the success of retention strategies, but how these factors operate is not yet well understood in the Indonesian context, particularly in NTB. The important factors that influence midwives to stay in remote areas of Indonesia are discussed in this chapter.

Unlike Chapter Five, this chapter will distinguish between the 'success cases' and the 'less success cases' because there are some distinctive factors in the 'success cases' that were not found in the 'less success cases'. The chapter begins with key factors that retain midwives in the 'success cases', then continues to explore the key factors that retain midwives in the 'less success cases'.

\subsection{Key Factors that Retain Midwives in the 'Success Cases'}

My findings from the 'success cases', drawn from six districts in NTB (namely West Lombok, East Lombok, Bima, Dompu, Sumbawa, and North Lombok) indicate some key factors that retain midwives in their workplaces. These are (i) community support; (ii) dedication to the job and community; (iii) financial incentives; (iv) cultural and belief systems; and (v) local hiring. These factors indicate that midwives stay in their workplaces because of a mix of financial and non-financial factors.

Other studies have identified similar factors. For instance, a retrospective study from Peña et al. (2010), using national data, suggests that a combination of incentives (financial and non-financial) is able to attract doctors to work in rural areas. Peña et al. (2010) show the importance of non-monetary incentives in determining a doctor's behaviour toward their patients in Chile; while Zinnen et al. (2012) suggest that working conditions need to be improved in order to satisfy health workers as well as to increase their motivation to work in rural areas. Franco et al. (2004) identify factors that influence health worker motivation in Jordan and Georgia, which include self-efficacy, pride, management openness, job properties, and values. 


\subsubsection{Community Support: Neighbourhood Solidarity}

The importance of social support is particularly, in my research, especially in relation to support from neighbours. Social support predominantly comes from informal sources, defined as close personal relationships arising from intensive interaction between midwives and the community. According to Umberson and Montez (2010), informal social support comes from outside formal structures; rather than agencies, organisations and institutions, it comes from the neighbours or community.

Emotional support and instrumental aid are the most common support received by village midwives. Emotional support involves concepts of interpersonal help systems which in turn involve commitment and sentiment toward individuals (SánchezMoreno, de La Fuente Roldán, Gallardo-Peralta, \& Barrón López de Roda, 2015). Instrumental aid support involves tangible aspects, such as money, food and clothing (Spilsbury \& Korbin, 2013).

Previous research has indicated an association between social supports and better health outcomes (Sánchez-Moreno et al., 2015; Spilsbury \& Korbin, 2013; Stopford, Winkley, \& Ismail, 2013). For example, Sánchez-Moreno et al. (2015) have identified the importance of informal social support in order to prevent stress and burnout syndrome among social workers in Madrid (Spain). Similarly, Spilsbury and Korbin (2013) point out that informal social support plays an important role in protecting children from abuse and neglect. These researchers indicate that social supports, particularly informal social supports, are more likely to be protective factors or have a buffer effect on health outcomes. 


\subsubsection{Emotional Support}

Community acceptance as a part of emotional support was the most frequently mentioned form of support for the participants in my study. The research participants expressed both explicitly and implicitly that acknowledgment as part of the family was a great feeling, and indicated that their work was appreciated by the community. A village midwife is seen as an asset to communities because they have the potential to create connections for the care of women (Barclay, 2008). They are able to provide, for example, more attention to women's emotional and practical support needs during and after pregnancy. Thus, community members are willing to treat village midwives as their own.

... it is the community that makes me stay here. Even though I come from a different island [Java Island], I can feel that we [the community members and me] have a really close relationship... It's even closer than my own relatives or siblings (Volunteer midwife$S C)$

... the midwives stay there [in the village] because of the acceptance from their neighbours. That is the reason why they stay in their workplace (Indonesian Midwives Association/IBI - SC)

I like the people here, even though sometimes they are difficult. They are open to new people like me who wear a veil and mask...

(Nationally-contracted midwife - SC)

Appreciation of village midwives is shown by community members in various ways, for example, through midwives being invited to various village occasions as an honoured guest. These occasions were used to show the communities' gratitude and respect for the village midwives. Emotional support emphasises fulfilling the needs of self-actualisation which makes a person feel good about engaging in their work. Thus, this type of emotional support potentially helps retain midwives in remote areas. My findings also indicate that the kinship value of the community influences midwives' motivation to work as well as stay in remote areas. The community highly values the work of the health workers, in my case village midwives, thus the village midwives feel a sense of belonging with the job as well as the community. These findings are consistent with the study from Frehywot et al. (2010), who confirm that health workers feel welcome and comfortable in their workplaces because of the support from the community. 
My background as a person who was born and brought up in Jakarta - the capital city of Indonesia - has provided me with inside knowledge of the Indonesian kinship system, and allows me to identify particular differences in this between urban and remote environments. While I was conducting my fieldwork I stayed a few nights in several villages and observed that people there highly value interpersonal relationships or have stronger kinship bonds than people in urban areas such as Jakarta. This value, the responsibility to take care of one another's well-being, can be seen in individuals' daily behaviour. According to Heady, Phillips and Briggs (2006), a rural community offers various values that have the potential to attract candidates to work and stay longer in the work postings. The values encompass neighbourliness, family solidarity, a sense of humour and beauty, humility, patriotism, faith and religion, and equality (Heady et al., 2006). Thus, government policies or programmes could also emphasise the positive environment to potential candidates, although this may be difficult in practice.

\subsubsection{Instrumental Aid Support}

In addition to emotional support, the community also provides instrumental support. Tangible support, such as food, money and clothing can directly provide for daily needs and may benefit midwives' financial situation. This instrumental aid support encompasses several types, as will be elaborated on in the following section.

\section{Local Produce}

The community often provides midwives with local produce, such as rice, fish, vegetables and fruits. The generosity of community members is not simply a matter of showing appreciation for the work of village midwives, but also demonstrates an interaction of giving and receiving between the community and midwives, which differs substantially in each village.

... when patients didn't bring money to pay, they gave me their local produce such as fruits. I am so happy because of that... they also helped me happily and didn't ask for anything in return... I have no difficulties in finding a caregiver for my daughter if I have to do home visits. The community are willing to take care of my daughter... they say 'let me take care [of] your kid 'Bu Bidan' [calling for a village midwife] (Regionally-contracted midwife/PTT Daerah - SC) 
When we did monitoring of the village, we figured out one of the reasons why midwives stay in their workplace... it relates to the kindness of the community. The midwives hardly used their salary for their daily expenditure [e.g. to buy food] ... they never bought rice, vegetables; the community brought it for them... (Indonesian Midwives Association/IBI - SC)

I [a village midwife] receive food, vegetables and other support from the community, so I don't have to buy food (Volunteer midwife - SC)

It is clear that community kindness can come in tangible or intangible forms. Tangible or instrumental aid support has benefited midwives. In such a case, a volunteer midwife is definitely helped by the generosity of the community as they have no or only a limited income.

\section{Partnership or Collaboration}

Partnership or collaboration between community members and midwives was another form of instrumental aid support mentioned by the research participants. This is categorised as an instrumental aid support because some people in the community, such as TBAs, Kader Posyandu and the village heads, can act as sources of information for midwives.

The roles of TBAs have changed since a collaboration programme between village midwives and TBAs was launched by the GoI in 2007 (UNICEF, 2008). The programme was intended to encourage pregnant women to utilise SBAs, particularly midwives during labour and shift the role of TBA from assisting delivery to providing support to midwives, such as cleaning the babies and mothers.

Since the programme was launched, TBAs still play a significant role in these communities as respected community members. Under the agreement, TBAs continue their traditional roles that involve reciting prayers, providing herbal drinks, and postpartum care (UNICEF, 2008) but all medical procedures are undertaken by midwives, who also pay the TBAs' fees out of their own compensation (UNICEF, 2008). 
The health-seeking behaviour culture has changed. Twenty years ago, many villages were located in very isolated areas. There was only one pregnant woman who came to the Polindes [where the village midwives live] to deliver the baby, the rest were helped by TBAs. Since 2000, many pregnant women prefer to deliver their babies with the village midwives... However, TBAs are still the partners of village midwives... (Indonesian Midwives Association/IBI - SC)

From 1998 to 2000, community members were still counting on the $T B A s$, so it was important to collaborate with them ... at the time, we're partnering with TBAs in handling pregnant women until the labour (Senior Midwife, Civil servant midwife/PNS - SC)

Acknowledging and engaging 'close-to-community' providers, such as TBAs, can benefit village midwives and ultimately the community. Two important elements midwives need to learn from TBAs: are how they communicate with pregnant mothers; and how they provide comfort to them. As D'Ambruoso et al. (2007) suggest, TBAs and other informal health practitioners could be 'a tool' for midwives to access the community.

The findings from my study confirm the importance of having a strong partnership between midwives and community members such as TBAs. Such collaboration better enables village midwives encountering problems in the community, helping them persuade pregnant women to have checks or go to health facilities, thereby gaining the trust of women to then allow them to help in the delivery of their babies.

TBAs in NTB are mainly women who come from the village; they are, therefore, considered very trustworthy. The TBA is a hereditary job and their position in the community is held in very high regard (Agus et al., 2012). Other Indigenous communities, such as Samoa, similarly regard TBAs in this way (Barclay, 2008).

Culture or beliefs are one of the absolute determinants of women's health-seeking behaviour in Indonesia (Penny, 1994), so obeying the advice of TBAs is considered essential (Agus \& Horiuchi, 2012; Agus et al., 2012; Wulandari \& Klinken Whelan, 2011). In addition, participants in my study also suggested that visiting TBAs and giving gifts was an effective way of gaining respect and trust from the community. 
Another important figure in the community who cannot be ignored is the Head of Village. Establishing a strong relationship with village heads is essential in order to gain both emotional and instrumental aid support. My findings indicate that a significant but indirect role of the village heads in NTB is retaining midwives in remote and very remote areas. An example of this is in relation to the common dilemma facing villages when referring patients to Puskesmas; finding transportation for them can be problematic. Village heads are able to help midwives not only in addressing these transportation issues, but also in convincing women to deliver their babies in health facilities. It appears that village heads are likely to have a great influence when it comes to motivating as well as mobilising the community. This can be very beneficial for midwives in the promotion of their health programmes, as well as in reducing their workloads.

It's really important to work with the Head of Village, especially in the beginning of my placement. The Head of Village has great power in the village... I have to admit if there had been no support from the Head of Village, we would not have survived... we propose and request many things to the Head... (Regionally-contracted midwife/PTT Daerah - SC)

We provided the facilities such as the Polindes. We bought the land for the Polindes and it was built by the community with the local government budget (The Head of Village - SC)

Another significant outcome of partnering with village heads, is that they can secure resources such as those required to improve health service facilities. The Head of Village is the number one person in the village and has great power in terms of allocating the village budget and developing the village. This management power aside, the Head of Village is also perceived as a respected position by the community, especially in remote areas of Indonesia.

The evidence shows that the Heads of Villages have great influence in the community which can improve midwives' job performance. Frehywot et al. (2010) also found that community leaders organised the health workers' workplaces, so they can perform their jobs effectively. This indicates that the Head of Village role cannot be ignored. The results of my study reveal the uniqueness as well as the limitations of the Head of Village's role. 
Historically, in maternal and neonatal health services, the Polindes were built as extensions of Puskesmas, with the aim of enhancing the quality and outreach of the Puskesmas. However, due to geographical limitations, the supervision of village midwives was handed over to the village heads, resulting in them controlling village midwives' services. In reality, it seems that the village heads still use an old paradigm when it comes to health service delivery, whereby health is solely the responsibility of DHOs or Puskesmas.

Ya... I know that I as the Head of Village should prepare proper health facilities or equipment for the Polindes... so far, the facilities and the health professionals have been provided by the DHOs (The Head of Village-SC)

Improving community health is considered less important by the village heads, who tend to focus on building infrastructures. One possible explanation for this may be that the power relationships between Puskesmas, the village heads and village midwives are unclear. Perhaps village heads have not fully understood their role in supporting the health system in Indonesia. It may also be possible that the Heads of Villages do not recognise childbirth as a health concern because it is a natural process and not a disease or illness.

Kader Posyand $u^{9}$, or a village health volunteer, also plays an essential role in retaining midwives in remote areas of the NTB province. Kader Posyandu provides instrumental aid support to midwives by mobilising women in villages to attend Posyand $u$ and voluntarily assisting midwives during Posyandu or other occasions when it is needed.

Kader Posyandu always stand by whenever I need them... even though it's late at night, they're always ready when I phone them... (Volunteer midwife - SC)

Many midwives work closely with Kader Posyandu because they are willing to support midwives in order to complete their tasks. Policy-makers should consider the place of this supporting system in the community, as it has a great influence on midwives' decisions to stay in remote villages.

\footnotetext{
${ }^{9}$ Kader is defined as a village health volunteer. Posyandu or Pos Pelayanan Terpadu is defined as an integrated post which is run by the Kader. Every village usually has one Posyandu with five Kaders.
} 
Community members such as neighbours, TBAs, village heads, and Kader Posyand $u$ all have another significant contribution to make in terms of retaining midwives in remote and very remote areas of the NTB province. The emotional and instrumental aid support they provide are more likely to have the protective effect of increasing village midwives' self-esteem which leads to their sense of belonging to the community. This sense of belonging in turn leads to a greater likelihood of staying in remote or very remote areas.

Informal social support has positive impacts on motivating midwives to stay in remote areas of $N T B$. The interpersonal interaction that occurs between community members and midwives was found in my research to trigger midwives' sense of belonging to the community. A conducive environment (i.e. safe and comfortable) is able to reduce the feeling of loneliness. This finding aligns with other research (Sánchez-Moreno et al., 2015; Spilsbury \& Korbin, 2013) which emphasises the importance of informal social support as a protective factor to reduce stress in social workers.

\subsubsection{Dedication to the Profession}

Another important topic discussed by the research participants was midwives' dedication towards their profession. Most of the research participants, including government officials and midwives, point out that dedication towards their profession is triggered by the internal motivation to help others to obtain a better health outcome. It seems this factor brings them satisfaction.

Initially it is hard to work in remote areas, but after you have done it for months your humanity's side is touched. Even though the patients want you [the village midwife] to go to their house at 12 am or lam, we [the village midwives] have to go. It is part of our responsibility as a midwife and we have moral obligation as well to help others (Nationally-contracted midwife - SC) 
According to me [a village midwife], and what I feel, I have to work in this village. Whether I am willing or not willing to work in this village, I have to accept it because this is my responsibility as a midwife. The characteristic of the community here is unique, when they [the community] call us [the village midwives] 'Bu Bidan [a call for a midwife] there is a patient who is going to deliver the baby', I have to go to the patients' house as soon as possible. I have to leave everything on hold, such as cooking rice, eating, and other activities. The point is I have to stop and go straight to the patients' house (Nationally-contracted midwife - SC)

Remember the oath to our profession, we [midwives] have to provide services to everyone... and like on our song [IBI theme song], we [midwives] have to be loyal to our job (Civil servant midwife/PNS $S C)$

They [the village midwives] stay in their workplaces because they have strong dedication to help others (Puskesmas - SC)

This finding raises the concept of personal factors which are often neglected by decision makers. It is clear that midwives' satisfaction is related to their ability and capability to provide services to their patients or communities. This is an intrinsic motivation embedded in the character of their job. Similar to this finding, Jenaro, Flores, Orgaz and Cruz (2011) point out the importance of understanding personal variables in order to improve work engagement between nurses and their supervisors, so that nurses can be retained in their workplaces. The relevance of personal factors are often neglected.

Personal motivation is undoubtedly influenced by societal or organisational factors. For instance, the dedication of midwives to their profession might come from various channels, such as the values of the midwifery schools or from the organisations where they worked and were trained. It seems the value of loyalty was introduced to midwives when they were in midwifery training. The values were introduced by using various tools, such as through 'the $I B I$ theme song'. This theme song strongly indoctrinates midwives into the how they should think about their profession (Box 3). 
Box 3: Ikatan Bidan Indonesia (Indonesian Midwives Association) Theme Song

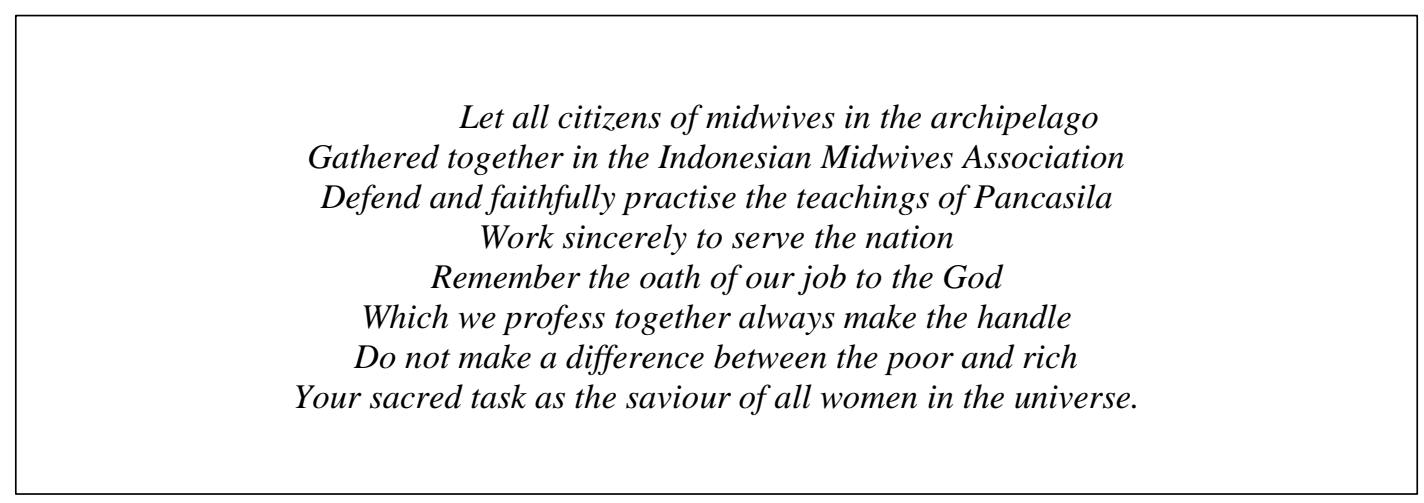

It should be noted that strong personal motivation has a strong influence on retaining midwives in remote areas. Thus, policy-makers should seriously consider this factor when crafting retention strategies for midwives.

\subsubsection{Direct Financial Incentives}

Direct financial incentives, such as salaries and additional monetary incentives, appear to be one of the key factors that retain midwives in remote areas of NTB. A desire to support the family finance was mentioned by the research participants. However, this factor is not the only factor that keeps village midwives in their workplace.

... As I mentioned earlier, I have no other choices. My husband and my family support my decision to work in remote areas. Economy is also one of the reasons I stay in this village (Nationally-contracted midwife/PTT Pusat - SC)

In my opinion, midwives stay in remote areas because their work is appreciated by the government in terms of high salary. For instance, nationally-contracted midwives receive pretty high salary... in a month midwives who work in very remote areas receive IDR 4,000,000 [around 307] as their salary, as a result many people want this position...they want the contract to be extended and don't want to move to other areas... and they are used to the community as well (The Indonesian Midwifery Association/IBI - SC) 
With PTT Daerah status, we [midwives] receive IDR 600,000 per month [around USD 60] which is good enough, better than receiving no salary at all (Regionally-contracted midwife/PTT Daerah - SC)

The conditions are good now, because we [the midwives] receive additional income from the hotel ${ }^{10}$ employees' reimbursement system (Volunteer midwife - SC)

The GoI estimated that $60 \%$ to $75 \%$ of village midwives have stayed in their villages since they were deployed in 1994, although the role that salary plays has not yet been clearly understood (Personal Communication, 2015). My study suggests that while high income attracts midwives to work in remote areas, retaining them requires that other factors are considered. Additionally, volunteer midwives and PTT Daerah receive no, or only a limited, salary, but most of them stay in the village because of other factors such as informal social support. This result is consistent with the study from Stretton and Bolon (2009), who point out that salary and benefits play an important role for hospital administrators in rural areas. Providing only monetary incentives has a minimal impact on the recruitment as well as retention of health workers (Franco et al., 2004; Stretton \& Bolon, 2009).

The salary that we [PTT Daerah] receive is different from PTT Pusat, we only receive IDR 600,000 [around USD 46] per month. Instead of every month, we often receive our salary once every four months (Regionally-contracted midwife/PTT Daerah - SC)

Amongst all midwives, the most vulnerable status is that of a volunteer midwife because they do not have a contract with the DHO or Puskesmas and as a consequence, cannot expect any kind of benefits including fixed salaries on a monthly basis.

Interestingly, despite the limited income and lack of legal protection, many volunteer midwives are committed to their jobs in the villages where they have worked for years.

${ }^{10}$ There is a luxurious resort on this island which hires local people. Each employee is provided with free healthcare or insurance. Thus, midwives in this areas receive additional income if any resort employee seeks treatment from the village midwives. 
Since the social security system was introduced by the GoI in 2004, all types of midwives have received additional income, such as reimbursement for services provided to the poor, and a capitation grant based on the enrolment in primary healthcare (Fasilitas Kesehatan Tingkat Pertama or FKTP) or a payment per capita from the Social Security Agency (Badan Penyelenggara Jaminan Sosial or BPJS) (BPJS regulation no. 2 year 2015). These two sources of income have helped the health providers, in this case Puskesmas, to allocate some money to pay the volunteer midwives and other types of midwives.

The WHO Annual Report on workforce alliance (GHWA, 2015) also suggests that this provides $79 \%$ of the total income while the rest comes from additional bonuses and reimbursement for services provided to the poor. For instance, each midwife who provides a service, namely assisting pregnant women when they give birth, will receive some payment For such a service, a midwife will receive IDR 600,000 (around USD 46) using a reimbursement system.

My study was found that the amount of the payment differs from the amount stipulated in regulations, and that the payment schedule also varies. For example, one of midwife participants in one district received a different payment to another midwife participant in another district, with the amount of the payment depending on the revenue tax in each district. It seems that such a payment is used to boost regional revenue and neglects the work of the midwives who deserve more appreciation.

In addition, the reimbursement process takes time. As a result, the payment is received by a midwife only once every few months. This unclear schedule of payment is considered unfair by village midwives as they have already provided healthcare to mothers based on their tasks. The village midwives, particularly regionally-contracted midwives or volunteer midwives, expect that payment is going to be made every month. Even though this issue has been raised with the DHO and $I B I$, the situation has not been changed, possibly contributing to job dissatisfaction. Decision-makers should ensure that the amounts paid are both accurate and timely. 
These research findings indicate some caveats encompassing delays in payment, and a complicated process. Volunteer midwives are the most affected group in regard to these problems because their income depends on this system. Although midwives handled these issues with a positive attitude, and patience, these caveats have potentially negative effects on midwives' motivation in the long-run. These issues need to be addressed by the government. Doing so would indicate the government's appreciation of midwives.

It took almost a year to receive our reimbursement... not all our reimbursement has been paid, only the reimbursement up to Feb 2014 was paid... (Puskesmas - SC)

Actually, there is not much that they [village midwives] could get in the village... one of the factors that helped them survive is by providing delivery services to pregnant mothers... they can reimburse their services [to BPJS] ... the payment is not fully received by the midwives... it is often cut around 30-40\% by the local government... so from IDR 600,000 [around USD 46], they receive around IDR 400,000 [around USD 30] (Indonesian Midwivery Association/IBI $S C)$

Capitation-based payment is another form of payment that all midwives received as additional income. A lump sum payment is used by the BPJS to the FKTP, so the capitation-based payment system does not require specification of services delivered. The aim of this system is to improve the effectiveness and efficiency of primary health services.

This system provides an opportunity for FKTP such as Puskesmas to allocate additional income to health workers with the hope that they will provide optimum care to the community. My findings indicate that all volunteer midwives receive 'salary' from the capitation payment. Although, the amount varies in each Puskesmas based on the budget, it helps Puskesmas show appreciation to midwives, especially volunteer midwives.

Capitation-based payment seems able to keep their work spirit up... (Puskesmas - SC)

Now we receive salary from capitation even though the amount is not big (Volunteer midwife - SC)

Capitation-based payment seems to be one of the solutions adopted for all midwives to gain extra incomes. 


\subsubsection{Locally Hired: 'Familiarity and Less-Culture Shock'}

Hiring local midwives has been a popular approach to reducing the turnover of midwives. Almost all the 'success cases' have implemented this approach because the local government believes that hiring local midwives has potential to retain them in their workplaces.

I am from this village, thus I feel comfortable here (Nationallycontracted midwife - SC)

Personally, I am from this village, so I have a moral obligation to improve health outcomes in my own community... (Nationallycontracted midwife - SC)

Firstly, this is my own village, I am originally from this village, so I like to stay in my own village (Volunteer midwife - SC)

I stay in this area because this is where I come from. Yet some senior ladies [who have known me since I was a kid] think that I am still a kid, so they don't trust that I am a midwife... (Volunteer midwife-SC)

This suggests that local hiring of midwives is less likely to involve issues such as culture shock and language barriers. In addition, hiring local midwives means that less time is taken to adjust to the local culture because the midwives have been exposed to local values since they were children. On the other hand, my findings indicate an interesting issue about 'trust'. The young midwives are occasionally doubted by some people in the community, particularly by senior people. This is due to the fact that new or young midwives have always been seen as children by senior people. In order to address this issue, the young midwives have to demonstrate their professionalism and thus gain the trust of the people.

\subsubsection{Cultural and Religious Beliefs}

Belief systems, in this case religion, have a significant influence on midwives' motivation to stay in remote areas. Islam provides the foundation of life for many Moslems in NTB. Islamic teaching constructs the midwives' view of life which influences their work ethic and their social interaction. 
There were three common expressions used by the majority of my participants that reflected their Islamic belief system. The common words they used were ikhlas, bersyukur and tawakal. These words were originally Arabic. Based on the etymology, ikhlas consists of three syllables (kha-la-sha) and has two potential definitions; 'released' or 'pure'. Ikhlas is also defined as releasing all ambitions and accepting what one has at that moment. In Arabic tawakal or tawakkul is derived from wa-ka-lat which means 'taking for oneself a representative', but could also mean 'surrender' or 'resignation' in English. Tawakkul can also be inferred as relying on Allah, yet relying on Allah can only occur when effort has been made. Furthermore, syukur or syakara/syukr in Arabic means 'be thankful'. This involves one's reaction and utilisation of anything that they have at that moment.

Though these three words have a different emphasis in meaning, they were often used interchangeably by my participants to indicate their inner motivation to survive in any circumstance. For example, tawakkul focuses more on 'the effort', syukur focuses on 'the utilisation' of one's belonging, and ikhlas focuses on 'the end product' (Figure 19). These three words emphasise one's effort in their journey of life.

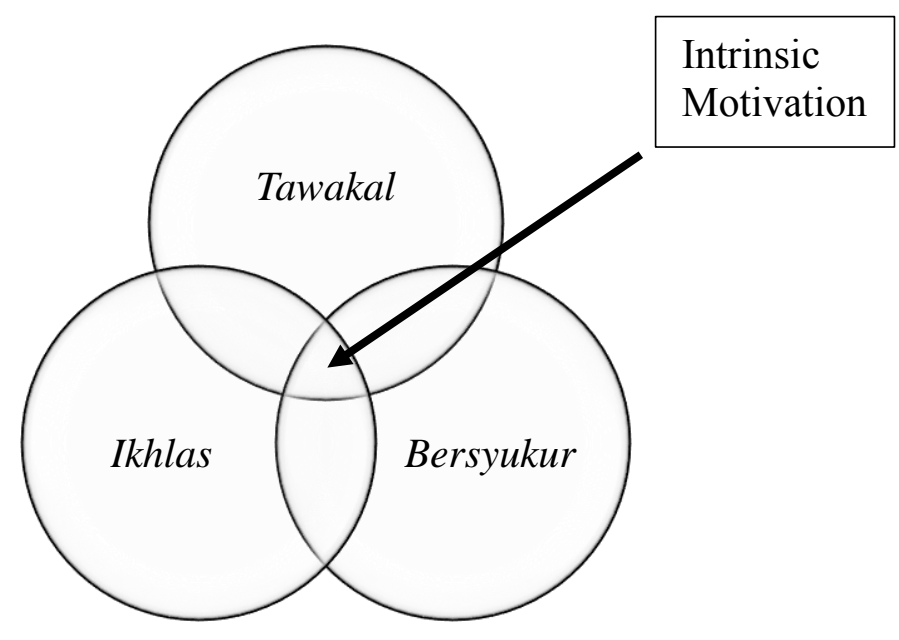

Figure 19: Religious Motivation 
From a theological perspective, ikhlas means 'purifying the religion'. For instance, 'Qul huwallahu ahad' is one of the verses in the Qur'an, 'Al-Ikhlas', 112: 1, which concentrates on the 'Oneness of God', explaining clearly that He is Allah (the One) and there is none co-equal or comparable to Him. Tawakkul is the placing of one's reliance on Allah which is often accompanied by patience. The concept of tawakkul can be meaningless when people are sitting idle or doing nothing. Yet tawakkul has the potential to increase the resistance as well as the perseverance of a human being. Syukr or thankfulness is another way to express one's gratitude to Allah for His kindness.

Firstly, we have to be ikhlas... just eccept whatever the patients gave us... just be ikhlas and don't request a lot of things... show them (the community or patients) our best, then we can ask something later... (Volunteer midwife - SC)

I [a village midwife] don't think about payment or salary or other things like that, the important thing for me is to work hard... the rest, for example the advancement, I leave that in the hand of God (Nationally-contracted midwife - SC)

My parents said to me 'Be patient and be patient and be patient'... I feel embarrassed to ask for money from my mother, as a result I just be grateful with what I have... (Regionally-contracted midwife/PTT Daerah - SC)

My friend told me that if we were meant to receive one million as our payment, but only received IDR 500,000 [around USD 38]... Just remember that Allah has given us health... That's how I feel 'being grateful'... (Regionally-contracted midwife/PTT Daerah - SC)

I believe that to be successful a person has to start from the bottom... it needs a process to be a successful person... (Volunteer midwife$S C)$

It is clear that the Islamic belief system increases midwives' tolerance for less favourable situations. This belief is often embedded in the midwife's personality due to intense indoctrination from the community environment. 
I am a village midwife in a very remote village in Sumbawa Besar District [Kabupaten Sumbawa Besar or KSB]. I am 29 years old now. This is a story about my experience being a village midwife for about seven years. I started my career as a regional contract-based midwife in 2009 in Taliwang sub-district. I became a nationally-contracted midwife in 2015.

I am from Java and I graduated from my midwifery school in 2008. I decided to move to KSB in July 2009 because I could see better career opportunities in KSB. I believe if I stayed in my hometown [East Java], I might not have had an opportunity to be a village midwife because the number of midwives in Java is higher than in West Nusa Tenggara.

My journey began when I was deployed in one of the villages in KSB. I did not enjoy it at the beginning. I was the only person from Java and I did not have friends and family with me. I was young and single. In the first year of my deployment, I asked for rotation, I wanted to be placed in the areas where I could meet other Javanese people. Short story, I moved to another village which is located even further away from where I was initially deployed. It is a transmigration area.

There were limited facilities such as poor quality of road and no electricity. To date, the electricity is only available from $6 \mathrm{pm}$ to $12 \mathrm{am}$ and phone signals are limited (only available in certain points). The main reason I stay in this village is because there are a lot of Javanese. From August 2009 to date, I have been a village midwife in this area.

I have to admit, initially I did not like it. I remember, it was Eid Al-Fitr I could not call my family because there was no phone coverage. I also had to stay in the 'birthing house' [Polindes] where the condition was really poor. I felt very isolated at that time. However, as Javanese, my motto in life is that I will not go back to my hometown if I have not achieved my goals.

Right now, I am not going to move to other villages because I enjoy working in this village. The community support has motivated me to stay here, we get along well. The community members are really nice to me. I have been building a good relationship with the community. I don't think I am ready to start over again in the other village. I feel really attached to this village. I have also some assets in this village that make it hard for me to move. 


\subsection{Key Factors that Retain Midwives in the 'Less Success Cases'}

My findings from the 'less success cases' (i.e. the Central Lombok District and West Sumbawa District) suggest that social supports - community support, cultural and belief systems, and experience - family support, and financial incentives are the main factors that influence midwives. In general, the key factors in the 'less success cases' are also found in the 'success cases', except the order is slightly different. For example, the findings in both 'success cases' and 'less success cases' highlight the importance of community support. They indicate that community has a protective effect on retaining midwives in workplaces because the community acts as a substitute for the midwives' families. The other two factors relevant in both cases are cultural and belief systems, and financial incentives. The similarity of the key factors should be a consideration for policy-makers to develop new policy interventions or programmes.

\subsubsection{Community Support: Neighbourhood Solidarity}

The same factors apply in influencing midwives' motivation in the 'less success cases'. The factors encompass neighbours, Kader, TBAs, and the Head of Village. This evidence shows that the community has a willingness to provide both emotional and instrumental aid support to midwives.

\subsubsection{Emotional Support}

Emotional support can be provided differently depending on the values in the community. Understanding community values is essential for village midwives as it helps them to adapt to their new environments.

The most important thing for me is community acceptance. Salary is important but the feeling of being accepted as part of the family is the most important... (Nationally-contracted midwife - LSC)

I [a village midwife] stay here because the people here are nice... When I first arrived, they [the community] welcomed me very well... (Nationally-contracted midwife - LSC)

My first motivation was for economy, but now community keeps me here (Nationally-contracted midwife - LSC) 
There is no doubt that acceptance as part of the community has a powerful influence on retaining midwives in their workplaces. This informal support from the community increases the chance of midwives staying in remote villages (Frehywot et al., 2010).

\subsubsection{Instrumental aid support}

Decisions about whether or not to stay in remote villages were also greatly influenced by instrumental aid support, such as money or other tangible support from the community. These factors, such as local produce and collaboration or partnership with community members, can also be found in the 'less success cases'.

Most of my [a village midwife] daily expenditure comes from my patients. Usually, I receive some additional income from providing other health services than assisting delivery or ANC. Usually, they [the patients] bring crabs, vegetables, or prawns. I also receive an additional income around IDR 20,000 per service [USD 1.5 per service] from providing family planning to the mothers (Volunteer midwife - LSC)

The evidence shows that some midwives receive indirect financial support from the community, such as local produce, thus the midwives are able to allocate their money for other necessities. For volunteer midwives, such support is essential: it can help their financial situation as they receive no or limited income from the government. I believe that this instrumental aid support from the community has the potential to retain midwives in their postings, yet this is not the only important factor that could keep them in their workplaces.

The TBAs are helpful as well. The TBAs say "it's better to bring the mothers to [the] Polindes"... I [a village midwife] give the TBA some money as a way to say thank you to them. The TBAs have helped me by encouraging the patient to come to me (Volunteer midwife - LSC)

I also received great support from the Head of Village. The Head of Village informed and coached the Head of Hamlet about the importance of giving birth in the Polindes [i.e. not at home] and assisted by a midwife (Civil servant midwife/PNS - LSC)

... [It happened one time] when the patient at high risk didn't want to be referred. I called the cadres [a community health volunteer] to persuade the patient to go to the Polindes, but it did not work. The Head of Hamlet also failed to persuade the patient. Finally, I called the Head of Village to persuade the patient... (Volunteer midwifeLSC) 
I [a village midwife] received an award as a village midwife with zero maternal and neonatal mortality... this is due to the fact that the Head of Village supported me in terms of providing and helping me prepare the facilities that were needed (Nationally-contracted midwife $-L S C)$

These responses echo those of the 'success cases' respondents in regards to collaboration with the members of the community, such as the TBAs and the Heads of Villages. My findings also confirm such collaboration enables village midwives encountering problems in the community, for instance persuading pregnant women to have checks or to go to health facilities, or gaining gain the trust of women to allow them to help in the delivery of their babies.

\subsubsection{Direct Financial Incentives}

Even though financial incentives are not the defining factor in retaining midwives in remote areas, this factor is also found in the 'less success cases', in reference to salary and additional income from the government and other sources.

Usually, if the motivation to be the village midwives is only because of money, they will only survive in the village more or less three years... (DHO - LSC)

I stay in this village because I can earn more money here... there are many infrastructure works here [e.g. bridge construction, road, and well], so I have additional income because many workers seek healthcare services from me (Nationally-contracted midwife - LSC)

Motivation about staying in remote areas was influenced by the ability to generate income, yet my findings reveal that this type of motivation is less likely to retain midwives in remote postings. Money is not the most or only important factor. Maslow's hierarchy of needs suggests that other important components such as selfactualisation need to be considered. A combination of factors needs to be taken into account by decision-makers in order to reduce the turnover of midwives as well as improve midwives' performance. 


\subsubsection{More Experiences to Obtain Better Skills}

Interestingly, gaining more experience is one of the key factors that retains midwives in the 'less success cases', which was not the case for 'success cases'.

Knowledge is expensive I [a village midwife] have to say, to gain more experience. We [the village midwives] are expert in theory, but poor in practice, so it has to be balanced between the theory and the practice (Volunteer midwife - LSC)

The people are nice here and I gain a lot of experience by working in remote areas by myself. If I work in the city, there are a lot of colleagues and senior midwives that take care of the job, so the experience that I gained is not going to be as much as if I work here in the remote village. I handle everything by myself (Nationallycontracted midwife - LSC)

The important thing is that we [the village midwives] have to show our work first... the knowledge that we gained from school can be used, so it will not disappear (Volunteer midwife - LSC)

The results indicate that midwives require continuous practice in order to maintain and improve their skills. Having the opportunity for 'real' practice is essential to many midwives, thus they are willing to work and stay as village midwives. Many midwives believe that by working in villages, they will have more 'real' experience than by working in city hospitals or other health facilities. This is because when working in villages they have to singlehandedly perform the treatment.

\subsubsection{Religious Beliefs}

Similar to my findings in the 'success cases', religious doctrine influences midwives' motivation to take or remain in remote postings. Their beliefs provide comfort to village midwives facing difficult situations.

... Ikhlas in doing your job and we [midwives] have to be positive about what we are doing... (Civil servant midwife/PNS - LSC)

One of the reasons is ikhlas, ikhlas to do your job. Ikhlas to do anything, every job has ups and downs, the important thing is ikhlas to help others. I [a village midwife] believe it will get better. If we only chase the money, it will not last long because when you find a problem [e.g. difficult patients and difficult working areas] you will give it up easily (Volunteer midwife - LSC) 
This motivation has driven most midwives to accept the challenges of working in remote areas in a positive manner. The decision to stay in remote postings is influenced by this factor, but the extent to which this factor can be incorporated in a policy document is a challenge.

\subsubsection{Family Support: Parents and Husbands}

The support from family was mentioned by the research participants in the 'less success cases' but had not been an area of focus in the 'success cases'. Emotional and instrumental support are the two main categories of support that are provided.

\subsubsection{Emotional Support}

Husbands are the most likely to influence midwives' decisions to stay or not stay in their workplace, suggesting that acknowledgement of village midwives' husbands is essential.

They [the village midwives] want to be rotated to the new workplace only because they follow their husbands... (Puskesmas - LSC)

... my husband says that we can let the kids finish their primary school here and then move to their grandparents' hometown in West Java... I will stay in the village because my husband works here as well... I will visit my kids once every two years... (Nationallycontracted midwife - LSC)

... I am surrounded by my family and relatives, my mother comes from this village (Volunteer midwife - LSC)

The above findings reveal the importance of 'recruiting' the support of the immediate families of the midwives, such as husbands. Such 'recruitment' needs to be considered by the decision-makers. The local patriarchal culture, as well as a maledominated approach to Islamist teachings, are highly influential in NTB; females are more likely to follow or obey decisions made by males. Accordingly, participants from the 'less success cases' identified that village midwives often willingly moved to new workplaces in order to follow or be with their husbands.

Positive support from within village midwives' most intimate environments, such as from their immediate family members, helps keep them in their workplaces. 
My family, especially my parents, support me. They said just do your best work, no need to think about salary... the important thing is you can use your skill to help others, so it will not disappear (Volunteer midwife - LSC)

Positive support from within village midwives' closest environments, such as from their immediate family members, keeps them in their workplaces.

\subsubsection{Instrumental Aid Support}

Midwives' families, especially their parents, provide various forms of instrumental support, such as helping with daily expenditure and shelter. Managing family assets that lead to enhancing midwives' earning capacities is another form of instrumental aid support.

The factors that motivate midwives to stay in their workplaces are support from the community and additional income... they have assets in the village, so they stay in their workplaces (DHO - LSC)

My family support me by allowing me to take care of their assets (land for farming), so I have additional income from taking care of my family's assets (Volunteer midwife - LSC)

Instrumental aid support from family appears to be another resource for a village midwife to survive in remote areas. In Indonesia, this is a common practice whereby family involves supporting their children in kind, including financial support.

\subsection{Other Essential Factors}

As well as the dominant factors that were revealed from both the 'success cases' and the 'less success cases', there are other essential factors worth addressing. While these factors were not mentioned by many research participants they are very interesting in that they are very personal factors. These factors encompass the expectation of appreciation, prestige, powerlessness, and marriages to local people. 


\subsection{1 "Hopeful Attitude": Opportunity to Growth}

Retention is a function of job satisfaction which includes career opportunities or continued professional opportunities. Employee satisfaction has always been a crucial issue for health workers in remote areas. According to Herzberg (2003), motivation or employee satisfaction encompasses five aspects: the work itself; achievement; recognition; responsibility; and advancement. Growth opportunity fits with the idea of advancement and recognition in Herzberg's model of job satisfaction. Employees at all levels need to be acknowledged for their successes as well as receive reward for loyalty and performance with advancement.

The results from both cases show advancement for village midwives, PTT Pusat and volunteer midwives was not well understood. The participants suggested that only midwives with PNS status have the opportunity to receive salary increases and promotions. These opportunities do not apply equally for contract based midwives or, especially, for volunteer midwives. PTT Pusat are expected to establish themselves in private practice.

I think the opportunity to be a civil servant or others is higher rather than to stay at home [not working] (DHO - LSC)

To be deployed in remote or very remote areas, they [the village midwives] hope to be promoted to a higher position, such as PTT Pusat. Who knows that they can be prioritised by the government? (Puskesmas - SC)

I heard after the contract is extended twice, we [the village midwives] are going to be promoted to become civil servant midwives (Nationally-contracted midwife - SC)

I am not sure, but I heard after a few years working in remote areas the village midwives will be promoted to become civil servant midwives (Volunteer midwife - SC)

Even though there is limited opportunity for the village midwives to grow, many of them stay and have faith that one day they will be promoted. This hope is probably triggered by previous experience where many older generation midwives were promoted to $P N S$ after a few years of serving in remote or very remote areas. In 1990, the new graduates automatically became PNS after three years of deployment in remote areas (Rokx et al., 2010). 
Promotional and continued professional opportunities to a higher level are expected by all participants. The expectation of promotion to PNS were mentioned most by my research participants. A possible explanation regarding midwives' expectation here is that such promotion guarantees job security and a career path. The heads of Puskesmas have limitations in managing their workforces, while DHOs seem to play more of a role in controlling the health workforce, such as PTT midwives.

This is a really interesting finding because one of the reasons midwives stay in remote areas is due to 'rumours'. Midwives keep their faith and hope that one day they will be promoted and develop their career. Transparency in the selection system was often criticised by the research participants. Village midwives in remote areas mostly depend on their superiors, who are located in Puskesmas, or friends to provide important promotional information. This practice has the potential for delaying information which was interpreted as a lack of transparency by some of the research participants. Understanding the geographical as well as the nature of health workers who work in remote areas is essential. Using high technology or internet-based methods to disseminate information is often impractical due to limited facilities.

Even though I did not find concrete evidence of nepotism, this was an issue being cited by the participants. Midwives' frustration cannot be neglected if they are to remain in their workplaces. Unclear regulations about promotions or the improvement of careers for the midwives might be the basis of the problem that needs to be solved.

\subsubsection{Prestige and Powerless}

In my research context, prestige is related to self-actualisation and being recognised by others. Prestige was mentioned by the research participants as one of the factors that attracted and retained midwives in remote villages and is a factor which has not been mentioned in other studies.

Being midwives is something that they [the village midwives] are proud of (Civil servant midwife/PNS - SC)

Self-actualisation is important because they [midwives] graduated from midwifery school, so they want to work as a midwife. They feel embarrassed if they have no job. Their parents also feel embarrassed if their daughters have no job after graduating, thus it is better for them to work in the village even though they have not been paid $(\mathrm{DHO}-\mathrm{SC})$ 
... wearing a midwife's uniform is prestige... (DHO - SC)

They [the village midwives] feel proud because of their uniform. It is interesting that uniform have a huge effect on their confidence (DHO $-S C)$

Wearing a uniform has a huge impact on midwives' motivation to take remote postings. They are willing to work with limited salaries and in isolated areas as long as they can wear the uniform. This value might not be found in Western society as much as it is in Asian countries. It is very symbolic, and yet powerful and tangible in that it keeps midwives in remote postings. It seems that wearing a uniform is a symbol of success, and has an effect on midwives and their families.

In addition, staying in remote areas is also triggered by feelings of powerless whereby midwives have limited or no options in their job. Ironically, a village midwife considers herself 'a lucky person' because she has a job even though she might not earn much money from her services.

I think they [the village midwives] stay in remote areas because the numbers of midwives are a lot in both urban and rural areas. So, rather than having no job, it is better to work with no or limited salary $(\mathrm{DHO}-\mathrm{LSC})$

I have no choice... my husband and my family support me... (Nationally-contracted midwife - SC)

Well, rather this than I don't have a job... (Volunteer midwife - SC)

Perhaps, there is no opportunity to work in other places, and rather than them [the village midwives] having no job, it is better for them to work. So, they can maintain their skills (Civil servant midwife/PNS $S C)$

Given the oversupply of midwives in many areas, many are willing to work under any circumstance. Moreover, many midwives decided to stay in remote areas despite the challenges because of their need to make their family proud. In Indonesia, parents tend to have an expectation that their children will work after graduating from their study. Thus, with the motivation to maintain family, particularly parental, pride, the village midwives stay in remote areas with limited income and facilities. 


\subsubsection{Marriage to Local People}

Marriage to local people is another factor that keeps midwives in remote areas. Initially, they have no intention of staying in their workplaces, yet many change their minds after they marry a local man. Midwives tend to move to other places or stay in their working areas because of their husbands.

... because they get married with the local man (DHO - LSC)

Another reason, I stay in this village because I found my husband here... my parents say to me 'don't get married with local man', instead I married to a local man... (Regionally-contracted midwife/PTT Daerah - LSC)

Because I married the local guy, I moved to stay here (Volunteer midwife - SC)

A strong reason that keeps them is that they [the village midwives] found their husbands there [in the remote villages] (Civil servant midwife/PNS - SC)

... our midwife from another island [Java Island] married a local man, so she is considered a local now (DHO - SC)

This finding is consistent with House, Umberson and Ladis (1988) who point out that macrosocial changes have a great impact on the structure and process of social relationships. They suggest that marital status is an example of the social integration of individuals in their community which has positive effects on individuals' health and wellbeing. My findings show that midwives feel more comfortable in their workplaces when they are married to a local man. Midwives are considered to be 'local' by the community when they marry a local man and gain more trust from the community, which in turn, greatly affects their decisions and motivation towards remote postings. 


\subsection{Conclusion}

The evidence shows key factors in the 'success cases' and the 'less success cases' that keep midwives in remote postings. Two key factors are found in both cases, namely community support and direct financial incentives. My findings suggest that social factors (which in my context are support from community - neighbours, TBAs, cadres, and the Heads of Villages) have tremendous impact on retaining midwives in remote areas. This is in agreement with the previous studies from Heady et al. (2006), Stretton and Bolon (2009) and Frehywot et al. (2010). They each point out that health workers are more likely to stay in their workplaces because they have complete support from the community in various ways, including emotional and instrumental aid support. My study specifically highlights community acceptance which has a significant influence on midwives' motivation for staying in their workplaces. Community acceptance indicates that 'trust' has been obtained by the midwives which makes them feel welcome and comfortable in providing their services.

The importance of collaboration with the community members is also important. This is consistent with Frehywot et al.'s (2010) study on recruiting health workers in remote and rural areas. They suggest that community leaders helped the health workers to settle in their workplaces. I found that wider collaboration with community members such as TBAs and cadres is essential because the TBAs and cadres have the ability to convince and reach out to the wider community, particularly in remote areas where road and communication facilities are very limited. Support from these community members could be a solution to midwives' difficulties in reaching out to the wider community.

It is clear that direct financial incentives become one of the key factors that retain midwives in remote areas as this factor was found in both cases. This finding raises a concern as there is a significant income gap among midwives. PNS and PTT Pusat receive a high monthly income compared to PTT Daerah and volunteer midwives. However, like other studies, my findings show that financial incentives attract and retain midwives in remote villages, but this is not the only factor to be considered by midwives. 
Despite community support and direct financial incentives, three other key factors, namely local hiring, dedication to the profession, and religious beliefs were found only in the 'success cases'. The DHOs and Puskesmas have a significant role in regulating as well as implementing policies or strategies in order to recruit and retain midwives in remote areas. In order to reduce the financial burden on DHOs and Puskesmas, they hire local midwives. In addition, hiring local midwives reduces the turnover of the village midwives in remote areas because they are less likely to suffer culture shock.

Dedication to the profession was another interesting factor which keep midwives from moving to new places. There were no studies of health worker motivation that found this. Their motivation to stay in remote areas was driven by intrinsic factors, in this case deriving pleasure from being a village midwife. According to Hollyforde and Whiddett (2002), intrinsic motivation is crucial to keeping workers in their duty longer than extrinsic motivation alone. This evidence could compel policymakers to provide a strategy or approach in order to trigger midwives' intrinsic motivation.

Moreover, social factors such as belief systems play an important role in retaining midwives in remote areas. Islam is the predominant religion in $N T B$, influencing the life of the people. The intensive indoctrination of Islamic values has shaped individuals' perception and decision-making. According to Maehr and Braskamp (1986, p. 9) external factors, namely task designs, social norms, payoffs and options have an influence on personal investment; in this case, choice, persistence, continuing motivation, passion and performance. These external factors are mediated through thoughts and emotions (thinking processes) which lead to actions.

My study raises an interesting fact in that the particulars of religious indoctrination in NTB (i.e. be thankful, patient, loyal and dedicated), introduced since childhood, is a strong influence on the work ethos of the village midwives. These values have been strongly embedded in the village midwives, thus, the motivation or decision to work in remote areas is greatly influenced by these values. 
According to Ghauri (2011), the deeper the spiritual level of a person, the bigger the force and energy that may improve one's resilience. My study suggests that the strength of midwives' belief systems enables them to carry out their work. There is also another possible explanation regarding the meaning of the words ikhlas, tawakal and bersyukur which involves a mixture of cultures and religions.

Interestingly, these three words, often expressed by the participants in my study, and in particular ikhlas, may carry ambiguous meanings. For example, ikhlas could connote 'no expectation of reward', or 'surrender', 'let go', thus compelling the faithful to surrender their problems to Allah. There is no doubt that midwives' perseverance is influenced by their beliefs and hence, the internal factors of religious or cultural motivation influence midwives to stay in their workplace.

Ghauri (2011) believes that religious motivation is an essential energy for every human being in order to drive actions beyond material motivation. He argues that material motivation cannot sustain the pressure of a harsh environment. The above findings indicate that religious motivation (being Muslim) is an actual stimulus or force for midwives that keeps driving them, even in the worst of situations. This type of motivation is classified as intrinsic motivation; thereby belief systems play a significant role in initiating long-lasting effects on individuals' motivational levels, beyond the tangible aspects.

In regard to the 'less success cases', there were two different key factors from the 'success cases', namely family support and obtaining more experience. Family support is seen as an important factor to retain midwives in remote areas based on the research participants in the 'less success cases'. Family provides comfort and support to the village midwives. In Indonesia, particularly NTB which has a patriarchal system, a husband's permission is an essential element for midwives to work and stay in remote areas.

An additional key factor that retains midwives in remote areas from the 'less success cases' is obtaining more experience. No studies could be located to support this finding as this is probably influenced by the particular characteristics of midwives' tasks which require regular practice to be maintained and improved. 
It is also interesting that many personal factors have influenced midwives' motivation to take and remain in remote postings. The results suggest some interesting factors such as 'hopeful attitude', 'prestige', and 'powerlessness' that need to be addressed in order to retain midwives. Some participants reveal that being a midwife is believed to be a prestigious job because it earns a lot of respect from others, particularly the people in the community. This is probably because of the nature of midwifery, providing and assisting with basic healthcare for mothers and the whole community in general.

Yet these factors, 'prestige' and 'obtaining more experience', often undermine midwives' burgeoning positions in the organisational sphere. Midwives, particularly volunteer midwives, have limited or no options in regards to their salary and career development. No research could be located that address these factors. There are two potential reasons why these factors appear in the current study: first, the oversupply of midwives in almost every district in $N T B$; and second, the local culture which values success by working in the public sector. 'The uniform effect' is also found to be an interesting factor that motivates midwives to work and stay in remote areas. The community, particularly in remote areas, perceive people wearing uniforms as successful and this commands respect.

To conclude, the evidence above suggests that midwives stay in remote areas for a variety of factors. Social and personal factors play an important role in retaining midwives in remote areas. This might suggest that personal factors are influenced by social factors, and, if so, this should be considered in crafting the retention strategies or policies. This would target both the retention and recruitment of midwives in Indonesia, particularly in remote areas of NTB. Intentional and unintentional macro social changes have powerful effects on the structures and processes of social interaction (Frehywot et al., 2010; House, Umberson, \& Landis, 1988; Stretton \& Bolon, 2009). However, current policies largely focus on short-term solutions which involve monetary incentives.

The next chapter will discuss in more detail how policies or programmes in Indonesia respond to and facilitate these key factors in attracting and retaining midwives in remote areas of Indonesia. 


\section{CHAPTER 7. POLICIES/PROGRAMMES VS REALITY}

\subsection{Introduction}

The Government of Indonesia has introduced various policies or strategies in order to improve accessibility to health workers, including midwives, in remote areas of Indonesia. The majority of the policies or strategies are intended to improve the provision of midwives or to reduce the maldistribution of health workers, particularly midwives between remote and urban areas. In this chapter, policies and programmes from the national and local governments relevant to the recruitment and retention of midwives in remote areas of Indonesia are canvassed, as part of data triangulation.

The chapter starts by analysing the relevant policy documents and strategies of the national government, and then analyses the relevant policy documents and strategies from the local government where the 'success cases' and the 'less success cases' are located. Finally, a summary of the key factors that are inherent in the recruitment and retention policies or strategies are compared with the key factors that emerged from the interviews.

\subsection{National Government Policies and Strategies}

Based on Act number 12 year 2011, the People's Consultative Assembly of Indonesia (Majelis Permusyawaratan Rakyat or MPR) clarified the official hierarchy of legislation as follows:

1. Undang-Undang Dasar 1945 (1945 Constitution)

2. Ketetapan MPR (MPR Resolution)

3. Undang-Undang (Act) or Peraturan Pemerintah Pengganti Undang-Undang

(Government Regulation Substituting an Act)

4. Peraturan Pemerintah (Government Regulation)

5. Keputusan Presiden (Presidential Decree)

6. Peraturan Daerah Provinsi (Regional Province Regulation)

7. Peraturan Daerah Kabupaten/Kota (Regional Regulation) 
In line with this hierarchy, I focused on several main documents from the national and regional governments to answer the question 'To what extent do the policies and programmes of the GoI respond to and facilitate factors that influence the recruitment and retention of midwives in remote areas of Indonesia?'

I also examined the main documents and strategies from the national government that I collected from secondary and primary resources, such as interviews with midwives and government officials, in order to understand the current situation and implementation of the policies.

Kurniati and Efendi (2012) identified around 23 policy documents which related to improving access to human resources for health in remote areas of Indonesia. In my study only documents and strategies related to the recruitment and retention of midwives to remote postings were analysed, starting from the 1945 Constitution as the foundation of Indonesian regulations.

The 1945 Constitution article 28H paragraph one (1) (Republik Indonesia, 1945) states

'Setiap orang berhak hidup sejahtera lahir dan batin, bertempat tinggal, dan mendapatkan lingkungan hidup baik dan sehat serta berhak memperoleh pelayanan kesehatan'or

'Everyone has the right to live in physical and spiritual prosperity, to reside in, and obtain, a good and healthy environment as well as the right to health services'

This is followed by article 34 paragraph three (3) (Republik Indonesia, 1945) that states

'Negara bertanggung jawab atas penyediaan fasilitas pelayanan kesehatan dan fasilitas pelayanan umum yang layak'or

'The State is responsible for the provision of healthcare facilities and public service facilities where feasible'. 
In line with the 1945 Constitution, the notion of providing equal healthcare facilities and professionals to all Indonesian citizens is accounted for in Act number 36 year 2009, particularly in chapter five (V), section one (I), article 21 to 29 which focuses on human resources for health (Republik Indonesia, 2009). Article 16 (Act number 36 year 2009) clearly stipulates that the GoI has a responsibility to provide equal health workers in every area in Indonesia to improve the health status of its citizens. In the same Act, chapter five (V), section one (I), article 21 Act number 36 year 2009, the stipulation regarding planning, provision, utilisation, capacity development, and supervision is covered by government regulations. These regulations clearly point out the rights to access adequate health facilities as wells as professionals throughout the archipelago, in order that better health outcomes can be obtained. As a result the $\mathrm{MoH}$ has introduced several government regulations related to the provision of health workers, including the provision of midwives.

1. President Decree No. 23 year 1994 regarding Recruitment of Non-Permanent Midwives;

2. President Decree No. 77 year 2000 regarding the Amendment of President Decree No. 23 year 1994 regarding Recruitment of Non-Permanent Midwives;

3. Ministry of Health Decree No. 508/MENKES/SK/SK/IV/2007 regarding Determination of the Length of Service and incentives for Non-Permanent Medical Staff and Midwives in Health Facilities;

4. Ministry of Health Regulation No. 1231/MENKES/PER/XI/2007 regarding Special Assignment of Health Workers;

5. Ministry of Health Decree No. 1235/MENKES/SK/XII/2007 regarding Provision of Incentives for Health Workers who Undertake Special Assignments;

6. Ministry of Health Regulation No. 1199/MENKES/PER/X/2004 regarding Guidelines for the Recruitment of Health Workers on a Contract Basis in Public Health Facilities;

7. Ministry of Health Regulation No. 23 year 2015 regarding Special Assignment of Team Based Health Workers to Support Nusantara Sehat Programme. 
Other strategies or programmes were also analysed because they too influence the recruitment and retention of midwives in remote areas of Indonesia. These strategies or programmes include:

1. Dual practice

2. 'A Village Midwives Programme' or Bidan di Desa $(B D D)$

Table 11 provides a summary of policies or programmes from the national government, their focus, and the benefits mandated. 
Table 11: Summary of National Government Policies

\begin{tabular}{|c|c|c|c|c|c|}
\hline \multirow[t]{2}{*}{ Year } & \multirow[t]{2}{*}{ Policies } & \multirow[t]{2}{*}{ Focus } & \multicolumn{2}{|c|}{ Benefits } & \multirow[t]{2}{*}{ Notes } \\
\hline & & & Financial & Non-Financial & \\
\hline $\begin{array}{l}\text { President Decree No. } \\
23 \text { year } 1994\end{array}$ & $\begin{array}{l}\text { Recruitment of } \\
\text { Non-Permanent } \\
\text { Midwives }\end{array}$ & Midwives & $\begin{array}{l}\text { Fixed monthly } \\
\text { income } \\
\text { Other financial } \\
\text { incentives, such as } \\
\text { relocation allowance, } \\
\text { insurance }\end{array}$ & $\begin{array}{l}\text { Article seven - } \\
\text { Extension possibility } \\
\text { for at least three } \\
\text { years (recently } \\
\text { amended in 2016) } \\
\text { Career opportunities } \\
\text { - Civil Servants or } \\
\text { Private Practice }\end{array}$ & $\begin{array}{l}\text { Contracted based } \\
\text { status (PTT } \\
\text { Midwives) }\end{array}$ \\
\hline $\begin{array}{l}\text { President Decree No. } \\
77 \text { year } 2000 \\
\text { (Amendment of President } \\
\text { Decree No. 23 year 1994) } \\
\text { further explanation is in } \\
\text { Ministry of Health Circular } \\
\text { Letter } \\
\text { (KP.01.02/Menkes/69/2016) }\end{array}$ & $\begin{array}{l}\text { Recruitment of } \\
\text { Non-Permanent } \\
\text { Midwives }\end{array}$ & Midwives & $\begin{array}{l}\text { Fixed monthly } \\
\text { income } \\
\text { Other financial } \\
\text { incentives, such as } \\
\text { relocation allowance, } \\
\text { insurance }\end{array}$ & $\begin{array}{l}\text { Article seven - } \\
\text { Extension possibility } \\
\text { for two times where } \\
\text { each extension is } \\
\text { three years } \\
\text { Career opportunities } \\
\text { - Civil Servants or } \\
\text { Private Practice }\end{array}$ & $\begin{array}{l}\text { Contracted based } \\
\text { status (PTT } \\
\text { Midwives) }\end{array}$ \\
\hline
\end{tabular}




\begin{tabular}{|c|c|c|c|c|c|}
\hline 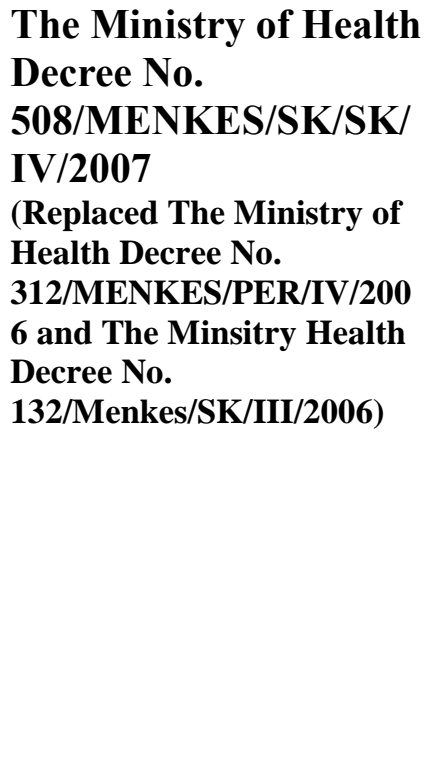 & $\begin{array}{l}\text { Determination of } \\
\text { the Length of } \\
\text { Service and } \\
\text { incentives for Non- } \\
\text { Permanent } \\
\text { Medical Staff and } \\
\text { Midwives in Health } \\
\text { Facilities }\end{array}$ & $\begin{array}{l}\text { Doctors } \\
\text { Dentists } \\
\text { Midwives } \\
\text { Nurses }\end{array}$ & $\begin{array}{l}\text { Regulates financial } \\
\text { incentives which } \\
\text { depend on each type } \\
\text { of health worker. } \\
\text { Specialist - IDR } \\
7,500,000 \text { (around } \\
\text { USD 523); } \\
\text { doctors/dentists- IDR } \\
\text { 5,000,000 (around } \\
\text { USD } 373 \text { ); Midwives } \\
\text { in remote areas and } \\
\text { work in very remote } \\
\text { public health } \\
\text { facilities IDR } \\
\text { 2,500,000 (around } \\
\text { USD 186) }\end{array}$ & $\begin{array}{l}\text { Midwives three years } \\
\text { contract with } \\
\text { extension possibility }\end{array}$ & $\begin{array}{l}\text { The amount } \\
\text { received by the } \\
\text { midwives is the } \\
\text { lowest among other } \\
\text { health workers } \\
\text { (doctors get double } \\
\text { the amount and } \\
\text { specialists triple the } \\
\text { amount) }\end{array}$ \\
\hline $\begin{array}{l}\text { The Ministry of Health } \\
\text { Decree No. } \\
\text { 1231/MENKES/PER/ } \\
\text { XI/2007 }\end{array}$ & $\begin{array}{l}\text { Special Assignment } \\
\text { of Health Workers }\end{array}$ & $\begin{array}{l}\text { Doctors } \\
\text { Dentists } \\
\text { Midwives } \\
\text { Nurses }\end{array}$ & $\begin{array}{l}\text { Focus on financial } \\
\text { incentives such as } \\
\text { return ticket, meals } \\
\text { allowance, and } \\
\text { additional financial } \\
\text { incentives, from the } \\
\text { local government } \\
\text { based on the local } \\
\text { government financial } \\
\text { allocation budget }\end{array}$ & $\begin{array}{l}\text { The minimum length } \\
\text { of contract is three } \\
\text { months with possible } \\
\text { extension }\end{array}$ & $\begin{array}{l}\text { The required } \\
\text { qualifications and } \\
\text { quota of health } \\
\text { workers are } \\
\text { determined by the } \\
\text { national } \\
\text { government, } \\
\text { acknowledging the } \\
\text { local government }\end{array}$ \\
\hline
\end{tabular}




\begin{tabular}{|c|c|c|c|c|c|}
\hline $\begin{array}{l}\text { The Ministry of Health } \\
\text { Decree No. } 1235 \text { of } \\
2007\end{array}$ & $\begin{array}{l}\text { Provision of } \\
\text { Incentives for } \\
\text { Health Workers } \\
\text { who Undertake } \\
\text { Special } \\
\text { Assignments }\end{array}$ & $\begin{array}{l}\text { Doctors } \\
\text { Dentists } \\
\text { Midwives } \\
\text { Nurses }\end{array}$ & $\begin{array}{l}\text { Regulates financial } \\
\text { incentives with } \\
\text { depend on each type } \\
\text { of health worker. } \\
\text { Specialist - IDR } \\
\text { 7,500,000 (around } \\
\text { USD 523); } \\
\text { doctors/dentists- IDR } \\
\text { 5,000,000 (around } \\
\text { USD 373); Midwives } \\
\text { with diploma IDR } \\
\text { 2,500,000 (around } \\
\text { USD 186) } \\
\text { The payment is paid } \\
\text { every month }\end{array}$ & $\begin{array}{l}\text { Contract based status } \\
\text { (three months up to } \\
\text { one year) } \\
\text { Extension Possiblility }\end{array}$ & $\begin{array}{l}\text { To support PTT } \\
\text { programme } \\
\text { The amount } \\
\text { received by the } \\
\text { midwives is the } \\
\text { lowest among other } \\
\text { health workers } \\
\text { (doctors get double } \\
\text { the amount and } \\
\text { specialists triple the } \\
\text { amount) }\end{array}$ \\
\hline $\begin{array}{l}\text { The Ministry of Health } \\
\text { Decree No. } \\
\text { 1199/MENKES/PER/X } \\
\text { /2004 }\end{array}$ & $\begin{array}{l}\text { Guidance in the } \\
\text { provision of health } \\
\text { workers in public } \\
\text { health facilities }\end{array}$ & $\begin{array}{l}\text { Doctors } \\
\text { Dentists } \\
\text { Midwives } \\
\text { Nurses } \\
\text { Other health } \\
\text { workers }\end{array}$ & $\begin{array}{l}\text { Financial incentives } \\
\text { encompass monthly } \\
\text { salary and allowances } \\
\text { The amount is varied } \\
\text { based on the health } \\
\text { workers' degree }\end{array}$ & $\begin{array}{l}\text { Non-financial } \\
\text { incentives encompass } \\
\text { annual leave, } \\
\text { acknowledgement of } \\
\text { work experience and } \\
\text { training }\end{array}$ & $\begin{array}{l}\text { The health workers } \\
\text { are not categorised } \\
\text { as civil servants or } \\
\text { PTT } \\
\text { This regulation } \\
\text { allows local } \\
\text { government to } \\
\text { recruit health } \\
\text { workers based on } \\
\text { their needs }\end{array}$ \\
\hline
\end{tabular}




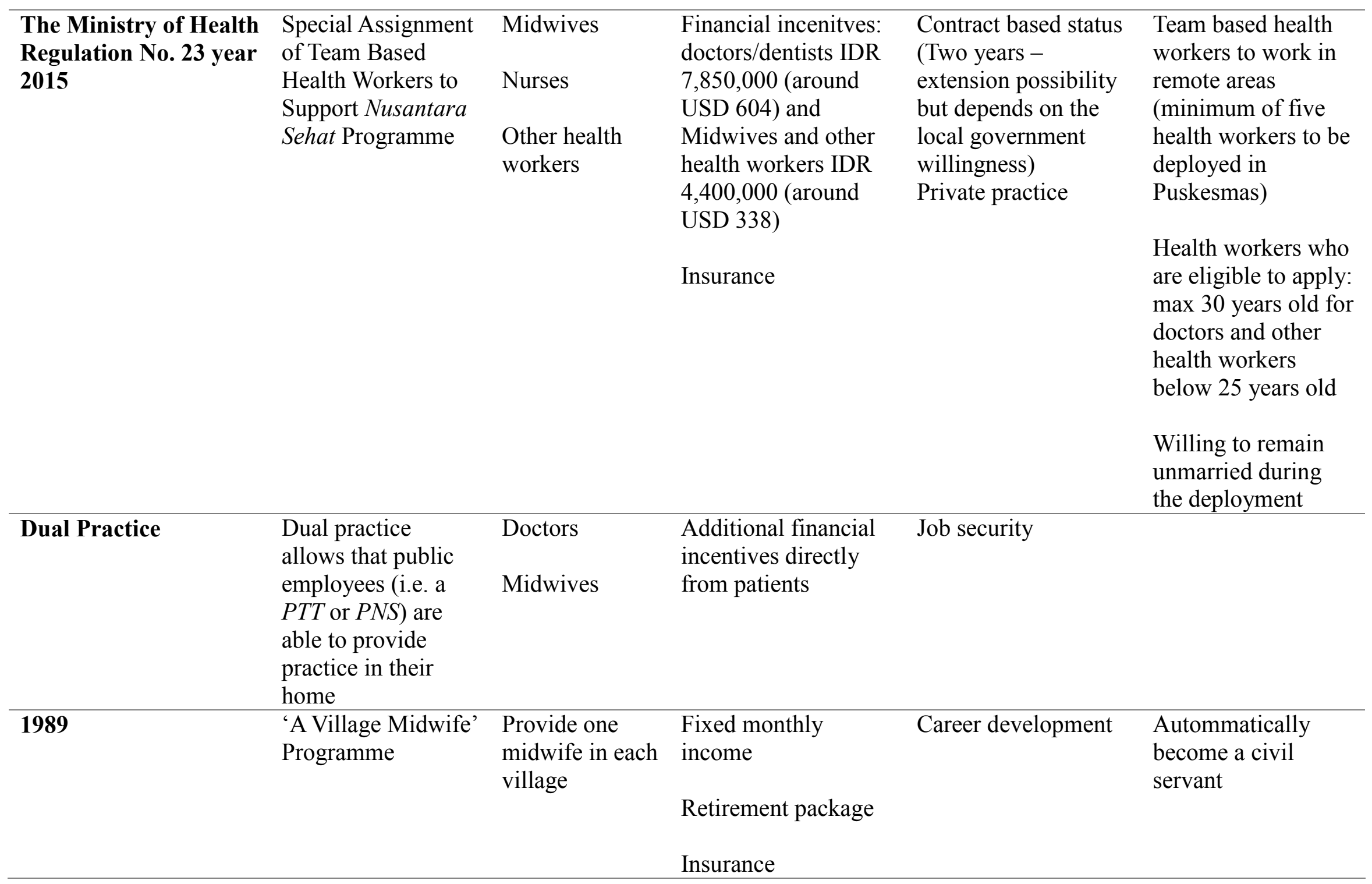


Table 11 shows that the GoI has introduced various policies to improve the provision of health workers, particularly midwives in remote areas of Indonesia. The following section will discuss in more detail the national government's policies or strategies that have had a significant impact on improving the deployment of midwives in remote areas.

\subsubsection{Nationally Contracted Health Workers}

The GoI introduced a Compulsory Service policy for nationally-contracted health workers, particularly for doctors and dentists. When this programme was introduced, however, midwives were hired under $B D D$ and so the programme does not apply to midwives. In the next section, the Compulsory Service programme is discussed briefly in order to provide some of the history of policy changes in Indonesia.

Compulsory service was introduced for those studying to become physicians and dentists, requiring them to serve at least three years in public facilities under the Law No. 8 of 1961 (Efendi, 2012). Hoping to meet the goal of achieving adequate coverage of the health personnel throughout the archipelago, new medical graduates, namely physicians and dentists, automatically became civil servants and, after graduation, were obliged to serve in government health facilities (i.e. Puskesmas), private health services, or the military for three to five years, as defined in the Government Regulation No. 1 of 1988 (Efendi, 2012; Rokx et al., 2010). Another GoI regulation, the President Instructions No. 5 of 1974, was drafted to support the deployment of the health workers'compulsory employment as government servants.

Due to a limited budget, and in consideration of health workers' freedom of choice, the GoI launched President Decree No. 37 of 1991, which mandated the implementation of the PTT Pusat scheme for doctors and dentists (Efendi, 2012). The changing of the policy also impacted on the 'A Village Midwife Programme'. For midwives, the initial PTT Pusat scheme was launched under President Decree No. 23 year 1994. A village midwife who was recruited under $B D D$ was no longer automatically PNS staff; instead, she was categorised as PTT Pusat staff. 
Under the PTT Pusat regulation, health workers, including physicians, dentists, and midwives, are assigned by the GoI for a minimum of six months and up to three years. The salary is paid according to geographical difficulties. The more difficult an area for a health worker to access, the higher the incentives offered to work there (Table 12). In addition, physicians benefit from this scheme as it gives them options to improve their careers; such options include pursuing higher education, going to the private sector, or receiving priority to become a civil servant by taking national examinations. The opportunities are slightly different for midwives. After PTT Pusat, midwives are expected to establish themselves in private practice or they can apply to be a civil servant by taking the national examination.

Table 12: Monthly Salary and Incentives for Pegawai Tidak Tetap

\begin{tabular}{lllllll}
\hline \multicolumn{1}{c}{ Profession } & \multicolumn{2}{c}{ Salary } & \multicolumn{2}{c}{ Incentive* } \\
\hline & Common & Remote & $\begin{array}{l}\text { Very } \\
\text { Remote }\end{array}$ & Common & Remote & $\begin{array}{l}\text { Very } \\
\text { Remote }\end{array}$ \\
\hline Doctor/dentist & $2,050,000$ & $2,050,000$ & $2,050,000$ & - & $3,350,000$ & $5,800,000$ \\
& (around & (around & (around & & (around & (around \\
& USD 157) & USD 157) & USD 157) & & USD 257) & USD 446) \\
\hline Specialist & $2,050,000$ & $2,050,000$ & $2,050,000$ & - & $7,850,000$ & $8,300,000$ \\
& (around & (around & (around & & (around & (around \\
& USD 157) & USD 157) & USD 157) & & USD 603) & USD 638) \\
\hline Midwife & $1,700,000$ & $1,700,000$ & $1,700,000$ & - & $1,700,000$ & $2,700,000$ \\
& (around & (around & (around & & (around & (around \\
& USD 130) & USD 130) & USD 130) & & USD 130) & USD 207) \\
\hline
\end{tabular}

Adaptation form Efendi (2012)

The new policy was moderated by adding more benefits to attract health workers to work and stay in remote areas (Kurniati, 2007). A retrospective national data study implemented by Peña et al. (2010) shows that a combination of incentives (financial and non-financial) is able to attract doctors to work in rural areas. However, a clear pattern for how this combination works for midwives has not emerged, as studies have focused only on how these incentives attract doctors to such areas. A robust knowledge base of programme outcomes and evidence of what motivates health professionals, in particular midwives, is needed. 
Table 11 and Table 12 also show that midwives receive the lowest salary for health professionals, even though midwives are 'the spearhead' of the health workers in the community. For instance, a village midwife who is deployed in a very remote area receives salary plus incentives of around IDR 4,400,000 per month (around USD 338), compared with the almost IDR 8,000,000 per month (around USD 615) paid to a doctor or dentist. However, since the introduction of national social security in 2014 , a village midwife is also entitled to additional benefits from capitation as well as reimbursement for their services, namely assisting pregnant women during delivery and providing ANC.

Although the village midwives receive a lower income than doctors, the amount is likely to be sufficient, particularly for living in remote or very remote areas. Workers living in remote areas tend to have higher purchasing power than those in urban areas. Income in those areas is more likely to have greater purchasing power than the corresponding income for those living in urban areas, due to the lower living cost in more remote regions. However, isolation from friends and family should be considered as contributing factors which discourage some from taking remote postings.

Aiming to attract midwives to remote areas and retain them, the PTT Pusat scheme has offered conditional job certainty by providing a reasonable length of work commitment (i.e. six months up to three years and a possibility of two time extensions). The President Decree No. 77 year 2000 (an amendment of the previous President Decree No. 23 year 1994, regarding the Recruitment of Non-Permanent Midwives) states that the length of service for PTT Pusat be extended twice after their first contract is finished. Each extension is three years of service; in total a midwife can work in their workplaces for up to nine years.

Hence, the PTT Pusat policy has provided the option of job security, even though it has not fully guaranteed being permanent staff or a civil servant. The WHO (2010a) and Rockers et al. (2012) point out that the length of the work commitment influences the recruitment and retention of health workers in remote areas. My findings show that one of the key factors that attracts midwives to remote areas is the possibility of job security, which means that midwives have the opportunity to work in an area on the basis of a long-term contract. 
An additional variable, but not clearly defined in the PTT Pusat policy, concerns the prospect of village midwives to open private practices after their contracts finish. Article 11 paragraph two of the President Decree No. 23 year 1994 regarding the Recruitment of Non-Permanent Midwives only points out that midwives who want to open a private practice are required to hold a certificate based on the regulations. The GoI, together with $I B I$, need to assist midwives who are interested in pursuing private practice. This might be an effective approach in retaining the village midwives in their workplaces as it is expected that by the time they have finished the contract, they would have enough experience, strong networks, and more confidence in providing services. In reality, most midwives live in the government facilities, or Polindes.

This situation might create some difficulties for village midwives wanting to open a private practice. In order to do so, a village midwife has to have at least their own place and provide standardised birthing equipment. These challenges need to be considered and addressed by the policy makers or $I B I$, enabling more village midwives to pursue this alternative.

The PTT policy attracted many health workers to work in remote areas, even though the guarantee of becoming PNS was no longer offered by the GoI. In 2010, there were 3,020 doctors, 904 dentists, 86 specialists, and 28,968 midwives that served under the PTT Pusat policy (Sediyanigsih, 2011 cited in Efendi 2012). Efendi (2012) found that health centres without doctors decreased from 30\% of 8,000 health centres in 2006 to $17 \%$ of the 9,000 very remote health centres in 2010 . The policy has improved the availability of health workers in both health centres and villages, and has had a considerable impact on overcoming health worker shortages. However, with such short contracts, sustainability and retention issues have not been solved through the policy's implementation. 


\subsubsection{Special Assignments}

The Special Assignment scheme was introduced in 2007. It aimed to counter the continuing health worker shortages in remote and very remote areas of Indonesia with the deployment of 300 health workers to work in health centres (Efendi, 2012). This policy was an addition to the PTT Pusat scheme and included nurses, sanitarians, nutritionists, and other health workers. The MoH Decree No.1231 of 2007 regarding the Special Assignment of Health Workers points out that work under the Special Assignment scheme takes place for at least three months and up to one year, renewable (Ministry of Health, 2007b). Under this regulation, the type of qualifications and allocation of health workers are determined by the national government with regard for local government requests. This situation shows the dependency of the local government when it comes to the provision of health workers, particularly midwives at the local level. The distribution of power is still dominated by the national government.

In addition to this regulation, the $\mathrm{MoH}$ introduced another MoH Regulation No. 1235 year 2007 regarding Provision of Incentives for Health Workers who Undertake Special Assignments. In this regulation, incentives are varied, based on the difficulties of the workplace and the profession - specialists receive IDR 7,500,000 (around USD 523), doctors/dentists receive IDR 5,000,000 (around USD 373), and midwives receive IDR 2,500,000 (around USD 186).

In principle, the Special Assignment policy takes a similar approach to the PTT Pusat scheme in terms of the payment system, but the length of work commitment is shorter. The financial incentives also appear to be the main focus of this policy. Nevertheless, this scheme has boosted the number of health workers working in undesirable locations, such as remote and very remote areas. In 2010, the GoI recruited 15 doctors, 56 midwives, 210 nurses, and 120 other health workers (Sediyanigsih, 2011 cited in Efendi 2012) under this scheme. 


\subsubsection{Nusatara Sehat (Healthy Indonesia Programme)}

The latest programme that the national government introduced is the Nusantara Sehat (Healthy Indonesia) in 2012. According to the MoH Regulation No. 23 year 2015 (Ministry of Health, 2015), this programme takes a team-based approach, deploying five to nine health workers (i.e. doctors, dentists, nurses, midwives, public health staff, and others) to isolated areas. The programme aims to improve health services in the Puskesmas, concentrating on the isolated, border, and outer island regions, and areas categorised as those with health problems. These health workers are deployed for two years. The GoI believes that by sending a team of health workers it is more likely to retain them in remote areas (Ministry of Health, 2015).

Every health worker is allowed to apply for these positions, provided they meet the requirements: (i) doctors and dentists have to be under 30 years of age; (ii) other health workers have to be under 25 years of age; (iii) they must remain unmarried during their deployment; (iv) they must hold a practice licence; and (v) they must be willing to be deployed in any area in Indonesia Although these positions are open to midwives from all over Indonesia, I argue that the requirements, as currently set, do not reflect my findings which suggest that hiring locally is more favourable in terms of retaining midwives in remote areas. Local midwives have more knowledge of what is culturally relevant to the community. In addition, limitations based on midwives' age and marital status during deployment are two aspects that infringe human rights.

Even though this programme is relatively new, it has been recruiting high numbers of health workers; for instance, from 2012 to 2015, 694 health workers were recruited. These health workers were deployed mainly in Papua, Maluku, the North Sumatera, and West Kalimantan (BPDPSK, 2016). This is a very ambitious programme from the national government aiming to create more job opportunities for health workers. It can tackle the high supply problem of midwives or other health worker, in some areas of Indonesia, because it is open to every health worker across Indonesia. In addition, this programme is able to reduce the maldistribution of health workers between urban and remote areas. 
However, another aspect to consider is the ongoing career of the health worker after their two year contract is finished. The national and local governments need to collaborate about the continuation of the programme, if local government is to avoid the burden of accommodating these health workers in their areas. Since this programme is new, reporting on this programme is limited to the current situation.

\subsubsection{Dual Practice}

Dual practice was introduced by the government in order to encourage doctors and midwives to stay longer in their appointed locations (Rokx et al., 2010). Dual practice means that public employees (i.e. a $P T T$ or $P N S$ ) are able to provide practice in their home (Rokx et al., 2010). According to the GHWA and WHO (2013 ), dual practice also covers fulltime health workers employed by the government as public service providers, undertaking extra, related work in order to obtain additional income, usually in the private sector. Additional income is usually acquired for personal benefit but sometimes involves profit-sharing with the relevant government authority. In Indonesia, dual practice is allowed with conditions: first, the health workers should have served in public health facilities for three years before they are allowed to privately practise; and second, the health workers can only practise privately after the official work day ends (Berman \& Dexter, 2004).

Most village midwives stay at the Polindes which allows them to open at any time they like. Thus, midwives can obtain more income from their private clinical practice. Ensor et al. (2008) point out that almost 75\% of midwives' incomes come from private clinical practice. Based on the aim of this policy, which was introduced to encourage midwives to stay in remote areas of Indonesia, the availability of the health workers can be maintained.

The dual practice policy could be an alternative means of attracting midwives to remote areas, and encouraging their retention, because it provides an opportunity for midwives to earn extra income. On the other hand, with many private health service providers located in urban areas, dual practice might cause more issues around the shortage of health workers in remote areas. Allowing government employees to provide services either during or outside their office hours might distract them from their main tasks which are to provide optimum services in the public health facilities, in this case Puskesmas or public hospitals. 
Despite the challenges, it seems that the dual practice policy is targeted at overcoming recruitment as well as retention issues, such as the high turnover or absenteeism of health workers. Similarly, the policy focuses on monetary rather than non-monetary incentives. Substantial monetary incentives are not the sole solution to attracting midwives to serve in rural and remote areas. A report on two provinces (East and West Nusa Tenggara) points out that many village midwives drop out from appointed areas due to inadequate community involvement, poor work facilities, and poor emergency referral systems (Ministry of Health, 2008).

\subsection{5 'A Village Midwife Programme'}

The first strategies to reduce the shortage of health workers, especially midwives in Indonesia, began in 1989. The national government introduced $B D D$ which aimed to deploy one midwife in every village in Indonesia in order to reduce the high maternal and child mortality rates (Frankenberg et al., 2005; Shankar et al., 2008; Shrestha, 2010; Shrestha, 2002). This programme was introduced by the GoI in response to the Nairobi Safe Motherhood Conference in 1987, the subject of which became a prominent issue in Indonesia at that time (Shrestha, 2010).

According to Shiffman (2003) and Shrestha (2010), BDD was the most significant strategy in terms of responding to the low number of SBAs, particularly in remote areas. Due to the limited number of existing midwives, the national government invested large amounts of money in training nurses to become midwives (Ministry of Health, 2008; Shankar et al., 2008; Shiffman, 2003). The nurses were trained for an additional year in midwifery skills, and then assigned to rural communities for a three year contract with the possibility of an extension to six years (Ministry of Health, 2008). 
Thus in the 1990s, the provision of midwives, particularly in remote areas of Indonesia, increased significantly. By the end of $1997,96 \%$ of midwives $(54,000$ 56,000 village midwives) were deployed throughout the Indonesian archipelago (Ministry of Health, 2008; Shankar et al., 2008; Shefner-Rogers \& Sood, 2004; Shiffman, 2003). This intervention indicated the willingness of the national government to improve accessibility to midwives throughout Indonesia, especially with a view towards reducing maternal and child mortality rates. $B D D$ was considered 'a silver bullet' aimed at addressing the shortage of midwives especially in remote areas. In addition, the programme increased and reduced the maldistribution of health workers between urban and remote areas.

Initially, job security was offered by the national government under $B D D$. Job security meant that the new graduates automatically became $P N S$ staff with long-term contracts until they reached retirement age (i.e. around 56 to 65 years old). On top of job security, being PNS staff means workers are eligible for a fixed monthly income, a retirement package, an insurance package, and possible career growth.

At the beginning of the Village Midwife Programme, all the fresh graduate midwives were automatically granted civil servants positions. The fresh graduates were recruited and deployed in remote villages, after which they were granted as civil servants (The Indonesian Midwives Association/IBI - SC)

It was about 20 years ago. I studied nursing (at a level equivalent to high school). At that time, there was the Village Midwife Programme. I was in the second batch of the programme. If I am not mistaken it was 1997, a lot of midwives were deployed in the villages, and then I was hired as a civil servant midwife (Civil servant midwife/PNS - SC)

It is clear that $B D D$ offered generous incentives that attracted nurses to undertake additional midwifery training for another year. Both financial and nonfinancial incentives were offered under this programme, indicating that both basic human needs reliant on earning were covered, along with other needs connected to the self-actualisation of workers, such as their career development. For instance, a midwife with PNS status is entitled to regular promotion which has an effect on her income. As PNS staff rise through levels of employment, their income and remuneration increase. 
Therefore, most health workers dream of being promoted to become PNS staff. Unfortunately, both national and local governments have only limited budgets with which to hire PNS health workers. An alternative approach, whereby health workers were nationally contracted, was introduced by the national government in order to improve the number of health workers in the community.

\subsection{Discussion}

The policies and strategies of the national government have tended to focus on reducing the shortage and improving the distribution of the health workers, particularly midwives, throughout Indonesia. This might be because of the limited supply of health workers at the time that the policies were introduced. Generous incentives - for instance, job security and direct financial incentives - were introduced as part of the initial policies or strategies in order to attract new graduates to remote postings. However, the level of financial incentive available has been adjusted from time to time, depending on the changing financial state of the national government.

Improving the availability of health workers in remote areas is continuously being addressed. Since the 1990s, many health workers, especially midwives, were recruited by the national government. These policies or strategies offered various packages, from fixed monthly incomes to additional direct financial incentives and job security, in order to attract health workers to remote postings.

After 2009, most of the policies introduced by the national government have added value, particularly with the aim of retaining health workers in their workplaces, a concern initially raised due to high turnover and absenteeism. The combination of financial and non-financial incentives was introduced by the national government in order to encourage health workers to remain in their appointed areas. 
It appears that the policies pay more attention to extrinsic factors, since addressing these is considered the most immediate way to encourage health workers to take employment in previously undesirable areas. Financial incentives have provided a significant influence in improving the availability of health workers, hence improving communities' accessibility to primary healthcare, particularly in remote villages. Many health workers are attracted to remote postings due to financial factors (Efendi et al., 2016; Frehywot et al., 2010), yet a high salary is not the only consideration for attracting midwives to remote postings (Mayo \& Mathews, 2006; Stretton \& Bolon, 2009; Yang, 2003).

Providing only financial incentives might have the potential to burden the national budget in the long run. Since the 2000s, the GoI has implemented, on and off, a zero recruitment policy for civil servants including health workers, due to a limited budget (Rokx et al., 2010). The GoI needs to consider other alternatives to protect national expenditure, and at the same time maintain the availability of midwives. For instance, some innovative approaches which involve non-financial incentives or understanding the intrinsic factors in order to continue the recruitment and retention of health workers, especially midwives, need to be developed. The findings from various studies have pointed out that non-financial incentives have protective effects in retaining health workers in their workplaces (Ensor et al., 2008; Ensor et al., 2009; Henderson \& Tulloch, 2008; Ministry of Health, 2008; Rokx et al., 2010). Hopefully, by understanding other factors outside financial incentives, the unequal distribution and retention of midwives can be eliminated.

The association between the provision of health workers and incentives has been examined by some scholars (Ensor et al., 2008; Ensor et al., 2009; Henderson \& Tulloch, 2008; Rokx et al., 2010). Ensor and colleagues (2009) show retaining and motivating workers in remote areas requires substantial benefits, in cash or in kind. The research of Yamamoto, Sunguya, Shiao, Amiya, and Jimba (2012) in the Pacific Islands emphasises the importance of non-financial incentives, such as career path incentives, in order to encourage health workers to work in their appointed places. 
In a similar manner, research conducted by Henderson and Tulloch (2008) found the importance of improving both financial (i.e. salaries, allowances and benefits) and non-financial (i.e. living conditions, safety, capacity development, and career pathways) incentives to encourage health workers to work in less developed areas. Exploring both monetary and non-monetary incentives could provide a solution to counteract the maldistribution of midwives and retain them in the rural and remote areas of Indonesia.

As well as various policies or strategies introduced by the national government, in the context of recruitment and retention of health workers, local government has also introduced various strategies. These policies or strategies aim to reduce the gap between the availability of health workers in urban and remote areas that cannot be addressed by the national government. Some innovative strategies have been crafted by local governments based on local needs and capacities.

\subsection{Local Government Policies or Strategies}

Since 2001, the GoI has reformed from a centralised to decentralised government system. The national government reform has affected the health system, where the local government, in this case at province and district levels, have complete power to manage health budgets and implementation programmes (Kristiansen \& Santoso, 2006; WHO, 2007). The local governments manage their domestic issues based on their needs.

In order to achieve a smooth power transition, The Minsitry of Health Decree number 922 year 2008 and then amended to the Law No. 23 year 2014 stipulated how power could be shared between national, provincial and regional governments in respect of managing the country's health system. In line with this, each district in NTB recruited midwives on top of the national government allocation. Several strategies or approaches were introduced by the 'success cases' and the 'less success cases'. The following section first explores the main strategies of recruitment and retention of midwives in remote areas implemented by the 'success cases', and follows with the main strategies in the 'less success cases'. Prior to these, Table 13 summarises the local government programmes. 
Table 13: Summary of Local Government Programmes

\begin{tabular}{|c|c|c|c|c|c|c|}
\hline \multirow[t]{2}{*}{ Year } & \multirow{2}{*}{$\begin{array}{c}\text { Policies or } \\
\text { Programmes }\end{array}$} & \multirow[t]{2}{*}{ Location } & \multirow{2}{*}{$\begin{array}{c}\text { Types of the } \\
\text { health workers }\end{array}$} & \multicolumn{2}{|c|}{ Benefits } & \multirow[t]{2}{*}{ Note } \\
\hline & & & & Financial & Non-Financial & \\
\hline \multicolumn{7}{|c|}{ The 'Success Cases' } \\
\hline 2008 & Scholarship Scheme & $\begin{array}{l}\text { West } \\
\text { Lombok } \\
\text { District }\end{array}$ & Midwives & $\begin{array}{l}\text { Fixed monthly income } \\
\text { (IDR } 800,000 \text { or around } \\
\text { USD 61) }\end{array}$ & $\begin{array}{l}\text { Long term contract ( } 10 \\
\text { years) }\end{array}$ & \\
\hline $2011-2014$ & $\begin{array}{l}\text { Regionally } \\
\text { Contracted } \\
\text { Midwives }\end{array}$ & Bima District & Midwives & $\begin{array}{l}\text { Fixed monthly income } \\
\text { (IDR 600,000 or around } \\
\text { USD 46) }\end{array}$ & On-the-job training & \\
\hline 2014 & The Job Midwives & $\begin{array}{l}\text { East Lombok } \\
\text { District }\end{array}$ & Midwives & $\begin{array}{l}\text { Fixed monthly income } \\
\text { (IDR 500,000 or around } \\
\text { USD 38) }\end{array}$ & On-the-job training & \\
\hline \multicolumn{7}{|c|}{ The 'Less Success Cases' } \\
\hline 2007 & $\begin{array}{l}\text { Regionally } \\
\text { Contracted based: } \\
\text { 1. DHO track }\end{array}$ & $\begin{array}{l}\text { Sumbawa } \\
\text { Besar District }\end{array}$ & Midwives & $\begin{array}{l}\text { Fixed monthly income } \\
\text { (very remote areas - } \\
\text { IDR 3,000,000 (around } \\
\text { USD 230); remote } \\
\text { areas - IDR 2,000,000 } \\
\text { (around USD 153); } \\
\text { 'normal' areas - IDR } \\
1,000,000 \text { (around USD } \\
76 \text { ). } \\
\text { Additional } \\
\text { transportation fees }\end{array}$ & $\begin{array}{l}\text { Contracted-based status } \\
\text { (one year contract with } \\
\text { potential extension) }\end{array}$ & \\
\hline
\end{tabular}




\begin{tabular}{|c|c|c|c|c|c|}
\hline & 2. Puskesmas track & $\begin{array}{l}\text { Sumbawa } \\
\text { Besar District }\end{array}$ & Midwives & $\begin{array}{l}\text { Fixed monthly income } \\
\text { (range from IDR } \\
400,000 \text { (around USD } \\
\text { 30) to IDR 600,000 } \\
\text { (around USD 46) }\end{array}$ & $\begin{array}{l}\text { Locals hired } \\
\text { Contracted-based status } \\
\text { (one year contract with } \\
\text { potential extension) }\end{array}$ \\
\hline \multirow[t]{6}{*}{2012} & $\begin{array}{l}\text { Internship } \\
\text { Programme }\end{array}$ & $\begin{array}{l}\text { Central } \\
\text { Lombok } \\
\text { District }\end{array}$ & $\begin{array}{l}\text { Midwives } \\
\text { Nurses } \\
\text { Public Health }\end{array}$ & Capitation & On-the-job training \\
\hline & \multicolumn{5}{|c|}{ The 'Success Cases' and The 'Less Success Cases' } \\
\hline & Volunteer Midwives & $\begin{array}{l}\text { Sumbawa } \\
\text { District }\end{array}$ & Midwives & Capitation & On-the-job training \\
\hline & Volunteer Midwives & $\begin{array}{l}\text { Dompu } \\
\text { District }\end{array}$ & Midwives & Capitation & On-the-job training \\
\hline & Volunteer Midwives & $\begin{array}{l}\text { North } \\
\text { Lombok } \\
\text { District }\end{array}$ & Midwives & Capitation & $\begin{array}{l}\text { On-the-job training } \\
\text { Opportunity for career } \\
\text { development }\end{array}$ \\
\hline & Volunteer Midwives & $\begin{array}{l}\text { Central } \\
\text { Lombok }\end{array}$ & Midwives & Capitation & $\begin{array}{l}\text { On-the-job training } \\
\text { Opportunity for career } \\
\text { development }\end{array}$ \\
\hline 2014 & Volunteer Midwives & Bima & Midwives & Capitation & On-the-job training \\
\hline
\end{tabular}




\subsection{The 'Success Cases': The Local Strategies}

My findings in the 'success cases' highlight two main programmes that have succeeded in attracting as well as retaining midwives in their areas, namely the Scholarship Scheme and Regionally Contracted midwives. These programmes were initiated by the local government to improve the provision of midwives as the national government had not allocated enough midwives to remote areas.

\subsubsection{Scholarship Scheme}

Among eight districts and two municipalities in $N T B$, the first policy breakthrough was introduced by West Lombok District. The policy was initiated by the head DHO which aimed to reduce maternal and child mortality rates in West Lombok District through improving the availability of midwives in every village.

In 2008, the MEP for remote areas was introduced by West Lombok District. This programme was expected to reduce the shortfall of midwives in West Lombok District. The logic behind this programme was to improve the health condition of mothers and children. In addition, the idea was inspired by the PTT Pusat programme. However, in the implementation many PTT Pusat experienced some challenges, such as culture shock and language difficulties. Most PTT Pusat came from Java Island or other provinces in Indonesia which have different cultures and languages. Some adjustments to the new environment were needed by these midwives. Some had no problems adjusting to the new environment, while others needed a longer time. However, because a lot of time was potentially needed for midwives to adjust to their new environments, equally, the quality of services could potentially be jeopardised.

Initially, the MEP was aimed at enabling the daughters of TBAs to pursue higher education in midwifery training for three years. The local government wanted to substitute trained midwives for TBAs in their areas. Many pregnant women seek help from TBAs due to their belief systems as well as limited health professional availability in their areas. 
Unfortunately, as might be expected, many TBAs' daughters were not qualified to enrol in this programme. Most TBAs' daughters had no formal education or had only reached primary school level. Due to the limited number of applicants, the programme was modified for high achiever students from around West Lombok District. Thirty-four students were recruited and trained as midwives for three years.

The programme covers all the expenses, namely tuition fees and living costs. All the students stay in dormitories during their study. The programme was funded from the regional budget, and, as a consequence, students have to serve for some years in their hometown to receive a salary every month.

In principle, this programme was binding - the students had to commit to work in remote areas or back at their home-base after graduation. The students signed an agreement that they would return to their home-base or be deployed to remote villages for 10 years with a salary of around IDR 700,000 per month (USD 53). Those students who failed to comply with these regulations, for instance, those who quit the job before the timeframe ended, were obligated to pay a fine valued at three times their training costs.

Job security is definitely offered by signing for 10 years' compulsory service, yet it might infringe on the midwives' right to grow. It indicates that midwives are more likely to be in the same position for at least 10 years. Nevertheless, the certainty of having a job after graduation attracts many applicants. This programme is believed to be having a positive impact in improving the distribution of midwives in West Lombok District, but also in retaining them in their workplaces.

By introducing this policy, in 2012, the West Lombok District improved the coverage of midwives in their areas, particularly in remote areas. They expected that one village would be served by two midwives. Based on my observation during my fieldwork, the programme has made a valuable impact on the accessibility of healthcare, particularly for pregnant mothers and children in remote areas where midwives can be found in every village. After the programme was introduced maternal mortality dropped to 75 per 100,000 livebirths, a $50 \%$ reduction from before the programme started. 


\subsubsection{Regionally Contracted Programme or PTT Daerah}

Also among the 'success cases', the PTT Daerah programme was introduced in the Bima District. This programme was introduced in 2011 but stopped in 2014 due to the limited budget that was allocated by the local government. Basically, PTT Daerah in Bima District was inspired by PTT Pusat. Each midwife with PTT Daerah status in Bima district receives the same salary per month regardless of their workplace. They only receive a minimum wage of around IDR 600,000 per month (USD 46). In terms of the length of employment, each midwife is given a one year contract with a potential extension depending on the available budget from the local government.

PTT Daerah very much depends on the financial capacity of local governments which leads to uncertainty in midwives' employment status. Job security cannot be guaranteed. This situation indicates the need for other approaches to improve the attraction and retention of midwives in remote areas of $N T B$. This is consistent with the World Bank Report (Rokx et al., 2010) findings which suggest that the government should find a long-term solution which is not going to burden the local or national budget, in order to sustain the programme. Thus, evidence-based information to support or craft appropriate policies or strategies is needed that includes aspects other than financial incentives.

Currently, Bima district has recruited volunteer midwives as a replacement for this programme. The volunteer midwives programme is expected to provide the necessary supply of midwives in remote areas, thus maintaining the availability of midwives in remote areas.

\subsubsection{The Job Midwives}

In 2014, the Job Midwives Programme was introduced by the East Lombok District. This is a similar programme to the Internship Programme. Those on the Job Midwives Programme are trained midwives but are not categorised as PNS or PTT Pusat and are hired by the DHO through several selection processes. 
This policy is expected to increase the availability of midwives in the remote areas and hence help reduce maternal and child mortality rates in the East Lombok District, which ranked seventh out of 10 districts in NTB for 2013. This concerning situation has encouraged the local government to create an innovative approach in order to reduce mother and child deaths. The DHO harnesses the high supply of midwives in their areas by deploying them to villages, thus every Polindes in each village is served by two midwives - one to assist the mother and the other to assist the baby.

The Job Programme midwives are expected to sign an agreement with the DHO. The agreement states some essential elements, such as: (i) job descriptions; (ii) ensuring the zero tolerance of mothers' and children's deaths; and (iii) a willingness to be deployed at any village around the East Lombok District. While they have to comply with all the regulations, the midwives receive limited appreciation and financial benefits. The DHO allocates a small income for the Job Programme midwives which does not cover the midwives' daily expenditure - around IDR 500,000 per month (USD 38 ) - with additional income from delivery reimbursement, with the amount of reimbursement varying according to the numbers of patients being assisted.

It appears that financial incentives are definitely not the main attraction of this policy. The potential reasons that attract midwives to enter this programme are the high supply of midwives as well as the opportunity to improve their skills. According to the key informants, about 400 applicants applied for the Job Midwives Programme, yet only 165 were recruited by the East Lombok District.

\subsection{The 'Less Success Cases'}

In the 'less success cases' there are other programmes intended to improve the availability of midwives in remote areas, but also to manage the oversupply of health workers that has occurred over the past five years. The following section explains both the situation of Internship health workers and the Sumbawa Besar District's Regionally Contracted Midwives Programme. In principle, this programme is the same as that implemented in Bima District, but Sumbawa Besar District uses two tracks in terms of recruiting midwives in remote areas which means the distribution of midwives in remote areas is obtained immediately. 


\subsubsection{Internship Health Workers}

As one of the responses to the high supply of new midwifery graduates and to enhance the availability of midwives in remote areas, an internship programme was introduced by the Central Lombok District in 2012. This programme was created by the DHO for various health professionals, including midwives, nurses, and public health personnel. Internship health workers are trained health workers who were recruited by the DHO and are ready to be deployed in any areas in the Central Lombok District.

The recruitment process includes collaboration with various health professional associations, such as IBI, the Indonesian Nursing Association (Persatuan Perawat Nasional Indonesia), and the Indonesian Public Health Association (Perhimpunan Sarjana Kesehatan Masyarakat Indonesia). The recruitment of these health workers starts with each association. All applicants should be registered as members of the relevant association. For instance, if you are a midwife, you have to first be a member of $I B I$ to be able to apply for the internship programme. In the second step, applicants apply for the internship programme at the DHO. Third, the successful applicants are deployed to the Puskesmas for six months. All the intern midwives have to sign an agreement letter, indicating they will receive no benefits of any kind.

After six months of the internship, the intern midwives have to attend a competency test that is organised by the DHO in collaboration with the Primary Clinical Training Centre (Pusat Pelatihan Klinik Primer or P2KP) and IBI. Those midwives able to pass the test are deployed to the Polindes for a year contract and supervised by the senior midwives. Unsuccessful midwives have to stay in the Puskesmas for additional training in order to improve their skills.

Since 2012, this programme has managed to distribute midwives to each village in the Central Lombok District and maintained two midwives in each Polindes - one senior midwife and one intern midwife. There should not be any reason for the community not to have access to health professionals. 
One of the districts that is categorised as a successful area also took a similar approach to the Central Lombok District. The Dompu District utilises the oversupply of midwives in order to improve the availability of midwives in their areas. The recruitment of the internship midwives in Dompu District is organised by the DHO. Each midwife has to complete an internship at the DHO for six months. During the six months the midwives rotate from one department to another at the DHO. Each volunteer midwife learns in each department for one month. This approach is taken by the DHO in order to enhance the skills of midwives, thus they are ready to be deployed in the village. It is expected that after the internship the midwives are able to respond when an emergency or unpleasant situation occurs.

The selling point of this programme is the opportunity for improving the skills of health workers through real experience. The midwives get more practice in assisting pregnant women during birthing which is very useful for improving their skills. Unlike some other professionals, midwives need regular practice in order to maintain or improve their skills. In addition, the intern midwives are able to learn more about a range of relevant government programmes providing them with very useful knowledge and experience for when they interact with the community. Thus, this programme has attracted many health workers, such as midwives, to remote postings, regardless of the limited income offered.

There is no guarantee that the intern midwives will receive a fixed income from the DHO or Puskesmas. Many Puskesmas provide a limited financial incentive to the intern midwives by using a capitation fund. The incentives are varied based on the capacity of each Puskesmas. It is clear that the local government has positive intentions to improve the health of the people, yet the incentives that are given are unbalanced. 


\subsubsection{Regionally Contracted Programme}

The Regionally Contracted Programme (Pegawai Tidak Tetap Daerah or PTT Daerah) operates in several districts in NTB. PTT Daerah has similar arrangements as the PTT Pusat, however, recruitment and payment are managed by the local government, in this case the DHO. PTT Daerah depends solely on local capacity, including funding, priority of development, and political will. One district might allocate higher or more limited funding then other districts based on their revenue. For example, Sumbawa Besar District provides a higher salary for the PTT Daerah midwives compared to other districts. This might be due to their greater natural resources that contribute to a higher regional revenue. Moreover, leadership and political will also plays an important role in determining the development strategies, particularly in the health sectors.

Initially, we were pretty much dependant on the allocation of the health workers, such as midwives from the national government. In 2008, we started to recruit our own midwives. At the moment, we have around 80 midwives and the payment system is organised by the local government $(\mathrm{DHO}-\mathrm{SC})$

In Sumbawa Besar District, midwives with PTT Daerah were recruited by the DHO with pay based on geographical difficulties. In this case, payment comes from the regional budget. There are two types of PTT Daerah in Sumbawa Besar District, namely PTT Daerah organised by DHOs (or PTT Daerah DHO track) and those organised by the PTT Daerah Puskesmas track.

In 2007, the first PTT Daerah DHO track was introduced by the local government in order to provide health workers, especially midwives, in every village Sumbawa Besar District. There were 49 villages, indicating that 49 midwives were needed. The local government offered generous incentives that attracted many new midwifery graduates or other midwives to remote postings. This incentive scheme is similar to PTT Pusat - the more difficult the area, the higher the incentives they receive (i.e. IDR 3,000,000 per month or equal to USD 230 for very remote areas; IDR 2,000,000 per month (around USD 153) for remote areas; and IDR 1,000,000 per month or equal to USD 76). The contract is valid for a year with a possible extension every year. In addition to their monthly income, each midwife receives a transportation fee from their house to their workplace. 
Another programme was introduced by the Sumbawa Besar District, namely the PTT Daerah Puskesmas track. These midwives sign a contract under DHO agreements, though the recruitment process is organised by the Puskesmas. Under this contract, applicants come from the community or are local people with midwifery qualifications. The main reason for undertaking this approach is to embrace and empower the local people. Limited financial incentives are given to these midwives. The midwives are attracted to this programme because they can stay closer to their family.

Both programmes are fully funded by the local government and organised by the DHOs. However, the payment of the PTT Daerah Puskesmas track is organised by the Puskesmas where each midwife receives around IDR 400,000 per month (around USD 31 ) to IDR 6,000,000 per month (around USD 461). The DHOs provide the PTT Daerah Puskesmas track with a very low income compared to the PTT Daerah DHO track. Perhaps, due to limited budget and in consideration of them staying in their own hometown, the PTT Daerah Puskesmas track only brings a very small salary, which is lower than the regional minimum wage.

The PTT Daerah DHO track focuses on providing adequate financial incentives, while the PTT Daerah Puskesmas focuses on the proximity of family and hometown, and was taken up by the local government. Recruiting local people seems to be an alternative worth considering because it will benefit not only local government but also the community. The midwives with local background have more knowledge about local values and culture that might not be had by other applicants from different areas. Probably, the combination of high income and hiring local midwives has an impact on attracting and retaining midwives to remote postings.

\subsection{The 'Success Cases' and The 'Less Success Cases'}

When I did my fieldwork, volunteer midwives were easily found in all districts in NTB. They normally act as an assistant to the nationally- or regionally-contracted midwives. The following section discusses the volunteer midwives' programme in the 'success cases' and the 'less success cases'. 


\subsubsection{Volunteer Midwives}

The Sumbawa, Dompu, North Lombok, and Bima Districts all use the term 'volunteer midwives'. The volunteer midwives have been taken on by local governments to reduce the unequal distribution between urban and remote areas. The high supply of midwives in each district has forced the local government to undertake action to overcome this issue. Hence, the common practice that sees local governments recruiting midwives under a volunteer midwives programme.

In this context, some DHOs provide extensive power to Puskesmas to hire the volunteer midwives. Puskesmas, as the implementer and gate keeper of primary basic healthcare, is able to take any action in order to improve the quality of healthcare for the community, including recruiting midwives to remote postings. Every Puskesmas in each district has different regulations and benefits for the volunteer midwives. It is difficult to draw a conclusion about this approach. The volunteer midwives are the most vulnerable midwives because their existence is not officially recognised by the government, but they have the same burden as other midwives.

We [the DHO] recruited volunteer midwives on the basis of helping them [fresh graduates] to maintain their skills. Volunteer midwives work under senior midwives'supervision. If they work in the remote villages then the supervision is conducted by the other senior village midwives (DHO-LSC)

Even though no or limited financial incentives are offered, the opportunity to receive additional training or on-the-job training attracts many midwives to dedicate themselves as volunteer midwives in remote areas. The volunteer midwives receive a little bit of income from the local government. It is not clear how much money each volunteer midwife is being paid, because there is no set standard.

Unlike other districts, the North Lombok District has implemented a different approach to their volunteer midwives. The DHO organises recruitment and implements a clear system. The volunteer midwives have to join an orientation at the DHO for one month, and after that they are sent to the hospital for another month to have hands-on practice. If they pass the orientation, they are then sent to the Puskesmas to have another orientation under the supervision of senior midwives. When the volunteer midwives pass all the requirements, they will be deployed to the Polindes in the village. 
The volunteer midwives have to sign an agreement with the DHO with some specific requirements, such as the stipulations that no financial benefits will be provided and they must be willing to be deployed in any village in the North Lombok District. For humanitarian reasons, the head of Puskesmas allocates some budget from the capitation fund to be given to the volunteer midwives. However, the payment is not given in their first three months. This indicates that midwives have limited or zero power to negotiate their rights for equal income. The volunteer midwives have no bargaining position because they have signed an agreement not to request any salary.

Being a volunteer midwife in these districts might gain nothing in terms of financial reward, however, the midwives have an opportunity to develop their careers or their skills. For example, in the North Lombok District, when there is a vacancy for a PTT Daerah, PTT Pusat, or PNS, the local government will prioritise the volunteer midwives to be promoted. However, there is no written document to conduct this recruitment process; recruitment is based on common practice or a consensus of government officials.

\subsection{Discussion}

Local government has responded positively to the maldistribution of midwives between urban and remote areas. The limited allocation of health workers by central government has triggered local government to create some innovative strategies, such as the scholarship programme in West Lombok District. The development of the local government strategies have been helped by the high supply of midwives for the last five years. This situation has brought some positive effects on the availability of midwives in remote areas. Most villages in the NTB province have two midwives simultaneously assisting mothers and babies. 
However, the only strategies that might have a positive effect on retention were introduced by the West Lombok District. The 10 year contract is more likely to prevent midwives from leaving their workplaces. The other local government strategies have attracted many midwives, yet the conditional job security (i.e. security based on their contractual obligations) has brought some worries for midwives concerned with the future of their careers. In addition, local government polices are less interested in the provision of monetary incentives to attract midwives to remote postings and retain them.

The local government has a limited budget for providing financial incentives for midwives. Most of the funding comes from the capitation system which varies in each district. The local government policies tend to emphasise the opportunity for improving the skills of the health workers. It seems that the local government has taken for granted the high supply of midwives in their areas. Midwifery is a highly labour-intensive job with a heavy workload, yet payment or appreciation is very limited.

\subsubsection{Do the Key Factors Match Up with the Existing Policies?}

There are around 19 policies or programmes related to the recruitment and retention of health workers, particularly midwives, in Indonesia, and NTB. The factors that are stipulated in the policies both at the national and local government level are varied, including both financial and non-financial incentives (Figure 20). The financial incentives encompass a fixed-monthly income, retirement package, insurance, direct financial incentives, permanent employment and capitations. The non-financial incentives involve a contract-based system, on-the-job training or experience, and career development. 


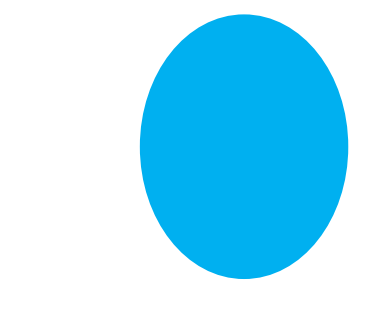

Fixed Monthly Income (14 Policies/Programmes)
Retirement Package

(1 Policy/Programme)

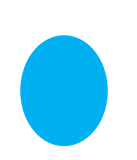

rance Package (7 Policies/Programmes)

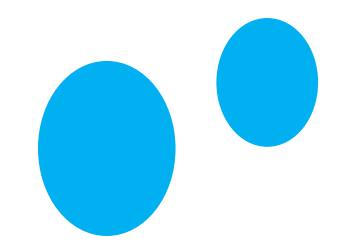

Capitation

(6 Policies/Programmes)

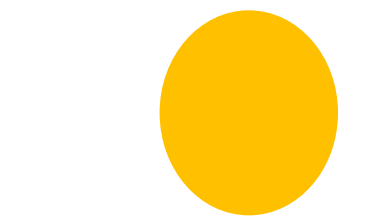

On the Job Training/Experiences (6 Policies/Programmes)

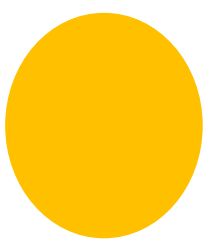

Contracted Based Midwives (14 Policies/Programmes)

\section{Non-Financial Incentives}

\section{Financial Incentives}

Permanent Contract (1 Policy/Programme)
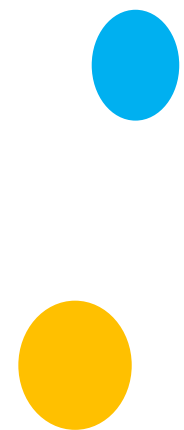

Career Development (4 Policies/Programmes)

Figure 20: The National and Local Government's Policies/Programmes: Financial and Non-Financial Incentives

Both national and local government are more likely to provide fixed-monthly income and other direct financial incentives in order to attract midwives to work in remote areas. Yet, as Figure 21 shows, the key factors that attract midwives to remote postings are varied and salary is not a major factor. My findings indicate that many midwives were attracted to work in remote areas because they want to have more experiences or 'the real' experience.

I was planning to get more experience in the village for about two years. Next, I intended to apply for a job in the public hospital... but I met my husband here (Regionally contracted midwife/PTT Daerah LSC) 
I want to work in the remote village because I will be exposed to many cases which could improve my experience. In the village, we [the village midwives] have to take care of the patients ourselves with limited or no help from other colleagues. Unlike in the Puskesmas, we have limited opportunity to take care of the patients because we have to take turns with other colleagues. Hence, we have less experience compared to midwives in the village (Volunteer midwife - SC)

Interestingly, on-the-job training is mostly embedded in the policies that the local government produced. This might be influenced by the limited salary that the local government can offer, thus by opening the opportunity for midwives to have 'real' experience the recruitment of midwives may be positively affected, particularly in remote areas. As a midwife, practising is essential as it maintains or improves skills.

In the context of retention, there are five main factors that influence midwives to stay in their workplaces: community support; dedication to community or the job; incomes or incentives; local hiring; and culture and beliefs. Government policies have responded to and facilitated some key factors that draw midwives to remote postings, through it is the extrinsic factors (i.e. financial incentives and on-the-job training) that are mainly the domain of policy approaches.

The other factors (i.e. culture and beliefs) are hardly seen in the policies or strategies introduced by the national and local government. Despite the difficulties in differentiating between the recruitment and the retention policies from both national and local governments, many non-financial incentives are neglected in the actual policies or strategies. Community support and culture play an important role in retaining midwives in remote communities, yet there has not been a single policy that taps into this major factor. 


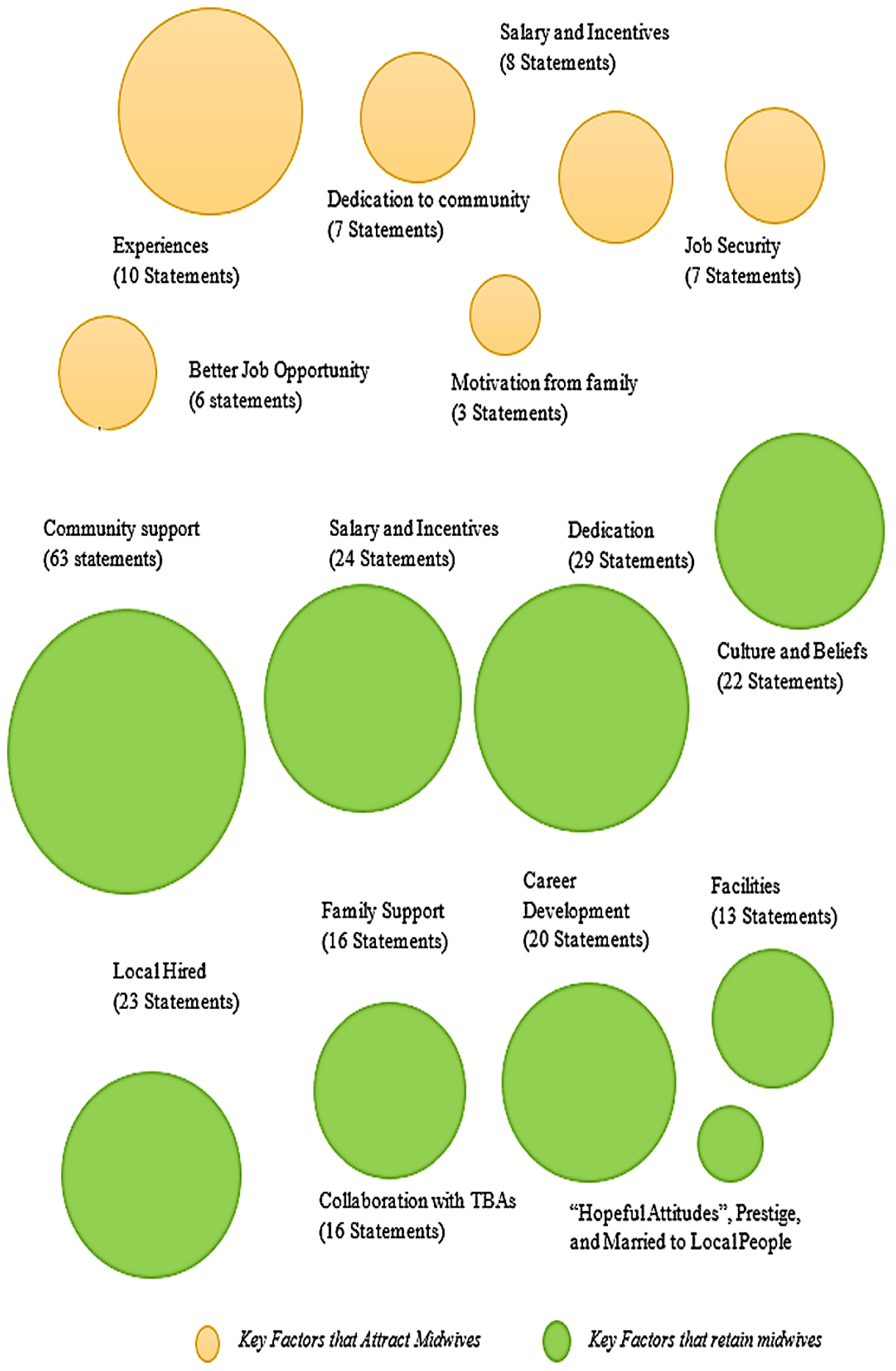

Figure 21: Key Factors that attract and retain midwives in remote areas: The 'Success Cases' and The 'Less Success Cases' 


\subsection{Conclusion}

Both central and local government have introduced policies surrounding the recruitment and retention of midwives in remote areas of Indonesia. The central government recruits PNS and PTT Pusat to be deployed in the areas where they are needed. The generous financial incentives or job security seem to be the selling point of these two policies. For instance, midwives with $P N S$ status receive a fixed income per month, a retirement package, length of work commitment, and other allowances. Midwives with PTT Pusat status receive generous incentives based on their workplaces. They receive generous financial incentives based on geographical difficulties. Unlike PNS midwives, the career development of PTT Pusat is not considered among the incentives offered.

In response to the maldistribution of health workers, local government has introduced several policies, such as the PTT Daerah and the volunteer midwives. Local government programmes are mainly concerned with accommodating the oversupply of health workers, especially midwives, in every district. These programmes do not offer generous financial incentives, or even any financial incentives at all. Instead they offer an on-the-job training programme for new midwifery graduates. Interestingly, although a limited amount of financial benefits are provided, the demand to be a village midwife is relatively high in every district.

This could be due to the fact that being a midwife is not like other professions. Midwives require adequate skills and regular practice. In order to maintain or improve their skills, midwives must have regular practice. 'Practice makes perfect' is an appropriate phrase to be used in this instance. Some midwifery programmes from local government offer an opportunity for midwives to maintain and improve their skills because they are exposed to real situations every day. Moreover, by being part of the system, the midwives have better access to more information about job vacancies or other opportunities that can improve their career. Therefore, many fresh graduate midwives are willing to be a volunteer midwife, even though limited financial incentives are offered. 
Finally, it seems that the existing polices or strategies cover key factors that attract midwives to remote areas, but those that influence the retention of midwives have not been well addressed. Figure 22 illustrates the imbalance of the interaction between policies/programmes and key factors on based on the findings of my study. It is clear that the interaction is only seen in extrinsic motivating factors, such as salary and incentives, job security, and career opportunity.

Intrinsic motivations have not been a focus for central and local governments. The situation suggests a need for some comprehensive and innovative strategies that move beyond those financial factors. The key factors identified that help retain midwives in remote areas can be used as an evidence-base to craft innovative programmes at both the national and local levels. 


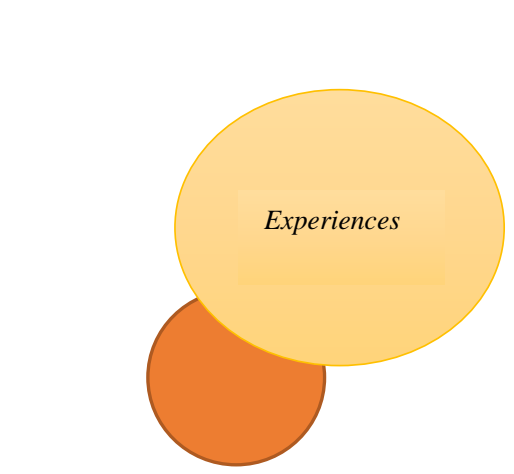

On the Job Training/Experiences

(7 Policies/Programmes)

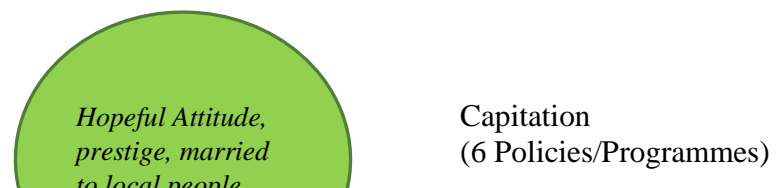

to local people

Insurance Package

(7 Policies/Programmes)

Fixed Monthly Income

(14 Policies/Programmes)

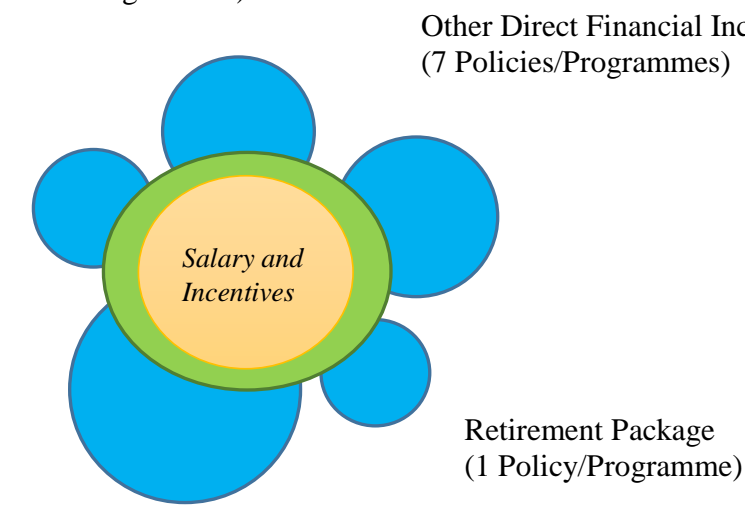

(1 Policy/Programme)

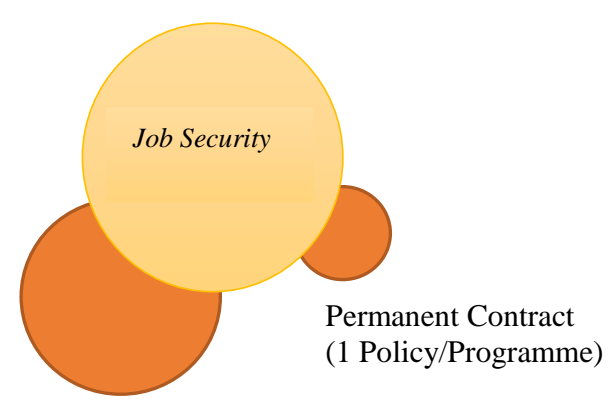

Contracted Based Midwives

(14 Policies/Programmes)
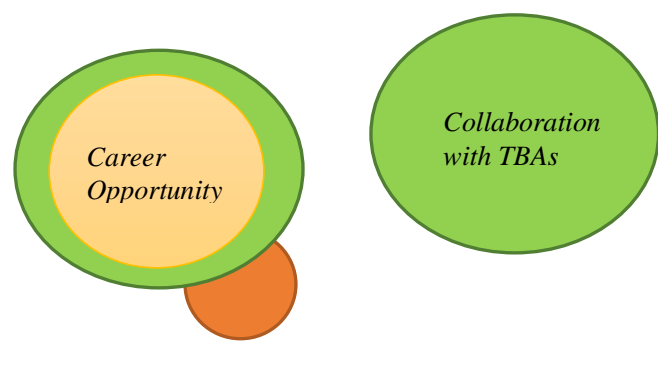

Career Development

(4 Policies/Programmes)

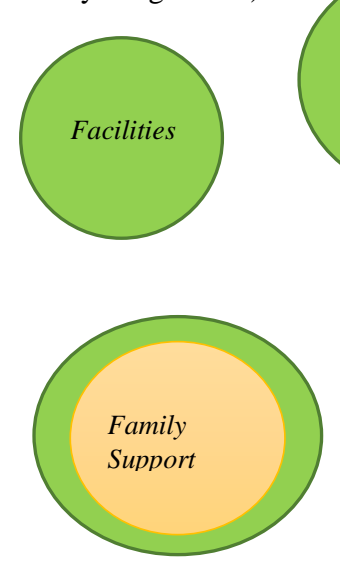

Locally

Hired

Figure 22: Interaction between Policies and Key Factors 


\section{CHAPTER 8. DISCUSSION AND CONCLUSION}

\subsection{Introduction}

In this chapter, the key findings of my research are discussed using the adapted multifaceted framework which I developed for this research. This is followed by recommendations for the government when crafting future recruitment and retention policies, and programmes for midwives in remote areas. Finally, the tree metaphor is used to illustrate the study.

\subsection{Discussion}

In order to address the research questions, 'How can qualified midwives be better attracted and retained in remote areas of Indonesia?', documentary evidence was analysed, and interviews with 75 participants (57 participants from the 'success cases' and 14 from the 'less success cases') were carried out. To address the main research question, this study has three sub-questions, which are:

1. What are the key factors that attract midwives to remote areas of Indonesia?

2. What are the key factors that retain midwives in remote areas of Indonesia?

3. To what extent do the policies and programmes of the GoI respond to and facilitate factors that influence recruitment and retention of midwives in remote areas of Indonesia?

Therefore, based on the above questions, the following sections discuss the factors that attract and retain midwives in the 'success cases' and the 'less success cases', and the role of the GoI in facilitating the recruitment and retention of midwives using the multifaceted framework.

\subsubsection{Similar Factors Emerge in Both Cases}

As Brinkerhoff (2005) points out, researchers or evaluators may intentionally emphasise success cases which highlight the positive impact of a programme or intervention that is being implemented. In my study, I deliberately sought midwives who worked and stayed in remote areas from both the 'success cases' and the 'less success cases'. 
Within this context, the SCM (Brinkerhoff, 2003) blended with AI (Cooperrider et al., 2008) have identified some intriguing factors that attract and retain midwives in remote areas of Indonesia, particularly in NTB. New knowledge or models were generated and constructed from the information gained from the research participants (Priest et al., 2013).

A significant amount of data was gathered and analysed using a TA approach to answer the research questions. The factors that emerged were then compared and contrasted between the 'success cases' and the 'less success cases' to identify the key factors that attract and retain midwives in remote areas.

Similarities emerged through the comparative examination of the 'success cases' and the 'less success cases'. The factors that were found in both cases are considered as the key factors that attract or retain midwives in remote areas. Therefore, the following sections will discuss the key factors that attract and retain midwives in remote areas, which appear in both the 'success cases' and the 'less success cases'.

\subsubsection{Attracting Midwives to Remote Areas}

The findings of my research show that there are no major differences between the 'success cases' and the 'less success cases' with regards to the key factors that attract midwives to remote areas. I discuss these in the following sections.

\section{Organisational Factors}

The first key factor relates to economic stability (monthly income and job security) that appeals to many new graduates, attracting them to work in remote areas. In this study, economic factors are categorised as organisational factors, because they involve other parties, such as the national and local government's capacity in recruiting and allocating budget for health workers' salary or incentives.

Economic stability was defined by the research participants as receiving a fixed income every month. Some midwives act as the breadwinner in the family, thus having a fixed income becomes the initial consideration. For humans, Maslow's hierarchy of needs requires that basic needs such as food, water, rest, and security be met; in the modern era these can only be fulfilled by having money. Thus, the ability to earn becomes essential for midwives to enable them to fulfil their basic needs. 
Another potential reason why financial incentives are attractive to midwives is the feeling of self-worth and accomplishment because they are able to earn some money. Herzberg (1987 cited by Hollyforde and Whiddett, 2002, p. 105) points out that salary has a positive effect on job satisfaction because of its relation to recognition rather than the amount of money itself. He argues that salary is a mover, and not motivator, thus it needs other factors to improve worker motivation.

A long-term contract offered to village midwives by the national or local government is another key factor that attracts midwives to remote areas. Having a fixed or even permanent contract is considered as a protective element by the village midwives because, at least for certain amount of time, they generate income. This means that midwives have job security for some years, in turn providing stable income. The findings show that many graduates were willing to move to other provinces or their hometowns in order to access employment opportunities.

However, these two factors - financial incentives and job security - depend on the availability of government funds as well as the 'political willingness' of the policymakers. There is an interaction between organisations (i.e. the $\mathrm{MoH}$ or $\mathrm{DHO}$ ) and the village midwives in terms of triggering midwives' motivation to work in remote areas. Even though financial incentives and job security are not the ultimate factors that attract midwives to remote postings, the government has an obligation to allocate the funding annually and potentially increase the budget as more midwives are recruited each year. In Indonesia, the $\mathrm{MoH}$ has provided an attractive incentive on top of a monthly salary for PTT Pusat and midwives under the Nusantara Sehat programme, based on geographical difficulties. This indicates that the GoI has realised that midwives' motivation to work in remote areas is influenced by adequate monetary incentives.

On the other hand, national or local government each have limited capacity to provide competitive salaries because of a dependence on government revenue. Thus, Franco et al. (2002) argue that focusing only on financial incentives to enhance workers' motivation can be very problematic. This approach could be very expensive in the long run and burden the governments' budgets (Franco et al., 2002); Rokx et al., 2010). 
It is clear an innovative approach is needed in order to complement any approach to recruitment where financial incentives are used. For instance, good facilities, support from management, education, a bonding system, and career advancement are all non-financial factors that were found to be important in previous studies (Efendi et al., 2015; Frehywot et al., 2010). However, I also found that dedication to community and obtaining work experience are further two factors that attract midwives to remote posts.

\section{Personal Factors}

Dedication to the community, perhaps understood as a 'moral calling' to enhance the health of the community, motivates midwives to work in less desired areas. On the other hand, it is possible that because midwives have grown up in districts where everything is so limited, including access to health facilities and health professionals, their motivation to work and stay in their own community is triggered.

Jack et al. (2013) point out that one of the key factors that attracts or retain health workers was a desire to help patients. In my study, I found that midwives want to improve the health outcomes for their communities. It means that their motivation is beyond just helping their main patients, namely mothers and children under five. They provide health services and promotion to other community members. As a health services provider, they are role models in the community.

This factor indicates that work motivation at an individual level can be shaped by extrinsic factors, in this case by the location where midwives are situated. Deci (2002) and Maehr and Braskamp (1986) point out that individuals' motivation can be determined by external factors, and dedication to the community is an excellent example of this.

My research also found that obtaining 'real' experience in order to boost skills is one of the key factors that attracts midwives to remote postings. A village midwife is the frontline health practitioner in many remote villages of Indonesia. Thus, working there is seen as an excellent 'lab' in which to learn and sharpen their skills as well as develop their knowledge. 
On the other hand, this presents a concerning situation because midwives with limited skills might jeopardise the health of the women in remote villages. The village midwives need to have adequate skills in order to maintain and improve the health of the people.

These two factors provide intrinsic motivations which are embedded in midwives' personalities. Willingness to dedicate their work to their own community and obtaining more experience are considered as personal investments (Maehr \& Braskamp, 1986) or as intrinsic motivations which some authors argue has more influence on individuals' motivation than extrinsic motivations (Hollyforde \& Whiddett, 2002; and Herzberg, 2003).

\subsubsection{Retaining Midwives in Remote Areas}

Moving on from the key factors that attract midwives to remote areas, this study also reveals key factors that retain midwives in remote areas. To begin with, I will address the retention factors that the 'success cases' and the 'less success cases' have in common. These factors encompass financial incentives and community support, as well as religious beliefs.

\section{Organisational Factors}

Financial incentives are considered organisational factors, while community support and religious beliefs are societal factors. Direct financial incentives were a key factor which can help retain midwives in remote areas in the 'success cases' and the 'less success cases'. However, it is unclear exactly what amount of money can keep midwives in remote areas, and it varies. For instance, some midwives suggest that IDR 5,000,000 (around USD 384) is an appropriate amount to receive in remote areas, while some midwives stay in their postings for years even though they only receive a limited income.

This factor becomes essential because some midwives are the breadwinner of the family. Despite a salary which may only fulfil basic needs, according to the research participants, one of the benefits of working in remote areas is the higher purchasing power because prices (i.e. of food and accommodation) are cheaper in remote areas, and, as a result, midwives are able to save some money or invest some money to buy property or land. 
As mentioned earlier, using financial incentives to retain midwives in remote areas heavily depends on organisational resources such as the annual budget allocation. A limited budget could possibly jeopardise the sustainability of policies and programmes designed to encourage midwives to stay in a remote location. For instance, one district in the 'success cases' decided to terminate or reduce the salaries or other monetary incentives for regionally-contracted midwives, due to limited regional revenue. Interestingly, many midwives are still willing to provide services in their workplaces, but expect that this situation is only temporary.

This issue has the potential to influence midwives' work motivation directly, because midwives have to earn an income in order to fulfil their needs or meet their personal goals. This situation contributes to the feeling of being treated poorly, which could affect their performance - in this case, their willingness to stay working in remote areas. According to Franco et al. (2002, p. 1257), "health worker motivation exists when there is alignment between individual and organisational goals, and when workers perceive that they can carry out their tasks". Thus, it is important to maintain financial incentives even though they are not the only factors that keep midwives in remote areas.

In my study, financial incentives were found to be a key factor attracting and retaining midwives in remote areas in both 'the success cases' and 'the less success cases'. This study argues that even though this is not the fundamental factor in attracting and retaining midwives, it has a protective effect (i.e. it prevents midwives from moving to different workplaces) because it not only attracts midwives, but also retains them in their workplaces. Thus, the GoI needs to pay attention to formulating an adequate annual budget to sustain midwives' salary or financial incentives.

\section{Societal Factors}

In addition to financial incentives, this study also found two other key factors that retains midwives in remote areas. These two factors, namely community support and cultural and religious beliefs, are categorised as societal factors. Societal factors construct midwives' personal motivation and influence their goals, actions, and decisions, in this case, the decision to stay in remote areas in both 'the success cases' and 'the less success cases'. 
Community acceptance is one of the key factors that retains midwives in remote areas, and was frequently mentioned by the research participants. Coleman's concept of social capital (1988) cited in Greeley (1997) provides a perspective on how social structures play a powerful role in human relationships. According to him, social capital is the interaction of various entities within social structures, such as neighbours and social networks, which promote a positive environment. In general, social support is defined as assistance available from one person to another that encompasses emotional support (acceptance, love and understanding) as well as instrumental aid (such as money, food and clothing) (Sánchez-Moreno, Roldán, Gallardo-Peralta \& De Roda, 2014; Spilsbury \& Korbin, 2013; Stopford, Winkley \& Ismail, 2013; House, Umerson \& Landis, 1988).

The relationship between village midwives and their neighbours (i.e. people living in the village) provided a highlight for my research. Being considered part of a family influenced midwives' willingness to stay in their working areas. Most remote villages in Indonesia place a high value on kinship which benefited the village midwives. This value creates a feeling of comfort and safety for the local midwives, especially for those who live far away from their immediate family or relatives.

The solidarity of the community was shown through the provision of emotional or instrumental support. Neighbours provided local produce to midwives in order to show their care and gratitude. This conducive environment is undeniably effective in keeping village midwives in remote areas. In the village setting, a conducive environment relates to how the community treats their midwives; the more positive the treatment the higher the possibility of midwives staying in their workplaces. However, it also depends on midwives' attitudes toward the community.

Umberson and Montez (2010) argue that social support can be gathered from both formal and informal sources. Formal support means that individuals receive support or assistance from co-workers, peers and supervisors, while informal support encompasses interpersonal help amongst two or a group of people that shapes the relationship between these groups. 
The thing that differentiates this factor from other studies is the type of community support for village midwives. As well as neighbours, this study argues that the support from TBAs, Kader Posyandu, and the Heads of Village may encourage midwives to stay in their workplaces. It is clear that the relationship between midwives and the existing 'community health structure', namely TBAs and Kader Posyandu, is a unique factor that needs to be considered in crafting policies or programmes. TBAs and Kader Posyandu are considered as influential community members who are able to reach the wider community and persuade mothers to deliver their babies at health facilities.

The uniqueness of this 'community health structure' in Indonesia has benefited midwives in delivering their services. For instance, having a good relationship with TBAs has the potential to break through an 'opposing culture', which might prevent pregnant women seeking healthcare from midwives.

Another example of community support is the role of Kader Posyandu in managing Posyandu activities every month. Kader Posyandu, with the help of midwives conduct Posyandu activities in order to monitor the health conditions of women and children under five years old. Active Posyandu helps midwives in completing or achieving their work, particularly improving the health outcomes for women and children as the midwives' main target population. Thus, establishing a good relationship between village midwives and Kader Posyandu is essential.

Thus, this study points out that community supports were found to be one of the dominant factors that retain midwives in remote areas, as it was mentioned frequently in both the 'success cases' and the 'less success cases'. Success features such as community support, particularly community acceptance and partnership with other 'community health structures', are part of the equation in retaining midwives in remote areas, and hence worth considering as a GoI policy initiative. However, this is a factor that is difficult for the GoI to control. Perhaps the strategy that can be taken is to train midwives to identify the key actors in the community, thus helping them to establish good relationships from the beginning of their deployment. 
Living for a while in one area or in the village has an indirect effect in retaining midwives in remote areas. An example from this study is when midwives marry local men. This is an interesting factor because many midwives had not intended to marry a local man; yet due to the high interaction with the community, some village midwives end up marrying local men. Some village midwives that I interviewed were planning to be a village midwife only until their contract finished, but then married a local man. As a result, the village midwife decided to stay in the village.

This suggests there is a trust and sense of belonging that needs to be established between midwives and community members. By marrying local men, the need to be part of a family or social group can be achieved, which motivates midwives to stay in their workplaces. However, this finding has limitations in terms of public policy, because it is a personal preference which cannot be regulated.

A unique contribution from midwives' beliefs was found in both the 'success cases' and the 'less success cases'. This very interesting finding has not been mentioned or has had only limited discussion in other studies in Indonesia and developing countries. The Islamic belief, with over 95 percent of midwives interviewed being Moslem, drives midwives' motivation to be more patient and accepting of the challenging environment they work in. The values such as ikhlas, bersyukur, and tawakal have been embedded in midwives' lives. This indicates that there is an internalisation process of values reflected in midwives' actions or behaviours, in this case, to stay working in remote areas with all the consequences this decision entails.

Cultural values (i.e. strong kinship) and religious beliefs (i.e. being Moslem) have triggered positive attitudes that retain midwives in remote areas. The results suggest that these positive values appear to be the higher order influencing midwives to stay in their workplaces. They believe that by 'doing good to others', goodness will in turn come to them in various forms. However, this research has not explored the religiousness of each participant; rather this factor emerged as a key topic from the data set. 
In addition, midwives are motivated by their expectations or possible opportunities. According to Herzberg (2002, p. 105), motivation includes achievement (i.e. completing a challenging job or solving a challenging issue). Midwives maintain their hope by believing that there will be promotion or career development if they keep working in remote areas. This sense of hope keeps them in their workplaces.

\section{Personal Factors}

In addition to the societal factors that were frequently mentioned by research participants, there were personal factors worthy of note, though only mentioned by a small number of participants. The other unique factors, namely, 'prestige', 'hopeful attitude', and being 'powerless', contribute to retaining midwives in remote areas, and are factors which have limited discussions in previous studies. Village midwives consider that working in remote areas is not easy, but it gives them hope to improve their skills as well as their career opportunities.

'Prestige', in my study, refers to 'the uniform effect'. Wearing a particular uniform creates a sense of pride in village midwives as well as in their families. This is mostly influenced by local values where wearing a uniform is identified with success and having a stable job. An additional motivation comes from the feeling of being appreciated by family and community, which boosts their sense of pride. This suggests that wearing a uniform can boost their self-esteem or confidence as human beings. Ironically, midwives are willing to stay in their workplaces with limited or no payment as long as they can wear the uniform.

As discussed in Chapter Six, a 'hopeful attitude' is driven by the expectation of the midwife. This is a very interesting finding because it suggests that a positive attitude may stop midwives from moving. Vroon $(2002$, p. 76) points out that expectancy is defined as "a momentary belief concerning the likelihood that a particular act will be followed by a particular outcome". Village midwives believe that working in remote areas is worthwhile and that it will benefit their future career. 
At the same time, this feeling also contributes to the feeling of being 'powerless'. The results of the study point out another interesting fact about the concept of being 'powerless'. In this case, the 'powerless' situation occurs with 'limited or no option' circumstances. Due to a high supply of midwives, and a desire to protect the pride of the midwives and their families, the village midwives often have to accept any job conditions. The pressure of having a job straight after graduating is another reason for midwives feeling 'powerless'.

From my perspective, this is an unfortunate situation, where midwives dedicate their time to providing quality health services to the community, yet have no control or picture of their future career. It seems that they live in the dark. I believe one thing that keeps them motivated, even though they have this feeling, is their religion. Their belief has also allowed them to accept the situation.

While these factors were found in both the 'success cases' and the 'less success cases', other key factors were only found either in the 'success cases' or the 'less success cases'. The following sections discuss the different factors that are found exclusively in the 'success cases' or the 'less success cases'.

\subsubsection{Factors that Differ: 'The Success Cases'}

While there were no differences found in the factors attracting midwives to remote areas in the 'success cases' and the 'less success cases', different key factors emerged in terms of dealing with retaining midwives in remote areas. Thus, it is essential to draw attention to the success features found only in 'the success cases' because these factors play a crucial role in retaining midwives in remote areas. These factors encompass organisational factors (i.e. hiring local midwives) and personal factors (i.e. dedication to the profession). 


\subsubsection{Retaining Midwives in Remote Areas}

\section{Organisational Factors}

The key initiative that retains midwives in remote areas and which distinguishes the 'success cases' from the 'less success cases' is hiring locally: the policy of hiring local midwives with the aim of integrating local graduates into the job market and distributing midwives in remote areas. This approach has a positive impact on retaining midwives in remote areas of Indonesia, particularly NTB.

The programme for hiring local midwives is one of the positive alternatives that needs to be considered and addressed by policy-makers. This programme has the potential to counter some issues with retaining health workers in undesired areas, such as cultural and language barriers.

My findings show that local midwives have a better understanding of the local context or culture because they grew up in the same community. They are also familiar with the challenges and opportunities of the community and the geographical conditions, and are thus more likely to be resilient compared to midwives coming from urban areas.

An excellent example from one of the 'success cases' is the implementation of a scholarship scheme which prioritised local people. The scholarship provides an opportunity for local people to obtain free education and a long-term contract after graduating from their study. Locally hiring encourages many young women in the village to become a midwife and work in their hometown as part of their dedication to the community. It is clear that hiring local midwives with knowledge of the community minimises potential culture shock and language barriers, and has the potential to not only attract midwives but also retain them in remote areas.

This finding could actually be connected with one of the key factors that attract midwives to remote areas. Midwives are willing to work in remote areas because they want to dedicate their services to their own community. The local midwives' motivation is driven by their willingness to improve the health outcomes of their community, particularly for maternal and child health. Based on these key factors (i.e. a local hiring policy and dedication to community), it is apparent that the government should continue to recruit local midwives. This policy has the potential to not only attract midwives to remote postings, but also retain them there. 
The national government reform (i.e. from centralised governance to decentralised governance) has significantly influenced the action of local government in regard to the provision of health workers in their areas. In the spirit of decentralisation, local government should be able to craft polices based on local needs, thus the availability of midwives is increased and turnover of midwives in remote areas could be reduced.

However, Kurniati and Efendi (2012) point out that while the local government in other Asian countries, such as the Philippines and China, have more power in recruiting, staff allocation, financial incentives and advancement than the local GoI, decentralisation has provided a great opportunity for local government, enabling them to improve health services in their areas. The dependency on the national government in terms of recruiting and retaining midwives in remote villages can be contained because the local government has the power to recruit midwives based on their financial capacity and identified need.

The dilemma that might be encountered in NTB in hiring local midwives is the ability to provide competitive financial incentives. NTB has lower financial capacity as measured by the Ministry of Finance of Republic of Indonesia (Kurniati \& Efendi, 2012). My study found that many midwives received no or limited financial incentives, but, interestingly, these village midwives are still motivated to work and stay in their workplaces. Therefore, it is important to design an innovative strategy which can accommodate local midwives.

Shifting from the organisational factors (such as locally hired), there are key factors that are influenced by a personal factor such as dedication to profession. 


\section{Personal Factors}

Dedication to the profession was mostly discussed in 'the success cases'. Dedication to the profession is the intrinsic factor that influences midwives to stay in remote areas. This factor has had limited or no discussion in previous studies. The midwifery training system and the oath to the profession have contributed to shaping midwives' views about their job. Dedication to the profession needs to be developed as early as possible during midwifery training. The dedication of midwives to their profession comes from the values that have been introduced by the midwifery schools or by the organisation to which they belong. $I B I$ as a midwifery union or organisation highly values their profession, which can be seen in their theme song, which says, 'work sincerely to serve remember the oath of our job to the God'. The song clearly teaches midwives to value their profession greatly.

Dedication to profession retains midwives in the 'success cases' and is related to being accountable for community health. Village midwives are given complete responsibility to provide quality services to mothers and children in their workplaces. This responsibility is manifested by village midwives providing quality services to mothers as well as to other community members at any time. Herzberg (2003, p. 105) points out that one of five motivators that has an effect on strengthening the connection with job satisfaction is 'responsibility'. According to him 'responsibility' means "being accountable for one's own efforts or those of others, and being given responsibility for resources and self-scheduling".

A plausible reason why dedication to the profession appears to be a key factor in retaining midwives in remote areas is because it is part of their self-esteem and selfactualisation. Maslow (1954, p. 95-96 cited in Hollyforde and Whiddett, 2002) points out that self-esteem is a desire for strength, achievement, adequacy, mastery, competence, and confidence, as well as a desire for a good reputation or glory. While self-actualisation is defined as an ability to grow and develop, Hollyforde and Whiddett (2002) argue that internal or intrinsic motivation is more likely to sustain workers' activities or actions compared to extrinsic motivation. 
When it comes to personal factors, such as dedication to the profession, it is difficult to regulate because it is personal preference and depends on the characteristics of the midwives itself. However, it appears that some activities can be introduced, namely training around dedication to their profession or capacity building around being village midwives. Thus, feelings of ownership of the job and dedication to the profession grows.

This study contributes to knowledge by pointing to some important factors that retain midwives in remote areas. These two key factors encompass local hiring policies and midwives' dedication to the profession. The GoI has to 'go local', in this case exploring and valuing local resources as important factors in attracting as well as retaining midwives in remote areas. These factors also indicate that non-financial incentives need to be considered by policy-makers in order to craft the policies or programmes around the retention of midwives in remote areas of Indonesia.

\subsubsection{Factors that Differ: The 'Less Success Cases'}

Gaining more experience to obtain better skills and family support were areas that differed from those articulated in the 'success cases'. These two factors, only found in the 'less success cases', still can be used to reflect or consider why they appeared even though in general these areas are less successful in retaining midwives. In this study, family support is categorised as a societal factor, while gaining more experience to obtain better skills is a personal factor.

\subsubsection{Retaining Midwives in Remote Areas}

\section{Societal Factors}

Societal factors in this case involve informal support from family, particularly immediate family members. Family support can be influential when it comes to retaining midwives in remote areas. It depends on the midwives' circumstances. Some midwives were hired locally which means they live with or near to their family.

In Indonesia, kinship among family members and community members is relatively strong, particularly in remote areas. Community members have no hesitation in providing support to midwives in various forms, including emotional and instrumental supports. 
This study shows that the bonding between parents and their children is relatively unique. This study points out that parents are often involved with or are responsible for their children's lives even though they have married. Therefore, the local midwives often receive both emotional and instrumental aid support from their family members. This situation is one of the reasons why midwives, particularly volunteer midwives or PTT Daerah, stay in their workplaces.

Similar to any other culture, parents or family roles shape individuals' values and beliefs. In this study, family is also a source of values that have an impact on midwives' lives. The values, such as ikhlas, bersyukur, and tawakal, have been embedded in midwives' lives because they have been introduced religiously by the midwives' family, schools, or community. Franco et al. (2002, p. 1263) identify this action as a 'mental programming' process.

In addition, in the Indonesian context, a midwife's husband is the decisionmaker in the family. In some specific circumstances, such as a midwife having to move from where she is situated with her family, her husband's permission is needed. This suggests that in order to retain midwives in remote areas, the GoI needs to accommodate the whole family, for example ensuring that children may have access to education. To create an environment which negates these issues is not easy, and may need an alternative solution which allows midwives and their families to get together on a regular basis.

Another factor that was found to differ from 'the success cases' is the acquisition of work experience in order to obtain better skills. In this study, this factor is categorised as one of the personal factors. 


\section{Personal Factors}

Obtaining more experience motivates midwives to stay in remote areas, particularly in the 'less success cases'. The plausible reason is because they want to maintain or improve their skills, thus village midwives are able to provide adequate services to the community. My findings suggest the lack of 'real' practice during midwifery training has triggered their willingness to work as a village midwife. I argue that having this motivation to be better or more skillful is essential for this profession because midwives are responsible for saving people's lives. However, making remote areas the midwives' pilot training is going to create more problems. This is probably one of the reasons why maternal and child mortality rates in Indonesia have not decreased significantly.

Interestingly, this factor also appears to be a key factor that attracts midwives to remote areas in both the 'success cases' and the 'less success cases'. At a certain point (i.e. when midwives feel skillful enough), midwives have the potential to move to other places which offer better training or practices. More professional development keeps midwives in the 'less success cases', but it is not a key factor for midwives who stay in the 'success cases', which suggests that it is not enough of a factor in terms of keeping them long-term.

\subsubsection{What is Working?}

Based on the extensive data generated, my findings provide some interesting evidence for factors that have not been discussed before or where there has only been limited discussion in previous research. While the key factors have been identified in this research, it is clear that they can be divided into three categories based on their impact: crucial factors; key factors; and factors to be considered which attract and retain midwives in remote areas. Table 14 summarises the successful features in both the 'success cases' and the 'less success cases'. 
Table 14: Key Factors of Attracting and Retaining Midwives in Remote Areas

\begin{tabular}{|c|c|c|c|}
\hline Category & $\begin{array}{c}\text { 'The Success } \\
\text { Cases' }\end{array}$ & $\begin{array}{l}\text { 'The Less Success } \\
\text { Cases' }\end{array}$ & Remarks \\
\hline \multicolumn{4}{|c|}{ Attracting Factors Midwives in Remote Areas } \\
\hline \multicolumn{4}{|c|}{ Organisational Factors } \\
\hline Better income & $\sqrt{ }$ & $\sqrt{ }$ & $* *$ \\
\hline Job Security & $\checkmark$ & $\sqrt{ }$ & $* *$ \\
\hline \multicolumn{4}{|l|}{ Personal Factors } \\
\hline $\begin{array}{l}\text { Dedication to } \\
\text { community }\end{array}$ & $\checkmark$ & $\checkmark$ & $* *$ \\
\hline $\begin{array}{l}\text { Attaining more } \\
\text { experiences }\end{array}$ & $\checkmark$ & $\sqrt{ }$ & $* *$ \\
\hline \multicolumn{4}{|c|}{ Retaining Factors Midwives in Remote Areas } \\
\hline \multicolumn{4}{|c|}{ Organisational Factors } \\
\hline Better income & $\checkmark$ & $\checkmark$ & $* *$ \\
\hline Locally hired & $\checkmark$ & & $* * *$ \\
\hline \multicolumn{4}{|l|}{ Personal Factors } \\
\hline $\begin{array}{l}\text { Dedication to the } \\
\text { profession }\end{array}$ & $\checkmark$ & & $* * *$ \\
\hline $\begin{array}{l}\text { Attaining more } \\
\text { experiences }\end{array}$ & & $\checkmark$ & $*$ \\
\hline \multicolumn{4}{|l|}{ Societal Factors } \\
\hline $\begin{array}{l}\text { Community } \\
\text { support }\end{array}$ & $\checkmark$ & $\sqrt{ }$ & $* *$ \\
\hline $\begin{array}{l}\text { Culture and } \\
\text { Religious beliefs }\end{array}$ & $\checkmark$ & $\sqrt{ }$ & $* *$ \\
\hline Family support & & $\checkmark$ & $*$ \\
\hline
\end{tabular}

Notes: *need to be considered **key factor $* * *$ crucial factor

These factors were determine based on the frequency of the responses.

While there are no major differences in terms of factors that attract midwives in the 'success cases' and the 'less success cases', there are some factors that only appear in the 'success cases' or the 'less success cases'. It is clearly important to pay more attention to the key factors that appear only in the 'success cases' because these are more likely to attract, or in this case retain, midwives in remote areas. The factors that only appear in the 'less success cases' need to be considered and possibly explored further. 


\subsubsection{The Government of Indonesia in Facilitating Recruitment and Retention of Midwives}

Moving on from the first sub-question, the following sections discuss the extent of government policies or programmes that respond to and facilitate factors that influence midwives to go to and stay in remote areas.

Recruitment and retention are an important part of human resources management. Recruitment as well as retention systems need to be well developed in order to attract high quality candidates. Over the past decade, Indonesia has made significant progress in increasing the numbers of health workers and in providing better access to health services and health professionals for its citizens, particularly in remote areas. With a focus on obtaining universal healthcare in Indonesia (Efendi, 2012; Rokx et al., 2010), Indonesia has introduced a number of programmes and policies focused on attracting and retaining health workers, including midwives. Midwives are seen as strategic health workers by the GoI because of their role in supporting the GoI's programme for reducing maternal and child mortality rates.

The national government launched policies or programmes in order to improve access to health professionals, particularly in undesired areas throughout the archipelago. The major programme $B D D$ was launched in late 1980s. This programme was considered a success because it increased the number of village midwives exponentially. However, many of them were located in Puskesmas with PNS status, instead of working in their deployment areas. Initially, this programme offered midwives $P N S$ status, which meant a permanent contract until they reached retirement age. Subsequently, the guarantee of being $P N S$ midwives was amended to a fixed-term contract. Many midwives are deployed under the PTT Pusat employment status. This programme appeals to many midwives, as generous financial incentives are offered. Recently, the MoH launched Nusantara Sehat which focuses on deploying a team of health workers in the undesired areas. 
These programmes or policies are the products of the national government which impact on every province in Indonesia. Thus, these programmes or policies are able to support local government in the provision of health workers, especially in remote areas. My findings show that these programmes are able to deploy midwives in remote areas of Indonesia, but this is not enough. Therefore, in the decentralisation era, local government has implemented programmes or policies to reduce the gap in provision of health workers, including midwives. Thus, the national programmes and local programmes are complementing each other to improve access to health workers, particularly midwives in remote areas.

One of the critiques of decentralisation in Indonesia is the unclear distribution of power between the national and local government. As mentioned earlier, even though decentralisation started in 2001, local government has been limited in making decisions about allocating midwives in their areas.

On the other hand, decentralisation has provided a great opportunity for the local government to recruit midwives based on the local government's capability, which involves financial availability and creating an innovative strategy. The districts under the 'success cases' and the 'less success cases' have introduced various policies and programmes in order to equally distribute and retain midwives in remote areas. A successful scholarship scheme was introduced in the 'success cases', and aimed to attract local people from remote areas to undertake midwifery training and then be deployed for 10 years as village midwives in their own areas. This means that the programme has facilitated one of the key factors (job security) that attracts midwives to remote areas.

Another example is the Job Programme that was introduced in successful areas and which provides an opportunity for local midwives to work in the village under the supervision of senior midwives. Midwives with this status receive limited income compared to midwives with PNS or PTT status. Additionally, the programme prioritises local midwives, which has the potential to retain midwives in their workplaces, particularly in remote areas. 
Interestingly, one of the aims of hiring local midwives was specifically implemented to deal with the oversupply of midwives in some areas of NTB. As a result, many local midwives have the opportunity of a career based on their profession. Additionally, even though the policy of hiring local midwives often offers limited financial incentives, this policy has the added benefit of helping midwives to improve their techniques or skills in delivering babies. Thus, it has the potential to retain midwives in remote areas because it provides an opportunity to obtain 'real' experience.

The evidence suggests that many of the programmes and policies only focus on a limited number of initiatives, such as monetary incentives, to influence worker behaviour, and neglect other aspects, such as the work itself, achievement and recognition. These multiple factors can motivate health workers positively or negatively which definitely affects their performance (Franco et al., 2004). It appears that 'the need for survival' from Maslow's hierarchy of needs is the initial attraction to remote postings, yet when it comes to retention, 'the need for self-actualisation' cannot be ignored. More than just money is required. Therefore, it is crucial that policy-makers consider a broad range of motivational determinants which could potentially improve programmes and policies in recruiting and retaining health workers in rural and remote areas.

My study argues that work motivation is complex depending on the interaction between a variety of factors. Franco et al. (2002) also argue that a combination of factors complement each other, rather than there being only one aspect. Clearly, a combination of intrinsic (personal) and extrinsic (societal and organisation) motivational factors can play an important role in attracting midwives to remote areas. Organisational factors and societal factors have driven midwives' motivation directly and indirectly. However, there are intrinsic factors that also influence worker motivation. Deci (2002) points out that in cognitive evaluation theory, there are internal and external loci of control. Midwives stay in remote areas because they are directed by others or because of the environment. The internal locus of control is defined by Deci (2002) as self-directed feeling, while Franco et al. (2002) similarly categorise it as a personal factor. 
These findings are aligned with other studies which show that non-financial incentives are factors that need to be addressed in order to attract more applicants to remote postings (Ensor et al., 2009; Frehywot et al.,2010; Titaley et al., 2010). What this study adds, however, are identified key factors that have only limited or no discussion in previous research, such as dedication to community, dedication to the profession, 'prestige', 'hopeful attitude', and religious beliefs.

In order to identify and understand the interaction between each factor, this study implemented a multifaceted framework (Franco et al, 2004), which includes personal, organisational and societal factors. This framework is able to untangle the complexity of work motivation which allows researchers to understand the influence of each factor (Figure 23). An adaptation of the original framework was used as the original framework did not show the intense interaction between factors.

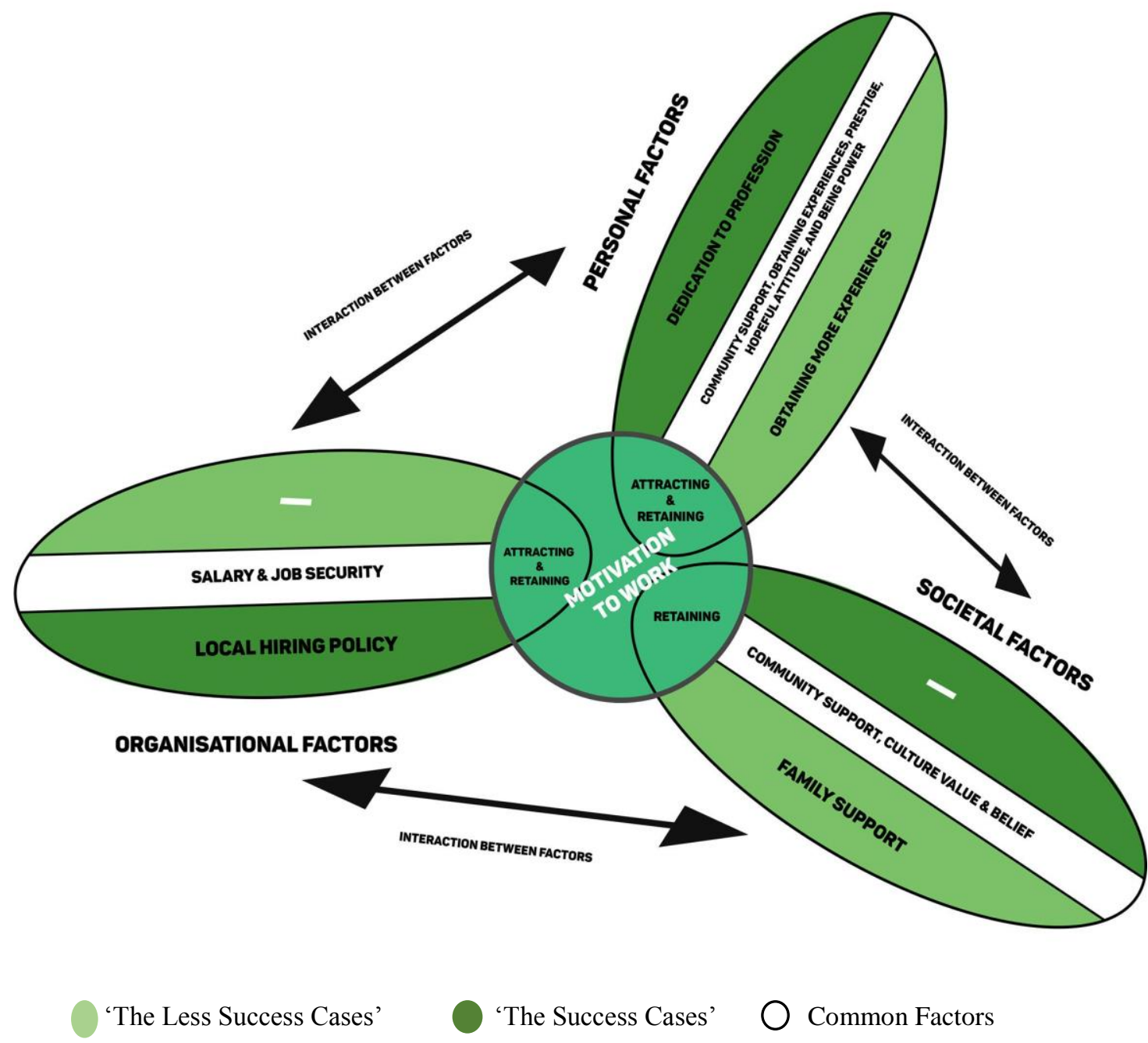

Figure 23: Pictorial Representation of the Adapted Framework (Adapted from Franco et al., 2004) 
Using SCM, blended with AI, achieved the purpose of finding out what is working best in attracting and retaining midwives in remote areas of Indonesia. I am confident that this method can be implemented in health policy settings particularly with a small sample rather than a large population. The IDI approach using AI guidance was carefully crafted and worded with the intention of exploring participants' views and experiences about attracting and retaining midwives in remote areas.

The results suggest that a financial incentive was one of the key factors that attract midwives to remote areas, yet this is not enough to retain them. The role of nonfinancial incentives cannot be disregarded, particularly in retaining midwives in remote areas. Societal factors (e.g. community support, cultural, and belief systems) were found to be the dominant factor in retention, yet interaction of factors, such as the relationship between village midwives and those in the community occurs naturally which is difficult to legislate or regulate.

This study also argues that personal factors are mainly influenced by societal factors that need to be developed by midwives themselves. However, this study also argues that these personal factors can be shaped or cultivated by societal and organisational factors, namely family, midwifery schools, IBI, Puskesmas, DHO, or $\mathrm{MoH}$.

This study argues that personal factors are mainly influenced by societal factors that need to be developed by midwives themselves. However, it also argues that these personal factors can be shaped or cultivated by societal and organisational factors, namely family, midwifery schools, IBI, Puskesmas, DHO, or MoH.

\subsection{Policy Recommendations}

This study is not a formal evaluation of the GoI policies surrounding the recruitment and retention of qualified midwives in remote areas, but it draws on existing factors that are important in attracting and retaining midwives. The recommendations are focused on the criteria of utility, feasibility, propriety, and accuracy (Engholm, 2016). 
Thus, with greater understanding of the key factors as well as an analysis of how the policies and programmes of the GoI have responded to and facilitated recruitment and retention of midwives in remote areas, there are some practical recommendations that could improve how qualified midwives can be better attracted to and retained in remote areas of Indonesia. Based on my research findings, the policy recommendations focus on four main aspects, which I have called 'LIVE' - Local hiring; Investing in career options; Values and belief system; and Evolution of midwifery training.

\subsubsection{LIVE - $\mathrm{L}$ is for Local Hiring}

Both national and local governments have successfully implemented a range of policies or programmes to improve the impact of and the availability of, health workers, particularly midwives in remote areas as part of providing Universal Health Coverage (UHC). The goal of UHC is to ensure that all people are able to obtain the health services they need without suffering financial hardship when paying for them (WHO, 2013).

The policies or programmes that attract midwives to remote postings provide higher financial incentives and consider local hiring with short to medium (one to six years) contract periods. In practice, unequal distribution of health workers remains a problem. Given the need to equalise the distribution of midwives across the country in a way that is effective, efficient, and affordable, the GoI has to refocus and change the emphasis of policies or programmes to ensure that midwives are attracted to and retained in remote postings.

While local hiring of health workers has been trialed with limited success within the medical profession (Anderson, et al., 2014), retaining midwives is a different situation. My research findings show that local hiring was a crucial factor in retaining midwives in remote areas in NTB. Therefore, it is worth further investigation to look at effective ways of hiring local people. Local hiring requires consultation with the local government, $I B I$, and midwives, so that policy-makers and relevant stakeholders understand local context, in order to create an effective policy that encompasses financial and non-financial incentives. 
The Nusantara Sehat programme focuses on improving the provision of health workers in remote areas by deploying a group of them, including doctors, nurses, and midwives, but the recruitment is centralised and thus does not take into account local needs and conditions. This approach should be modified to instead hire local health workers where possible. Another aspect that needs to be considered is the hurdle of adjusting to local culture and languages when outsiders are hired. Therefore, the local government must work within their authority and regulations to recruit local health workers where possible.

A successful programme that needs to be maintained is the combination of scholarships for students from remote areas plus the long-term bonding system. Despite unreasonable requirements implemented by the local government (i.e. midwives are not allowed to get married during the first year of their service), this programme has had a great impact on attracting and retaining midwives in remote areas in NTB. This programme allows local students to be dedicated to their community, which is another important factor that motivates midwives to work in remote areas. Thus, it is important to develop a strategic approach in order to maintain the availability of midwives in remote areas.

PTT Pusat policy was introduced more than two decades ago and has experienced some modifications in addressing recruitment issues. Even though this policy has embraced local hiring, the way in which it is carried out varies and is inconsistent even within a local district. There would be advantages in rationalising and simplifying the regulation in the recruitment process of PTT Pusat as part of midwives' career development which would have great potential in motivating midwives to work and stay in remote areas. This leads on to the next policy recommendations, which focus on investing in career development opportunities for midwives. 


\subsubsection{LIVE - I is for Investing in Career Options}

Investing in career options is another approach that needs to be addressed by the Indonesian government. The local government could, and should, consider an effective approach to incentivise midwives' services by providing options for midwives' career development. My findings suggest that job security, regular income, and attaining more experience are key factors attracting and retaining midwives in remote areas. The government needs to develop or revise strategies for addressing those key factors, for example, by promoting internal career advancement (Figure 24).

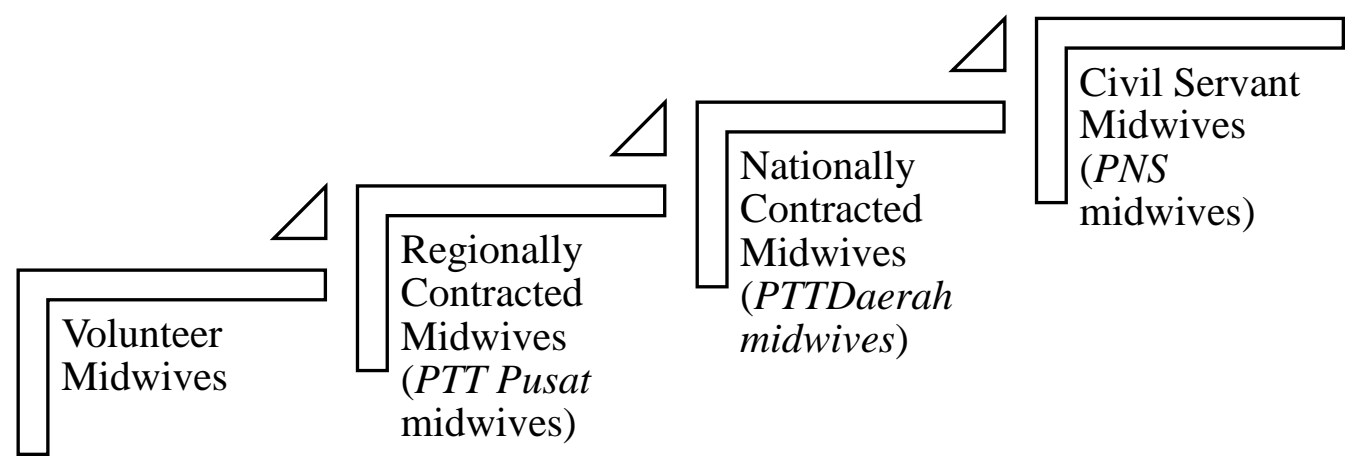

Figure 24: Internal Promotion Scheme

The evolution of PTT Pusat policy for midwives indicates that the GoI is determined to solve the complex problem of improving the availability of midwives in remote areas. However, in practice, this has not been entirely satisficatory. IBI has tried to advocate for this internal promotion system among village midwives when the opportunity to become PNS or PTT Pusat midwives has arisen. 
Currently, there is no clear career development pattern for midwives. Rather, there are many divergent paths and factors for recruiting midwives in NTB. I believe that the GoI may benefit from more diverse recruitment policies than its current monolithic approach, but it is crucial to develop a national and local based policy context on internal promotion first. Developing the regulations or guidance on internal promotion can mean circumvents a long and costly recruitment process, as well as recruitment of a well-trained midwife.

In practice, the article 11 of President Decree No. 23 year 1994, then amended to President Decree No. 77 year 2000 only stipulates that midwives are allowed to be in $P N S$, open a private practice, or pursue higher degrees as part of their career development. Initially, PTT Pusat midwives, after three years of service, automatically became $P N S$. However, due to a limited budget as an effect of the global financial crisis in the late 1980s, the GoI introduced overall zero growth of the PNS in the 1990s (Anderson et al., 2014). For midwives, from 1994, PTT Pusat was no longer automatically produced PNS staff.

Recently, the $\mathrm{MoH}$ introduced a regulation under MoH Regulation No. 7 year 2013 which created the possibility of up to two contract extensions for PTT Pusat midwives enabling nine years service. After they have finished this service, they are able to re-register as PTT Pusat, apply as PNS midwives or open a private practice. PTT Pusat midwives who want to re-register as PTT Pusat, need to submit a written letter to the $\mathrm{MoH}$ at least three months prior to their contract's end. Applications may be rejected if they do not meet administrative requirements; the requirements for PTT Pusat midwives in the districts are already met; or the budget is inadequate for future hiring. 
The Government of Indonesia needs to consider moving forward from PNS based career development to an alternative career development, such as revisiting the dual practice policy for midwives. In Indonesia, dual practice refers to fulltime health workers in public health services earning additional income in the private sector (Berman and Dexter, 2004). Most village midwives in Indonesia stay at the Polindes which provides an opportunity to open a private practice after office hours or on the weekend. According to Anderson et al. (2014) and Ensor et al. (2008) health workers receive income from various sources, such as from private practice, private incentives (private hospital), fixed salary, incentives (public hospital), health insurance, lecturing fees, incentives from pharmaceutical, industry, and laboratories. The income from private sources has always been the largest component (above 60\%).

Enabling midwives to have a private practice can reduce the burden on the national and local government annual budget. The national government allocated approximately IDR 54 trillion (approximately USD 41 million) in 2015 as its total health budget (Ministry of Health, 2016). Around 40\% (approximately IDR 30 trillion or USD 23 million) of this total health budget was allocated to payments for health workers. This allocation has been increased each year. According to Anderson et al. (2014), Indonesia should consider less expensive ways to encourage health workers to work and stay in remote area, especially as also Rokx et al. (2014) suggest concentrating on financial incentives may burden the national finances in a long run.

Indonesia may benefit from exploring different types of dual practices, for instance, public-on-public, public-on-private or private-on-private. The culture of entrepreneurship could be a new paradigm for developing an alternative solution to address the financial burden in health. I suggest that the national and local governments invest in more research on the cost effectiveness and development of dual practice, which has the potential to address key factors that motivate health workers, particularly midwives to remote postings (Figure 25). 
According to Haryani and Sanusi (2006), the government (in this case DHO and $I B I)$ have responsibility for facilitating and monitoring the establishment as well as implementation of, health services in private practice. I suggest in the initial set-up, the government facilitate an internship for midwives with public health care providers, to build capacity for starting-up a private practice, and provide some basic facilities (i.e. beds for patients and basic equipment). Midwives who set up a private practice would benefit from the opportunity to consult with $I B I$ or revelant government officials to clarify issues as part of working toward improving their practice.

Additionally, the government needs to anticipate 'predatory practice' by health workers. Private practices trigger competition for patients among health workers, which can jeopardise the quality of care. Therefore, it is also important to standardise the cost of services. Ferrinho et al. (2004) point out that dual practice may increase the potential for abuse of power, particularly in regard to limited time allocation for public services and the use of public sector facilities.

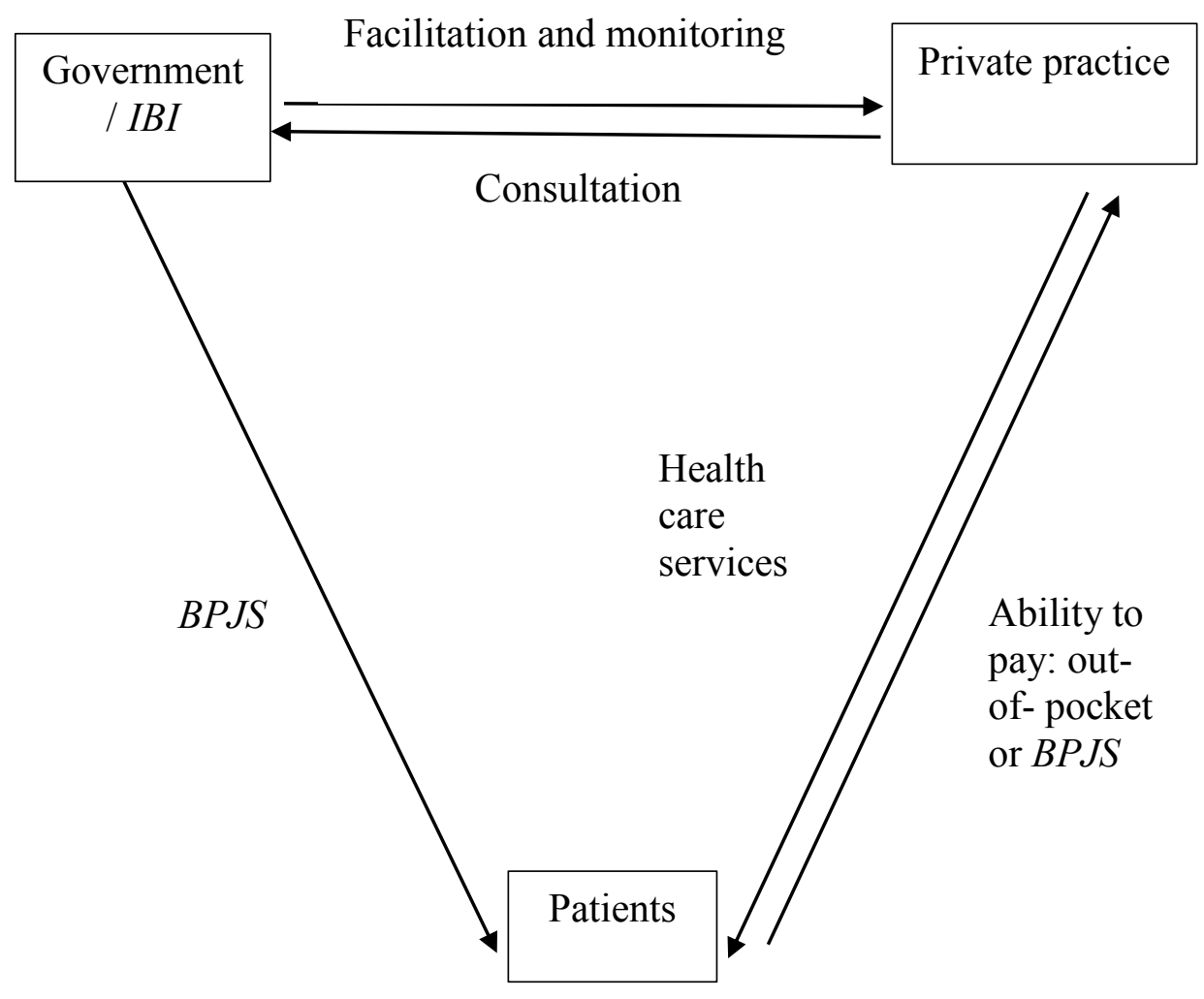

Figure 25: Developing Dual Practice Scheme 


\subsubsection{LIVE $-\mathrm{V}$ is for Values and Beliefs}

Indonesia is a diverse country with an enormous variety of ethnicities, religions, and culture. Such variety indicates that a 'one size fits all' programme might be limited in the local context. The findings point out the importance of understanding local values and beliefs, these key factors influencing midwives' motivation to stay in their workplaces. For instance, people who live in remote areas highly value kinship which contributes to retaining midwives in such areas. Community support also has an important role. There is a need, therefore, to introduce a policy or programme that allows for community participation in supporting village midwives.

The 'Village Alert' programme trialled in some areas accommodates community participation, but this programme has barely continued in many areas in Indonesia. The programme aims to increase community participation to improve the health status of community members, particularly in maternal and neonatal health. I believe there is worth in re-examining this programme, in order to maintain the availability of midwives or health workers in communities, particularly in remote areas.

Additionally, Islamic teaching provides the foundation for midwives' view of life, which greatly influences their work ethic. These key factors might not be found in other areas, therefore, there is an argument for the national or local government to trial different approaches based on their local context and needs.

\subsubsection{LIVE - E is for Evolution of Midwifery Training}

Evolution of midwifery training should be addressed by the GoI. Indonesia needs to consider moving from 'passive' approaches to 'active' approaches. In practice, most midwifery schools and training facilities are located in cities, which limits access for midwives living outside these areas and reduces their opportunities to improve their skills and knowledge. Midwives might not have time to travel to the cities, or may not be able to leave the village due to their workload and the expense of travel. 
Thus, outreach professional development programmes (providing distance learning and short courses) for midwives who live in remote areas is an essential activity in order to improve and refresh their skills. In areas with good facilities, such as a viable telecommunication system, this can be done online, but it will not in work in many remote areas of Indonesia, that have poor communication infrastructures.

Regular refresher courses for village midwives need to be conducted in remote villages instead of the city. Local training or mentoring, conducted once or twice a year could be part of their professional development programme. This could have an impact on building a good network and sharing experiences with other midwives in their areas.

Collaboration or partnership between $\mathrm{MoH}, \mathrm{DHO}, I B I$ and Midwifery schools needs to be organised effectively for skills improvement. Midwifery schools and IBI formulate training or activities that focus on reinforcing midwives' dedication to the profession. Additionally, the training may encompass a need to improve midwives' emergency response skills, as many remote areas have difficulties in accessing health facilities. In addition, it might be worth sending midwifery students to do an internship in remote villages as part of the curricula.

\subsection{Limitations and Recommendations for Further Research}

The study was implemented through SCM blended with AI to ascertain the success features for keeping midwives in remote areas in eight districts in Indonesia. Given the fluidity of the statistics and difficulty in obtaining a reliable time series, further research could be conducted looking at other districts in Indonesia; this could include the participants I was not able to interview - midwives who had worked in the 'less success cases' but moved to other places.

In addition, as my findings of the study suggest that the strength of the Muslim beliefs held by the majority of the Indonesian population was an influential factor in the retention of midwives in remote areas, interviewing midwives in an area that is not predominantly Muslim would be an interesting piece for further research. 
It would also be useful to conduct a survey with midwives from across Indonesia, incorporating into the survey the key factors that I have identified in this study; this would assist in quantifying the most important factors that attract and retain midwives in remote areas.

\subsection{Conclusion}

Recruitment and retention of midwives in remote areas has continuously been an issue, in both developed and developing countries. I wondered what the contributory factors to this issue are. Are there any areas that can attract as well as retain midwives in remote areas? If yes, what are the contributory factors of their success? This study provided an opportunity to unpack the factors that attract and retain midwives in remote areas as well as the role of policies/programmes of the GoI.

The results of my research are illustrated using the tree metaphor (Figure 26). The tree is a symbol of life and protection which starts from a small beginning and then grows. By listening to government officials and midwives tell of their experiences including those who were PNS, PTT Pusat (i.e. remote and very remote areas), regional contract-based, and volunteer midwives, it is clear that each participant has a different perspective on their position in the community.

The soil as the source of nutrients is used to illustrate midwives' experiences, views, and their attitudes that were examined. And then the roots absorb and store the nutrients so they provide food for the tree to grow. These nutrients are the various factors that have a positive influence on retaining midwives. The three main factors are personal, societal and organisational.

In order to grow a healthy big tree with dense foliage, the trunk has a significant role in delivering food and water. Each concentric layer of the trunk indicates a year of growth. In this context, each concentric layer signifies each factor which influences the midwives. Personal factors appear to be dominant in influencing midwives to stay working in remote areas. The metaphor also suggests that no midwife stays in her working area because of a single factor. Rather, her decision reflects an interaction between various factors. 
The midwives are represented as leaves that thrive to provide oxygen for the birds. The birds are the symbol of mothers, children, and other members of the community that finally have better access to basic health care. However, it is important to understand that there are other factors that need to be considered in order to stop the leaves from falling off the tree. Each factor has a varying degree of influence in the life of the midwife.

... responsibility to our profession, that makes us survive. We do not care about the money, our concern is our patients. We want them safe... when we see pregnant women, we will standby and pray to be able to help them, so the mothers and the babies are healthy... We feel satisfied to see the mother and the baby safe... (Civil servant midwife/PNS - SC) 


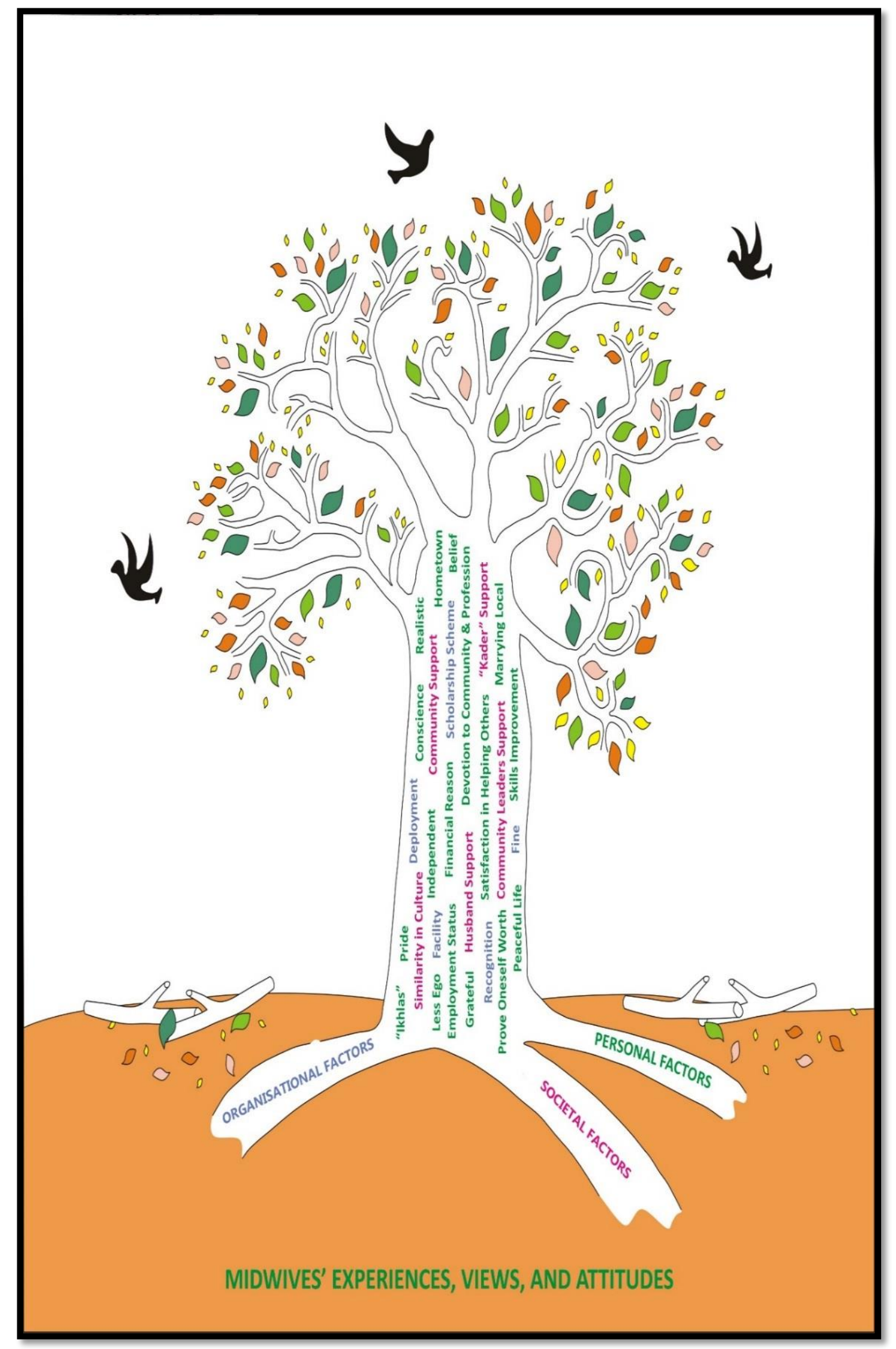

Figure 26: The Tree Metaphor 


\section{REFERENCES}

Achadi, E., Scott, S., Pambudi, E. S., Makowiecka, K., Marshall, T., Adisasmita, A., . . Ronsmans, C. (2007). Midwifery provision and uptake of maternity care in Indonesia. Tropical Medicine \& International Health, 12(12), 1490-1497. doi:10.1111/j.1365-3156.2007.01957.x

Agus, Y., \& Horiuchi, S. (2012). Factors influencing the use of antenatal care in rural West Sumatra, Indonesia. BMC pregnancy and childbirth, 12(1), 9-9. doi:10.1186/1471-2393-12-9

Agus, Y., Horiuchi, S., \& Porter, S. E. (2012). Rural Indonesia women's traditional beliefs about antenatal care. BMC research notes, 5(1), 589-589. doi:10.1186/1756-0500-5-589

Ainy, A., Makky, M., Fajar, A. N. (2012). Alert village: An awareness and health promotion programme on healthy behaviours. $B M C$.

Ambaretnani, P. (2012). Paraji and Bidan in Rancaekek: integrated medicine for advanced partnerships among traditional birth attendants and community midwives in the Sunda region of West Java, Indonesia: Leiden Ethnosystems and Development (LEAD), Faculty of Science, Leiden University.

Andajani-Sutjahjo, S., \& Manderson, L. (2004). Stillbirth, neonatal death and reproductive rights in Indonesia. Reproductive Health Matters, 12(24), 181-188. doi: $10.2307 / 3776593$

Anderson, I.,Meliala, A., Marzoeki. P., Pambudi., E. (2004). The production distribution, and performance of physicians, nurses, and midwives in Indonesia: An update. WHO. NW, Washington.

Baird, J., Ma, S., \& Ruger, J. P. (2011). Effects of the World Bank's maternal and child health intervention on Indonesia's poor: Evaluating the safe motherhood project. Social Science \& Medicine, 72(12), 1948-1955. doi:http://dx.doi.org/10.1016/j.socscimed.2010.04.038

BAPPENAS. (2012). Report on the achievement of Millennium Development Goals in Indonesia 2011. Jakarta National Development Planning Agency (BAPPENAS) Retrieved from http://www.undp.org/content/dam/undp/library/MDG/english/MDG\%20Country $\% 20$ Reports/Indonesia/Report $\% 20$ on $\% 20$ the $\% 20$ Achievement $\% 20$ of $\% 20$ the $\% 2$ 0MDGs\%20in\%20Indonesia\%202011.pdf.

Barclay, L. (2008). Woman and midwives: position, problems and potential. Midwifery, 24(1), 13-21. doi:10.1016/j.midw.2006.07.003

Baron, R. A. (1991). Motivation in work settings: Reflections on the core of organizational research. Motivation and Emotion, 15(1), 1-8. doi:10.1007/bf00991472 
Bennett, S., \& Franco, L. (2000). Health worker motivation and health sector reform.

Berman, P., \& Dexter, C. (2004). Multiple public-private jobholding of health care providers in developing countries. London. Retrieved from http://www.heartresources.org/wp-content/uploads/2012/10/Multiple-public-private-jobholdingof-healthcare-providers.pdf

BPDPSK. (2016). Program Nusantara sehat untuk masyarakat Indonesia. Jakarta. Retrieved from http://www.bppsdmk.depkes.go.id/web/index.php?select=berita\&bid=480\&judu $1=$ Program $\% 20$ Nusantara $\% 20$ Sehat $\% 20$ untuk $\% 20$ masyarakat $\% 20$ Indonesia\&ni $\mathrm{d}=350$

Braun, V., \& Clarke, V. (2006). Using thematic analysis in psychology. Qualitative Research in Psychology, 3(2), 77-101. doi:http://dx.doi.org/10.1191/1478088706qp063oa

Braun, V., \& Clarke, V. (2012). Thematic Analysis (Cooper, H ed.). Washington: APA books.

Brenes, J. M. (2012). " Si Se Puede" Latino students can succeed in school: A success case method Study. (Ph.D. ), Western Michigan University, Michigan

Brinkerhoff, R. O. (2003). The success case method: Find out quickly what's working and what's not. San Francisco, CA: Berrett-Koehler.

Brinkerhoff, R. O. (2005). The Success Case Method: A strategic evaluation approach to increasing the value and effect of training. Advances in Developing Human Resources, 7(1), 86-101. doi:10.1177/1523422304272172

Brinkerhoff, R. O., \& Dressler, D. E. (2003). Using the success impact evaluation method to enhance training value \& impact. The Learning Alliance all reserved. San Diego, CA.

Bushe, R. G., \& Kassam, F. A. (2005). When is Appreciative Inquiry transformational? . The Journal of Applied Behavioural Science, 41(2), 161-181. doi:10.1177/0021886304270337

Clarke, V., \& Braun, V. (2013). Teaching Thematic Analysis: Overcoming challenges and developing strategies for effective learning. The Psychologist, 26(2), 120123.

Cooperrider, D. L., Whitney, D. K., \& Stavros, J. M. (2008). Appreciative inquiry handbook: for leaders of change. California; Brunswick, $\mathrm{OH}$ : Crown Custom Publishing, Inc.

Countdown. (2012). Building a future for women and children: The 2012 report Retrieved from http://www.countdown2015mnch.org/documents/2012Report/2012Complete.pdf. 
Creswell, J. W. (1998). Qualitative Inquiry and research design: Choosing among five traditions. California: Sage Publications.

Creswell, J. W. (2009). Research design: qualitative, quantitative, and mixed methods approaches. Los Angeles: Sage.

Crotty, M. (1998). The foundations of social research: meaning and perspective in the research process. St Leonards, NSW: Allen \& Unwin.

Curry, A. L., Nembhard, M. I., \& Bradley, H. E. (2009). Qualitative and mixed methods provide unique contributions to outcomes research. American Hearh Association, 119, 1442-1452.

D’Ambruoso, L., Achadi, E., Adisasmita, A., Izati, Y., Makowiecka, K., \& Hussein, J. (2007). Assessing quality of care provided by Indonesian village midwives with a confidential enquiry. Midwifery, 25(5), 528-539. doi:10.1016/j.midw.2007.08.008

D’Ambruoso, L., Byass, P., \& Qomariyah, S. N. (2010). 'Maybe it was her fate and maybe she ran out of blood': Final caregivers' perspectives on access to care in obstetric emergencies in rural Indonesia. Journal of Biosocial Science, 42(2), 213-241. doi:10.1017/s0021932009990496

D’Ambruoso, L., Byass, P., Qomariyah, S. N., \& Ouédraogo, M. (2010). A lost cause? Extending verbal autopsy to investigate biomedical and socio-cultural causes of maternal death in Burkina Faso and Indonesia. Social Science \& Medicine, 71(10), 1728-1738. doi:10.1016/j.socscimed.2010.05.023

Deci, E. L. (2002). Cognitive Evaluation Theory. In S. Hollyfrode \& S. Whiddett A(Eds), The Motivation Handbook (pp. 39-47). London. Chartered Institute of Personnel and Development.

Denzin, N. K., \& Lincoln, Y. S. (2000). Introduction: The discipline and practice of qualitative research. In N. K. Denzin \& Y. S. Loincoln (Eds.), Handbook of Qualitative Research (2nd ed., pp. 1-28). Thousand Oaks, CA: Sage.

Dieleman, M., Cuong, P. V., Anh, L. V., \& Martineau, T. (2003). Identifying factors for job motivation of rural health workers in North Viet Nam. Human resources for health, 1(1), 10-10. doi:10.1186/1478-4491-1-10

Dierckx de Casterlé, B., Gastmans, C., Bryon, E., \& Denier, Y. (2012). QUAGOL: A guide for qualitative data analysis. International Journal of Nursing Studies, 49(3), 360-371. doi:http://dx.doi.org/10.1016/j.ijnurstu.2011.09.012

Dolea, C., Stormont, L., \& Braichet, J.-M. (2010). Evaluated strategies to increase attraction and retention of health workers in remote and rural areas. Bulletin of the World Health Organization, 88(5), 379-385. doi:10.2471/BLT.09.070607

Efendi, F. (2012). Health worker recruitment and deployment in remote areas of Indonesia. Rural and remote health, 12(2008). 
Efendi, F., Chen, C.-M., Nursalam, N., Andriyani, N. W. F., Kurniati, A., \& Nancarrow, S. A. (2016). How to attract health students to remote areas in Indonesia: a discrete choice experiment. The International Journal of Health Planning and Management, 31(4), 430-445. doi:10.1002/hpm.2289

Egger, D., Lipson, D., \& Adams, O. (2000). Achieving the right balance: The role of policymaking processes on managing human resources for health. Geneva: World Health Organization.

Ellis, C. (2004). The ethnographic I: A methodological novel about authoenography. Walnut Creeek, CA: AltaMira Press.

Engholm, K. R. (2016). A meta-evaluation of the Success Cases Method applied to a leadership development programme. (Doctor of Psychology), The State University of New Jersey, New Brunswick, New Jersey

Ensor, T., Nadjib, M., Quayyum, Z., \& Megraini, A. (2008). Public funding for community-based skilled delivery care in Indonesia: To what extent are the poor benefiting? The European Journal of Health Economics, 9(4), 385-392. doi:10.1007/s10198-007-0094-x

Ensor, T., Quayyum, Z., Nadjib, M., \& Sucahya, P. (2009). Level and determinants of incentives for village midwives in Indonesia. Health Policy and Planning, 24(1), 26-35. doi:10.1093/heapol/czn040

Forshee, J. (2006). Culture and customs of Indonesia. Westport, Conn: Greenwood Press.

Franco, L. M., Bennett, S., \& Kanfer, R. (2002). Health sector reform and public sector health worker motivation: A conceptual framework. Social Science \& Medicine, 54(8), 1255-1266. doi:10.1016/S0277-9536(01)00094-6

Franco, L. M., Bennett, S., Kanfer, R., \& Stubblebine, P. (2004). Determinants and consequences of health worker motivation in hospitals in Jordan and Georgia. Social Science \& Medicine, 58(2), 343-355. doi:10.1016/S0277-9536(03)00203$\mathrm{X}$

Frankenberg, E., Butternheim, A., Sikoki, B., Suriastini, W. (2009). Do women increase their use of reproductive health carewhen it becomes more available? Evidence from Indonesia. Study on Family Planning. 40(1), 27-38.

Frankenberg, E., Suriastini, W., \& Thomas, D. (2005). Can expanding access to basic healthcare improve children's health status? Lessons from Indonesia's 'midwife in the village' programme. Population Studies, 59(1), 5-19.

doi:10.1080/0032472052000332674

Frankenberg, E., \& Thomas, D. (2001). Women's health and pregnancy outcomes: Do services make a difference? Demography, 38(2), 253-265. doi:10.2307/3088304 
Frehywot, S., Mullan, F., Payne, P. W., \& Ross, H. (2010). Compulsory service programmes for recruiting health workers in remote and rural areas: do they work? Bulletin of the World Health Organization, 88(5), 364-370. doi:10.2471/BLT.09.071605

Ghauri, M. T. (2011). Religious motivation: A multiplying force. The Dialogue, 6(2).

Glaser, B. G., \& Strauss, A. L. (1967). The discovery of grounded theory: Strategy for qualitative research. Piscataway, New Jersey Transaction

Global Health Workforce Alliance. (2015). Health workforce 2030. Geneva. Retrieved from

http://www.who.int/workforcealliance/knowledge/resources/strategy_brochure920-14.pdf?ua=1

Global Health Workforce Alliance, \& World health Organization. (2013 ). A universal truth: No health without a workforce Geneva: WHO Retrieved from http://www.who.int/workforcealliance/knowledge/resources/GHWAa universal truth report.pdf?ua $=1$.

Greeley, A. (1997). Coleman revisited: Religious structures as a source of social capital. The American Behavioral Scientist; 40(5); 587-594.

Hatt, L., Stanton, C., Makowiecka, K., Adisasmita, A., Achadi, E., \& Ronsmans, C. (2007). Did the strategy of skilled attendance at birth reach the poor in Indonesia? Bulletin of the World Health Organization, 85(10), 774-782.

Heady, H. R., Phillips, D., \& Briggs, E. (2006). Rural health-care: How to recruit and retain health professionals. Journal of Medical Practice Management, 21(4), 403-224.

Henderson, L., \& Tulloch, J. (2008). Incentives for retaining and motivating health workers in Pacific and Asian countries. Hum Resour Health, 6. doi:10.1186/1478-4491-6-18

Hennessy, D., Hick, D., Koesno, H. (2006). The training and development needs of midwives Indonesia: Paper 2 of 3. Pubmed. 4(9).

Haryani, N., Sanusi, R. (2006). Kebijakan praktek bidan. Penegakan kebijakan registra dan praktek bidan swasta di kota Jambi. Working Paper Series No. 25.

Heywood, P., Harahap, P. N., Ratminah, M., Elmiati. (2010). Current situation of midwives in Indonesia: Evidence from 3 districts in West Java Province. BMC. 3(287).

Herzberg, F. (2003). One more time: How do you motivate people? Harvard Business Review on Motivating People. Boston: The Harvard Business School Publishing 
Heywood, P., \& Choi, Y. (2010). Health system performance at the district level in Indonesia after decentralization. BMC International Health and Human Rights, 10(1), 3 .

Hollyforde, S., \& Whiddett, S. (2002). The motivation handbook. London: Chartered Institute of Personnel and Development.

Hoope-Bender, P. T., Campbell, J., Fauveau, V., \& Matthews, Z. (2011). The state of the world's midwifery 2011: Delivering health, saving lives. International Journal of Gynecology and Obstetrics, 114(3), 211-212.

House, J. S., Umberson, D., \& Landis, K. R. (1988). Structures and processes of social support. Annual Review of Sociology, 14, 293-318.

Howieson, J. (2011). A constructive inquiry approach:belnding appreciative inquiry with traditional research and evaluation methods. Evaluation Journal of Australasia, 11(2), 14-22.

Indrawati, S. M. (2002). Indonesian economic recovery process and the role of government. Journal of Asian Economics, 13(5), 577-596. doi:http://dx.doi.org/10.1016/S1049-0078(02)00176-8

Jack, H., Canavan, M., Taylor, L., Bradley, E., \& Ofori-Atta, A. (2013). Recruitment and retention of mental health workers in Ghana. PloS one. doi:10.1371/journal.pone.0057940

Jenaro, C., Flores, N., Orgaz, M. B., \& Cruz, M. (2011). Vigour and dedication in nursing professionals: towards a better understanding of work engagement. Journal of advanced nursing, 67(4), 865-875.

Kanfer, R. (1990). Motivation theory and industrial and organizationalpPsychology. In M. D. Dunnette \& L. M. Hough (Eds.), Handbook of Industrial and Organizational Psychology. California: Consulting Psychologists

Kanfer, R. (1999). Measuring health worker motivation in developing countries. Bethesda, Maryland: Partnership for Health Reform Project.

Krauss, S. E. (2005). Research paradigms and meaning making: A primer. Qualitative Report, 10(4), 758-770.

Krefting, L. (1991). Rigor in qualitative research: The assessment of trustworthiness The American Journal of Occupational Therapy, 45(3), 214-222.

Kristiansen, S., \& Santoso, P. (2006). Surviving decentralisation?: Impacts of regional autonomy on health service provision in Indonesia. Health Policy, 77(3), 247259. doi:http://dx.doi.org/10.1016/j.healthpol.2005.07.013

Kurniati, A. (2007). Incentives for medical workers and midwives in very remote areas an experience from Indonesia. Paper presented at the 2nd Conference of Asia Pasific Action Alliance on HRH, Beijing, China. 
Kurniati, A., \& Efendi, F. (2012). Kajian SDM Kesehatan di Indonesia. Jakarta Salemba Medika.

Lakshminarayanan, R. (2003). Decentralisation and its implications for reproductive health: The Philippines experience. Reproductive Health Matters, 11(21), 96107. doi: $10.2307 / 3776674$

Lather, P. (2006). Paradigm proliferation as a good thing to think with: Teaching research in education as a wild profusion. International Journal of Qualitative Studies in Education, 19(1), 35-57. doi:10.1080/09518390500450144

Leimena, S. L. (1989). Posyandu: A community based vehicle to improve child survival and development. Asia-Pasific of Public Health. 3(4), 264-267.

Liu, X., Dou, L., Zhang, H., Sun, Y., \& Yuan, B. (2015). Analysis of context factors in compulsory and incentive strategies for improving attraction and retention of health workers in rural and remote areas: a systematic review. Human resources for health, 13(1), 61. doi:10.1186/s12960-015-0059-6

Liu, X., Martineau, T., Chen, L., Zhan, S., \& Tang, S. (2006). Does decentralisation improve human resource management in the health sector? A case study from China. Soc Sci Med., 63. doi:10.1016/j.socscimed.2006.05.011

Lo Bianco, J. (2010). The importance of language policies and multilingualism for cultural diversity. International Social Science Journal, 61(199), 37-67.

Maehr, M. L., \& Braskamp, L. A. (1986). The motivation factor. Canada: D.C. Heath and Company

Map of Indonesia. (2014). Retrieved from http://bing.com/images/search?. 12 May 2014.

Martin, C., Southall, A., Shea, E., \& Marr, A. (2008). The importance of a Multifaceted Approach in the assesment and treatment of childhood feeding disorders. Sage, $7(2)$.

Maslow, A. H. (1954). Motivation and personality New York: Harper and Row

Mayo, E., \& Mathews, M. (2006). Spousal perspectives on factors influencing recruitment and retention of rural family physicians. Canadian Journal of Rural Medicine, 95(1), 42-48.

Merriam, S. B. (2009). Qualitative research: A guide to design and implementation. San Fransisco, CA: Jossey-Bass.

Merriam, S. B., Johnson-Bailey, J., Lee, M.-Y., Kee, Y., Ntseane, G., \& Muhamad, M. (2001). Power and positionality: Negotiating insider/outsider status within and across cultures. International Journal of Lifelong Education, 20(5), 405-416. doi:10.1080/02601370120490 
Ministry of Health. (2004). Peraturan Menteri Kesehatan Republik Indonesia No. 1199/MENKES/PER/X/2004 (Ministry of Health Regulation No.

1199/MENKES/PER/X/2004 regarding Guidelines for the Recruitment of Health

Workers on a Contract Basis in Public Health Facilities). Jakarta Kemerntrian

Kesehatan Republik Indonesia Retrieved from

Http://perpustakaan.Depkes.Go.Id:8180/bitstream//123456789/1086/3/permenke s\%20ri\%20no.\%201199-menkes-per-x-2004.Pdf.

Ministry of Health. (2007a). Keputusan Menteri Kesehatan Republik Indonesia No. 1235/MENKES/SK/XII/2007 (Ministry of Health Decree No.

1235/MENKES/SK/XII/2007 regarding Provision of Incentives for Health

Workers who Undertake Special Assignments). Jakarta: Republik Indonesia

Retrieved from

https://kbmalmuthmainnah.files.wordpress.com/2010/03/kepmenkes-no-1235-

2007-ttg-insentif-penugasan-sdm-depkes1.pdf

Ministry of Health. (2007b). Peraturan Menteri Kesehatan Republik Indonesia No.

1231/MENKES/PER/XI/2007 tentang Penugasan Khusus Sumber Daya

Manusia Kesehatan (Ministry of Health Regulation No.

1231/MENKES/PER/XI/2007 regarding Special Assignment of Health Workers).

Jakarta Republik Indonesia

Ministry of Health. (2007c). Keputusan Menteri Kesehatan Republik Indonesia No.

508/MENKES/SK/IV/2007 (Ministry of Health Decree No.

508/MENKES/SK/SK/IV/2007 regarding Determination of the Length of Service and incentives for Non-Permanent Medical Staff and Midwives in Health Facilities). Jakarta: Republik Indonesia.

Ministry of Health. (2007d). Peraturan Menteri Kesehatan Republik Indonesia No. 949/MENKES/PER/VIII/2007 (Ministy of Health Regulation No. 949/MENKES/VIII/2007 regarding criteria for remote and very remote health facilites). Jakarta: Republik Indonesia.

Ministry of Health. (2008). Measuring the Fulfilment of Human Rights in Maternal and Neonatal Health. Jakarta

Ministry of Health. (2011a). Rencana Pengembangan Tenaga Kesehatan Tahun 2011 2025. Jakarta: Kementrian Kesehatan Republik Indonesia Retrieved from http://www.who.int/workforcealliance/countries/inidonesia_hrhplan_2011_2025 .pdf.

Ministry of Health. (2011b). Riset Kesehatan Dasar (RISKESDAS). Jakarta

Ministry of Health. (2012). Profil Data Kesehatan Indonesia Tahun 2011. Jakarta

Ministry of Health. (2013). Profil Kesehatan Indonesia 2012. Jakarta 
Ministry of Health. (2015). Profil Kesehatan Indonesia Tahun 2014. Jakarta.

Kementrian Kesehatan Republik Indonesia Retrieved from

http://www.depkes.go.id/resources/download/pusdatin/profil-kesehatan-

indonesia/profil-kesehatan-indonesia-2014.pdf.

Ministry of Health. (2015). Peraturan Menteri Kesehatan Republik Indonesia No. 23

Tahun 2015 tentang Penugasan Khusus Tenaga Kesehatan Berbasis Team (Ministry of Health Regulation No. 23 year 2015 regarding Special Assignment of Team Based Health Workers to Support Nusantara Sehat Programme).

Ministry of Health. (2016). Profil Kesehatan Indonesia Tahun 2015. Jakarta

Ministry of Rural Development of Disadvantaged Regions, and Transmigration Republic of Indonesia (Kementrian Desa, Pembangunan Daerah Tertinggal dan Transmigrasi or KDPDTT). (2014). Provinsi Tertinggal. Retrieved from http://www.kpdt.go.id/index.asp.

Ministry of Health and Ministry of Home Affair. (2010). Pedoman pengembangan desa and kelurahan siaga aktif. Keputusan Menteri Kesehatan Republik Indonesia No. 1529/Menkes/SK/X/2010. Jakarta.

Morse, J. M. (1994). Designing funded qualitative research In N. K. Denizin \& Y. S. Lincoln (Eds.), Handbook of Qualitative Research (2nd ed.). California: Sage

Munga, M. A., Songstad, N. G., Blystad, A., \& Mæstad, O. (2009). The decentralisation-centralisation dilemma: recruitment and distribution of health workers in remote districts of Tanzania. BMC International Health and Human Rights, 9(9). doi:10.1186/1472-698x-9-9

Nancy, D. L., \& Edith, K. (1994). The health of women, beyond maternal and child health. In R. P. David \& V. Yola (Eds.), Health and Development (first ed., pp. 122-137). London: Routledge.

Patton, M. Q. (1990). Qualitative Evaluation and Research Methods. Beverly Hills, CA: Sage

Patton, M. Q. (2001). Qualitative research and evaluation methods: Integrating Theory and Practice. California SAGE.

Patton, M. Q. (2002). Qualitative research and evaluation methods. Thousand Oaks, California: SAGE Publications.

Peña, S., Ramirez, J., Becerra, C., Carabantes, J., \& Arteaga, O. (2010). The chilean rural practitioner programme: a multidimensional strategy to attract and retain doctors in rural areas. Bulletin of the World Health Organization, 88(5), 371378. doi:10.2471/BLT.09.072769

Penny, P. (1994). Maternal and child health care strategies. In R. P. David \& V. Yola (Eds.), Health and Development (pp. 138-155). London: Routledge. 
Perdok, H., Jans, S., Verhoeven, C., Henneman, L., Wiegers, T., Mol, W. B., . . Jonge, d. A. (2016). Opinions of maternity care professionals and other stakeholders about integration of maternity care: a qualitative study in the Netherlands. $B M C$ pregnancy and childbirth, 16(188).

Piggot-Irvine, E. (2009). Evaluation of a special education professional development program. Evaluation Journal of Australasia, 9(1), 20-30.

PMMRC. (2015). Ninth Annual Report of the Perinatal and Maternal Mortality Review Committee. Retrieved from New Zealand.

Priest, K. L., Kaufman, E. K., Brunton, K., \& Seibel, M. (2013). Appreciative Inquiry: A tool for organizational, programmatic, and project-focused change. Journal of Leadership Education Journal Article, 12(1), 18-33.

Pritchard, D. R., \& Ashwood, L. E. (2008). Managing Motivation New York: Routledge.

Pugh, D. S., \& Hickson, D. J. (2007). Writers on organisations (Sixth ed.): Penguin Books

Reinharz, S. (1992). Feminist methods in social research. Oxford Oxford Press.

Republik Indonesia. (2014). Undang-Undang Republik Indonesia No. 23 Tahun 2014. Jakarta Republik Indonesia. Retrieved from www. Indolaw.org. 3 July 2017.

Republik Indonesia. (1945). Undang-Undang Dasar Negara Republik Indonesia Tahun 1945 (The 1945 Constitution). Jakarta Republik Indonesia Retrieved from https://portal.mahkamahkonstitusi.go.id/eLaw/mg58ufsc89hrsg/UUD_1945_Per ubahan.pdf.

Republik Indonesia. (2000). Keputusan Presiden Republik Indonesia No. 77 Tahun 2000 (President Decree No. 77 year 2000 regarding the Amandement of President Decree No. 23 year 1994 regarding Recruitment of Non-Permanent Midwives). Jakarta: Republik Indonesia Retrieved from http://www.hukumonline.com/pusatdata/download/f127207/node/19069.

Republik Indonesia. (2009). Undang -Undang Republik Indonesia Nomor 36 Tahun 2009 Tentang Kesehatan. Jakarta Republik Indonesia Retrieved from http://sireka.pom.go.id/requirement/UU-36-2009-Kesehatan.pdf.

Robertson, I., \& Smith, M. (1985). Motivation and job design: Theory, research and practice. London: Institute of Personnel Management.

Rockers, P. C., Jaskiewicz, W., Kruk, M. E., Phathammavong, O., Vangkonevilay, P., Paphassarang, C., . . . Tulenko, K. (2013). Differences in preferences for rural job postings between nursing students and practicing nurses: evidence from a discrete choice experiment in Lao People's Democratic Republic. Human resources for health, 11(1), 22. doi:10.1186/1478-4491-11-22 
Rockers, P. C., Jaskiewicz, W., Wurts, L., Kruk, M. E., Mgomella, G. S., Ntalazi, F., \& Tulenko, K. (2012). Preferences for working in rural clinics among trainee health professionals in Uganda: a discrete choice experiment. BMC health services research, 12(1), 212. doi:10.1186/1472-6963-12-212

Rokx, C., Giles, J., Satriawan, E., Marzoeki, P., Harimurti, P., \& Yavuz, E. (2010). New insight into the provision of health services in Indonesia. Washington DC: The World Bank

Ronsmans, C., Scott, S., Qomariyah, S. N., Achadi, E., Braunholtz, D., Marshall, T., . . Graham, W. J. (2009). Professional assistance during birth and maternal mortality in two Indonesian districts. Bulletin of the World Health Organization, 87(6), 416-423. doi:10.2471/blt.08.051581

Sánchez-Moreno, E., de La Fuente Roldán, I.-N., Gallardo-Peralta, L. P., \& Barrón López de Roda, A. (2015). Burnout, informal social support and psychological distress among social workers. Oxford University Press on behalf of The British Association of Social Workers, 45(8), 2368-2386. doi:10.1093/bjsw/bcu084

Schwartz, S. H. (1997). Value and culture In D. Munro, J. F. Schumaker, \& S. C. Carr (Eds.), Motivation and Culture. New York: Routledge

Schwartz, S. H. (1999). A theory of cultural value and some implications for work. Applied Psychology: An International Review, 48(1), 23-47.

Shankar, A., Sebayang, S., Guarenti, L., Utomo, B., Islam, M., Fauveau, V., \& Jalal, F. (2008). The village-based midwife programme in Indonesia. Lancet, 371(9620), 1226-1229. doi:10.1016/s0140-6736(08)60538-3

Shefner-Rogers, C. L., \& Sood, S. (2004). Involving husbands in safe motherhood: Effects of the Suami Siaga campaign in Indonesia. Journal of Health Communication, 9(3), 233-258. doi:10.1080/10810730490447075

Shetty, P. (2013). More midwives needed to improve maternal and newborn survival. Bulletin World Health Organisation, 91(11), 804-805.

Shiffman, J. (2003). Generating political will for safe motherhood in Indonesia. Social Science \& Medicine, 56(6), 1197-1207. doi:http://dx.doi.org/10.1016/S02779536(02)00119-3

Shrestha, R. (2010). The village midwife program and infant mortality in Indonesia. Bulletin of Indonesian economic studies, 46(2), 193-211. doi:10.1080/00074918.2010.486109

Shrestha, S. (2002). Increasing contraceptive acceptance through empowerment of female community health volunteers in rural Nepal. Journal Health Population Nutrition, 20.

Smith, I. E. (2002). Facing evaluation challenges in the real world: A case-based approach. Rollins School of Public Health. Emory University, Atlanta, GA. 
Smith, J., \& Firth, J. (2011). Qualitative data analysis: the framework approach. Nurse researcher, $18(2), 52-62$.

Spilsbury, J. C., \& Korbin, J. E. (2013). Social networks and informal social support in protecting children from abuse and neglect: Community ties and supports promote children's safety. Child Abuse \& Neglect, 37, Supplement, 8-16. doi:http://dx.doi.org/10.1016/j.chiabu.2013.10.027

Stopford, R., Winkley, K., \& Ismail, K. (2013). Social support and glycemic control in type 2 diabetes: A systematic review of observational studies. Patient Education and Counseling, 93(3), 549-558. doi:http://dx.doi.org/10.1016/j.pec.2013.08.016

Stretton, D. V., \& Bolon, D. S. (2009). Recruitment and Rrtention of rural hospital administrators: A Multifaceted Approach. Hospital Topics, 87(1), 10-14.

Struthers, J. (2012). Analytic autoethnography: A tool to infrom the lecturer's use of Self when teaching mental health nursing? (Doctoral Thesis), Lancaster University UK. Retrieved from http://eprint.lancs.ac.uk/62512/1/Struthers_John_Final_2013_Feb.pdf

Swaminatha, S., Matsumoto, T., Nuget, B. J. (2010). Midwives and maternal mortality: How effective has Indonesia's village midwife programme been? USDS, University of Tokyo and the Western Economic Association. http://s3.amazonaws.com/zanran_storage/dornsife.usc.edu/ContentPages/25281 08758.pdf

Syptak, J. M., Marsland, D. W., \& Ulmer, D. (1999). Job satisfaction: Putting theory into practice. Family practice management, 6(9), 26.

Theodore, H. M. (2007). The Global human right to health: Dream or possibility. United Kingdom: Radcliffe Publishing Ltd.

Thind, A., \& Banerjee, K. (2004). Home deliveries in Indonesia: who provides assistance? Journal of community health, 29(4), 285-303. doi:10.1023/B:JOHE.0000025327.70959.d3

Thompson, A. (1998). Midwives make childbirth safer. World Health Organisation, 51. Titaley, C. R., Dibley, M. J., \& Roberts, C. L. (2009). Factors associated with nonutilisation of postnatal care services in Indonesia. Journal of epidemiology and community health, 63(10), 827-831. doi:10.1136/jech.2008.081604

Titaley, C. R., Dibley, M. J., \& Roberts, C. L. (2010). Factors associated with underutilization of antenatal care services in Indonesia: results of Indonesia Demographic and Health Survey 2002/2003 and 2007. BMC public health, 10(1), 485-485. doi:10.1186/1471-2458-10-485

Titaley, C. R., Hunter, C. L., Dibley, M. J., \& Heywood, P. (2010). Why do some women still prefer traditional birth attendants and home delivery?: a qualitative study on delivery care services in West Java Province, Indonesia. BMC pregnancy and childbirth, 10(1), 43-43. doi:10.1186/1471-2393-10-43 
Umberson, D., \& Montez, J. (2010). Social relationships and health: A flashpoint for health policy. Journal of Health and Social Behavior, 51, S54-S66.

United Nations Children's Fund. (2008). Annual report 2008. Retrieved from https://www.unicef.org/publications/files/UNICEF_Annual_Report_2008_EN_0 72709.pdf.

United Nations Development Programme. (2004). Indonesia Progress Report on the Millennium Development Goals.

United Nations Children's Fund. (2012). Maternal and child health. Retrieved from http://www.unicef.org/indonesia/A5-_E_Issue_Brief_Maternal_REV.pdf.

United Nations Children's Fund. (2013). At a glance: Indonesia. Retrieved from http://www.unicef.org/infobycountry/indonesia_statistics.html

United Nation Development Program. (2004. Indonesia Progress Report on the Mellennium Development Goals.

United Nations Population Fund. (2011). The state of the world's midwifery. UNFPA.

Vroom, V. (2002). Expectancy Theory. In S. Hollyfrode \& S. Whiddett A(Eds), The Motivation Handbook (pp. 39-47). London. Chartered Institute of Personnel and Development.

Willis, J. (2007). Foundations of qualitative research: interpretive and critical approaches. Thousand Oaks: SAGE.

World Health Organization. (2004). Making pregnancy safer: The critical role of the skilled attendant: A joint statement by WHO, ICM and FIGO. Geneva: WHO Retrieved from http://apps.who.int/iris/bitstream/10665/42955/1/9241591692.pdf.

World Health Organization. (2007). WHO country cooperation strategy for Indonesia 2006-2011. Retrieved from http://www.who.or.id/eng/contents/WHO\%20CCS\%20Indonesia\%20as\%20at\% 2018\%20Jan\%202007.pdf

World Health Organization. (2010a). Increasing access to health workers in remote and rural areas through improved retention: Global policy recommendations. Geneva: WHO Retrieved from http://apps.who.int/iris/bitstream/10665/44369/1/9789241564014_eng.pdf.

World Health Organization. (2010b). WISN: Workload Indicators of Staffing Need. Geneva: WHO.

World Health Organization. (2012). Millennium Development Goals (MDGs). Fac sheet $N$ 290. Retrieved from http://www.who.int/mediacentre/factsheets/fs290/en/index.html 
World Health Organization. (2013). World health statistics 2013. Switzerland. Retrieved fromhttp://www.who.int/gho/publications/world_health_statistics/2013/en/index .html.

Wold Health Organization, CapacityPlus-USAID, The World Bank (2012). How to conduct a Discrete Choice Experiment for health workforce recruitment and retention in remote and rural areas: A used guide with case studies. Geneva: WHO. Retrieved from http://www.who.int/hrh/resources/DCE_UserGuide_WEB.pdf?ua=1

Wulandari, L. P. L., \& Klinken Whelan, A. (2011). Beliefs, attitudes and behaviours of pregnant women in Bali. Midwifery, 27(6), 867-871. doi:10.1016/j.midw.2010.09.005

Yamamoto, T. S., Sunguya, B. F., Shiao, R. M., Amiya, Y. M., \& Jimba, M. (2012). Migration of Health Workers in the Pacific Islands: A bottleneck to Health Development. Asia Pacific Journal Public Health, 24(697).

Yang, J. (2003). Potential Urban-to-Rural Physician Migration: The Limited Role of Financial Incentives Canadian Journal of Rural Medicine, 8(2), 101-106.

Yin, R. K. (2014). Case study research: design and methods. Los Angeles: SAGE.

Zinnen, V., Paul, E., Mwisongo, A., Nyato, D., \& Robert, A. (2012). Motivation of human resources for health: a case study at rural district level in Tanzania. The International journal of health planning and management, 27(4), 327-347. doi:http://dx.doi.org/10.1002/hpm.2117 


\section{APPENDICES}

Appendix A: Information Sheet

\section{Participant information sheet}

\section{Project title: Attracting and Retaining Village Midwives in Indonesian Remote Postings: 'Success Cases' From West Nusa Tenggara}

\section{What is the research about?}

My research aims to explore the ways in which midwives are recruited and retained in rural and remote areas of Indonesia. The research will fill the current gap in practical and theoretical understanding around recruiting and retaining midwives in rural and remote areas.

\section{Who is doing this research?}

My name is Endah Setyaningsih and I am a student in Public Policy at Victoria University of Wellington (VUW), New Zealand. My research has received approval from the VUW Human Ethics Committee and it is carried out under the supervision of two academic supervisors. It is also in accordance with the policies and procedures of the university. In addition, my research has received approval from the Government of Indonesia.

\section{What will happen if I take part in this research?}

With your consent, you will be interviewed by me at the venue that suits you, and at a time that is convenient for you. The interview will take around an hour of your time, but maybe longer depending on our discussion. Your interview will be audio-recorded to help me when I analyse it. It will be used for my $\mathrm{PhD}$ thesis, academic and professional journals, and for presentation at relevant conferences. A copy of my completed thesis will be deposited in the Library of Victoria University of Wellington, and will be available electronically in the institutional repository.

\section{What happens to the information I share?}

- Your participation in this research is voluntary.

- You are free to decline without giving any reason and withdraw any data provided, up to one month from the date on which you provide such data. It that case, the data collected will be destroyed. 
- The result of the research will be anonymously presented in my thesis and subsequent publication.

- If direct quotes are used they will be written in a way that the person and the organisation cannot be identified.

- The interview will be audio recorded and then transcribed with your consent. However, you can ask me to switch off the recorder at any time during the interview session and you are free to refuse to answer specific questions.

- All raw data will be kept confidential. All collected data will be destroyed five years after the end of my doctoral degree.

- Translators will sign confidential agreements that guarantees confidentiality of all information gathered.

\section{Who do I contact if I have any questions?}

If you have any questions or would like to receive further information about the research, please contact me at the information below.

\section{Researcher:}

\section{Endah Setyaningsih}

PhD student

School of Government

Victoria University of Wellington

PO Box 600

Wellington, New Zealand

Email: endah.setyaningsih@vuw.ac.nz

Phone: +64-4-4639571

Under supervision of:

\section{Professor Jackie Cumming}

Primary Supervisor

Director Health Services Research Centre

School of Government

Victoria University of Wellington

PO Box 600

Wellington, New Zealand

Email: jackie.cumming@vuw.ac.nz

Phone: +64-4-4636567
Dr Lynne Russell

Secondary supervisor

Health Services Research Centre

School of Government

Victoria University of Wellington

PO Box 600

Wellington, New Zealand

Email: lynne.russell@vuw.ac.nz

Phone: +64-463 6527 


\section{Letter of Consent}

\section{Project title: Attracting and Retaining Village Midwives in Indonesian Remote Postings: 'Success Cases' From West Nusa Tenggara}

Please tick the boxes to indicate that you have read and agree with the following statements:

I have read the information sheet for this study and understand the explanation given.

I have read the opportunity to ask questions and have had them answered to my satisfaction.

I understand that I have the right to ask further questions at any time.

I agree to the interviews being audio-recorded.

I understand that I can withdraw myself (or any information I have provided) from this study within one month from the date of the interview and all information related to me will be destroyed.

$\square \quad$ I understand that the data I provide will be kept secure at all times, and will be kept confidential to the researcher and the researcher's supervisors and it will be destroyed five years after the conclusion of the project.

I understand the data will only be used for the researcher's $\mathrm{PhD}$ thesis, journal articles or conference presentations. Any further use will require my written consent.

$\square \quad$ I understand that neither my name nor the name of my organisation will be used in the study, and the information that I provide will not be used in any way that will identify me.

I understand that I will have an opportunity to provide feedback on the preliminary findings after all interviews have been undertaken.

Participant's Name

Participant's Signature

Date of Interview 
Appendix C: Interview Schedule

INTERVIEW CHECK LIST

Policy Makers (National level, Provincial level, District level, Sub District level)

1. Can you please tell me a little bit about yourself (age, gender, department, title, educational background); your role and your involvement in policy focused on health personnel, especially midwives in remote areas of Indonesia?

Prompts: compulsory service, contracted staff, village midwives programme, etc.

2. What do you think works well with current policies and programmes are regarding recruitment of midwives for remote areas of Indonesia?

3. What do you think works well with current policies and programme are regarding retention of midwives for remote areas of Indonesia?

4. What are the opportunities for improving the recruitment system of health personnel especially midwives in remote areas?

5. What are the opportunities for improving the retention system of health personnel especially midwives in remote areas?

Prompts: salary, recognition, advancement, finances, lifestyle, culture and family factors.

6. You have mentioned $\mathrm{x}, \mathrm{y}$, and $\mathrm{z} .$. . What are the THREE THINGS that you think would impact recruitment and retention of midwives THE MOST?

7. What would it take to create change on this issue?

8. Is there something else that you think would make a difference?

9. What challenges do you see in creating this change? How might these be met?

10. To summarise, what could make the most difference to the future of recruitment and retention of midwives in rural and remote Indonesia?

11. Any other comments?

THANK YOU

Thank you for your time today. If you would like a copy of the preliminary findings, please give me your contact details that I can email or post them to you.

If you have any questions or queries about the research, please feel free to contact me on endah.setyaningsih@vuw.ac.nz. 


\section{INTERVIEW SCHEDULE}

\section{Midwives (Senior, mid-range, new)}

1. Can you please tell me about yourself (age, employment status, marital status)? How long have you been working as a midwife in this community? Have you ever been working in other areas beside this community?

2. What is it about your profession that supports or motivates you to work in remote areas?

3. What is it about your profession that motivates you to stay in remote areas?

4. What is important to you about working in remote areas?

Prompts: compulsory service, contracted staff, village midwives programme

5. What do you think works well with current policies and programmes are regarding recruitment of midwives for rural and remote areas of Indonesia?

6. What do you think works well with current policies and programme are regarding retention of midwives for rural and remote areas of Indonesia?

7. From your experience, what do you think has made the most difference in recruiting and keeping you here (please identify three things)?

8. How would this work for recruitment and retention other midwives?

9. What improvements would help you to continuing carrying out your work in remote areas?

10. Is there something else that you think would make a difference?

11. Any other comments?

\section{THANK YOU}

Thank you for your time today. If you would like a copy of the preliminary findings, please give me your contact details that I can email or post them to you.

If you have any questions or queries about the research, please feel free to contact me on endah.setyaningsih@vuw.ac.nz. 
Appendix D: Travel Buddy/ Translator Agreement

\section{TRANSLATOR CONFIDENTIALITY AGREEMENT}

I agree to maintain total confidentiality as a translator for this research project

Attracting and Retaining Village Midwives in Indonesian Remote Postings: 'Success Cases' From West Nusa Tenggara

I will not disclose any information relating to the interviews, to any person aside from the Principal Researcher, Endah Setyaningsih.

$\square$ I will not directly or indirectly acquire any interest in any item or product, containing, based upon or derived from the information, except as may be expressly agreed to in writing by the Principal Researcher, Endah Setyaningsih.

Signed

Print Name

Date 
MEMORANDUM

['hone 0-1-4635676

Fax 0-1-4635209

Email Altison.kirkman@vi:w.ac $\pi z$

\begin{tabular}{l|l}
\hline TO & Endah Setyaningsih \\
\hline COPY TO & Jackie Cumming \\
\hline FROM & Dr Allison Kirkman, Convener, Human Ethics Committee \\
\hline
\end{tabular}

\begin{tabular}{l|l|}
\hline DATE & 4 December 2014 \\
\hline PAGES & 1 \\
\hline
\end{tabular}

SUBJECT

Ethics Approval: 21038

Recruitment and Retention of Midwives in Rural and Remote Areas of Indonesia: A Case Study

Thank you for your application for ethical approval, which has now been considered by the Standing Committee of the Human Ethics Committee.

Your application has been approved from the above date and this approval continues until 4 December 2017. If your data collection is not completed by this date you should apply to the Human Ethics Committee for an extension to this approval.

Best wishes with the research.

Alison Kirkman

Human Ethics Committee 
Appendix F: Research Approval Letter from the National Government

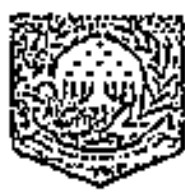

KEMERITERIAN! DALAM MEGERI

REPUBLLK INDONESIA

DIREKTORAT JENDERAL KESATUAN BANGSA DAN POLITIK

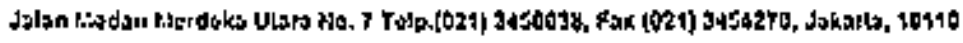

\section{REROIALNDAEI PERSLITTAN

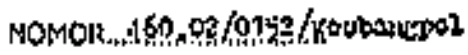

5. Eusar

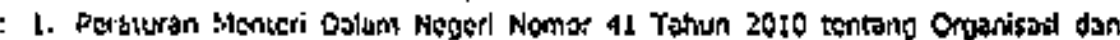
7 jta Kerja kenitnterian Qslom Negect (Berto Negara Repubilk Indonoxis Tahun

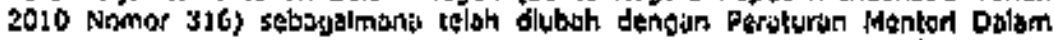

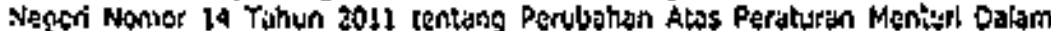
Pegeri kounor 41 Tashul 2010 tantang Organlsosi dan Tata Korda Kementerian Dilem Neqeri (Borita Nepira kicpublik Indonesia Tahun 2011 Nomox I65);

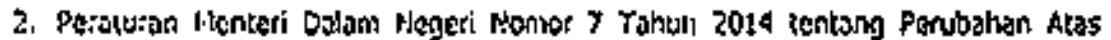

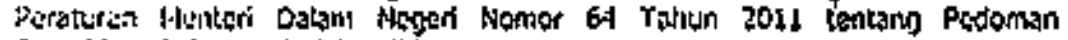
Psnerlitisa Rokonicadast Denclition:

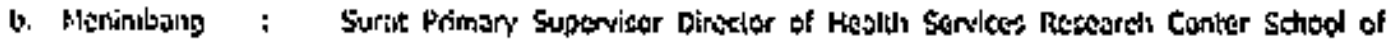
Gowoments Victork Uiluwerticy of Wellington Selanfis osu Tanggal 12 Januar 3015 pertihal PCrnohoinat Rekomendosi fesmelition.

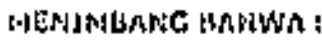

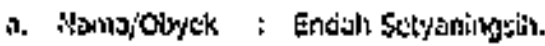

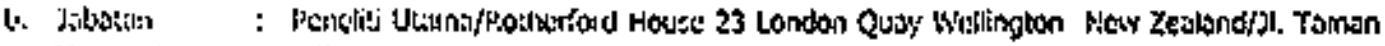

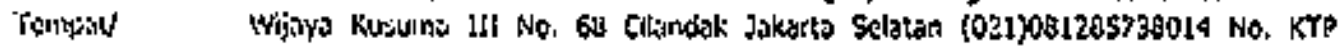

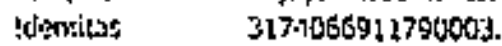

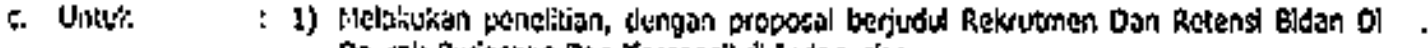

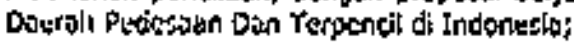

2) Lotasi Denclition : Drovinsi Nuझ TLnggara Barat (1 preninel);

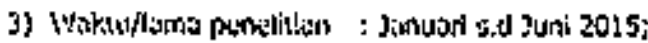

4) Asiggoto úrn postchlition : ·

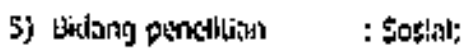

b) Stulus pineliast : Disu;

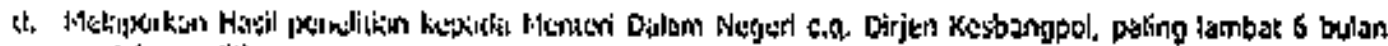

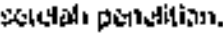

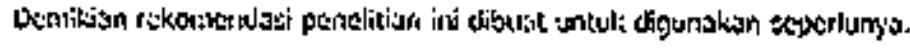

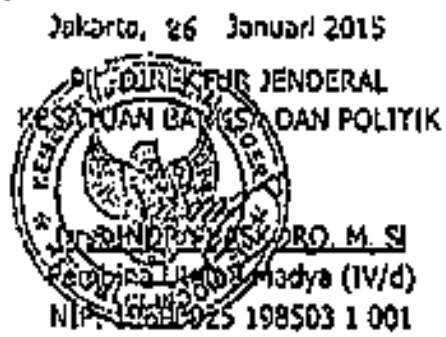

Imistrion:

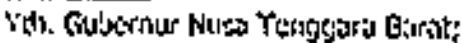

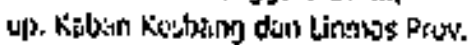




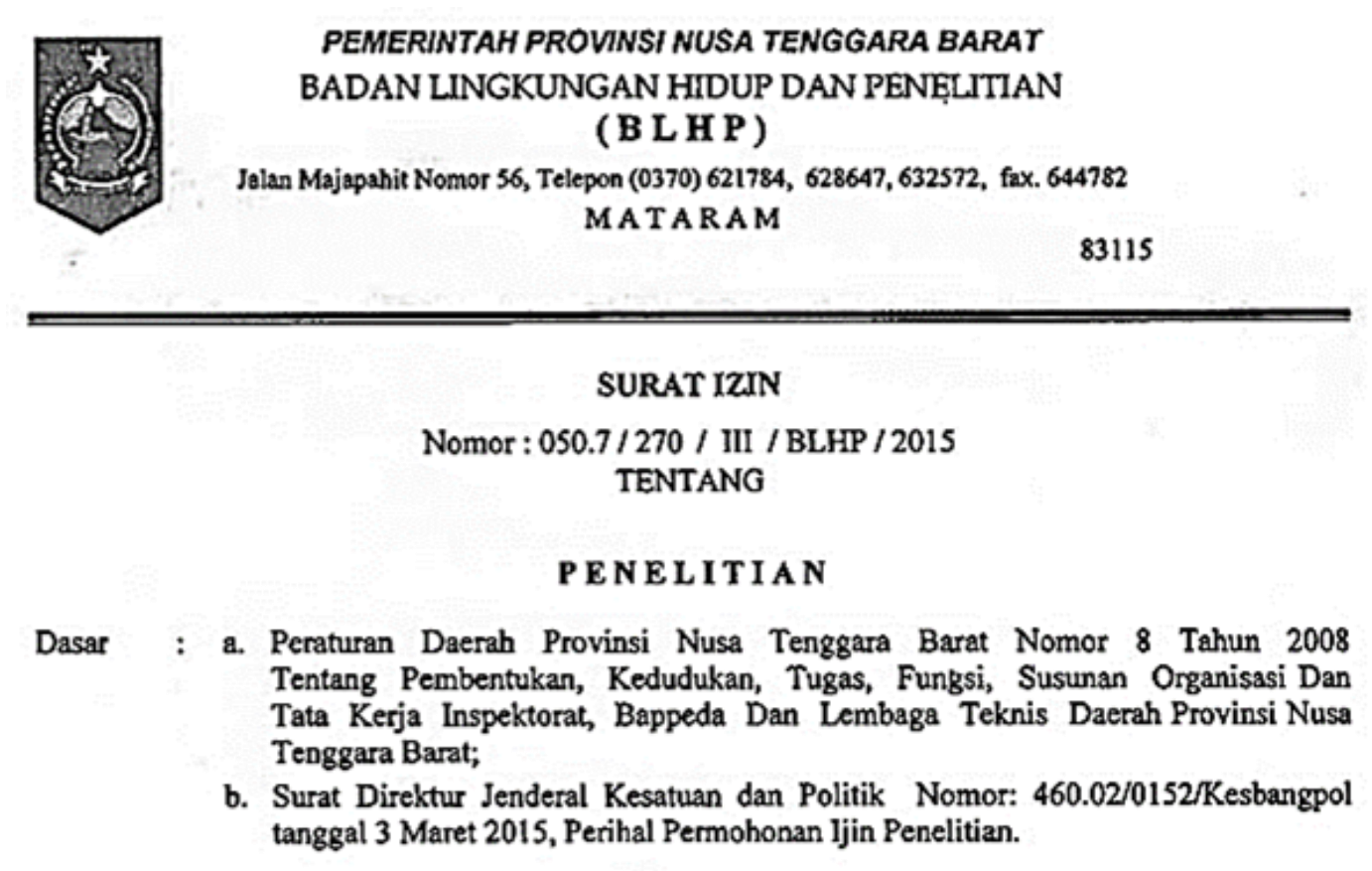

\section{MENGIZINKAN}
Kepada
$\mathrm{Nama}$ aNDAH SETYANINGSIH
NIM 300312915
Alamat: Jakarta Selatan
Untuk : Melakukan penelitian dengan judul :
"Rekrutmen Dan Retensi Bidan di Daerah Tertinggal di Indonesia."
Lokasi. Provinsi Nusa Tenggara Barat
Waktu Selama 6 (Enam) bulan sejak Izin Penelitian ini diterbitkan.
Demikian Surat Lin Penelitian ini dibuat agar dapat dilaksanakan dengan penuh Tanggungjawab.

TEMBUSANdisampaikan kepada Yut:

1. Gubernur NTB di Mataram (sebagai laporan);

2. Bupati Se-Nusa Tenggara Barat;

3. Kepala Dinas Kesehatan Provinsi Nusa Tenggara Barat;

4. Ketua Jurusan/Program Study;

S. Dinas/nstansi Terkait;

6. Pertinggal; 
